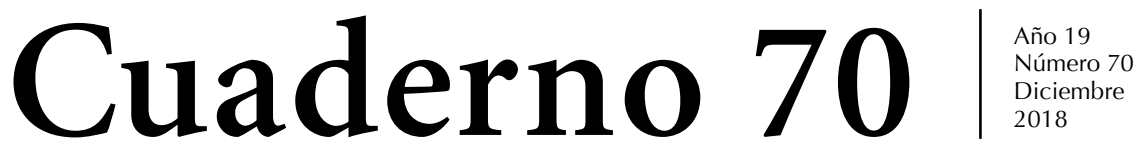

Cuadernos del Centro de Estudios en Diseño y Comunicación [Ensayos]

\section{Materialidad difusa. Prácticas de diseño y tendencias}

Daniel Wolf: Prólogo de la Universidad de Palermo | Jorge Pokropek y Ana Cravino: Algunas precisiones sobre la borrosa noción de "Materia" para el diseño interior | Leila Lemgruber Queiroz: Desmaterialización e inmaterialidad en el contexto contemporáneo del Diseño| Maximiliano Zito: La sustentabilidad de Internet de las Cosas | Gabriela Nuri Barón: La des-materialización de productos tangibles en una perspectiva de sustentabilidad | Marina Andrea Baima: El proceso de diseño desde la génesis de los materiales | Marinella Ferrara and Valentina Rognoli: Introduction by the School of Design of Politecnico di Milano | Marinella Ferrara and Anna Cecilia Russo: The Italian Design Approach to Materials between tangible and intangible meanings | Linda Worbin: Designing for a start; irreversible dynamic textile patterns | Zurich Manuel Kretzer: Educating smart materials | Murat Bengisu: Biomimetic materials and design | Valentina Rognoli and Camilo Ayala Garcia: Material activism. New hybrid scenarios between design and technology | Giulia Gerosa and Laura Daglio: Diffuse materiality in public spaces between expressiveness and performance | Giovanni Maria Conti: Material for knitwear: a new contemporary design scenario | Giulio Ceppi: Slow+Design as sustainable sensoriality: an innovative approch aimed to explore the new relationships among design, innovation and sustainability.

Centro de Estudios en Diseño y Comunicación.

Facultad de Diseño y Comunicación. Universidad de Palermo. Buenos Aires.

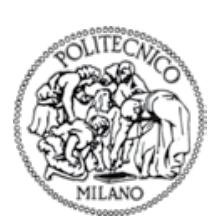




Cuadernos del Centro de Estudios en

Diseño y Comunicación

Universidad de Palermo.

Facultad de Diseño y Comunicación.

Centro de Estudios en Diseño y Comunicación.

Mario Bravo 1050. C1175ABT.

Ciudad Autónoma de Buenos Aires, Argentina.

www.palermo.edu

publicacionesdc@palermo.edu

\section{Director}

Oscar Echevarría

\section{Editora}

Fabiola Knop

Coordinación del Cuaderno no 70

Daniel Wolf. (D\&C, UP. Argentina)

Marinella Ferrara (School of Design - Politecnico di

Milano - Italy)

Valentina Rognoli (School of Design - Politecnico di

Milano - Italy)

\section{Comité Editorial}

Lucia Acar. Universidade Estácio de Sá. Brasil.

Gonzalo Javier Alarcón Vital. Universidad Autónoma

Metropolitana. México.

Mercedes Alfonsín. Universidad de Buenos Aires.

Argentina.

Fernando Alberto Alvarez Romero. Universidad de

Bogotá Jorge Tadeo Lozano. Colombia.

Gonzalo Aranda Toro. Universidad Santo Tomás. Chile.

Christian Atance. Universidad de Buenos Aires. Argentina.

Mónica Balabani. Universidad de Palermo. Argentina.

Alberto Beckers Argomedo. Universidad Santo Tomás.

Chile.

Renato Antonio Bertao. Universidade Positivo. Brasil.

Allan Castelnuovo. Market Research Society. Reino

Unido.

Jorge Manuel Castro Falero. Universidad de la Empresa.

Uruguay.

Raúl Castro Zuñeda. Universidad de Palermo. Argentina.

Mario Rubén Dorochesi Fernandois. Universidad Técni-

ca Federico Santa María. Chile.

Adriana Inés Echeverria. Universidad de la Cuenca de

Plata. Argentina.

Jimena Mariana García Ascolani. Universidad Iberoame-

ricana. Paraguay.

Marcelo Ghio. Instituto San Ignacio. Perú.

Clara Lucia Grisales Montoya. Academia Superior de

Artes. Colombia.

Haenz Gutiérrez Quintana. Universidad Federal de Santa Catarina. Brasil.

José Korn Bruzzone. Universidad Tecnológica de Chile. Chile.

Zulema Marzorati. Universidad de Buenos Aires.

Argentina.

Denisse Morales. Universidad Iberoamericana Unibe.

República Dominicana.

\section{Universidad de Palermo}

Rector

Ricardo Popovsky

Facultad de Diseño y Comunicación

Decano

Oscar Echevarría

Secretario Académico

Jorge Gaitto
Nora Angélica Morales Zaragosa. Universidad Autónoma Metropolitana. México.

Candelaria Moreno de las Casas. Instituto Toulouse Lautrec. Perú.

Patricia Núñez Alexandra Panta de Solórzano. Tecnológico Espíritu Santo. Ecuador.

Guido Olivares Salinas. Universidad de Playa Ancha. Chile. Ana Beatriz Pereira de Andrade. UNESP Universidade Estadual Paulista. Brasil.

Fernando Rolando. Universidad de Palermo. Argentina. Alexandre Santos de Oliveira. Fundação Centro de Análise de Pesquisa e Inovação Tecnológica. Brasil.

Carlos Roberto Soto. Corporación Universitaria UNITEC.

Colombia.

Patricia Torres Sánchez. Tecnológico de Monterrey.

México.

Viviana Suárez. Universidad de Palermo. Argentina.

Elisabet Taddei. Universidad de Palermo. Argentina.

\section{Comité de Arbitraje}

Luís Ahumada Hinostroza. Universidad Santo Tomás. Chile.

Débora Belmes. Universidad de Palermo. Argentina.

Marcelo Bianchi Bustos. Universidad de Palermo.

Argentina.

Aarón José Caballero Quiroz. Universidad Autónoma Metropolitana. México.

Sandra Milena Castaño Rico. Universidad de Medellín. Colombia.

Roberto Céspedes. Universidad de Palermo. Argentina.

Carlos Cosentino. Universidad de Palermo. Argentina.

Ricardo Chelle Vargas. Universidad ORT. Uruguay.

José María Doldán. Universidad de Palermo. Argentina.

Susana Dueñas. Universidad Champagnat. Argentina.

Pablo Fontana. Instituto Superior de Diseño Aguas de La

Cañada. Argentina. 
Sandra Virginia Gómez Mañón. Universidad Iberoamericana Unibe. República Dominicana.

Jorge Manuel Iturbe Bermejo. Universidad La Salle. México.

Denise Jorge Trindade. Universidade Estácio de Sá. Brasil. Mauren Leni de Roque. Universidade Católica De Santos. Brasil.

María Patricia Lopera Calle. Tecnológico Pascual Bravo. Colombia.

Gloria Mercedes Múnera Álvarez. Corporación Universitaria UNITEC. Colombia.

Eduardo Naranjo Castillo. Universidad Nacional de Colombia. Colombia.

Miguel Alfonso Olivares Olivares. Universidad de Valparaíso. Chile.

Julio Enrique Putalláz. Universidad Nacional del Nordeste. Argentina.

Carlos Ramírez Righi. Universidad Federal de Santa Catarina. Brasil.

Oscar Rivadeneira Herrera. Universidad Tecnológica de Chile. Chille.

Julio Rojas Arriaza. Universidad de Playa Ancha. Chile. Eduardo Russo. Universidad Nacional de La Plata.

Argentina.

Virginia Suárez. Universidad de Palermo. Argentina. Carlos Torres de la Torre. Pontificia Universidad Católica del Ecuador. Ecuador.

Magali Turkenich. Universidad de Palermo. Argentina. Ignacio Urbina Polo. Prodiseño Escuela de Comunicación Visual y Diseño. Venezuela.

Verónica Beatriz Viedma Paoli. Universidad Politécnica y Artística del Paraguay. Paraguay.

Ricardo José Viveros Báez. Universidad Técnica Federico Santa María. Chile.

\section{Textos en inglés}

María Verónica Barzola

\section{Textos en portugués}

Mercedes Massafra - María Verónica Barzola

Diseño

Francisca Simonetti - Constanza Togni

1० Edición.

Cantidad de ejemplares: 100

Ciudad Autónoma de Buenos Aires, Argentina.

Diciembre 2018.

Impresión: Artes Gráficas Buschi S.A.

Ferré 250/52 (C1437FUR)

Ciudad Autónoma de Buenos Aires, Argentina.

ISSN 1668-0227
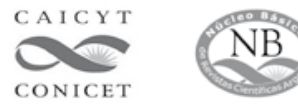

El Ministerio de Educación, Ciencia y Tecnología de la República Argentina, con la resolución No 2385/05 incorporó al Núcleo Básico de Publicaciones Periódicas Científicas y Tecnológicas -en la categoría Ciencias Sociales y Humanidades- la serie Cuadernos del Centro de Estudios en Diseño y Comunicación [Ensayos]. Facultad de Diseño y Comunicación de la Universidad de Palermo. En diciembre 2013 fue renovada la permanencia en el Núcleo Básico, que se evalúa de manera ininterrumpida desde el 2005. La publicación en sus versiones impresa y en línea han obtenido el Nivel 1 (36 puntos sobre 36).

\section{latindex}

La publicación Cuadernos del Centro de Estudios en Diseño y Comunicación [Ensayos] (ISSN 1668-0227) está incluida en el Directorio y Catálogo de Latindex.

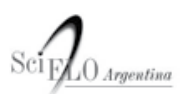

La publicación Cuadernos del Centro de Estudios en Diseño y Comunicación [Ensayos] (ISSN 1668-0227) pertenece a la colección de revistas científicas de SciELO.

\section{○ Dialnet}

La publicación Cuadernos del Centro de Estudios en Diseño y Comunicación [Ensayos] (ISSN 1668-0227) forma parte de la plataforma de recursos y servicios documentales Dialnet.

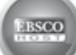

La publicación Cuadernos del Centro de Estudios en Diseño y Comunicación [Ensayos] (ISSN 1668-0227) se encuentra indexada por EBSCO.

Cuadernos del Centro de Estudios en Diseño y Comunicación [Ensayos] on line

Los contenidos de esta publicación están disponibles, gratuitos, on line ingresando en:

www.palermo.edu/dyc $>$ Publicaciones DC $>$ Cuadernos del Centro de Estudios en Diseño y Comunicación.

Prohibida la reproducción total o parcial de imágenes y textos. El contenido de los artículos es de absoluta responsabilidad de los autores. 



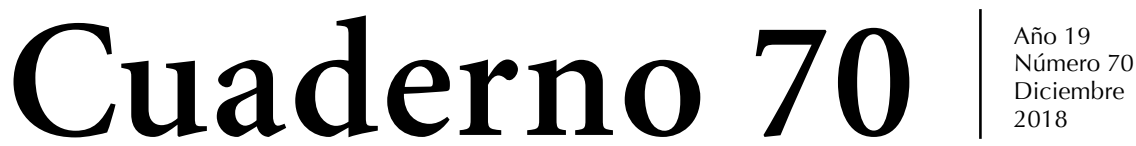

Cuadernos del Centro de Estudios en Diseño y Comunicación [Ensayos]

\section{Materialidad difusa. Prácticas de diseño y tendencias}

Daniel Wolf: Prólogo de la Universidad de Palermo | Jorge Pokropek y Ana Cravino: Algunas precisiones sobre la borrosa noción de "Materia" para el diseño interior | Leila Lemgruber Queiroz: Desmaterialización e inmaterialidad en el contexto contemporáneo del Diseño| Maximiliano Zito: La sustentabilidad de Internet de las Cosas | Gabriela Nuri Barón: La des-materialización de productos tangibles en una perspectiva de sustentabilidad | Marina Andrea Baima: El proceso de diseño desde la génesis de los materiales | Marinella Ferrara and Valentina Rognoli: Introduction by the School of Design of Politecnico di Milano | Marinella Ferrara and Anna Cecilia Russo: The Italian Design Approach to Materials between tangible and intangible meanings | Linda Worbin: Designing for a start; irreversible dynamic textile patterns | Zurich Manuel Kretzer: Educating smart materials | Murat Bengisu: Biomimetic materials and design | Valentina Rognoli and Camilo Ayala Garcia: Material activism. New hybrid scenarios between design and technology | Giulia Gerosa and Laura Daglio: Diffuse materiality in public spaces between expressiveness and performance | Giovanni Maria Conti: Material for knitwear: a new contemporary design scenario | Giulio Ceppi: Slow+Design as sustainable sensoriality: an innovative approch aimed to explore the new relationships among design, innovation and sustainability.

Centro de Estudios en Diseño y Comunicación.

Facultad de Diseño y Comunicación. Universidad de Palermo. Buenos Aires.

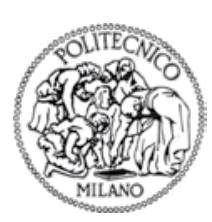


Cuadernos del Centro de Estudios en Diseño y Comunicación. [Ensayos], es una línea de publicación cuatrimestral del Centro de Estudios en Diseño y Comunicación de la Facultad de Diseño y Comunicación de la Universidad de Palermo. Los Cuadernos reúnen papers e informes de investigación sobre tendencias de la práctica profesional, problemáticas de los medios de comunicación, nuevas tecnologías y enfoques epistemológicos de los campos del Diseño y la Comunicación. Los ensayos son aprobados en el proceso de referato realizado por el Comité de Arbitraje de la publicación.

Los estudios publicados están centrados en líneas de investigación que orientan las acciones del Centro de Estudios: 1. Empresas y marcas. 2. Medios y estrategias de comunicación. 3. Nuevas tecnologías. 4. Nuevos profesionales. 5. Diseño y producción de objetos, espacios e imágenes. 6. Pedagogía del diseño y las comunicaciones. 7. Historia y tendencias.

El Centro de Estudios en Diseño y Comunicación recepciona colaboraciones para ser publicadas en los Cuadernos del Centro de Estudios [Ensayos]. Las instrucciones para la presentación de los originales se encuentran disponibles en: http://fido.palermo.edu/servicios_dyc/publicacionesdc/ vista/instrucciones.php

Las publicaciones académicas de la Facultad de Diseño y Comunicación de la Universidad de Palermo actualizan sus contenidos en forma permanente, adecuándose a las modificaciones presentadas por las normas básicas de estilo de la American Psychological Association - APA. 
Cuadernos del Centro de Estudios en

Sumario

Diseño y Comunicación [Ensayos] № 70

ISSN 1668-0227

Facultad de Diseño y Comunicación.

Universidad de Palermo. Buenos Aires.

Diciembre 2018.

\section{Materialidad difusa. Prácticas de diseño y tendencias}

Prólogo de la Universidad de Palermo

Daniel Wolf.

..pp. 11-13

Algunas precisiones sobre la borrosa noción de "Materia" para el diseño interior

Jorge Pokropek y Ana Cravino.

Desmaterialización e inmaterialidad en el contexto contemporáneo del

Diseño

Leila Lemgruber Queiroz.

..pp. 29-35

La sustentabilidad de Internet de las Cosas

Maximiliano Zito.

La des-materialización de productos tangibles en una perspectiva de sustentabilidad

Gabriela Nuri Barón. .pp. $45-52$

El proceso de diseño desde la génesis de los materiales

Marina Andrea Baima. .pp. 53-61

Introduction by the School of Design of Politecnico di Milano

Marinella Ferrara and Valentina Rognoli. ..pp. 63-66

The Italian Design Approach to Materials between tangible and intangible meanings

Marinella Ferrara and Anna Cecilia Russo.

.pp. $67-80$ 
Designing for a start; irreversible dynamic textile patterns

Linda Worbin.

Educating smart materials

Zurich Manuel Kretzer.

Biomimetic materials and design

Murat Bengisu.

Material activism. New hybrid scenarios between design and technology

Valentina Rognoli and Camilo Ayala Garcia

Diffuse materiality in public spaces between expressiveness and performance

Giulia Gerosa and Laura Daglio. .pp. 117-124

Material for knitwear: a new contemporary design scenario

Giovanni Maria Conti. .pp. 125-134

Slow+Design as sustainable sensoriality: an innovative approch aimed to explore the new relationships among design, innovation and sustainability Giulio Ceppi. .pp. 135-146

Publicaciones del Centro de Estudios en Diseño y Comunicación .pp. 147-169

Síntesis de las instrucciones para autores. .pp. 170 


\title{
Prólogo de la Universidad de Palermo
}

\author{
Daniel Wolf*
}

Resumen: La avanzada tecnológica que viene convirtiendo en aplicaciones virtuales toda nuestra experiencia de contacto con el mundo real, pareciera estar posicionando al diseñador industrial como un profesional dedicado a una práctica primitiva, solo rescatable en su modesto rol de operador de dispositivos de representación digital, o en la ambiciosa expresión del diseño de experiencias.

Esta tendencia se ve potenciada por el desarrollo de nuevos materiales, por la miniaturización hasta el vacío de los artefactos y por el extrañamiento de la realidad que nos produce el nuevo ecosistema de las redes sociales.

Asumiendo los condicionantes y oportunidades del momento, este Cuaderno intenta abordar -desde diversas realidades- posibles caminos de acción. Acción sobre la realidad, sobre los materiales y sobre los proyectos.

Palabras clave: Materiales - Diseño - Tecnología - Consumo - Tendencia - Proyecto - Diseño Industrial - Materialidad - Prospectiva.

[Resúmenes en inglés y portugués en las páginas 12-13]

${ }^{(*)}$ Diseñador Industrial (UBA, 1998). Docente Autorizado (FADU-UBA, 2008). Es Coordinador del Área de Diseño de Objetos y Productos y el de Investigación y Producción de la Facultad de Diseño y Comunicación (UP).

El avance del sistema tecnológico generó, hacia fines del siglo XIX, las condiciones para el surgimiento de un área del conocimiento dedicada a la recreación de artefactos que garantice su aceptación en un incipiente mercado de consumo.

La aparición de novedosos sistemas mecanizados de producción, que mejoraban la productividad a costa de una notoria pérdida de calidad de los objetos manufacturados, exigió la creación de nuevos lenguajes formales que se encontraran acorde a las posibilidades técnicas del momento. Desde entonces, el mercado con su ansia de lucro, y la técnica con su obsesión por reducir los costos, han definido los márgenes en los cuales las disciplinas del proyecto se han desarrollado. Los habituales debates centrados en la díada formafunción, además de resultar obsoletos, tienden a soslayar la franca dependencia que las disciplinas de diseño tienen de la tecnología, en sus orígenes, límites y posibilidades y cuya constante y acelerada transformación resulta uno de los signos de nuestro tiempo. 
Este contexto, donde las transformaciones -producidas por el bolsillo más que por la mano del hombre- nos obligan a realizar permanentes reflexiones acerca de los compromisos, tradiciones y escenarios de disciplinas que deben constituirse en la crítica para poder modificar el mundo que nos rodea.

Materialidad Difusa es producto de la colaboración entre el Politécnico de Milán y la Universidad de Palermo con la intención de proponer miradas desde y sobre distintas realidades y disciplinas. La publicación, organizada en un apartado europeo y otro sudamericano contiene artículos de autores, docentes, investigadores y profesionales de diversos campos del diseño que se desempeñan en más de 9 países y que comparten un común denominador: la convicción en la potencia del diseño como herramienta de transformación.

En el capítulo sudamericano Cravino y Propokep proponen entender la materia como un conjunto de datos a ser interpretados. Realizan, a partir de esta mirada, un derrotero donde el proyecto y los materiales se definen, descubren y reconfiguran. Donde la arquitectura y el diseño de interiores actúan como excusa para recorrer la relación dialéctica entre materia y proyecto; entre el diseñador y su mundo.

La inmaterialidad como insumo de la posmodernidad es el eje que orienta el texto de Leila Lembgruber, quien anclándose en su propio campo disciplinar desarrolla una mirada crítica que hace foco en la impostura de un sistema que declama sustentarse en la insustancialidad.

La irrupción de los sistemas de información en todas las dimensiones de nuestra vida cotidiana es otro de los signos de los tiempos. Sus beneficios y ventajas se convirtieron en un lugar común. Maximiliano Zito propone en su texto una lectura comprometida que, cuestionando el discurso instalado, indaga sobre las eventuales consecuencias de estos cambios y sus inevitables costos.

El rol del diseñador en un sistema en constante crisis queda bajo el análisis de Barón, quien con claridad conceptual deconstruye conceptos consolidados con la idea que la disciplina puede avanzar - no sin dificultad- pero con claridad y convicción en un contexto difuso. Nuevas tecnologías deben comprometer nuevas metodologías. En esta línea Marina Baima aporta una mirada que apuesta a la innovación colaborativa, una metodología abierta, que cuestiona activa y productivamente muchas de las tradiciones disciplinares.

Materialidad Difusa propone miradas diversas que convergen en el compromiso de comprender para aceptar el desafío, y que asumen al diseño como parte del problema, pero también como una posible vía de solución -o al menos de debate- dentro de los conflictos de nuestro tiempo.

Abstract: Technological advancement is turning our entire experience of contact with the real world into virtual applications, seems to be relegating industrial design to a practice only redeemable in its way of operating digital representation devices, and in misty designs like the design of Experiences or thinking design.

This trend that blurs the scope of the profession is enhanced by the development of new materials, by the miniaturization to the vacuum of the artifacts and by the estrangement of the reality that gives us the new way of dwelling in social networks. 
Assuming the conditions and opportunities of the moment, this book tries to approach -from different realities- possible ways of action from and for a discipline committed to reality, matter and projects.

Key words: Materials - Design - Technology - Consumption - Trend, Project - Industrial Design - Materiality - Foresight.

Resumo: Os avanços tecnológicos -que estão convertendo em aplicações virtuais toda nossa experiência de contato com o mundo real-, estão posicionando ao designer industrial como um profissional dedicado a uma prática primitiva, somente resgatável em seu modesto papel de operador de dispositivos de representação digital, ou na ambiciosa expressão do design de experiências.

Esta tendência está potenciada pelo desenvolvimento de novos materiais, pela miniaturização até o vazio dos artefatos e pelo estranhamento da realidade que produz o novo ecossistema das redes sociais.

Assumindo os condicionantes e oportunidades do momento, este Caderno intenta abordar, desde diversas realidades, caminhos de ação possíveis. Ação sobre a realidade, os materiais e os projetos.

Palavras chave: materiais - design - tecnologia - consumo - tendência - projeto - design industrial - materialidade - prospectiva. 

Fecha de recepción: octubre 2017

Fecha de aceptación: mayo 2018

Versión final: diciembre 2018
Algunas precisiones sobre la
borrosa noción de "Materia"
para el diseño interior
Jorge Pokropek ${ }^{*}$ Ana Cravino ${ }^{*}$

Resumen: El propósito de este texto es reflexionar sobre las nociones de materialidad y su empleo en la praxis proyectual de los diseñadores de interior, con la intencionalidad de revisar aquellos criterios e instrumentos conceptuales en los que la noción de Materia juega un rol protagónico en dicha praxis. Con este objeto indagaremos sobre las relaciones que se establecen entre Forma y Materia, así como sobre la tensión dialéctica entre espacio configurado y mostración superficial.

Palabras clave: Forma - Materia - espacio configurado - espacialidades - mostración superficial - textura.

[Resúmenes en inglés y portugués en la página 27]

${ }^{(*)}$ Arquitecto, UM. Especialista en Lógica y Técnica de la Forma, FADU-UBA. Magíster en Lógica y Técnica de la Forma, FADU-UBA. Doctorando, FADU-UBA. Profesor adjunto regular de Morfología General, Morfología 1 y Morfología 2, FADU-UBA. Profesor Adjunto a cargo de Morfología 2, Universidad Nacional de Moreno. Profesor del Doctorado de Diseño, Universidad de Palermo.

${ }^{(* *)}$ Arquitecta, UM. Profesora Superior Universitaria, UM. Magíster en Gestión de Proyectos Educativos, CAECE. Doctora en Arquitectura, FADU-UBA. Investigadora Categorizada del Programa de Incentivos del Ministerio de Educación de la Nación. Investigadora de la UBA y de la Universidad Nacional de la Pampa. Docente de las Universidades de Buenos Aires, ITBA y Palermo.

\section{Introducción}

Este breve escrito pretende establecer algunas reflexiones sobre las nociones de Materia o materialidad y su empleo en la praxis proyectual de los diseñadores de interior, con el fin de alumbrar esa praxis mediante la revisión de aquellos criterios e instrumentos conceptuales en los que la noción de Materia juega un rol protagónico. Para ello será menester revisar ciertos conceptos estructurantes de nuestro marco teórico, estipulando los rasgos fundamentales de aquellos términos que los constituyen. 
Comencemos por señalar que hablar de diseño interior implica hablar de una práctica proyectual específicamente orientada a la configuración eficaz de entornos habitables o espacialidades arquitectónicas organizadas para estimular, permitir y plenificar el desarrollo de prácticas sociales estructuradas mediante ceremonias y rituales que requieren objetos y espacialidades coherentes con aquellas.

El diseñador de interiores operará proyectualmente dentro y desde la espacialidad arquitectónica intencionadamente estructurada para una o varias prácticas sociales compatibles, tomando esta configuración inicial como "materia prima" de su acción proyectual. Ésta consistirá básicamente en la selección y distribución armónica y coherente de objetos de equipamiento necesario para cada práctica social, así como del adecuamiento del conjunto de elementos o superficies que constituyen la envolvente arquitectónica de la espacialidad envuelta.

Será obvio que para seleccionar y distribuir objetos, así como para intervenir eficazmente en la envolvente, el diseñador deberá saber establecer el grado de coherencia existente entre la envolvente dada y la práctica social a la que está destinada, potenciando o modificando, según el caso, los rasgos que no tiendan a plenificar esa práctica. Para ello deberá ser capaz de comprender los límites y posibilidades de cada tipo espacial arquitectónico, sus lógicas de coherencia y el modo en que estimulan experiencias estéticas, así como los requisitos simbólicos, conductales y emocionales que cada práctica social requiere.

Sinteticemos diciendo, desde este enfoque, que la acción proyectual del diseñador de interiores consiste en producir una "Forma" que organiza la relación armónica entre prácticas sociales, objetos y envolventes; siendo estos elementos conceptuales y físicos la inicial “materia" de trabajo que impone, a su vez, posibilidades y límites.

Una ambientación espacial eficaz y creativa, que tienda a potenciar y mejorar el desarrollo de las conductas humanas mediante el incremento de las experiencias estéticas que esta ambientación estimula, exige comprender profundamente las relaciones existentes entre Forma-Conducta, Forma-Emoción, y Forma-Significado. Es por ello conveniente aquí profundizar y extender los conceptos inherentes a la relación Forma-Materia intentando construir una mirada rigurosa que guíe un accionar más rico.

\section{Revisando la relación entre Forma y Materia}

Ya sabemos que las nociones de Forma y Materia constituyen un par dialéctico en el que tiende a originarse toda acción proyectual. Esta tensión dialéctica a la que los antiguos griegos llamaron "Hilemorfismo" ha preocupado a generaciones de filósofos y diseñadores. (Ferrater Mora, 1997, pp. 842-844) Veamos, por ejemplo, que Gastón Breyer (1977) (1978) (2003) sostiene que la Forma nace cuando la masa informe, amorfa, de Materia Bruta (la Hyle de los griegos) es organizada por la razón e impuesta como demanda y deseo. Interesa aquí destacar que, para Breyer, siguiendo a Aristóteles, la Materia no tiene "Forma" previa, es "amorfa", "bruta", sin embargo tiene ciertas características o cualidades que estimulan al productor de formas a "organizarla" dándole un principio de orden que permita satisfacer ciertas necesidades o deseos humanos. En rigor, la Materia sólo es 
"amorfa" desde cierto enfoque filosófico generalista, pues en cuanto le descubrimos esos rasgos o cualidades específicas advertimos sus potencialidades y límites configurativos. Podríamos decir que la Materia es, en síntesis, un conjunto de datos a ser interpretados. Para Héctor Federico Ras (2006) la noción de Materia se sustituye por la de "energía" al decir que la Forma es la expresión de la energía organizada.

Recordemos que para Aristóteles la noción de Forma representa la esencia del objeto, aquello que hace que una cosa sea lo que es, mientras que la Materia es, simplemente, "aquello de lo que está hecho algo". (Ferrater Mora, 1997, p. 716)

La Forma tiene "Telos", principio de acción o sentido; la Materia conceptualmente pura, no. Pero ya hemos advertido que los diseñadores trabajamos con "materiales" que ya no son materia bruta y pura sino formas primarias, datos, que exigen y estimulan interpretación y organización.

Estos "materiales", al exigir una interpretación correcta sobre sus posibilidades de uso tienden a establecer o estimular criterios valorativos sobre el modo en que se emplean, determinando posiciones conceptuales sobre la percepción correcta o incorrecta, verdadera o falsa, de su expresión. La cultura ha construido dos términos específicos para estas cuestiones: la palabra "Reología" alude al comportamiento "natural" de los materiales, y la palabra "Etopeya" refiere al uso habitual y desempeño atribuido a objetos y materiales. Es desde este enfoque que podemos entender a Louis Kahn (2012, p. 344) cuando preguntaba enigmáticamente cuál era la forma adecuada de la viga de ladrillo y contestaba que la viga de ladrillo "es un arco"..., ya que el ladrillo no puede absorber esfuerzos de flexión.

En un sentido parecido Roberto Doberti (2003) advierte "Las apariencias engañan, las Formas no". Y en esta frase no sólo alude a la noción de forma emparentándola con la de estructura (matriz inmaterial que organiza las Formas. Lo que no cambia en la evolución de ellas), sino que emparenta a la apariencia o mostración superficial de las formas y envolventes, con la capacidad de "mentir", estimulando la búsqueda de la verdad subyacente en la Forma que sostiene la apariencia...

Y aquí interesa como se vinculan las nociones de "verdad" y "belleza” en la expresión de los materiales, influyendo durante años en los criterios de diseño de la habitación humana.

Recordemos, por ejemplo, como en el siglo XIX, a tono con el espíritu moralista victoriano, John Ruskin (1964, p. 62) formula entre las Siete lámparas de la arquitectura la "Lámpara de la verdad" planteando una nueva relación entre Forma y Materia, cuestionando como "mentiras" arquitectónicas: "la sugerencia de una forma de estructura o soporte que no es la verdadera", tanto como "las superficies pintadas imitando algún otro material distinto al que es en realidad", así como "ll uso de ornamentos de cualquier clase, hechos con molde o mecánicamente". Ruskin cuestionaba los efectos de la Revolución Industrial en la arquitectura y el diseño. Para él una obra genuina debería manifestar la armonía entre las leyes "naturales" de los materiales utilizados y el empleo de los mismos de manera artesanal; es por eso que exige "verdad" en la construcción, marcando su preferencia por materiales como madera y piedra, y sentenciando que "la verdadera arquitectura no admite el hierro como material constructivo"...

Pensamiento similar expresa hacia 1925 Egon Friedell (1931, pp. 299-300) quien cuestiona la artificiosidad de los interiores de la alta burguesía en Viena: 
Las suyas no eran viviendas, sino casas de empeño y tiendas de curiosidades... Tenían manía por artículos de decoración enteramente desprovistos de significación..., manía por superficies de raso: por la seda, el raso y el cuero lustrado; por los marcos dorados, los estucos dorados y los bordes dorados; por el carey, el marfil y la madreperla, así como por artículos de decoración enteramente desprovistos de significación... ( ) En conexión con esto, había una clara ausencia de todo cuanto pudiese aludir a alguna utilidad o función; todo estaba allí para ser visto.

Señalando críticamente, al igual que Ruskin, que en aquellos interiores "Todos los materiales empleados intentaban aparentar más de lo que eran. Máscaras de hojalata pintadas de blanco pasaban por marfil; el cartón piedra, por palo de rosa; el yeso, por fúlgido alabastro; el vidrio, por ónice suntuoso..."1

Durante la naciente modernidad, en la Escuela de la Bauhaus los problemas emergentes de la relación entre Forma y Materia alcanzaron un papel protagónico en torno a la definición de los diseños. Sin embargo, a partir de 1927 cuando asumiera la dirección de la institución Hannes Meyer el compromiso político y social del diseñador sería prioritario, debiendo servir a satisfacer las necesidades de los sectores más vulnerables, evitando las tentaciones formalistas y esteticistas que habían guiado el quehacer de otros movimientos como el Arts and Craft y la Deutsche Werkbund, de manera tal, que la relación Forma-Materia debería ser mediatizada por la Utilidad, lo que no era otra cosa que volver a la clásica triada vitruviana. Es por ello que Luis Arenas (2008, p. 10) sostiene que en ese período de la Bauhaus "Tanto un edificio como una modesta silla era el producto de una planificación sistemática que debía estar acorde con las exigencias del material y con las necesidades del usuario". En 1927, siguiendo la impronta marcada por Meyer, Mies van der Rohe (1927, p. 59) señalaba que no existían problemas de forma, sólo problemas de construcción...2

Es obvio que con esto Mies (1923, p. 1) quería romper el desprecio academicista por los problemas tecnológicos, pero menos evidente es el vínculo profundo que durante la década del veinte y comienzos del treinta se estableció entre el Círculo de Viena y la Bauhaus. De tal modo que el aparente rechazo explicitado hacia la Forma no es otro que la oposición a la metafísica que sostiene el positivismo lógico. No es casual entonces que el Manifiesto del Círculo de Viena concluyera con:

Experimentamos cómo el espíritu de la concepción científica del mundo penetra en creciente medida en las formas de vida pública y privada, en la enseñanza, en la educación, en la arquitectura, y ayuda a guiar la estructuración de la vida social y económica de acuerdo con principios racionales. La concepción científica del mundo sirve a la vida y la vida la acoge. (Hahn-Neurath-Carnap, 2002, p. 124)

Al mismo tiempo que el ubicuo Mies afirmaba de manera similar "una forma real presupone una vida real. ( ) La vida es para nosotros el factor decisivo". En ese contexto es que la conferencia que dictara en la Bauhaus en 1929 Rudolf Carnap, miembro del Círculo de Viena, se llamaría "Ciencia y vida" mientras que simultáneamente Hannes Meyer definiría 
al acto de construir como la organización de los procesos vitales. Es interesante notar que Kenneth Frampton (1987, p. 9) destaca la "desmaterialización materializada" de la arquitectura de Mies, ya que éste "veía el material como una substancia en sentido fenoménico, esto es, lo consideraba un material nuevo que había que abordar mediante la inversión de los modos tradicionales de la concepción y la percepción arquitectónica”.

Durante la vigencia del Movimiento Moderno, a pesar de numerosos dichos acerca de la importancia del empleo de nuevos materiales y tecnologías, así como de la industrialización de la construcción, el nuevo par, celebrado por el funcionalismo, estableció la potente relación entre Forma y Función. Vale en este sentido mencionar la investigación realizada oportunamente por Juan Pablo Bonta (1977, pp. 220-232) sobre la inasible materialidad constructiva del Pabellón Alemán realizado por Mies en Barcelona...

Recordemos asimismo dos definiciones: Alison y Peter Smithson (1965, p. 590) estipulaban que:

Esencialmente una arquitectura moderna fue (a) Cúbica, o parecía tallada desde cubos. (b) Organizada geométricamente y muy abstracta en su interpretación de las actividades humanas. (c) Algo completo, en sí mismo. (d) Colocada, no enraizada a su sitio. (e) Normalmente blanca y de colores fuertes, o hecha de materiales brillantes. (f) Los materiales naturales cuando eran usados aparecían como substitutos de materiales artificiales todavía no inventados.

Coincidiendo en este punto con las consideraciones que Frampton formularía sobre Mies Mientras que Montaner (1993) dice que:

Tres son los principios formales básicos de esta arquitectura: la arquitectura como volumen, como juego dinámico de planos más que como masa; el predominio de la regularidad en la composición, sustituyendo a la simetría axial académica; y la ausencia de decoración añadida que surge de la perfección técnica y expresividad del edificio a partir del detalle arquitectónico y constructivo.

En estas dos caracterizaciones la materialidad se expresa como un aspecto menor del diseño, quedando, de esta manera, el material constreñido a la tecnología empleada, con la implícita condición que la categoría textural del material -ligada a las técnicas artesanales superadas- desapareciera en pos de alcanzar una máxima abstracción geométrica. Este propósito manifestaba la paradoja tecnológica de la modernidad: alcanzar una materialidad inmaterial o como diría Frampton "desmaterializada".

En su serie de libros sobre Materiales de Proyecto, Helio Piñón (2005, p. 5) sostiene en el prefacio que:

$\mathrm{Al}$ situar el proyecto de arquitectura en el ámbito de las ideas, e identificarlas con la manifestación de meras intenciones, se desvanece su condición esencialmente formal -estructurante, ordenadora-, lo que provoca el 
eclipse de la noción de materia: en efecto, la consideración del material constructivo -elementos físicos con que se afronta la construcción- es obviada, en general, por considerarla un momento secundario respecto de "la idea", de modo que a menudo ésta se describe sin ninguna alusión a la materialidad del objeto.

Esta devaluación de la materia, en su sentido más cotidiano -el de material de construcción- que reaparece de una manera nueva en el siglo XXI, se diferencia de aquel otro desprecio de lo constructivo que tuvieran los arquitectos a fines del novecento que implicó la diferenciación entre el oficio del ingeniero orientado a operar con la prosaica materia y el del arquitecto que se definía a la manera de Alberti como "decorador de fachadas", como un manipulador de la etérea belleza. En este tiempo presente que vivimos, los materiales no son ya un obstáculo prosaico para la idea sublime: la forma puede prácticamente materializarse de muchas maneras...

Observemos por cierto que Piñón (2005, p. 5) le da un nuevo enfoque a la noción de "Materia", y esto va entrañar:

Hablar de material de proyecto, es decir, aquellos elementos, criterios, o soluciones, pertenecientes a la experiencia propia o ajena, que constituyen la materia prima del proyecto a la que el sentido del orden de quien proyecta conseguirá dotar de estructura formal.

Esta definición abre el juego hacia un número importante de "materiales", es decir todo aquello que tendrá en cuenta el diseñador en el momento de iniciar su proceso proyectual, desde los requerimientos, recursos y condicionantes que se explicitan en esta instancia germinal hasta aquellos otros, no tan obvios ni conscientes que constituyen la estructura conceptual, los referentes, los valores, la sensibilidad o las herramientas proyectuales que posee el propio diseñador.

\section{Los materiales en el Diseño de Interiores: lo espacial y lo textural}

Cuando hablamos de Diseño de Interiores debemos diferenciar entre el espacio configurado y los materiales configurantes. Sin embargo estos configurantes, al perder su papel de estructura soporte y abrigo (dominados por la arquitectura) quedarán limitados a su mostración superficial o textura, textura que debe ser reconquistada en todas sus cualidades. Respecto al hueco configurado debemos recordar los trabajos iniciales de Arnheim (2001) y Ras (1989) (1999) (2006), así como la taxonomía elaborada por Pokropek (2015) donde se redefinen las nociones de patio, claustro, ambulatorio, enclave, recinto adscripto y recinto adyacente, así como las espacialidades ambiguas como la partición de un continuo y la fusión en continuo, incluyendo también los intersticios espaciales entre figuras plásticas o volúmenes macizos...

En función de la condición material o virtual, es decir, llena o vacía, de las figuras protagónicas, podremos establecer tres grandes grupos o "estados" de la espacialidad organizados 
categorialmente, es decir, sobre un eje que vincula nociones opuestas en cada extremo y establece un territorio intermedio de ambigüedad o equilibrio.

Desde este enfoque clásico tendremos en un extremo del modelo polar al conjunto de las organizaciones formales cuyas entidades o figuras protagónicas pueden describirse como recintuales, vacías o virtuales por tratarse esencialmente de lo que solemos denominar "Recintos" o "Habitaciones". Podemos advertir que al experimentar estas espacialidades el sujeto se percibe "dentro" de una burbuja o membrana virtual que, merced a sus proporciones es perceptualmente más nítida o pregnante que el conjunto de entidades materiales que la configuran. El universo formal de las figuras huecas o "recintuales", es vasto y merece oportunas profundizaciones futuras. (Pokropek, 2015)

En el extremo opuesto del eje categórico encontramos las espacialidades compuestas por entidades o figuras protagónicas factibles de percibirse como "llenas", macizas o "plásticas". Tradicionalmente llamamos a estas organizaciones formales como "sostén de figuras plásticas" por estar "sostenidas" o "consistir" en conjuntos de volúmenes perceptualmente llenos o macizos, oponiéndole los sistemas formales definibles como "sostén de figuras recintuales". El lenguaje es estricto al respecto: se está "dentro" de un recinto o se está "entre volúmenes macizos" o "en" un territorio intersticial.

Siguiendo a Ras (2006) recordemos ahora que la noción de "Intersticio" alude a una condición espacial carente de la suficiente fortaleza formal o aptitud figurativa que impide leerla como figura protagónica. En el caso de las espacialidades del tipo "Sostén de figuras Plásticas" el territorio intersticial constituye el necesario y fundamental "fondo" donde se recortan o leen las "figuras". Obvio es señalar que intersticios espaciales puede haber tanto entre figuras plásticas como entre figuras recintuales. Su proliferación y protagonismo formal en algunas espacialidades pueden llevarnos a clasificarlas, oportunamente, como "fusión en continuo".

Reinterpretando la noción de "ámbito" empleada por Ras, diremos que, para nosotros, "Fusión en continuo" reemplaza este término ambiguo, e involucra al conjunto de espacialidades cuya organización formal presenta un equilibrio dinámico, homogeneizador entre las diversas partes del sistema que dificulta percibirlas como individuos para subsumirlas en una sensación de globalidad e ilimitación donde radica la coherencia del sistema. Según Ras, el tipo configurativo "Ámbito" (Fusión en continuo) tiene su principio de consistencia en percibir precisamente como protagónica la relación equilibrada entre las diversas partes, pudiendo ser éstas: Plásticas, Recintuales o Mixtas. Este equilibrio dinámico depende fundamentalmente de la distribución relativamente homogénea de las partes del sistema y de su capacidad de subordinación figurativa en función del todo merced a una "fusión textural" que dificulta segregar cada entidad del conjunto.

Para Ras las tramas espaciales, cuando se expresan no como organizadoras de una figura sino como protagónicas participantes de la organización formal, tienden a constituir un ámbito (fusión en continuo en nuestra nomenclatura). La interioridad selvática es, asimismo, otro ejemplo posible donde la noción de textura vegetal se impone a la percepción de cada planta. Desde ese mismo enfoque un conjunto ilimitado de recintos transparentes tiende a percibirse como fusión en continuo.

Actualmente se están explorando organizaciones formales a partir del plegado de una entidad laminar protagónica (Toyo Ito, Ben van Berkel, etc.) la cual, en función de sus 
desplazamientos espaciales tiende simultáneamente a fragmentar y vincular inestables recortes espaciales que tienden, según el caso, a proponerse como vacíos figurativos. Advirtamos que una organización espacial así configurada deberá clasificarse como fusión en continuo mientras se lea como figura protagónica del sistema a la relación dialéctica entre los pliegues de la lámina material y sus intersticios espaciales o vacíos no figurativos. No sucedería lo mismo si, manteniendo un equilibrio dinámico entre llenos y vacíos, los pliegues laminares tendieran a configurar vacíos figurativos. En este caso estaríamos en presencia del cuarto tipo configurativo espacial básico nominado tradicionalmente por Ras como "Partición de un continuo".

Recordamos que, según Ras:

Se entiende por "partición de un continuo" al sistema formal en el cual la fortaleza figural de los elementos plásticos que lo integran se equilibra con la de las formas huecas que ellas proponen. Es un caso de ambigüedad en la categoría de consistencia.

Observemos que la experiencia espacial que el sujeto experimenta al recorrer una organización formal del tipo "Partición de un continuo" consiste en advertir la tensión espacial generada en la insatisfacción configurativa de los vacíos con vocación recintual merced a la estratégica disposición y tamaño de placas o láminas materiales.

Clasificar y nombrar "Partición de un continuo" a este particular sistema formal ubicado en la zona de ambigüedad entre las espacialidades recintuales y plásticas, obedece al deseo de expresar lo más diáfanamente posible la compleja pero no inefable experiencia mental de percibir simultáneamente un continuo espacial a punto de fragmentarse en sucesivos recintos, o un débil recinto a punto de diluirse o fluir en un continuo espacial... Experiencia frecuente en museos o galerías de arte.

En síntesis, habiéndonos "metido" en la organización formal de una espacialidad interior merced a que ésta es penetrable y recorrible, advertiremos que las entidades o "figuras", materiales ("llenas") o virtuales ("vacías"), que constituyen la organización formal, poseen características específicas de ubicación que determinan la estructura del sistema, y características específicas de mostración o apariencia que determinan su textura.

Arnheim (2001) señala que:

El diseño, naturalmente, no es ni más ni menos que la creación de las formas tangibles y visibles de un edificio. ¿Cómo, entonces, el diseño puede llegar a ser considerado como algo de lo que se puede prescindir? ( ) ¿ $\mathrm{O}$ esta aversión es una protesta contra una cruzada más reciente de desnudez, que esconde la variedad de los impulsos humanos en una geometría pura pero a menudo vacía? Sea cual fuere la causa, cualquier intento de evitar la responsabilidad última del arquitecto debe ser vano. Se puede desdeñar la forma de un objeto, pero no es posible prescindir de ella.

Esta sentencia de Arnheim pareciera ser una respuesta a aquel ambiguo Mies de 1927. La geometría pura no elimina al diseño, la racionalización no reemplaza en modo alguno a la 
experiencia perceptual de un sujeto que interactúa en, dentro o entre estas espacialidades. Sin embargo la noción de tangibilidad termina cruzada por lo perceptual, de tal modo que real y virtual muchas veces se cruzan y se desdibujan...

En este sentido recordemos que las estructuras pueden ser explícitas o implícitas según la materialidad o inmaterialidad de las entidades que la forman. Para su percepción sensible requieren de una materialidad visible que expresa ciertas características formales. Ya dijimos que esta expresión de la materialidad sensiblemente percibida recibe el nombre de textura o mostración superficial. Ras (2006, p. 24) dice que se puede definir la textura como la modalidad según la cual se pone de manifiesto la superficie o volumen de un objeto, "in abstracto" de él. Ras también propone un listado de categorías formales texturales cuyo empleo frecuente permite establecer patrones en las relaciones forma-conducta, forma-emoción.

Los pares categóricos texturales más empleados en el análisis de las espacialidades así como en su configuración intencionada son: homogéneo-heterogéneo, denso-diáfano, transparente-opaco, esquemático-farragoso, céldico-ambitual, luminoso-oscuro, brillosomate, permeable-impermeable, rugoso-liso, áspero-suave, cálido-frío, artificial-natural, blando-duro, etc. Categorías que podrían ser expresadas con diferentes materiales físicos y cuya concreción dependerá de aspectos perceptuales o fenoménicos y de la intencionalidad estética propuesta. Vale en este sentido mencionar el clásico análisis de Sven Hesselgren (1973, p. 323) donde vincula los aspectos ópticos con los táctiles en los tradicionales materiales de construcción: "el hecho de que la percepción táctil da expresión al material no parece resultar de la experiencia individual ni de asociaciones privadas, sino que parece ser, evidentemente, un fenómeno humano espontáneo y común (intersubjetivo)”. Es interesante además notar que estas "transferencias metafóricas" entre sentidos habían sido ya reconocidas por Nelson Goodman (1990, p. 25) cuando, por ejemplo, se califican categorías visuales con predicados atribuibles a lo auditivo o táctil como es el caso de estridente y atenuado, o suave y áspero....

Esta convergencia fenomenológica y sensorial puede apreciarse en la caracterización que realiza Simon Unwin (2010, p. 215) de los Baños Termales de Vals, obra de Peter Zumthor donde sostiene que "se trata de un edificio que ofrece para todos los cinco sentidos, la vista, el tacto, el oído, el olfato y gusto, pero promete otras sensaciones también...”

Señalemos que los listados posibles de características texturales o estructurales pueden extenderse según la conveniencia del diseñador, quien podrá hacer uso protagónico de categorías formales aquí no enumeradas. El mismo Peter Zumthor (2006, p. 22) rescata lo que el denomina la "consonancia de los materiales", ya que éstos tienen miles de posibilidades de empleo, pero no cualesquiera, dependiendo su uso de la sensibilidad del proyectista, destacando asimismo cómo estos materiales pudieran reflejar la luz y el sonido, lo cual redunda obviamente en la experiencia espacial. Parecida conclusión formula Christopher Williams (1984) quien sentencia que:

Todos los materiales poseen sus características idiomáticas. El idioma de ese material es una exigencia formulada a su usuario, para que comprenda su identidad personal y su significado, sus fuerzas y sus debilidades, su estructura, sus formas más cómodas, su mejor uso. 
Es por ello que Luis Moreno Mansilla (2005, p. 146) pareciera concluir diciendo que: "porque la materia no cambia cuando la miramos, pero nuestros ojos sí. El espacio de la arquitectura es entonces el instante en que se desdobla el perfil de las cosas, de la materia." No podemos en este punto eludir tanto las exploraciones actuales de Herzog \& Meuron en torno a lo textural, de Toyo Ito, Kazuyo Sejima y Shigeru Ban sobre la porosidad de los elementos configurantes, como aquellas otras iniciadas entre el 50 y 60 por Franco Albini, Carlo Scarpa y Mario Ridolfi que implicaron no sólo una oposición a la abstracción moderna sino también una crítica al brutalismo entonces vigente, tarea que se fundamentó a partir de la consideración que "el ejercicio de análisis y de explicitación del material provisto por las leyes de construcción y conformación del objetivo arquitectónico era la substancia principal...", lo cual había significado por un lado tanto la "negación del valor de la construcción como material portante..." como "un renacimiento de interés por la decoración, o mejor por el ornato (según la distinción que Rogers hacía de estos dos términos)". (Gregotti, 1985, p. 2)

Vale también en este sentido observar obras que enfatizan los aspectos texturales de los configurantes como los interiores del nuevo hotel en Atenas de los hermanos Campana, el Museo Groninger de Alessandro Mendini, el restaurante Switch de Dubai de Karim Rashid o el Hotel Mandarin Oriental de Barcelona de Patricia Urquiola, texturas que contribuyen a la ambitualización espacial, e incluso a la propia desmaterialización de los configurantes...

\section{Conclusiones provisorias}

Esta breve reflexión sobre la relación entre la noción de Materia y la praxis proyectual de los diseñadores de interior debe, necesariamente, intentar ofrecer una síntesis que guíe esa praxis.

Digamos entonces que, como hemos señalado, la noción de materia admite desdoblarse en dos grandes grupos conceptuales básicos.

En un grupo ubicaremos aquellas materias o materiales de carácter abstracto, intangible o simbólico al que Pinón conceptualizara como "Materiales de Proyecto", es decir al conjunto de ideas, preexistencias proyectuales, y requisitos específicos de las prácticas sociales. Este conjunto de datos previos, de interpretación inevitable y creativa, orientará la estrategia proyectual, instrumentada mediante operaciones de diseño sobre materiales tangibles, concretos, con estructura y textura dada, con historia propia y significados intrínsecos y atribuidos, así como respuestas percetuales específicas que tienden a estimular emociones y conductas prefijadas en el receptor habitante mediante códigos interpretativos de origen filogenético y ontogenético ${ }^{3}$.

Profundicemos en estos últimos dichos por su importancia para el saber hacer proyectual. Ya dijimos que el receptor-habitante al percibir el conjunto de elementos que configuran un entorno habitable intencionado para satisfacer una práctica social experimenta diversos estímulos traducidos en sensaciones e interpretados simbólicamente que pueden organizarse para producir una experiencia estética cuando el principio de orden que los guía produce un efecto de sentido que trasciende las funciones utilitarias para alcanzar la función estética. 
Interesa aquí hacer hincapié en la importancia de la relación estímulo-respuesta. Hemos mencionado que el receptor-habitante experimenta su entorno físico mediante un mecanismo mental que los psicólogos de la Gestalt llaman "mecanismo de transformaciones propioceptivas". Este mecanismo establece que todas las percepciones visuales tienden inevitablemente, en traducirse experiencialmente como percepciones olfativas, gustativas, auditivas y hápticas. Asimismo estas percepciones encadenadas armónicamente determinan interpretaciones o lecturas de significados intrínsecos a la organización formal y a su mostración textural. Hablamos entonces de calidez o frialdad, solemnidad o espontaneidad según el modo en que el entorno ha sido organizado.

Desde este enfoque será fundamental que el diseñador de interiores sepa establecer mediante la sabia selección de texturas, organizaciones espaciales y objetos aquellas cadenas armónicas perceptuales que tiendan a estimular intencionadamente la adecuada relación entre emociones, conductas y significados.

El hábil manejo de categorías sintácticas enhebradas armónicamente en función de una intención estética constituye el núcleo del saber hacer proyectual.

La distancia entre espacialidades que estimulen experiencias opuestas, tales como la espiritualización anímica versus la sensualidad o el hedonismo, dependen, insistimos, de la selección de cadenas armónicas de polos que guíen la selección y el diseño de las texturas del entorno. La interpretación de espacios espiritualizados, propicios para prácticas solemnes y simbólicamente trascendentes, suele organizarse dentro del borroso concepto de "minimalismo", un sistema formal definido, esquemático, céldico, frío, homogéneo, diáfano, con iluminación difusa que tiende a interpretarse como ascético, sobrio, esencial, "verdadero", y por lo tanto, espiritualmente profundo. Propicio para el pensar pero no para el amor y la gula. El goce erótico convoca, en cambio, lo indefinido, farragoso, ambitual, cálido, heterogéneo, con iluminación escasa o sectorialmente focalizada y, atmósfera densa. Estas categorías tienden a leerse como protagónicas de una espacialidad rica, exuberante, amable por blanda y versátil, propicia para reuniones sociales distendidas y alegres.

Las nociones de lujo, elegancia, juventud, libertad, alegría o tristeza, se "materializan" mediante texturas y lógicas organizativas. Sobre ellas y desde ellas debe trabajar el diseñador de interiores, respetando en principio la lógica proyectual propuesta inicialmente por la espacialidad arquitectónica dada, y por la adecuación a la práctica social protagónica. Por ahora, nada más.

\section{Notas}

1. Friedell, Egon (1932). A Cultural History of the Modern Age,, Alfred Knopf, Nueva York, Pág. 299-300. https://monoskop.org/images/a/ae/Friedell_Egon_A_Cultural_History_of_the_Modern_Age_Vol_3.pdf

Citado también por (Janik, - Toulmin, 1998, p. 121)

Parecido "horror vacui" se presenta en la crónica del casamiento de Carlos María de Alvear con María Mercedes Elortondo según una nota publicada en el diario El Nacional de mayo de 1882 en el se describe el Palacio de la familia. 
2. Citado también en (Banham,1985, p. 271) (Drexler, 1961, p. 7) (Neumeyer, 1995, pp. 393-394).

3. Recordar la función primaria y secundaria de Umberto Eco...

\section{Bibliografía}

Arenas, L. (2008). La casa como gesto. La arquitectura en Wittgenstein y el neopositivismo vienés. Disponible en http://www.unizar.es/seminario/archivos/luis_arenas_la_casa_ como_gesto.pdf

Arnheim, R. (2001). La forma visual de la arquitectura. Barcelona: Editorial Gustavo Gili.

Banham, R. (1985). Teoría y diseño en la primera hora de la máquina. Barcelona: Paidós.

Bonta, J. P. (1977). Sistemas de significación en arquitectura. Barcelona: Editorial Gustavo Gili.

Breyer, G. (1978). "La heurística del diseño" en Revista Summa No 131, Buenos Aires, diciembre de 1978.

Breyer, G. (1977). "Morfología y heurística" en Sumario No 9/10, Buenos Aires, 1977.

Breyer, G. (2003) . “Introducción” en Giordano, D.; Wainhaus, H.; Pescio, S.; Pereyra, C. y Frigerio, M. C. (2003). Cinco notas sobre Heurística del Diseño, FADU/Cuadernos de Cátedra, Buenos Aires.

Doberti, R. (2008). Espacialidades. Buenos Aires: Ediciones Infinito.

Drexler, A. (1961). Mies Van der Rohe. Barcelona: Editorial Bruguera.

Ferrater Mora, J. (1997). Diccionario de Filosofía, Tomo I y Tomo II, Sudamericana, Buenos Aires.

Frampton, K. (1987). "Modernidad y tradición en la obra de Mies van der Rohe" en Summarios No. 114, 1987

Friedell, E. (1932). A Cultural History of the Modern Age, Alfred Knopf, Nueva York en https://monoskop.org/images/a/ae/Friedell_Egon_A_Cultural_History_of_the_Modern _Age_Vol_3.pdf

Gregotti, V. (1985). "El ejercicio del detalle" en Summarios No 93 "Dios está en los detalles", septiembre de 1985.

Kahn, L. (2012). “Amo los inicios” en Hereu, P.; Montaner, J. M. y Oliveras, J. (ed.) (2012) Textos de arquitectura de la modernidad. Barcelona Editorial: Nerea.

Goodman, N. (1990). Maneras de hacer mundos. Madrid: Visor.

Janik, A. y Toulmin, S. (1998). La Viena de Wittgenstein. Madrid: Taurus.

Hahn, H.; Neurath, O. y Carnap, R. (2002). "La concepción científica del mundo: el Círculo de Viena" en REDES Revista de Estudios sobre la Ciencia y la Tecnología Vol. 9, № 18, junio de 2002, Buenos Aires.

Mies van der Rohe, L. (1923). "Bauen" publicada en la revista $G N^{\circ} 2$, septiembre de 1923.

Mies van der Rohe, L. (1927). "Ubre die Form in der Architektur”, publicada en la revista Die Form No 2. 1927.

Montaner, J. M. (1993). Después del Movimiento Moderno - Arquitectura de la segunda mitad del siglo XX - Arquitectura ConTextos. Barcelona: Editorial Gustavo Gili.

Moreno Mansilla, L. (2005). "Sobre la confianza en la materia” en Moreno Mansilla, L.; Rojo, L. y Tuñón, E. (2005). Escritos Circenses. Barcelona: Editorial Gustavo Gili. 
Neumeyer, F. (1995). Mies van der Rohe, la palabra sin artificio. Madrid: El Croquis Editorial. Pokropek, J. (2015). La Espacialidad Arquitectónica. Buenos Aires: Nobuko.

Ras, H. F. (1989). Ensayo. Memorias sobre Morfología, Conducta y Estética. Buenos Aires: Serie Ediciones Previas - FADU- UBA.

Ras, H. F. (1999). El entorno y su imagen. Buenos Aires: Editorial Laf.

Ras, H. F. (2006). Las Expresiones de la Arquitectura. Buenos Aires: FADAU-UM.

Ruskin, J. (1964). Las siete lámparas de la arquitectura. Pamplona: Aguilar.

Smithson, A. y Smithson, P. (1965). "El período Heroico de la arquitectura moderna" en Architectural Design No 12, Diciembre 1965.

Unwin, S. (2010). “Thermal Baths, Vals” en Twenty Buildings Every Achitect Should Understand. Routledge, Taylor \& Francis Group. London - New York.

Williams, C. (1984). Los orígenes de la forma. Barcelona: Ed. Gustavo Gili.

Zumthor, P. (2006). Atmósferas. Barcelona: Ed. Gustavo Gili.

\begin{abstract}
This paper reflects on the notions of materiality and its use in the design praxis of interior designers. The purpose is to review those criteria and conceptual tools in which the notion of Matter has a leading role. With this object we will inquire about the relations that are established between Form and Matter, as well as about the dialectical tension between configured space and superficial display.
\end{abstract}

Key words: Form - Matter - Configured space - specialities - Superficial display - Texture.

Resumo: este artigo apresenta uma reflexão sobre as noções de materialidade e seu uso na prática Projetual dos designers de interior, com a intenção de revisar critérios e instrumentos conceptuais onde o conceito de matéria tem um papel primordial nessa prática. Com esse objetivo, se indagará nas relações que se estabelecem entre Forma e Matéria, assim como a tensão dialética entre espaço configurado e expressão superficial.

Palavras chave: forma - matéria - espaço configurado - espacialidades - expressão superficial - textura. 



\section{Desmaterialización e inmaterialidad en el contexto contemporáneo del Diseño}

Leila Lemgruber Queiroz *

Resumen: Este artículo incluye reflexiones sobre la importancia de considerar, en la actitud proyectual del diseño, la desmaterialización y la inmaterialidad. El enfoque va dirigido a los atributos de sostenibilidad en el escenario de la Posmodernidad. Lo que se pretende recalcar son paradigmas innovadores sobre la configuración de artefacto que decontruyen el sistema convencional de producción, distribución y consumo. Las cuestiones que se tratan en el texto se refieren a los factores condicionantes de la cultura material, así como de la cultura inmaterial.

Palabras clave: Desmaterialización - Inmaterialidad - Posmodernidad - Sostenibilidad Diseño.

[Resúmenes en inglés y portugués en la página 35]

${ }^{(*)}$ Doctora y Master en Diseño de la PUC-Rio con MBE en Gestión de Sustentabilidad por el Instituto de Economía de UFRJ.

\section{Introducción}

En un mundo lleno de objetos, lo que se pone en cuestión es la deconstrucción del concepto clásico de la cultura material. En esta visión, el campo del diseño imprime su marca a través de la configuración de los objetos. Ya sea por su rediseño o la introducción de nuevos artefactos. A partir de este escenario, se presenta una reflexión sobre la posibilidad de deconstruir el concepto sobre el campo del diseño que se está relacionado con esta actitud proyectual sobre la configuración de objetos. Por lo tanto, se tratará aquí este proceso de deconstrucción a través de dos condiciones anteriores al proyecto de diseño: desmaterialización e inmaterialidad. Cabe destacar que estas dos condiciones se las pondrán aquí en ejes temáticos distintos, aunque tienen una raíz común. De esta manera, lo que se pretende señalar son algunos atributos del campo de la sostenibilidad en el escenario contemporáneo, entendido aquí como la posmodernidad, que conducen a la reinvención de nuevos hábitos y paradigmas en el campo del diseño.

Lo que se presentará en este texto se refiere a las preguntas y reflexiones sobre qué y cómo configurar objetos en la era de la posmodernidad. Sobre todo, porque la formulación de 
los problemas de posmodernidad es una oscura tarea. El volatilidad y la fragmentación, atributos de esta edad, impiden una visualización clara y directa de sus problemas.

Teniendo en cuenta el panorama contemporáneo, nuestra reflexión va dirigida a la movilidad, con gran aceleración. Utilizamos el concepto de Bauman sobre la Modernidad Líquida con el fin de que logramos sumergirnos en este mundo en el que el grado de éxito se mide por el estándar de la posesión, consumo de bienes materiales, demasiada información y, más aún, involucrados que están los individuos en la desechabilidad permanente, por lo que corre siempre en busca de la próxima la innovación, objetual o virtual. Impera la aceptación de lo efímero, lo descontinuo y los cambios caóticos.

Las cuestiones relacionadas con la sostenibilidad, para la configuración de nuevos artefactos, absorben no solo el sentido fragmentario, pero los riesgos y las incertidumbres de la escena contemporánea. Por lo tanto, se hace urgente introducir diferentes paradigmas en los procesos de configuración, producción, distribución y consumo.

Si movemos nuestro foco al campo del diseño, podemos asumir una actitud, a primera vista radical, de que el diseño proporciona una mejor calidad de vida a través de proyecto de múltiples artefactos, cuando lo que importa sobre todo es el mantenimiento de la producción de mercancías.

Se habla que el diseño cumple con las necesidades, cuando sabemos que éstos se construyen en rebeldía del sujeto e incorporadas a su vida como inexorablemente esenciales. Inventadas como fábulas. A veces, incluso placenteras.

La reconfiguración de la cadena de suministro contemporáneo, impuesta por el capitalismo flexible, permite la aceleración de los impactos ambientales y sociales. Sobre todo porque la no linealidad de los procesos dificulta la visibilidad de todo el sistema productivo. Destacamos aquí que la industria contemporánea presenta estas características: la materia prima puede ser de una región del planeta y su fabricación de la región opuesta. Pero los usuarios están esparcidos por todas las regiones. Sin embargo, el producto final pertenece a la misma marca. Esta es la economía descentralizada del capitalismo flexible.

Cabe señalar que los residuos derivados de la producción y consumo afectan nuestros suelos y migraran, a veces, a países que acepten absorben materiales contaminados. La cuestión del proceso del reciclaje no se desarrollará aquí ya que entendemos que es un proceso ya comprobadamente envuelto con características económicas negativas por su alto coste de energía y logístico.

$\mathrm{Al}$ hacer referencia puntualmente al diseño, estando él al servicio de la economía de mercado, destacamos su colaboración para que el papel de comando que se ha atribuido a los artefactos se ponga exacerbado. Se introduce este comando a un ritmo creciente que supera el proyecto del propio artefacto para instalarse en la construcción de escenarios de nuestra vida cotidiana. Todo se convierte en "diseño": desde el olor que se debe oler hasta la estética que se debe tragar.

Preguntar y reflexionar sobre estas premisas, que han producido la industria de consumo, es factor determinante al oficio del diseñador.

Varios teóricos han abordado en sus escritos el papel del diseño en el mundo contemporáneo mediante la promoción de la reflexión crítica. Sin embargo, Hal Foster ha realizado una crítica más aguda. En el artículo Diseño y Delito, Foster se deshilacha el tejido del diseño contemporáneo con sus conceptualizaciones insertadas en el contexto actual. 
Según Foster, la estética y lo utilitario no se encuentran solo fundidos, pero por encima de todo incluidos en todo lo que pasa a nuestro alrededor. Desde los vaqueros a los genes como recalca Foster.

Hal Foster, en el siglo XXI insinúa el papel “desviado" del diseño. Su acción maléfica está esparcida en todos los grupos sociales. Según el autor, hay demasiado diseño en el mundo hoy en día. La penetración del diseño en la vida contemporánea es total. No hay espacio para escapar de este marco impuesto por un sistema. En este sistema, el mundo del diseño total se impone como nuevo ingrediente para poner en marcha la competitividad en los negocios, haciendo uso cada vez más de la seducción. A causa de esta situación, el embalaje lleva mayor importancia que el producto que lo contiene.

Foster desarrolla su pensamiento que justifica la inflación del diseño en el escenario actual, a causa de vectores como la flexibilidad de la economía, el valor exacerbado que asigna a las marcas y al crecimiento de industrias medianas en la economía. En esta política económica de diseño, no se piensa el producto como un objeto a producir, sino como una cosa a manipular, es decir, ser "diseñado" y "rediseñado", consumido y reconsumido. De esta manera, las cuestiones que se desarrollan en la reflexión crítica sobre el papel del diseño en el escenario posmoderno, se refieren, en este texto, acerca de otras posibilidades que interfieren en la materialidad como condición previa proyectiva.

\section{La reflexión sobre las condiciones proyectuales: desmaterialización e inmaterialidad}

Hay una conformidad de pensamiento que impregna la sociedad, entre la incompatibilidad del proceso industrial y el medio ambiente. Los ecologistas caracterizan la industria como destructiva, a causa de la forma convencional de uso de los recursos naturales, su procesamiento y posterior desecho de sus productos en la basura. Por otro lado, los industriales ven el ecologismo como un obstáculo para la producción y el crecimiento. Para que el medio ambiente sea "saludable", según el pensamiento convencional, las industrias necesitan encontrarse bajo cierto control, a través de reglamentos. Otra corriente de pensamiento con respecto a los límites que se deben imponer al consumo: compre menos, gaste menos energía, tenga menos hijos y... reduzca su basura. Usando este paradigma, los seres humanos necesitan hacer algunos sacrificios para salvar el planeta.

McDonough\&Braungart comienzan el libro Cradle to Cradle, citando el pensamiento de Einstein: "El mundo no va a superar su crisis actual utilizando el mismo pensamiento que ha creado esta situación." A partir de esta concepción, los autores introducen un nuevo modelo de producción. La cuestión clave no es reducir, minimizar o evitar el desperdicio, sino eliminar el propio concepto de generación de impactos, a través de nuevos paradigmas, a través del diseño sistémico.

¿Cómo puede el ser humano vivir sin culpa en su planeta, disfrutando de las comodidades que proporcionan el mundo contemporáneo? Esta pregunta contiene todas las cuestiones relacionadas con el dilema entre el consumo y la posibilidad de degradación del medio ambiente. 
La sociedad actual se refiere al individuo como un "consumidor". De hecho, en realidad poco se consume. Se puede hablar de lo que se come o bebe como ejemplos de lo que se consume. El resto está diseñado para arrojar fuera cuando su uso tiene el orden decretado, por el propio individuo o por el sistema industrial. Sin dejar de mencionar que además de la acumulación de la materia desechada, se desecha también toda la toxicidad presente en el producto, lo que causa efectos desastrosos en el ecosistema. De esta manera, el aire, el agua, el suelo no absorben de forma segura los desechos, a menos que estén exentos de riesgo: sanos y biodegradables.

Fritjof Capra desarrolla su pensamiento sobre la Ecología basado en una perspectiva sistémica. De acuerdo con este punto de vista, las propiedades esenciales de un organismo o un sistema vivo son propiedades del todo, que ninguna de las partes tiene por separado. Estas ideas que vienen de los biólogos organicistas durante la primera mitad del siglo $\mathrm{XX}$ han ayudado a introducir una nueva forma de pensar, el pensamiento sistémico. Esta comprensión de que los sistemas son totalidades integradas, ha desatado una revolución en distintos campos del conocimiento científico. La física cuántica ha cambiado la forma con la que, desde Newton, se creía que los fenómenos físicos podrían "reducirse a las propiedades de las partículas materiales rígidas y sólidas". La teoría cuántica ha presentado el hecho de que los objetos materiales antes identificados por la física clásica como siendo sólidos, de hecho se disuelven "en el nivel subatómico en estándares de probabilidades similares a las ondas”. Por lo tanto, en la Teoría Cuántica no llegamos a una sola cosa, sino también a las interconexiones. Los componentes de las moléculas y los átomos descritos como partículas subatómicas, no pueden considerarse como entidades aisladas sino de acuerdo con sus interrelaciones.

A partir de esta concepción, sobre la Ecología, se puede entender más claramente, el pensamiento de Manzini sobre la Ecología Industrial. Cabe señalar que el modelo de la Ecología Industrial, el sistema de producción y de consumo tiende a organizarse acercándose del funcionamiento de un sistema natural que combinan los "tecnociclos y biociclos".

Tecnociclos se definen como el conjunto de procesos tecnológicos cerrado en sí mismo, por lo que busca la mayor proximidad posible a una autonomía del medio ambiente, que no tiene en él ninguna influencia. En este caso, la orientación se mueve a la no interferencia en la biosfera. Este proceso es una forma de buscar, pero en su totalidad, no se puede lograrlo, porque todo lo que el sistema de producción, habrá el intercambio de energía y producción de entropía.

En cuanto a los biociclos, el objetivo de dirigirse un sistema a la biocompatibilidad es hacer que el sistema de producción y el consumo se basa en recursos renovables sin crear residuos que no se absorben por los ciclos naturales.

En la definición de la Ecología Industrial, el término residuo pasa a tener la connotación de un nuevo proceso de producción. De hecho, la propuesta a través de la puesta en marcha de la Ecología Industrial se puede comparar con la propiedad de buscar un nuevo estado de equilibrio, como sistemas auto-organizadores, por el ejemplo los seres vivos que todos sus componentes están unidos por una red de interdependencia, que implican flujos de materia y energía en ciclos continuos.

La "vecindad" industrial es otro factor relevante en ecología industrial. Las actividades que se han considerado complementarias requieren una proximidad territorial para que haya 
una simbiosis industrial. En consecuencia, en el sistema de la Ecología Industrial, es necesaria la presencia de la red de comunicaciones. Cabe señalar que esta red de comunicación pertenece al paradigma del pensamiento sistémico.

Como informa McDonough \& Braungart, hay dos metabolismos en el planeta Tierra. El primero es un metabolismo biológico, la biosfera, los ciclos de la naturaleza. El segundo es un metabolismo técnico, la tecnósfera, los ciclos de la industria. Proyectando correctamente, todos los productos y materiales fabricados por la industria, se convertirán en alimentos seguros para estos dos metabolismos, lo que proporciona nutrientes para producir algo nuevo.

El nutriente biológico es un material o producto que está diseñado para volver al ciclo biológico. Se consumirán este material los microorganismos en el suelo y otros animales. Según los autores, la mayoría de los embalajes debe pertenecer a esta clase de material, ya que no tiene sentido que duran más décadas o siglos que sus contenidos. Como un ejemplo, los embalajes de crema dental, champú, yogur y muchos otros. En este caso, nos estamos refiriendo a un proceso de desmaterialización de los artefactos. Se programa la materia prima que está relacionada con estos artefactos para descomponerse y absorberse por los procesos que pertenecen al medio ambiente natural. En esta clase de artefactos, incluyen aquellos biodegradables.

Hay que señalar aquí que se considerarán con atributos de desmaterialización también aquellos que están diseñados para absorberse como alimento para el sujeto como un usuario del artefacto. Por ejemplo, con el fin de abordar el tema de la desnutrición en India, una gran empresa de productos alimenticios ha propuesto la introducción de un embalaje de yogur que, después de haber consumido su contenido, podría hervirlo y convertírselo en comida. Otro ejemplo son los platos de sopa que se sirven a la población sin hogar cuyos embalajes son comestibles.

Hacemos hincapié como condición de la desmaterialización la existencia, en algún momento anterior, de la materia que compone del artefacto. Especialmente porque hay casos en los que la materialización solo causa una disminución de la suma final de la materia prima en la fabricación del artefacto. Puede ocurrir esta sustracción de materia prima total en el artefacto, de forma tan radical, mediante la sustitución de la materia prima original. En ambas situaciones, el artefacto se convierte en algo más ligero, con su composición más favorable a impactos relacionados con su producción, distribución y consumo. En este caso, hay una disminución en el proceso entrópico.

Cabe recalcar la diferencia semántica que aquí ponemos en el término desmaterialización y el otro, inmaterialidad. Cuando evocamos la desmaterialización de los artefactos, señalamos la retirada, la sustracción de parte del material que constituye el artefacto en cuestión. Llegando al punto de, en algunos casos, la posibilidad de disolución total de la materia. Por lo tanto, no estamos aquí rechazando la existencia de la materia de los artefactos, pero señalando dos maneras distintas: en primer lugar, la desmaterialización puede ocurrir por la desintegración de la materia que compone el artefacto. En este caso, estamos hablando de la condición de biodegradabilidad. Esta biodegradabilidad se produce mediante el desecho en un medio adecuado o la posibilidad de ser un material compuesto apto para el consumo humano. En segundo lugar, se ha tratado otro camino descrito en este documento mediante la disminución del volumen total de la materia prima en la fabricación de artefactos. 
Trataremos ahora de la inmaterialidad. En este caso, conviene sacar a colación las tecnologías digitales que están al servicio del diseño contemporáneo. En este caso, destacamos la realidad aumentada, así como todos los procesos que hacen uso de la holografía, tanto en el alcance del diseño de los juegos como en el diseño que participa en la elaboración de procesos innovadores para la investigación científica, tales como imágenes holográficas del cuerpo humano.

Cabe señalar que esta falta de materialidad también se identifica cuando tratamos de la cultura inmaterial. En lo concerniente al diseño, cabe considerar, por ejemplo, el conocimiento tradicional de una determinada comunidad como un estudio de caso de su investigación. Por lo tanto, la cultura, la tradición, el arte y todas las formas de ser de un determinado grupo de personas conforman lo que llamamos cultura inmaterial.

Para que podamos extender nuestra reflexión sobre la inmaterialidad, recurrimos a Vilém Flusser al relatar sobre la importancia de "no-cosa" en la escena contemporánea. No hace mucho tiempo, las "cosas" invadían los espacios y las vidas de las personas. Pero ahora las "no-cosas" suplantan las "cosas". Y estas "no-cosas" se denominan información. Cabe resaltar que esta información pertenece a la categoría de lo inmaterial tales como los datos almacenados en el computador, hologramas, los softwares y las imágenes electrónicas de la pantalla de la televisión. Estamos interesados en la actualidad en consumir información. Por el contrario, una gran parte de la sociedad está ocupándose en la producción de esta información. En esta familia de información, hay también el diseño de experiencias. Experimentar distintos momentos: un nuevo valor en el mercado de la posmodernidad. En esta nueva lógica surge el Homo Ludens.

Las manos, esenciales para el Homo Faber, perdieron su importancia. Las puntas de los dedos comandan la inmaterialidad. Al pulsar una tecla, se abre un mundo infinito de experiencias: inmaterialidad se presenta al Homo Ludens.

\section{Consideraciones finales}

En este texto, pretendemos poner de relieve los procesos innovadores que cruzan la desmaterialización de los artefactos y también su inmaterialidad. Cabe señalar que este artículo tiene como meta imprimir una reflexión que no se agota en estas páginas. Por encima de todo, hace hincapié en que los sistemas innovadores también pueden ser meras utopías. Pero son que podremos movernos hacia una nueva lógica de permanencia del sujeto en el mundo. Y esta permanencia depende, en gran medida, de cómo manejamos una nueva mirada al campo del diseño. La desmaterialización y la inmaterialidad son atributos de sostenibilidad. Por lo tanto, la actitud proyectual del diseño en nuestra contemporaneidad hace falta insertar las condiciones a priori que están relacionadas con el campo de la sostenibilidad.

\section{Referencias}

Capra, F. (2001). A Teia da Vida: uma nova compreensão dos sistemas vivos. São Paulo: Cultrix. 
Bauman, Z. (2001). Modernidade Líquida. Traducción de Plínio Dentzien. Rio de Janeiro: Zahar.

Flusser, V. (2007). O mundo codificado: por uma filosofia do design e da comunicação. Traducción de Raquel Abi-Samara. Org. Rafael Cardoso. São Paulo: Cosac Naify.

Foster, H. (2002). Design and Crime: and other diatribes. London: Verso, part two.

Manzini, E. e Vezzoli, C. (2002). O Desenvolvimento de Produtos Sustentáveis: os Requisitos Ambientais dos Produtos Industriais. São Paulo: Edusp.

Mcdonough, W. \& Braungart, M. (2002). Cradle to Cradle: remaking the way we make things. Nueva York: North Point Press.

Queiroz, L. L. (2014). Utopia da sustentabilidade e transgressões no design. Rio de Janeiro: 7letras.

\begin{abstract}
This paper includes reflections on the importance of considering dematerialisation and immateriality in the projectual attitude of design. The focus is directed to the sustainability attributes in the Post-Modernity scenario. What it is intended to highlight are innovative paradigms of the configuration of artifacts that deconstruct the conventional system of production, distribution, and consumption. The issues addressed in the text refer to the conditioning factors of material culture as well as immaterial culture.
\end{abstract}

Key words: Dematerialisation - Immateriality - Postmodernity - Sustainability - Design.

Resumo: Este artigo inclui reflexões sobre a importância de considerar, na atitude Projetual do design, a desmaterialização e a imaterialidade. O enfoque dirige-se aos atributos de sustentabilidade na cena da pós-modernidade. Pretende-se recalcar paradigmas inovadores sobre a configuração de artefatos que desconstroem o sistema convencional de produção, distribuição e consumo. Tratam-se os temas relacionados com os fatores condicionantes da cultura material e imaterial.

Palavras chave: desmaterialização - imaterialidade - pós-modernidade - sustentabilidade - design 

Fecha de recepción: octubre 2017

Fecha de aceptación: mayo 2018

Versión final: diciembre 2018
La sustentabilidad de Internet de las Cosas

Maximiliano Zito *

Resumen: El término Internet de las Cosas ha permeado nuestra sociedad en los últimos años de manera especialmente intensa en los medios de comunicación. Si bien el término no es nuevo, la masificación de dispositivos electrónicos, la posibilidad real de analizar grandes cantidades de datos a través del Big Data y de extraer conclusiones útiles de ellos parece haber abierto definitivamente la puerta para una explosión del IoT.

El presente artículo busca reflexionar acerca de un problema que no parece tratarse de manera adecuada: sus implicancias ambientales y sociales. En definitiva, en su sustentabilidad. En un mundo que está alcanzando sus límites, ¿es posible que Internet de las Cosas pueda desarrollarse? y en caso de hacerlo, ¿será para todos, ayudando a reducir la brecha entre los que más tienen y los que menos poseen? o por el contrario, ¿aumentará dichas diferencias?

Palabras clave: Internet de las Cosas - IoT - Sustentabilidad - Impactos ambientales - Paradoja de Jevons - Límites del crecimiento.

[Resúmenes en inglés y portugués en las páginas 43-44]

${ }^{(*)}$ Investigador especializado en al área de Diseño para la Sustentabilidad, Centro INTIDiseño Industrial. Diseñador Industrial, Facultad de Arquitectura Diseño y Urbanismo (FADU), Universidad de Buenos Aires (UBA). Especialista en Gestión Ambiental de Producto (ISM-España), Maestría en gestión de la Energía (Universidad de Lanús), Especialista en Gestión Estratégica de Diseño (FADU-UBA).

El término Internet de las Cosas, también denominado con sus siglas en inglés IoT (Internet of Things) ha permeado nuestra sociedad en los últimos años de manera especialmente intensa en los medios de comunicación. Si bien el término no es nuevo, también es cierto que las capacidades tecnológicas para implementarlo de manera más efectiva son más recientes. La masificación de dispositivos electrónicos, la posibilidad real de analizar grandes cantidades de datos a través del Big Data y de extraer conclusiones útiles de ellos parecen haber abierto definitivamente la puerta para una explosión del IoT.

El término IoT está en desarrollo y por ende aún no tiene una definición aceptada universalmente. Una encuesta realizada a varios investigadores en 2013 refleja esta situación ${ }^{1}$. Sin embargo, se podría definirlo como un concepto que se refiere a la interconexión digital 
de objetos cotidianos con internet ${ }^{2}$. Con objetos cotidianos se hace referencia a todo tipo de productos como ser heladeras, licuadoras, automóviles, iluminación y en general cualquier aparato que interactúe de alguna forma con una persona.

Otro término que se comienza a escuchar es Internet de Todo, como se lo conoce por sus siglas en Inglés IoE (Internet of Everything). En este caso, se hace referencia a la conexión inteligente no sólo de las cosas, sino también de las personas, procesos y datos. Es decir que a IoT se la agregaría la inteligencia necesaria para que todo el sistema pueda funcionar de una manera convergente y orquestada.

Ahora bien, más allá de las definiciones, lo cierto es que si actualmente se busca información de estos conceptos, rápidamente se pueden encontrar numerosos artículos y notas cuyos contenidos podría agruparse en dos tópicos. Por un lado las bondades que traerá poder controlar todos estos dispositivos y como ello facilitará la vida cotidiana; y por el otro, los peligros implícitos de tanto control. Estos últimos básicamente agrupados en torno a la pérdida de privacidad y a la posibilidad de que un hacker se haga del control de nuestros objetos, y por extensión de nuestra vida.

El presente artículo no pretende ahondar sobre estos temas. No porque carezcan de importancia, sino mas bien porque ya hay mucho escrito, y por personas más entendidas del tema. Aquí más bien se busca reflexionar acerca de otro problema relacionado a Internet de las Cosas que no parece tratarse de manera adecuada: sus implicancias ambientales y sociales. En definitiva, en la sustentabilidad de IoT.

El mundo, como se sabe, está alcanzando sus límites en la disponibilidad de varios de sus recursos físicos. Esa situación se encuentra bien documentada por parte de numerosos estudios de conocidos organismos como la Organización para la Cooperación y el Desarrollo Económicos $(\mathrm{OCDE})^{3}$ y del sector privado como la consultora privada $\mathrm{KPMG}^{4}$, por mencionar solo algunos. El mecanismo de crecimiento desmedido que luego se frena abruptamente al encontrarse con los límites que le impone su entorno en realidad se puede aplicar a muchos otros órdenes de la vida y comúnmente se lo conoce como Crecimiento Exponencial. En la ecología por ejemplo, se aplica a cómo una población de una determinada especie puede crecer exponencialmente (si tiene las condiciones propicias en su ambiente), hasta llegar al límite de sus recursos. En este punto el crecimiento se frena y luego sobreviene una fuerte caída en la cantidad de individuos.

La IoT, como tecnología emergente, debería tener en cuenta estas limitaciones a la hora de plantear su crecimiento. De igual manera que una especie de seres vivos lo hace con los recursos disponibles en el ambiente.

Veamos algunos datos para considerar esta cuestión.

En una conferencia sobre el tema ${ }^{5}$, se pudo observar que las tendencias indican que para el año 2020 habrá entre 17 y 30 billones (si, billones) de objetos conectados entre sí. Y por supuesto, detrás de ellos, la descomunal cantidad de datos que se compartirán. Los mismos estudios los estiman en 4.3 ZB anuales. ¿Cuánto es esto? Para entender estas magnitudes se deben hacer algunos cálculos. Por ejemplo, cuando comenzó la era de Internet entre 1990 y 1995, se calcula que se utilizaban en todo el mundo 204 Terabyte (TB) al mes. Esto equivale a 200 computadoras Imac como la que están en cualquier oficina de diseño gráfico en la actualidad. Continuando en el tiempo, de 2005 a 2010 aumentó dicho consumo a unos 20 mil Petabyte (PB) al mes. Es decir a la capacidad de almacenamiento de más de 
20 millones de Imac. Y si se llega a los mencionados 4.3 Zettabyte (ZB), serían unas 4600 millones de computadoras de la manzanita. Para dimensionar mejor este número, se trata de más de la mitad de la población mundial. Y no se continúa del 2020.

La pregunta que surge luego es si toda esta capacidad colosal de almacenamiento es gratuita para nuestro planeta. No ya en términos monetarios, que son relativos, sino en términos de recursos físicos. Se puede estar seguro que no. Cada Megabyte de almacenamiento tiene un costo ambiental. Utiliza materiales físicos, se mueve desde el sitio de fabricación al de uso, emplea energía para poder utilizarse por internet y para ser refrigerado, y por último, al finalizar su vida útil debe ser reprocesado (en el mejor de los casos).

¿Cuál es el costo ambiental de extraer los minerales, transformarlos en materiales y utilizar ese almacenamiento? Para realizar estos cálculos se suele utilizar la metodología de Análisis de Ciclo de Vida, la cual contempla cuantificar el impacto ambiental de un producto a lo largo de cinco etapas: extracción, fabricación, uso, distribución y fin de vida.

Además, hasta ahora se mencionó el costo ambiental de crear y utilizar el almacenamiento. Para realizar la cuenta completa, habría que sumarle este mismo costo ambiental de producir todos los nuevos objetos inteligentes. Porque seguramente, no se podrá utilizar la misma licuadora, o los mismos anteojos, o el mismo automóvil que existen hoy día. Es decir, hay que reconvertir toda la población mundial de objetos. Claro que desde un punto de vista económico, este cambio ofrece inmensas oportunidades de negocios. Pero se insiste en la necesidad de reflexionar sobre los impactos ambientales y sociales de esta enorme transformación que se avecina.

$\mathrm{Al}$ igual que una moneda que tiene dos caras, IoT tiene un lado ambiental positivo. Tanto control de aparatos permitirá poder regular mejor el uso de energía, del agua y de otros muchos consumibles. Las computadoras podrán decidir de manera más racional y eficiente que las personas cuando bajar la temperatura de un aire acondicionado, cuando levantar una persiana para que ingrese más luz natural o cuando apagar una luz en un cuarto que no hay nadie. También podrá conducir un automóvil de manera más eficiente, racionalizando el consumo de combustible.

Muchos de los productos que requieren consumibles en su utilización (como agua, energía, aceites y otros), presentan sus mayores impactos ambientales en la etapa de uso. Esto no es mera teoría, ya que mediante la misma metodología mencionada anteriormente del Análisis de Ciclo de Vida se ha verificado esta premisa en numerosos aparatos. Aires acondicionados, lavarropas, heladeras, cafeteras y un sin fin de productos similares entran dentro de este grupo. En este sentido, la IoT puede realizar aportes muy significativos. En primer lugar, el poder recopilar en gran escala datos acerca de las conductas de consumo por parte del público abre la puerta a tener la posibilidad de generar políticas de ahorro y eficiencia basadas en datos contrastados. Asimismo, la verificación del cumplimiento de dichas políticas también será una realidad alcanzable. Es evidente que esto abre oportunidades para mejoras de eficiencia enormes, lo cual podría traducirse en significativos ahorros. 


\section{Jevons y su paradoja}

Pero como en esta vida no siempre todo lo que reluce es oro, las mencionadas mejoras en la eficiencia no necesariamente podrían conducir a un ahorro global en los recursos. Ejemplos de ello hay muchos, como ser los motores de automóviles. Comparados con los motores de hace 15 o 20 años, los actuales son más chicos y consumen menos combustible por kilómetro recorrido, es decir que se puede afirmar que en promedio, cada automóvil hoy es más eficiente que uno de hace 20 años. Sin embargo, la cantidad global de vehículos ha crecido de forma exponencial en el mundo, con lo cual el ahorro a nivel global no existe. Es más, hoy se consume mayor cantidad de combustible que hace 20 años.

Esta situación, donde mejoras de eficiencia individuales no conducen a los supuestos ahorros globales en realidad ya fue observada en el siglo XVIII. En aquel momento un economista inglés de nombre Jevons, en plena Revolución Industrial fue encomendado para analizar y estimar la duración de las reservas de carbón en Inglaterra. El carbón era estratégico porque en aquel entonces era la fuente energética principal para alimentar a las máquinas de vapor.

Lo que Jevons descubrió es que a medida que las máquinas mejoraban su eficiencia individual, éstas eran utilizadas en mayor cantidad de tareas. Por consiguiente, a pesar de que cada máquina consumía menos carbón para realizar la misma actividad, a nivel global se utilizaban cada vez más máquinas y el consumo general de carbón crecía.

Esta paradoja, donde a pesar de mejorar la eficiencia a nivel individual se obtiene como resultado un mayor consumo global se la llamó Paradoja de Jevons.

\section{Redefiniendo el confort}

Como ya se explicó, uno de los aspectos más promocionados de la Internet de las Cosas es la mejora que provocará en el confort de los usuarios. Para ello se suelen dar argumentos acerca de lo fácil que será que una heladera nos informe que falta leche, o que se acabó tal o cual queso que siempre consumimos. Pero claro, en el mundo real nada es "gratis". Y este servicio, tiene un costo ambiental. Aparece entonces la dicotomía entre ambiente y confort. ¿Qué se debe priorizar? ¿La comodidad de que la heladera me recuerde que falta leche, o más aún que mande a comprarla en mi lugar? o por el contrario, ¿El cuidado del ambiente, en cuyo caso funciones como la mencionada no deberían tener lugar?

En este punto llegamos a la espinosa cuestión de precisar que entendemos por confort. La Real Academia Española define al término como "Bienestar con comodidad material", aunque por supuesto que esta definición tiene un alto grado de subjetividad.

Entender este término de manera adecuada es crucial para los diseñadores, ya que en definitiva es el usuario del producto quién tiene la última palabra. Y es claro que un producto que ofrece mayor confort, será más valorado por el usuario.

Pero, ¿hasta dónde avanzar en la búsqueda de más confort?

Muchos de los objetos que hoy nos proporcionan esta cualidad -y a los que no estamos dispuestos a renunciar de manera voluntaria- hasta hace unas décadas atrás apenas se consideraban necesarios. Si se le pregunta a la mayoría de las personas que hoy tienen 60 
o 70 años, seguramente contestarán que de jóvenes vivían en condiciones más austeras y no por ello consideraban que vivían sin confort. Es decir, que el confort es subjetivo, según la época y el contexto.

\section{Contexto mundial, ¿alcanzando los límites?}

Como ya se mencionó, para que la Internet de las Cosas se pueda implementar y masificar, es necesario una enorme transformación de los productos -tanto que usan los usuarios como los que sirven de soporte para que funcionen éstos-, lo cual probablemente exigirá una gasto fenomenal de capital natural. Llamamos a esto todas las materias primas y la energía necesaria para transformarlas en los productos requeridos. Sin contar por supuesto con la energía que consumirá toda esta gigantesca red de aparatos interconectados de manera permanente. Estos aspectos espinosos se suelen pasar por alto.

La electrónica de precisión, los láseres, las turbinas de energía eólica y muchos otros aparatos de nueva tecnología necesitan de muchos minerales específicos para funcionar. El Servicio Geológico de los Estados Unidos (USGS por sus siglas en inglés) tiene bajo seguimiento las reservas y consumo global de 58 Recursos Naturales No Renovables (RNNR) -minerales, energía y metales-, y según información de la agencia muchos de éstos no tienen reservas para seguir incrementado su extracción de manera significativa. Una situación similar se da con las llamadas Tierras Raras ${ }^{6}$. Neodimio, Cerio y Lantano son algunos de estos elementos sumamente necesarios para la tecnología actual. China posee prácticamente el monopolio de su producción ${ }^{7}$, y a partir del 2010 viene aplicando restricciones a su exportación. Todo esto sugiere que el mundo no puede contar con la cantidad y a un precio asequible lo que necesita, y esto sucede hoy, con una demanda mucho menor de la previsible.

Recordando que el término Sustentabilidad (o Sostenibilidad) ${ }^{8}$ refiere no solamente a lo ambiental sino también a lo social y económico, se hace necesario mencionar estos dos aspectos adicionales para analizar la sustentabilidad de Internet de las Cosas.

En este sentido es importante entender la tendencia que siguen los precios de algunos de los minerales y metales para estimar como se comportarían en un previsible escenario futuro de mayor demanda.

Jeremy Grantham, cofundador de GMO - una de las mayores gestoras de activos del mundo-, sorprendió a todos cuando publicó un impactante informe $e^{9}$ en el que diseccionaba meticulosamente la situación de los recursos no renovables del mundo. Ya en el inicio del informe, se hace eco de un dato demoledor: en tan solo 8 años se han revertido 100 años de tendencias a la baja en los precios de las materias primas. Para ello utiliza un Índice de commodities GMO, el cual sintetiza el comportamiento de 33 materias primas, y donde se puede observar el incremento que vienen sufriendo como tendencia a mediano plazo. Por lo tanto, un escenario donde la mayor demanda de materias primas se golpeará con límites físicos, cabe preguntarse si la masificación de la IoT será una realidad, ó solo quedará restringida a un grupo reducido de la población mundial, ampliando la brecha de desigualdad actual. 


\section{Reflexión final}

Quizá para el público general el concepto de la Nube evoca algo etéreo, intangible. Pero se puede estar seguro que atrás de cada megabyte que circula existen elementos muy físicos que deben existir, y que deben convivir en una estructura sumamente compleja para que funcionen como se espera.

Es necesario reflexionar sobre el confort, aspecto espinoso y directamente relacionado. Hasta ahora, se puede decir que el ser humano en término generales ha ido subiendo su umbral de confort. Por supuesto que hay enormes cantidades de personas en el mundo que están lejos de dicho umbral, pero podemos decir que en términos generales el ser humano a logrado aumentarlo. También es cierto, que mucho de ese confort está relacionado a poseer determinados objetos físicos. En todo caso, lo que es indudable es que el aumento de confort trajo aparejado un incremento en el uso de distintos recursos naturales. En definitiva, un mayor impacto ambiental.

Hoy se está llegando a la encrucijada de haber definido un nivel de confort muy alto -en términos ambientales-, el cual debido a una incipiente pero creciente restricción de recursos naturales, cada vez se revela más difícil de alcanzar para toda la humanidad. La Huella Ecológica ${ }^{10}$ es un indicador que claramente muestra esta situación, donde para compensar el consumo actual global se necesitan 1,4 mundos. Y este resultado es un promedio, donde un importante sector de la población mundial está marginado de los parámetros de consumo -y confort- de los países desarrollados. Si todos vivieran según éstos, se estiman que se requerirían 4 planetas tierras para sostenerlo.

Internet de las Cosas, como está promocionado hoy en día, apunta sin duda a elevar aún más el estándar de confort.

¿Seremos capaces de utilizarla como herramienta para mejorar el ambiente y la sociedad, incorporando a los excluidos de hoy y de mañana? O por el contrario, nuestra insistencia en quererlo todo, en un mundo finito, provocará que IoT sea utilizada por una reducida minoría de la población, incrementando el impacto sobre nuestro planeta y aumentado la brecha entre los afortunados y los desposeídos.

En definitiva, sólo el tiempo dirá la forma de implementación de la IoT. Lo que sí es seguro es que para que ésta pueda crecer como anuncian los gurúes del tema, será necesario que continúe vigente el modelo actual. Es el escenario que en las simulaciones se lo suele denominar Business as Usual (expresión que podría traducirse en Negocios como Siempre). Es el modelo vigente. Es, en definitiva, el modelo que hasta ahora ha logrado burlar los límites de la física. ¿Por cuánto tiempo logrará hacerlo?

\section{Notas}

1. Charith Perera, Arkady Zaslavsky, Peter Christen, and Dimitrios Georgakopoulos (2013). «Context Aware Computing for The Internet of Things: A Survey». Communications Surveys Tutorials, IEEE. Early Access (n/a): 1-44. doi:10.1109/SURV.2013.042313.00197.

2. Conner, Margery (27 de mayo de 2010). Sensors empower the "Internet of Things" (Issue 10). pp. 32-38. ISSN 0012-7515. 
3. OECD Environmental Outlook to 2050: The Consequences of Inaction -ISBN 978-9264-122161 @ OECD 2012.

4. Informe Future State 2030: The global megatrends shaping governments, pág. 43 (2014 KPMG).

5. Fábricas Inteligentes: Sistemas Ciberfísicos para la Producción. Ing. Victorio Bentivogli, ADIMRA (30/08/2016).

6. Tierras Raras es el nombre común de 17 elementos químicos: escandio, itrio y los 15 elementos del grupo de los lantánidos (lantano, cerio, praseodimio, neodimio, prometio, samario, europio, gadolinio, terbio, disprosio, holmio, erbio, tulio, iterbio y lutecio).

7. Concern grows over China's dominance of rare-earth metals, Physics Today (mayo 2010). http://scitation.aip.org/content/aip/magazine/physicstoday/article/63/5/10.1063/1. 3431322

8. Se define "el desarrollo sostenible como la satisfacción de «las necesidades de la generación presente sin comprometer la capacidad de las generaciones futuras para satisfacer sus propias necesidades". (Informe titulado "Nuestro futuro común" de 1987, Comisión Mundial sobre el Medio Ambiente y el Desarrollo).

9. Viviendo en un planeta finito, reporte Estado del Liderazgo en la Sustentabilidad (Universidad de Cambridge, diciembre 2012)

10. Desarrollada por la organización Global Footprint Network. Es un indicador que contabiliza la cantidad de territorio necesario para producir los recursos y asimilar los residuos de una población específica por un tiempo indefinido.

\section{Bibliografía y fuentes}

Analizando el Internet de las Cosas. Primera Parte. Disponible en: http://ax3s.blogspot. com.ar/2015/01/IdC-09.html

Analizando el Internet de las Cosas. Segunda ParteDisponible en: http://ax3s.blogspot.com .ar/2015/01/IdC-10.html

El internet de las cosas, ¿una amenaza para la humanidad? (5 julio de 2016). Disponible en: http://www.expoknews.com/el-internet-de-las-cosas-una-amenaza-para-la-humanidad/

Servicio Geológico de Estados Unidos. Disponible en: https://www.usgs.gov/

Definición de Desarrollo Sostenible, ONU. Disponible en: http://www.un.org/es/ga/presi dent/65/issues/sustdev.shtml

Bureau International des Poids et mesures. Disponible en:http://www.bipm.org/en/ measurement-units/prefixes.html

The Coal Question. An Inquiry Concerning the Progress of the Nation, and the Probable Exhaustion of Our Coal-Mines (W. Stanley Jevons, 1865). ISBN 978-0-678-00107-3.

Internet de las Cosas. Disponible en: https://es.wikipedia.org/wiki/Internet_de_las_cosas

Abstract: The term Internet of Things (IoT) has permeated our society in recent years, especially in the media. Although the term is not new, the massification of electronic 
devices, the real possibility of analyzing large amounts of data through Big Data and drawing useful conclusions from them, seems to have definitely opened the door for an IoT explosion.

The present article seeks to reflect on a problem that does not seem to have been adequately addressed: its environmental and social implications. In other words, in its sustainability. In a world that is reaching its limits, is it possible that Internet of Things can develop? And if so, will it be for all, helping reduce the gap between those who have the most and those who have the least? Or on the contrary, will these differences increase?

Key words: Internet of Things - IoT - Sustainability - Environmental Impacts - Jevons Paradox - Growth Limits.

Resumo: O termo Internet das Coisas (IoT) penetrou na sociedade nos últimos anos de modo especialmente intensa nos meios de comunicação. Embora o termo não é novo, a massificação de dispositivos eletrônicos, a possibilidade real de analisar grandes quantidades de dados através do Big Data e de tirar conclusões úteis deles abriu definitivamente a porta para uma explosão do IoT.

Este artigo procura refletir sobre um problema que não parece tratado de modo adequado: suas implicâncias ambientais e sociais; finalmente, em sua sustentabilidade. Num mundo que está alcançando seus limites, é possível que Internet das Coisas possa desenvolver-se? Em fato de fazê-lo, será para todos, ajudando a reduzir o fosso entre os que mais têm e os que menos têm? Ou, pelo contrário, aumentará essas diferenças?

Palavras chave: Internet das Coisas - IoT - sustentabilidade - impactos ambientais - Paradoxo de Jevons - limite do crescimento. 
Fecha de recepción: octubre 2017

Fecha de aceptación: mayo 2018

Versión final: diciembre 2018

\section{La des-materialización de productos tangibles en una perspectiva de sustentabilidad}

Gabriela Nuri Barón *

Resumen: En el ejercicio de pronóstico de escenarios futuros para un desarrollo sostenible, los paradigmas occidentales de libre mercado se están viendo profundamente amenazados por nuestros límites ecológicos. Ahora está claro que la crisis ambiental está directamente relacionada con el consumo y no puede abordarse con respuestas técnicas tradicionales. Las innovaciones más prometedoras que presentan soluciones viables a la crisis ambiental son de naturaleza social. Dentro de esta perspectiva, los diseñadores parecen haber llegado a un callejón sin salida en relación a la creación material. Lejos de desalentar, estos límites han arrojado luz sobre todo un nuevo espectro de oportunidades profesionales hacia el bienestar social, donde los diseñadores tienen el liderazgo como facilitadores creativos. La desmaterialización se convierte en un curso de acción desafiante, atractivo y viable, colocando a las personas como el material principal para el cambio.

Palabras clave: servicización, colaboración, inacabado, enfoque sistémico, bienestar, consumo, desmaterialización, desarrollo sostenible.

[Resúmenes en inglés y portugués en la página 52]

${ }^{(*)}$ Becaria Doctoral CONICET - Universidad Tecnológica Nacional Argentina). Especialista en Diseño para la Sustentabilidad e Innovación Social. Diseñadora Industrial graduada en Argentina, realizó un master en el Politécnico de Milán realizando proyectos en Argentina, Italia y Asia.

\section{Introducción}

Cuando los diseñadores proyectan escenarios futuros en relación a materiales nuevos, una deslumbrante serie de innovaciones despierta nuestro espíritu creativo y estimula nuestra mente con oportunidades ilimitadas. Pero solo una mirada al estilo de vida actual es suficiente para comprender lo difícil que es conectar inocentemente la palabra futuro con la palabra material. Las oportunidades solo parecen ser ilimitadas. Resulta ingenuo y peligroso para los diseñadores visualizar futuros sin tener en cuenta nuestros propios límites naturales. No será necesario citar la vasta cantidad de datos científicos que describen el estado de emergencia que este mundo está atravesando. Como sociedad somos partícipes de un deterioro ambiental que nos llevará a la extinción como raza. De acuerdo a las Nacio- 
nes Unidad, para el año 2030 necesitaremos "dos planetas" de recursos para sostener la población mundial (Moore et al., 2012). Esta crisis ambiental está estrictamente ligada a una crisis social y ética de inequidad, ya que unos pocos países consumen la mayoría de los recursos ( $20 \%$ de la población consume $80 \%$ de los recursos mundiales), mientras las consecuencias ecológicas se sufren en todo el planeta (FAO, 2003).

Se justifica decir que la culpa la tienen los patrones de consumo predominantes. Aquí es donde el rol tradicional del Diseñador Industrial es profundamente desafiado, ya que la base de su labor es la concepción de productos para ser industrialmente producidos. Numerosas aproximaciones por parte del diseño han surgido como respuesta al problema de la sustentabilidad, pero hay preguntas fundamentales que debemos hacernos: Cuál es el rol ético del diseñador en una sociedad híper-consumista? Dónde recae el peso ético de decidir cuales productos contribuyen a solucionar la crisis y cuales contribuyen al problema? El diseño, al estar profundamente ligado a la producción y al consumo, juega un papel crucial en la transición hacia una sociedad más sustentable. (Martilla, 2011)

\section{Des-materialización y consumo}

La idea de desmaterialización implica una reducción material, de energía, agua y tierra para obtener iguales (o mejores) resultados económicos. De acuerdo al Programa Ambiental de Naciones Unidas (UNEP, 2011):

La Desmaterialización describe principalmente la reducción de requisitos materiales de economías en su totalidad. Requiere de (a) la reducción de intensidad material de productos y servicios (ej. aumentar la eficiencia material) y (b) la reducción de recursos materiales primarios (ej. El cambio a una economía circular).

A través del diseño y la innovación en productos y procesos, basado en el "Pensamiento de Ciclo de Vida" (EU, 2010), los productores, proveedores y diseñadores están aprendiendo a hacer más con menos: usar menos material, extender la vida de los materiales, usar procesos con menor intensidad energética para transformar estos materiales, y finalmente cuestionar si ese producto material brinda la mejor solución a la necesidad que lo legitima. En este último punto, en el nivel más profundo, el concepto de des-materialización lleva a menos consumo y la consecuente menor demanda de productos. Así se llega a la pregunta clave: Cuando la mayoría de los productos comercializables no sólo son innecesarios, sino materialmente inviables en un futuro realista, cuál es el rol del Diseñador Industrial? La respuesta a esta pregunta requiere que de una dura y crítica mirada a la concepción tradicional de nuestra profesión, sin pasar por alto las consecuencias éticas que están en juego. Numerosos autores han reflexionado acerca de esta problemática en particular y han brindado análisis crítico, marco metodológico y herramientas que amplifican el rol del diseñador, agregando valor a sus capacidades técnicas, creativas y comunicacionales. A lo largo de este artículo se presentan algunos de estos enfoques, colocando la des-materialización como centro estratégico para un desarrollo sustentable. 


\section{Enfoques sistémicos para la des-materialización}

A través de un enfoque sistémico, la des-materialización se puede obtener mediante técnicas que abordan desde el producto en sí hasta las dimensiones culturales y sociales en sus niveles más profundos. El pensamiento sistemático fue introducido por el profesor Jay Forrester en 1956 para la comprensión de sistemas sociales complejos (Forrester, 1994). En vez de separar el objeto de estudio en partes más pequeñas (como lo hace el análisis tradicional), el pensamiento de sistemas observa las interacciones de las diferentes piezas del objeto estudiado, expandiendo el alcance con el propósito de integrar todas sus relaciones. Dentro de este marco, el diseño adquiere un mayor potencial para resolver temas ambientales desde la etapa proyectual. Un ejemplo puede ser la exitosa adaptación de herramientas de Análisis de Ciclo de Vida (ACV) en el "Diseño para la Sostenibilidad". (Vezzoli y Manzini, 2008)

Tukker (2004) propone niveles de intervención que van desde los aspectos materiales, como "mejora del impacto de la eficiencia tecnológica" (energías limpias) y producción eficiente (menor consumo energético en la producción), tratan también los aspectos sociales como la planificación de la intensidad de uso (uso compartido, uso público) y el aumento de funcionalidades inmateriales, hasta la creación de contextos sin necesidades. Se llega a la conclusión de que la tarea de adoptar una sustentabilidad verdadera ya no es predominantemente científica o tecnológica, sino cultural y social. (Hamilton, 2010)

Similarmente, Vezzoli y Manzini (2008), en su libro Design for Environmental Sustainability, presentan cuatro niveles de intervención donde la des-materialización se logra de la siguiente manera:

1. El re-diseño ambiental de sistemas existentes: este nivel implica la reducción de materia y energía incluidas en el producto. Existen varias metodologías publicadas que actúan en este nivel, que generalmente se aplican a diferentes etapas de su ciclo de vida. Como un ejemplo, se podría pensar en una botella de agua descartable/reciclable realizada con menor cantidad de plástico debido al re-diseño de su forma estructural mediante paredes más finas de material. Este re-diseño no sólo refleja el menor uso de materia prima, también el peso del producto se reduce, necesitando menor energía para su transporte, así como su forma puede facilitar la compactación, significando menos volumen de almacenamiento como residuo, etc. Este nivel no requiere un cambio en los patrones de consumo y la des-materialización sólo ocurre a niveles técnicos.

2. El diseño de nuevos productos y servicios: Este nivel implica el remplazo de los productos existentes con nuevos productos concebidos para ser ambientalmente eficientes en cada etapa de su ciclo de vida. Aunque también se trabaja en un nivel técnico, las propuestas resultantes tienden a experimentar dificultades para encajar en los patrones de consumo existentes y requieren de un cambio en los valores y el contexto cultural del usuario. Siguiendo con el ejemplo de la botella de agua, este nivel se ilustra con las botellas de plástico rígido concebidas para su rellenado y re-uso. La botella en si misma posee más intensidad material para su durabilidad, pero la des-materialización es alta considerando la extensión en su vida útil. 
3. El diseño de nuevos Sistemas de Productos y Servicios: En este nivel se cambia el foco desde el diseño del producto en sí mismo hacia la satisfacción de la necesidad que motiva la existencia del producto. Este enfoque le permite al diseñador realizar propuestas radicalmente diferentes (e intrínsecamente sustentables) que satisfacen la misma necesidad. La des-materialización sucede, no sólo a nivel de ciclo de vida de todos los productos y servicios involucrados, sino también en cambios de comportamiento de los actores participantes. Para que estas propuestas sean efectivas deben ser social y culturalmente apropiadas (principalmente a través de la comunicación estratégica). Este nivel implica una des-materialización radical a través de cambios profundos en patrones de consumo, tales como el uso compartido.

4. La propuesta de nuevos escenarios de estilos de vida sustentables: este nivel trabaja directamente en la re-orientación de los patrones de producción y consumo dominantes. La des-materialización se logra a través de elecciones de vida subsecuentes, que se promueven mediante el escenario propuesto. Los escenarios operan en la esfera cultural ya que se basan en la investigación, colección y re-interpretación de casos (exitosos y prometedores) existentes. Este nivel reconoce la transversalidad de la problemática y sus profundas raíces sociales, trabajando no sólo la faceta ambiental del Diseño Sustentable, sino también sus implicaciones sociales y económicas. Como ejemplo de este nivel, el consumidor cuestionaría críticamente la forma en la que se comercializa el agua embotellada (y sus consecuencias ambientales), renunciaría a ser parte de ese sistema y participaría activamente (co-creación) en la propuesta de una alternativa de consumo de agua.

Los autores resumen brillantemente los niveles mencionados diciendo que "el Diseño para la Sustentabilidad Ambiental implica facilitar la respuesta a la demanda social de bienestar por parte del sistema de producción, reduciendo drásticamente la cantidad de recursos ambientales necesarios para el sistema actual" (Vezzoli y Manzini, 2008). En síntesis, ellos proponen la des-materialización del bienestar.

Es importante resaltar que las estrategias mencionadas no implican una pérdida de bienestar por parte del usuario, sino un cambio en los valores que definen el bienestar en sí mismo. En este contexto, la crisis ambiental y social ha llegado a tales profundidades que la gente está comenzando a cuestionarse la creencia base que establece que la mejora del bienestar depende del crecimiento ilimitado del nivel de consumo (Hamilton, 2010). Como ejemplo de este cambio ecológico profundo en el comportamiento, aparecen fenómenos sociales como el downshifting, movimiento en el que los adeptos toman la decisión voluntaria de reducir los ingresos y el consumo propios, a favor de una mayor calidad de vida. Estos innovadores sociales comprenden que poseer más tiempo para actividades que mejoran su nivel de bienestar (que generalmente involucran a la familia, amigos, salud, pasatiempos, etc.) es más satisfactorio que destinar el tiempo a trabajar para ganar dinero para comprar cosas que prometen aumentar su bienestar. 


\section{Des-materialización mediante in-terminación y colaboración}

Una profunda reflexión de la evolución del diseño puede realizarse al analizar la evolución de los sistemas naturales. Una aproximación complementaria, que observa a la naturaleza con el propósito de encontrar estrategias evolutivas de adaptación a la crisis ecológica, es la de admisibilidad del error o "Error-Friendliness" (Von Weizaker, 1988). Este concepto está íntimamente ligado al diseño para la sustentabilidad, en el sentido de la concepción de productos con ciclos de vida largos. Ezio Manzini (1994) elabora sobre el concepto de admisibilidad del error, al criticar los productos super-especializados que no admiten versatilidad o evolución temporal. Mientras la super-especialización frecuentemente lleva a la extinción en contextos de cambio radical, los productos sub-óptimos habilitan su adaptación por parte de los usuarios y sobreviven a cambios contextuales, extendiéndose su vida útil.

Una estrategia para la admisibilidad del error es proyectar productos que no estén "terminados", lo que llamaremos in-terminación. Los productos no-terminados se transforman en una herramienta que permite al usuario co-crear el producto finalizado que satisfaga su necesidad. La clave se encuentra en la versatilidad. Un claro ejemplo podría ser un juego de ladrillos Lego: desde su invención han jugado con ellos generaciones y generaciones de niños de un amplio rango de edades, independientemente de su género, y al día de hoy se utilizan por adultos como herramientas de Design Thinking, etc. Es un juguete durable y versátil que sobrevive a las modas. En un ejemplo más complejo se podría pensar en un sistema modular de equipamiento para oficinas que puede mutar, adaptarse y cambiar en el tiempo. Los beneficios ambientales son numerosos: extensión de la vida útil del sistema, reposición por partes para su reparación, posibilidades de expansión, consumo compartido, personalización y demás. En síntesis, los sistemas tecnológicos basados en soluciones modulares, descentralizados y diversos en su producción y funcionamiento, intrínsecamente admiten mayor grado de error. (Manzini, 1994)

A nivel de satisfacción del consumidor, los productos no-terminados están abiertos a la colaboración, participación y co-creación, con todos los beneficios de la auto-organización. Cuando un sistema de productos es versátil, permite diferentes combinaciones, completándose con las capacidades de los usuarios. Los resultados pueden ser inesperados, pueden evolucionar o mutar en el tiempo, pueden ser resilientes a los errores y socialmente innovadores. Un buen ejemplo de esto es el movimiento de software de código abierto, que ha llevado a resultados sin precedentes como Wikipedia o Linux.

\section{Des-materialización mediante servificación}

La des-materialización puede suceder a una escala mayor si uno se mueve desde una economía basada en los productos a una economía basada en los servicios. La economía de los servicios se basa en la optimización del uso de bienes y servicios, y por lo tanto en la gestión de la riqueza existente (bienes, conocimiento, recursos). El objetivo económico de la economía de servicios es "crear el valor de uso más alto durante el mayor tiempo posible, consumiendo la menor cantidad de recursos energéticos y materiales posibles" 
(Stahel, 2001). Si un consumidor no poseyera un producto y lo alquilara, un productor posee el incentivo de diseñar productos durables, reparables, actualizables y reusables. (Dooley, 2013)

Las empresas se están dando cuenta de que aunque vendan productos, la gente compra el servicio que éstos satisfacen. Se dan cuenta de que los usuarios compran productos para satisfacer necesidades que requieren de otros productos y servicios para brindar satisfacción, y que poseen necesidades emocionales que van más allá de lo que el producto puede brindar. Al completar su oferta con servicios que agregan valor al producto, refuerzan, habilitan, educan y expanden la experiencia del producto y crean una economía del sentido. Estas compañías pueden ser con o sin fines de lucro, parte de un modelo económico social o no. Su valor agregado se financia en el precio y a través de las transacciones repetidas con los consumidores, que se fidelizan mediante el servicio (Oliva and Kallemberg, 2003). La base de este comercio se vuelve la relación y no la transacción. Las estrategias de servificación aumentan la eficiencia material del modelo de producción y consumo, habilitando beneficios sociales que van más allá de la des-materialización.

Finalmente y de mayor importancia, está el hecho de que los servicios se han tornado una fuente sustentable de ventaja competitiva al hacer uso del recurso más abundante del planeta: el trabajo humano.

\section{Conclusiones}

Las tecnologías y materiales del futuro posibilitan nuevas perspectivas para la des-materialización a nivel de producto, donde la liviandad de un nuevo producto puede reducir su impacto ambiental. Sin embargo, en un mundo finito materialmente, que enfrenta una crisis ambiental sin precedentes, los diseñadores necesitan ampliar su rol profesional para satisfacer las necesidades sociales con propuestas de radicalmente menor intensidad material. El diseño industrial como profesión se enfrenta actualmente a una gran crisis ética, ya que su propósito es la satisfacción de necesidades humanas (en ambos niveles, el técnico y el emocional) mediante un proceso continuo de diseño y re-diseño, que implica producción, comercialización y compra repetida. Mientras que la base de esta crisis ambiental es el modelo de producción-consumo en el que la profesión del diseñador se basa, un escenario futuro optimista implica la elección de consumir menos en pos de una mayor calidad de vida, desafiando este modelo.

No es una conclusión personal cuando afirmo que la única perspectiva viable es la de cambio radical e innovación sistémica, numerosos autores han llegado a la misma drástica y desafiante conclusión. En este escenario, los diseñadores poseen las herramientas y el conocimiento para actuar como promotores de nuevas interpretaciones del bienestar basadas en menor consumo de objetos materiales y mayor cantidad de valor inmaterial. Consecuentemente, se han propuesto numerosas estrategias de diseño que proponen la des-materialización en diferentes niveles, desde el nivel de producto al nivel de comportamiento. La servificación y la interminación se vuelven estrategias prometedoras para la reducción drástica de intensidad material en los productos. Estas aproximaciones poseen un fuerte contenido social, ya que enfatizan la interacción ampliada (y sistémica) entre los actores, 
la participación de los usuarios y la distribución abierta de los resultados. Aquí, los roles del diseñador, del productor y del consumidor son más permeables, con límites borrosos que habilitan formas altamente innovadoras de hacer las cosas. Estas nuevas formas pueden necesitar nuevas herramientas, pero se basan mayormente en la comunicación estratégica y la habilidades creativas para la resolución de problemas.

No se puede concebir visiones del futuro material sin considerar los límites de nuestros recursos materiales. Los límites son parte de nuestro ecosistema y cualquier sistema concebido para su crecimiento ilimitado (como el sistema capitalista) es insostenible y lleva al colapso. Los límites materiales son oportunidades para liberarnos de paradigmas tradicionales, abrirnos a nuevos roles profesionales hacia nuevas posibilidades de intervención. La des-materialización estratégica se propone como un camino viable, desafiante y atractivo hacia un futuro sostenible. Los diseñadores debemos provocar a los paradigmas existentes, e innovar colocando a la gente como el material primario para el cambio. Como dijo Ezio Manzini: en un planeta superpoblado, el recurso humano es el más abundante.

\section{Referencias}

Dooley, K. (2013). Product design: Do it with Dematerialization. CSR Wire, 14-16. Retrieved from: http://www.csrwire.com/blog/posts/1078-product-design-do-it-withdematerialization

EU - European Union (2010). Making sustainable consumption and production a reality. ISBN: 978-92-79-14357-1 DOI: 10.2779/91521. Available at http://bookshop.europa. eu/en/making-sustainable-consumption-and-production-a-reality-pbKH3109259/

FAO - Food and Agriculture Organization of the United Nations (2003). The state of food insecurity in the world. ISBN 92-5-104986-6. Rome, Italy.

Forrester, J. W. (1994). System dynamics, systems thinking, and soft OR. Syst. Dyn. Rev., 10: 245-256. doi:10.1002/sdr.4260100211

Hamilton, C. (2010). Consumerism, self-creation and prospects for a new ecological consciousness. Journal of Cleaner Production, 18(6), 571-575. http://doi.org/10.1016/j. jclepro.2009.09.013

Manzini, E. (1994). Physis and design. Interaction between nature and culture. Article available at: https://www.researchgate.net/publication/39085531. Retrieved on: 02 August 2016

Marttila, T. (2011). Dematerialization by Design - Sustainability in the consumer society. Position paper for ARKTIS Summer School 2011. Design Connections Doctoral Program. Aalto University, School of Art and Design.

Moore, D.; Galli, A.; Cranston, G. R. and Reed, A. (2012). Projecting future human demand on the Earth's regenerative capacity. Ecological Indicators, 16, 100-112. http://doi. org/10.1016/j.ecolind.2011.06.017

Oliva, R. and Kallenberg, R. (2003). Managing the transition from products to services. International Journal of Service Industry Management, Vol. 14, No. 2, pp. 160-172.

Stahel W. (2001). Sustainability and Services, in Sustainable Solutions - Developing products and services for the future, Charter, M. and Tischner, U. (edit by), Greenleaf publishing, UK. 
Tukker, A. (2004). Eight types of product-service system: eight ways to sustainability? Experiences from suspronet, Business Strategy and the Environment, vol. 13, no. 4

UNEP (2011). Prepared by Meghan O'Brien and Stefan Bringezu, Wuppertal Institute. Draft Glossary of Terms Used by the International Resource Panel. Page 3.

Vezzoli, C. (2007). System Design for Sustainability. Milano: Maggioli Editore.

Vezzoli, C., \& Manzini, E. (2008). Design for Environmental Sustainability. London: Springer London. http://doi.org/10.1007/978-1-84800-163-3.

Weizaker, E. i C., Von (1988). Come vivere con gli errori. II valore evolutivo degli errori. Ceruti, M., Laszlo, E.

\begin{abstract}
In the practice of future scenario forecasting for a sustainable development, the western free market paradigms are becoming deeply threatened by our ecological limits. It is clear now that the environmental crisis is directly linked to consumption and cannot be tackled with traditional technical responses. The most promising innovations that present viable solutions to the environmental crisis are of social nature. Within this perspective, Designers seem to have arrived to a dead-end road in relation to material creation. Far from discouraging, these limits have shed light on a whole new spectrum of professional opportunities towards social-well-being, where Designers have the lead as creative facilitators. Dematerialization becomes a challenging, attractive and viable course of action, placing people as the primary material for change.
\end{abstract}

Keywords: servicization - collaboration - unfinishedness - systemic approach - well-being - consumption - dematerialization - sustainable development.

Resumo: No exercício de prever cenários futuros para o desenvolvimento sustentável, os paradigmas ocidentais do livre mercado estão sendo profundamente ameaçados pelos nossos limites ecológicos. É agora claro que a crise ambiental está diretamente relacionada com o consumo e não pode ser tratada com respostas técnicas tradicionais. As inovações mais promissoras que apresentam soluções viáveis para a crise ambiental são de natureza social. Nessa perspectiva, os designers parecem ter chegado a um impasse em relação à criação material. Longe de desanimar, esses limites lançaram luz sobre todo um novo espectro de oportunidades profissionais para o bem-estar social, onde os designers têm liderança como facilitadores criativos. A desmaterialização se torna um campo de ação desafiador, atraente e viável, colocando as pessoas como o principal material para a mudança.

Palavras chave: servicização - colaboração - inacabado - abordagem sistêmica - bem-estar - consumo - desmaterialização - desenvolvimento sustentável. 
Fecha de recepción: octubre 2017

Fecha de aceptación: mayo 2018

Versión final: diciembre 2018

\section{El proceso de diseño desde la génesis de los materiales}

Marina Andrea Baima *

Resumen: Las nuevas dinámicas de generación de producción y difusión del conocimiento, y la interrelación con las plataformas de innovación aplicadas a los sistemas productivos locales, definen nuevos escenarios de innovación.

La profunda comprensión de las operatorias de la complejidad contemporánea amplia el espectro de acción del proceso proyectual.

La inclusión de la génesis de los materiales en el proceso proyectual redefine las posibles hipótesis de diseño y fomenta una dinámica de co-creación entre múltiples disciplinas.

Palabras clave: nuevos materiales - diseño industrial - innovación abierta - co construcción.

[Resúmenes en inglés y portugués en la página 61]

${ }^{(*)}$ Diseñadora Industrial, Posgrado en Gestión de Ciudades y Emprendimientos Creativos, maestrando en Ciencia Tecnología y Sociedad. Especializada en gestión estratégica CTI y dirección de proyectos centrados en las bioeconomías y el conocimiento colectivo.

\section{Introducción}

En el marco de un cambio de paradigma en las tecnologías y modos de producción, la generación de nuevos diagramas de producción del conocimiento, como la innovación abierta y la co-creación, surgen en un contexto en el cuál se le demanda a las industrias manufactureras una creciente diferenciación de sus productos. Asimismo, la relevancia de las actividades de base tecnológica digital son cada vez más pronunciadas, y es creciente la vinculación de los productos a valores de sustentabilidad social, ecológica y cultural. Sobre la base de estas explotaciones, el diseño toma dimensiones cada vez más complejas. Este estudio pretende contribuir al análisis del diseño, como objeto de co-creación, a partir de un paquete de metodologías que orientan, ordenan y traducen procesos que favorecen la apertura de sus fronteras y promueven como resultado el desarrollo de nuevos materiales con aplicabilidad específica.

En las últimas décadas se ha generado abundante literatura orientada a la indagación de las dimensiones analíticas que influyen y condicionan la construcción de la ciencia y tecnología en los procesos de nuevos materiales, aquí nos concentraremos en desarrollar un enfoque en el diseño y su proceso de innovación, como agente que contribuye en la 
apertura de la caja negra del proceso científico tecnológico para la generación de nuevos materiales; eficientes, sensibles, dinámicos y como resultado de creación consiente.

Sobre este objeto se intentará comprender e identificar dimensiones subyacentes de las actividades de diseño como proceso de intervención en la génesis de los materiales.

\section{Proceso abierto creativo y bordes invisibles}

La ciencia y la tecnología aparecen en las esferas de las discusiones actuales como moderadores o creadores de las soluciones que demandan las estructuras sociales dinámicas hacia el nuevo paradigma sostenible.

El diseño, dentro de éstos fenómenos de construcción de soluciones aplicables, replicables, apropiables, deben impulsar reflexiones de cómo la disciplina proyectual está mutando hacia un proceso de transformación transversal que surge del nexo entre ciencia, tecnología, cultura y poder. Es por ello, que no debe configurarse solo como un vestigio del formalismo y estética que muchas veces banaliza la actividad del diseño.

Entender que todo cambio paradigmático trae una fase de destrucción creadora (Schumpeter) para poner en vanguardia innovaciones radicales ayuda a comprender las nuevas vertientes del diseño que renace de sus últimas versiones devenidas del materialismo inmediato, para centrar y profundizar los nuevos conceptos en que la sociedad se encuentra demandando.

Incorporar al proceso de diseño el entendimiento de la utilidad social, el centro de la necesidad real, permite reflexionar como a partir de metodologías proyectuales propias del diseño industrial, los materiales pueden incorporar estas lógicas sustentables y así obtener resultados innovadores y generadores de nuevas oportunidades.

En este contexto, los procesos de innovación proyectual, requieren nuevos mecanismos y herramientas híbridas de creación y gestión. Para el logro exitoso, las redes sociales de innovación abierta exigen nuevas estructuras y procesos; esfuerzos permanentes de moderación, coordinación y seguimiento para esta apertura y flexibilidad que pueden ser configurables en el desarrollo de nuevos materiales.

En las dimensiones de los productos industriales, la intensidad del cambio tecnológico, así como el incremento de la complejidad y la incertidumbre en los mercados a causa de un acortamiento en el ciclo de vida de los productos, del incremento en la movilidad de las personas y de la diseminación del conocimiento, han provocado que pocas empresas puedan innovar utilizando sólo sus recursos internos. En este aspecto, lo fundamental son los procesos que permiten generar e intercambiar el conocimiento dentro de las empresas (OECD, 2005). Comprender este proceso, sustenta la movilidad de las fronteras del diseño como estímulo creador para el proceso de innovación en la generatriz de los nuevos materiales.

Una parte central del diseño en los procesos de innovación se refiere a la forma de encontrar ideas que se puedan materializar y comercializar. En este contexto, el diseño como línea metodológica para la generación de materiales adaptables a las nuevas improntas del mercado, puede ser adoptado de manera estratégica para alcanzar y mantener innovaciones (Schumpeter, 1912, 1942; Rosenberg, 1982; Von Hippel, 1986). Conjuntamente 
con la estrategia de innovación, desde nuestro enfoque, el proceso debe configurarse de manera abierta (Chesbrough, 2003) en donde la innovación abierta se define como una estrategia para reorganizar, exteriorizar y mejorar la forma de innovar mediante alianzas de colaboración con otras organizaciones, las actividades de $\mathrm{I}+\mathrm{D}+\mathrm{i}$, la gestión intelectualindustrial, la búsqueda de fuentes externas de conocimiento y los mecanismos alternativos de salida al mercado.

La génesis abierta de los nuevos materiales, desde este enfoque toma como partícipes la ciencia, la tecnología y al diseño, siendo el último una herramienta colaborativa para vehiculizar y dar soluciones viables a partir del conocimiento generado y aplicado hacia la génesis de los materiales como la unión transversal entre ciencia, como elemento creador, y sociedad como el soporte del lenguaje objetual.

La co-producción implica que, tanto en el orden natural como en el orden social, se produce conjuntamente, y que ninguno de los órdenes prevalece por encima del otro (Jasanoff, 2004), entendiendo a la dimensión del diseño como elemento sistémico que aporta a esa cadena de producción para la incorporación de lenguajes no clásicos hacia los materiales y su fabricación. La información aplicada no es solo constructiva, sino simbólica, interpretativa, de exploración y manipulación en torno a una funcionalidad ampliada y dirigida hacia el usuario. (Norman \& Draper, 1986)

El entorno que se propone pensar es el que subyace a la sociedad en un ecosistema formado a través de materiales, que se transformar y conforman en ese entorno a partir de las capacidades de evolución a productos de diseño industrial, siendo sus significados, pregnancias, utilidades y motivos contextuales los que definen ese entorno y recrean las relaciones entre los individuos y los objetos.

Desde el objeto de estudio de la génesis de los materiales, a través de tecnologías proyectuales de diseño, el ecosistema conformado como material, construido a través de dinámicas de innovación abierta, sectoriales, productivas y de desarrollo científico y tecnológico, deben validarse y aceptarse en el mercado.

Desde esta hipótesis, la secuencia proyectual y sus barreras de co-coonstrucción empiezan a dilatarse para encontrar un sentido más comprometido, que puede re orientar ese conocimiento científico abstracto, hacia algo tangible, amigable, electivo que de un pasaje hacia una utilización, apropiación, difusión y transmisión de ese conocimiento experto, hacia un material objeto como resultado de un proceso proyectual.

El diseño como paquete tecnológico para el desarrollo de un nuevo material, se inscribe en un proceso complejo que implica interdisciplinariedad para su factibilidad. El objeto de estos nuevos materiales como portador de utilidad social, devienen de una metodología de diseño proyectual como elemento que interpreta las necesidades de los nuevos usuarios, y se complementan con otros grupos heterogéneos de conocimientos para que el procesos innovativo recree estos materiales.

Es así, que el diseño industrial se identifica como un elemento partícipe de la co-construcción de los nuevos materiales, que proporciona el conocimiento del entendimiento de las nuevas necesidades y que se constituye como un proceso creativo, tecnológico y multidisciplinar, orientado a la creación como proceso de nuevos materiales con utilidad social. 


\section{Revalorizar los ciclos activos y el pensamiento crítico de la materialidad y vida del producto}

Las dimensiones sustentables son fenómenos contemporáneos que ponen temáticas en cambio climático, biodiversidad, ética y equidad para intentar resignificar la demanda cultural. Estas premisas permiten reflexionar cómo los sistemas materiales, relevantes por su papel protagónico al ser una unidad compositiva que configura productos y objetos para el desarrollo de la interface humana, deban re enfocarse frente a estas necesidades sociales y naturales con conciencia ecológica, humana y económica. Donde conocimiento metodológico del diseño puede desempeñar un propósito integrador que confluya en sistemas tecnológicos, científicos, biológicos, físicos con ciencias sociales, antropología, sociología, a través de su propuesta proyectual.

La ciencia y la tecnología definen nuevos escenarios que dan una perspectiva para las oportunidades en donde el diseño puede proponer aportes dentro de los procesos de creación colaborativa. La sociedad de la información y el conocimiento están cambiando los modos de entender el diseño y modificando los perfiles profesionales sociales, estratégicos y sustentables.

Los nuevos materiales toman dimensiones de compuestos biológicos y tecnológicos: biomateriales, nanomateriales, materiales imprimibles, materiales compuestos y los futuros pre configurables. Nacen como consecuencia de la convergencia de diversas ramas del conocimiento.

En este escenario, nos enfocaremos a los biomateriales, como potencial de desarrollo estratégico en Argentina, donde por las ventajas competitivas propias de nuestro país se pueden generar una nueva disciplina creativa emergente y donde los esfuerzos relevantes de $\mathrm{I}+\mathrm{D}$ dan resultados prácticos, estratégicos, con interés social, económico y productivo. La nanotecnología permite desarrollar materiales configurables átomo por átomo, dando oportunidad al diseño en pensar esa configuración para realzar propiedades y pensar desde lo taxativo mediante un enfoque sistémico que contribuya a conceptualiza y evaluar las ideas para poder llevarlas a un formato funcional y formal traducido a un material o nuevas estructuras tecnológicas.

En el campo de la génesis de los materiales, el diseño como tecnología puede pensarse en la desconstrucción de las propiedades técnicas y mecánicas para que su desempeño permee a las demandas desde las dimensiones de: percepción, estética, emoción y significado, adoptando una actitud reflexiva sobre la relatividad del material como producto que emerge hacia un contexto complejo. Así el apoyo teórico/ metodológico del diseño, pueda estructurar la actividad creadora para aumentar las capacidades y reflexiones sobre los materiales y su impacto.

Esta situación de innovación colaborativa es un reto hacia el diseño en donde el re ordenamiento molecular de la biología y la nanotecnología como motor de las nuevas oportunidades pragmáticas y sintácticas pensando el diseño desde materiales a partir de la reconfiguración de los conocimientos existentes o la recombinación de los mismos son el soporte de la dimensión del diseño de estructuras con amplias posibilidades y configuraciones que determinen las características de los materiales. 
Como promotor de estas dinámicas, los Fab Labs o Laboratorios de Fabricación Digital se inscriben en un cambio de paradigma en las tecnologías y modos de producción, que ayudan a las dinámicas de los nuevos materiales que surgen en un contexto en el cuál se le demandan a las industrias manufactureras una creciente diferenciación de sus productos. Asimismo, la relevancia de las actividades de base tecnológica digital son cada vez más pronunciadas, y es creciente la vinculación de los productos a valores de sustentabilidad social, ecológica y cultural.

En este marco, la revolución informática está dando lugar a una nueva revolución industrial, tal como lo desarrolla Chris Anderson en su libro Makers, The New Industrial Revolution. Estamos rodeados por bienes físicos y la mayoría de ellos son producto de una economía industrial que durante el siglo pasado se transformó de todas las maneras posibles siguiendo una fuerte production push. Es aquí donde las nuevas estrategias de generación de conocimiento comienzan a tener un rol central, en tanto posibilitan la fabricación innovadora de productos físicos, en ambientes que facilitan la colaboración abierta y la transferencia.

La impresión 3D como herramienta naturalizada en el proceso de prototipado rápido en los diseñadores ya toma dimensiones propias y puede coadyuvar al diseño de materiales o pensarse como una reprogramación para este evento creativo material. En línea con la fabricación digital, como un fenómeno radical y de disrupción innovativa desde la revolución industrial, los materiales y su coexistencia objetual toman la misma radicalidad. Desde esta perspectiva los materiales son un ciclo proyectual y son el insumo de soluciones creativas tanto por su génesis como por su descomposición. Los biomateriales, o materiales biológicos, transformados en a partir de fuentes renovables configurables en: materiales biodegradables, biocompatibles, bioinertes, para aplicarse en todas los ecosistemas necesarios para la sociedad y los aspectos culturales como base para definir las competencias de los materiales y su atractivo sustentable.

\section{Experiencias materiales, diseños aplicados, proyecciones argentinas}

En el contexto de los cambios en las dinámicas de producción de los materiales, señalamos al diseño como factor clave para generar esa adaptabilidad, siendo una tecnología de proceso. El diseñador como un eslabón del sistema, responde a las dinámicas de proyección de soluciones coherentes y coexistentes a la génesis innovativa.

Los recursos naturales renovables están siendo protagonistas. Se están debatiendo el "cómo" se afronta ese cambio y "quiénes" serán los protagonistas de generar ese acercamiento a su utilización y apropiación constante. Sobre la base de lo expuesto anteriormente podemos decir que existen al menos tres planos que tienen especificidades en sus contenidos y diferentes aplicaciones: ciencia, tecnología y diseño.

La identificación de las problemáticas asociadas a los nuevos paradigmas de los consumidores recrean una visión aguas abajo de las cadenas proyectuales, donde el desarrollo de nuevos productos con los indicadores de eficiencia, sustentabilidad y el nuevo contexto paradigmático recrean y se reformulan a través de nuevos escenarios. 
La dinámica sobre la cual se sustenta este estudio como punto de partida hacia las aplicaciones en el campo de la búsqueda de soluciones abiertas y diseñadas para los nuevos materiales, en donde la materia prima y su vida útil deben ser congruentes al tiempo, modo de uso de los productos y que su ciclo contemple su procesamiento, impacto ambiental. Desde el objeto de este estudio, avanzamos en la exploración de casos paradigmáticos locales donde existen aportes e integraciones de la disciplina del diseño en la génesis de nuevos materiales.

\section{Placa biodegradable orgánica para la incorporación de nutrientes y celulosa de manera directa}

El objeto de este caso visibiliza el material como consecuencia de su necesidad funcional, el desarrollo termina en fase producto: surcos autoportantes biodegradables para ser utilizado en el momento de siembra, cuya materialidad interpreta el ciclo de producto que es el mismo de su ciclo de vida.

Es un compuesto de material orgánico que incorpora nutrientes y celulosa y se aglutina aplicando calor y aglutinante para su conformación final. En contacto con el agua, comienza a desarmarse y se incorpora al suelo, al cual aporta sus diversos componentes y es el punto más innovativo del material. Bajo este funcionamiento, el método permite, evitar la erosión y la pérdida de nutrientes, sin modificar el sistema de regado por surco, pero haciéndolo biodegradable.

El material que queda depositado en la tierra luego de su utilización, pasa a ser parte de ella y la nutre para el próximo ciclo productivo. La placa puede aplicarse a surcos longitudinales y perpendiculares durante los distintos períodos de sembrado, tanto en verano como en invierno, para responder a las diferentes condiciones climáticas y a las necesidades de las hortalizas en los cinturones verdes de las ciudades.

El proyecto fue desarrollado por una técnica agropecuaria y estudiante de Diseño Industrial. Analía Rojas (Agencia CTyS).

\section{Algatex. Textil dermo-protector con algas marinas}

Textil con propiedades dermo-protectoras, desarrollado a partir de configuraciones nanotecnológicas para el aprovechamiento sustentable del recurso natural: algas marinas, que tienen un potencial en la incorporación de sustancias químicas relevantes en dermatología. El material textil está orientado al campo del cuidado de la piel. El desarrollo del proyecto está siendo llevado a cabo por D.I. Ma. Alejandra Martínez en el Instituto de Investigaciones en Ciencia y Tecnología de Materiales en el área de materiales compuestos (COMP) - INTEMA - (CONICET-UNMdP), en una escala de laboratorio, para luego proyectarlo a una escala de producción industrial. 


\section{Ceras biodegradables a partir de aceite de soja}

Ceras de soja a partir de procesos oleoquímicos con características orgánicas, biodegradables, no tóxicas ni nocivas para el medioambiente.

Estos productos tienen uso industrial y comercial, y alto valor de mercado. Específicamente para ser utilizadas como recubriendo de frutas y hortalizas frescas.

Es un bioagente de recubrimiento superficial para frutas y hortalizas. Tiene alta efectividad en abrillantar, proteger y minimizar la pérdida de peso.

A diferencia de las ceras existentes en el mercado nacional, éste es un producto orgánico que presenta una mayor performance y durabilidad que los productos sustitutos, es biodegradable y no tóxico, no es nocivo para el medioambiente y lo más destacado está en que no afecta a los consumidores finales.

Por sus características, puede competir a nivel internacional y a partir de la intervención del diseño estratégico se sometió a diferentes modificaciones moleculares para cambiar los puntos de fusión e incorporarse como antidesmoldantes, recubrimientos para embeberse en embalajes, entre otros.

Desarrollado por el departamento de I+D de la firma Bio Productos S.R.L a cargo del Ing. Enrique Bosio.

\section{Paradigmas y experiencias materiales en la nueva cosmogénesis abierta}

El propósito de estos ejemplos es avanzar en la definición de las capacidades requeridas para conseguir una penetración eficaz de las tecnologías, modelos proyectuales y productivos apropiados y apropiables en diferentes niveles del diseño de nuevos materiales, mediante el relevamiento de información y la construcción metodológica para la recolección de datos que permitan evaluar la situación actual y elaborar dinámicas para la génesis de los mismos. Se trata de romper el paradigma de los sistemas de producción lineales, hacia sistemas cíclicos e interactivos. Así como los elementos naturales se transforman o son aprovechables por el mismo sistema, los productos también pueden ser pensados desde esta perspectiva metabólica (McDonough, 2002), trasladando este concepto al diseño de materiales.

Desde esta lógica, se visibiliza como el diseño puede ampliar sus posibilidades proyectuales a través de estrategias competitivas dentro de la cadena de valor de la génesis de los materiales, incorporando las dimensiones ambientales, sociales, productivos, sus cualidades físicas, entre otras oportunidades de nuevos productos y desempeños a partir de esta nueva concepción. El diseño industrial y los productos de su creatividad proyectual pueden enmarcase dentro de las nuevas configuraciones materiales, la introducción de cambios conceptuales de los materiales que los conforman hasta reconfiguraciones de nuevas sintaxis que devienen del re diseño, eco diseño, diseño competitivo y estratégico como co-esfera (Jassanof) de integración social, científica y tecnológica.

Podemos asociar como la historia ha sido marcada en su evolución a través de la significación del material en vínculo con su manipulación hacia el desarrollo, edad de piedra, edad de bronce y edad de hierro. En contraparte, podemos nombrar como la sociedad del conocimiento surge y como hoy ese conocimiento se acerca a las definiciones de apertura, donde 
la integración de la innovación, pilar en el diseño, como traductor de las necesidades y problemáticas hacia esa producción del material como símbolo de estas etapas de cambio de paradigma pueden construirse o reconstruirse desde la metodología proyectual.

Las tecnologías avanzan como el mismo sistema científico, proyectual e industrial, desde el hierro como clave para las primeras revoluciones industriales hasta los polímeros y su secuencia de masividad, los biomateriales como producto de la ciencia en las barreras cercanas del conocimiento y la revolución biotecnológica y TIC. Pensando el rol del método proyectual del diseño puede limitar o extralimitar las posibilidades de configuraciones y oportunidades de desarrollo material.

Es el momento de evolucionar hacia la integración como elemento emergente de la construcción proyectual, donde el material como protagonista del ciclo portante del proceso de vida de producto, se inscribe en la red transversal del paquete tecnológico del diseño. Las necesidades actuales demarcan nuevas oportunidades entorno al desarrollo de materiales. El diseño en su actividad proyectual como un espacio de co-creación abierto, dinámico y participativo propone abordar la génesis de los materiales desde una óptica integrada social y científica hacia el nuevo paradigma de sostenibilidad.

\section{Bibliografía}

Ashby, M. (2005). Designing Hybrid Materials. In M. Ashby, Materials selection in Mechanicals Design (pp. 339-376).

Chambouleyron, M.; Arena, A. y Pattini, A. (..) Diseño de productos y desarrollo sustentable estrategias de revalorización de productos manufacturados para su introducción en un nuevo ciclo de vida. INCIHUSA (Instituto de Ciencias Humanas y Sociales) CRICYT-CONICET.

Chesbrough, H. (2003). Open Innovation: The New Imperative for Creating and Profiting from Technology. Harvard Business School.

Design Council (2002). "Competitive advantage through design”.

Hippel, E. (1986). Lead users: a source of novel product concepts. Volume 32 Issue 7, Pages 791-805.

Jasanoff, S. (2004). The Co-Production of Science and Social Order.

Galán, B. (2009). "El rol del diseño en las economías creativas", en Impacto del Diseño en la Argentina, inti.

Karana, E.; Barati, B.; Rognoli, V. \& Zeeuw van der Laan, A. (2015). Material driven design (MDD): A method to design for material experiences. International Journal of Design, 9(2), 35-54.

Norman, D. A. \& Draper, S. W. (1986). User Centered System Design: New Perspectives on Human-computer Interaction.

Maldonado, T. (1993). El diseño industrial reconsiderado. Barcelona: G. Gili.

Manzini, E. (1999). Strategic design, an introduction, conferencia dictada en el máster en Diseño estratégico del Politécnico de Milán.

McDonough, W. (2002). Design for the triple top line: new tools for sustainable commerce.

McDonough, W. (2007). Cradle-to-cradle design: creating healthy emissions - a strategy for eco-effective product and system design. 
OCDE (1982a). Manual de Frascati, Medición de las Actividades Científicas y Tecnológicas. Robert, V. y Yoguel, G. (2011). The complex dynamics of economic development, en Antonelli, C. (ed.), The system dynamics of technological change. Cheltenham: Edward Elgar. Rosenberg, N. (1982). Inside the black box technology and economics. Cambridge, London. Sanders, E. B.-N. \& Stappers, P. J. (2008). Co-creation and the new landscapes of design. CoDesign, 4(1), 5-18.

Sharifi, S. y Pawar, K. (1996). "Product design as a means of integrating differentiation", Technovation, vol. 16, $\mathrm{N}^{\circ} 5$.

Shigley, J. E. y Mischke, Ch. R. (1989). Diseño en ingeniería mecánica. McGraw-Hill.

Shumpeter, J. (1967). Teoría del desenvolvimiento económico. México: Fondo de Cultura Económica.

Tung, F.-W. (2012). Weaving with rush: Exploring craft-design collaborations in revitalizing a local craft. International Journal of Design, 6(3), 71-84.

Yoguel, G.; Becerra, P. y Silva Failde, D. (2010). La caja negra del diseño: algunas consideraciones metodológicas aplicadas al sector de indumentaria en la Argentina. Redes, Diciembre-Sin mes, 75-112.

Walsh, V. (1995). Design, innovation and the boundaries of the firm, Research Policy, $\mathrm{N}^{\circ} 25$. Walsh, V.y Roy, B. (1985). “The designer as a gatekeeper in manufacturing industry”, Design Studies, No 6.

Walsh, V.; Roy, R. \& Bruce, M. (1988), “Competitive by design”, Journal of Marketing Management, $\mathrm{N}^{\circ} 2$.

Abstract: The new dynamics of generation of production and diffusion of knowledge, and the interrelation with innovation platforms applied to the local production systems, define new innovation scenarios.

The deep understanding of the operations of contemporary complexity expands the spectrum of action of the design process.

The inclusion of the genesis of materials in the design process redefines the possible design hypotheses and encourages a dynamic of co-creation between multiple disciplines.

Key words: new materials - industrial design - open innovation - co-construction.

Resumo: As novas dinâmicas de geração de produção e difusão do conhecimento, e a inter-relação com as plataformas de inovação aplicadas aos sistemas produtivos locais, definem novos cenários de inovação.

A profunda compreensão das operatórias da complexidade contemporânea estende o espectro de ação do processo Projetual.

A inclusão da gênesis dos materiais no processo Projetual redefine as possíveis hipóteses de design e propicia uma dinâmica de co-criação entre múltiplas disciplinas.

Palavras chave: novos materiais - design industrial - inovação aberta - co-construção. 

Fecha de recepción: octubre 2017 Fecha de aceptación: mayo 2018 Versión final: diciembre 2018

\author{
Introduction by the School of \\ Design of Politecnico di Milano \\ Marinella Ferrara * and Valentina Rognoli **
}

Resumen: En el panorama contemporáneo del diseño, los materiales ganan un papel preponderante. Somos testigos de una increíble aceleración en la evolución de las prácticas de diseño y de los procesos relacionados con los desarrollos de materiales y aplicaciones. En este paper queremos introducir y formalizar el concepto de "materialidad difusa", con el objetivo de describir estos cambios significativos en el campo de los materiales para el diseño. De hecho, todas las clases de materiales se están transformando en algo diferente: los plásticos se convierten en bio, los materiales compuestos se convierten en inteligentes, los residuos agrícolas se convierten en materiales de cultivo, los de producción industrial en materiales avanzados y el material orgánico se convierte en frontera del diseño futuro. Para definir el concepto de materialidad difusa nos hemos centrado en el contexto europeo, y hemos recogido varias contribuciones de los académicos que describen su perspectiva personal acerca de los materiales. En la siguiente introducción, hay una breve descripción de todos estos artículos.

Palabras clave: materialidad - diseño - materiales - tendencias de diseño - prácticas de diseño - experiencia en materiales - significación de los materiales.

[Resúmenes en inglés y portugués en las páginas 65-66]

${ }^{(*)}$ Architect, $\mathrm{PhD}$ in Industrial Design and associate professor at the Design School of the Politecnico di Milano, Design Department. She is the coordinator of the Research Centre of Material Design Culture (www.madec.polimi.it). Her researches and didactic activities deal with the relationship between design and techno-scientific innovation, with a particular focus in emerging materials in the field of product and interior design. She is an expert in the dissemination and communication of the design contents.

${ }^{(*)}$ Designer, $\mathrm{PhD}$ in Industrial Design and assistant professor at the Design Department of the Politecnico di Milano. She has been working in the field of materials for design for almost twenty years gaining expertise on this topic both in research and education. She has always been interested on the expressive-sensorial dimension of materials and their emotional aspects. Currently, her research and education activities are focusing on emerging materials experiences, Materials Driven Design (MDD) method, materials interactions, DIY Materials, tinkering with materials, CMF (colour, material and finishing) design, repairing and imperfection. 
The twenty-first century has shown an unprecedented speed of evolution of materials that modified the concept of materiality forever. The designers learnt that the design activities and practices could influence the materials development.

The raw material is transformed, shaped and processed following quantity and quality that have no precedent in human history: the traditional materials gain new forms and performances. Plastics become bio, composite materials change into smart, agricultural wastes transform into growing materials and those of industrial production in advanced materials, and the organic material becomes the border of the future design.

While the contemporary design is challenging with new material qualities and properties, considering these as key elements for innovation in expressive languages and success of artefacts, the design research helps define the new features and performance of materials capable of giving life to new experiences in everyday objects.

These extensive activities "on" and "with" materials are strongly influencing the imagery of design, and they become powerful tools that can generate new trends, can affect the human senses and culture, only changing the appearance, behaviour and essence of daily artefacts. Considering this, the number 70 of Cuadernos del Centro de Estudios en Diseño y Comunicación, produced in partnership between Facultad de Diseño y Comunicación de la Universidad de Palermo and the School of Design of Politecnico di Milano, offers a framework for research and design practice in which materials and manufacturing processes are elements of inspiration and reflection on the meanings of innovation in the field of design.

The aim of the issue is to compose a reasoned collection of original and unpublished contributions that address the reflection on the materials and their applications in many areas of design: product, communication, interior, fashion.

This part, edited by Marinella Ferrara and Valentina Rognoli, is constituted with different contributions selected to shape the editors' personal idea of "diffuse materiality". In general, it is an overview of the material research in Europe, especially in Italy, where the scientific community agrees that materials are the key elements in the design process because materials participate in the creation of the sensorial-expressive dimension of products enhancing unique experiences.

Each contribution offers a different thematic approach, and a diverse research aspect, both for the amplitude of the context and for the deepness of the analysis.

Marinella Ferrara and Anna Cecilia Russo highlight on the idea of a Design-driven approach as the "Italian way" for product innovation, which is based on subtle and historical dialogue between materials and aesthetics, and on the focus of designers on the communicative and symbolic value of materials. This design model has led to the generation of products that still marvel for their unsettling and sophisticated use of materials and techniques, as well as the elaboration of ideas that have enhanced consolidated knowledge by introducing elements of discontinuity with respect to current thinking, anticipating aspirations social and working with the sprouting of new lifestyles. Linda Worbin focused on the idea of temporality as a design variable, which is an alternative dimension towards products sustainability through changeability. Using new potentials in material and production, she crafts colours that evolve over times for her textiles design showing a possible new direction for textiles and products. 
Manuel Kretzer's article presents a didactic model for integrative and explorative smart material education as a means to enrich existing educational frameworks. Rather than prescribing a particular method or predefined solution, the idea is providing open access to information and suggests a broad range of relevant possibilities, encouraging students to learn "how-to-do" by offering a stable and reliable framework for independent selfdevelopment.

From smart materials, we move to biomimetic materials, thanks to the article by Murat Bengisu that elaborates on five biomimetic approaches: imitation, inspiration, functional, process-based, and ecosystem-based. For all these approaches, the case studies explain how biomimetic research can help solve different problems in design.

After this series of article concentrated on new technologies and emerging materials, we turn to what the authors indicated as the hybrid scenarios between design and technology called Material Activism. Valentina Rognoli and Camilo Ayala present here the concept of Material Activism as a way to understand the growing phenomena that are allowing materials to democratize through a bottom-up approach.

It is time to focus on applications and correct context. In fact, Giulia Gerosa and Laura Daglio have developed a contribution for discussing the innovative use of traditional materials or the use of new materials in public spaces design, highlighting two possible trends in the search for the quality enhancement of urban places: expressiveness and performance. Selected case studies are disclosed to present how new forms, with attention on perceptual values and the environmental impact and comfort, as well as durability, are the primary goals of material innovation in this field.

As a new contemporary design scenario, we considered the Giovanni Conti's contribution about the materials for knitwear, where knitwear design is defined as a complex process, combining ancient techniques of traditional knowledge with experimentation and technological innovation.

With Giulio Ceppi's intention to transfer of the "slow" approach into design practice, coining the expression of Sustainable Sensoriality to combine the worlds of sensoriality with sustainability. Using conceptual and operational dimensions of design, this new concept would contribute in the field of systems and steer the transformations underway towards sustainable ways of living and producing.

With this hope our recognition about the diffuse materiality, edited by Marinella Ferrara e Valentina Rognoli, closes.

Abstract: In the contemporary panorama of design, materials are gained an important
role. We are the witnesses of an incredible acceleration in the evolution of the design
practices and processes related to materials developments and applications.
In the present issue, we want to introduce and formalised the concept of "diffuse
materiality" for describing these significant changes in the field of materials for design.
In fact, all the classes of materials are transforming in something different: plastics
become bio, composite materials change into smart, agricultural wastes turn into growing 
materials and those of industrial production in advanced materials, and the organic material becomes the border of the future design.

For defining the concept of diffuse materiality we focused on the European context, and we collected various contributions from scholars describing their personal approach to materials. In the following introduction, there is a short description of all these articles.

Key words: materiality - design - materials - design trends - design practices - innovation through materials - materials experience - materials meanings.

Resumo: No panorama contemporâneo do design, materiais adquiriram um papel de liderança. Somos testemunhos de uma aceleração incrível na evolução das práticas de design e processos relacionados com o desenvolvimento de materiais e aplicações.

Neste artigo apresentamos e formalizamos o conceito de "materialidade difusa" para descrever essas mudanças significativas no campo de materiais para o projeto. Na verdade, todos os tipos de materiais estão sendo transformados em algo diferente: plásticos são transformados em bio; materiais compostos em inteligentes; resíduos agrícolas em materiais de cultivo; aqueles de produção industrial em materiais avançados; e o material orgânico no futuro do design.

Para definir o conceito de materialidade difusa focamos no contexto europeu, e recolhamos várias contribuições de estudiosos que descrevem a sua perspectiva pessoal sobre os materiais. Na seguinte introdução, há uma breve descrição de todos esses itens.

Palavras chave: materialidade - design - materiais - tendências de design - práticas de design - experiência com materiais - significância de materiais. 
Fecha de recepción: octubre 2017 Fecha de aceptación: mayo 2018 Versión final: diciembre 2018

\section{The Italian Design Approach to Materials between tangible and intangible meanings}

Marinella Ferrara * and Anna Cecilia Russo **

Resumen: Este artículo aborda el enfoque del diseño italiano de materiales, basado en una larga tradición de desafíos de intercambio entre prácticas intelectuales. Sobre la base de sus estudios anteriores, los autores, centrándose en el diseño y la historia de las empresas, explican el enfoque y las razones del proceso osmótico entre la tecnología y las humanidades en Italia y cómo estos intercambios desafiantes repercuten tanto en la producción como en los desarrollos futuros. Una visión general del paisaje cultural europeo de los tiempos ayuda a centrarse en las principales teorías que todavía representan un bastión de las Humanidades del Diseño. Explorar el significado semiótico de los materiales mejora las exploraciones sobre sus aplicaciones así como las investigaciones nuevas y en curso en el campo del Diseño de Materiales, también en términos de sostenibilidad e interacción.

Palabras claves: Diseño Italiano - Diseño de Materiales - Historia del Diseño - Uso Creativo de la Tecnología - Análisis Metafórico de Diseño - Humanidades del Diseño.

[Resúmenes en inglés y portugués en las páginas 79-80]

${ }^{(*)}$ Architect, $\mathrm{PhD}$ in Industrial Design and associate professor at the Design School of the Politecnico di Milano, Design Department. Coordinator of the Research Centre of Material Design Culture (www.madec.polimi.it). Her researches and didactic activities deal with the relationship between design and techno-scientific innovation, with a particular focus in emerging materials in the field of product and interior design. She is an expert in the dissemination and communication of the design contents.

${ }^{* *} \mathrm{PhD}$ in Communications Studies (Thesis in Design Aesthetics) from Université Sorbonne Nouvelle-Paris3. After 9 years in Design Journalism at CondéNast Italy, she embarked a new career in Design Humanities, ending up to Academic Research and Teaching (V. Flusser Archive in Berlin; APPLA and École Boulle in Paris, Politecnico di Milano, and recently IES abroad-Università Cattolica). She previously freelanced for Museums, Cultural Institutions and Collectors in Europe and US.

\section{Behind Material Design}

If objects remain important as a symbolic location of experience (V. Margolin; R. Buchanan, 1995 ) it is thanks to the materials they are made up with that they mark the difference in 
terms of perception, usability and communication. This has been always a clear evidence for the Italian approach to Material Design. In fact, Italian designers have never faced materials "solely as elements of a problem of constructive correctness." Instead, materials have always been "used as a creative input and part of the linguistic and poetic palette of a project," which can be interpreted with their inherent potential for expression and use. (Ferrara, Lucibello, 2012; Ferrara, Lecce, 2015). This can be properly named as "creative approach to technology" by design (Ferrara, Lucibello, 2012). The design approach to materials can be recognized as one of the principles of European industrial design. To this concern it is possible to recall Gottfried Semper's theory, where the function of materials acquires predominant importance at the service of the idea, which is defined as "the quality of the content and purpose", in other terms, the qualities of a given material are brought into close relationship with both structural and symbolic roles that materials acquire in a project. However, no materials have any intrinsic meaning. They rather acquire meanings by being used in specific objects and contexts according to the design vision. Also French poet and writer Paul Valéry reminds in his essay Introduction to the method of Leonardo da Vinci the impact of materials starting from the creation process in architecture, which can also be deduced from a design perspective: "Constructing takes place between a project or a particular vision and the materials that one has chosen", highlighting that kind of alchemy attaining when projects and materials literally fuse: "The wonder is that we sometimes receive an impression of accuracy and consistency from human constructions made of agglomeration of seemingly incompatible elements, as though the mind that arranged them had recognized secret affinities" (Valéry, 1929). The mechanism of producing associations in terms of affinities, and then generating different timbres, able to evoke, provoke, reassure, rather than calm or disturb, can be linked to the sphere of perception that works through the specific symbolic values we tend to assign to material things. According to Nelson Goodman, for instance, and more specifically to his theories expressed in his work Ways of Worldmaking (1978), art masterpieces are not the only things that symbolize in terms of philosophical approach. That is to say, even objects of common use can turn into symbols, evoking, recalling, amplifying the specific function they were designed for, turning into more complex entities, even able to generate aesthetic experiences. Approaching the theory and the history of Material Design, especially in the specific context of its Italian determination, implies dealing with a deep knowledge in terms of around-the-world renowned method and strategy. Indeed, in Italy, a specific design method, still attested as a true Italian way of approaching design, led to a generation of designers collaborating with remarkable manufactures, considered of great impact in terms of the use of sophisticated materials and techniques, as well as for the elaboration of ideas. They broke up with a consolidate knowledge, introducing elements of discontinuity -in relation to common thought- and anticipating social aspirations and supporting the growth of new life styles (Bosoni, Ferrara, 2014). This "Italian way" of doing innovation, has been constantly revived, acquiring a mighty role especially during some specific times. Such an Italian approach to technology has been broadly communicated through exhibitions, the finishing of visual artifacts, papers and communications diffused by media, gradually turning into a sort of mythology, still supporting the image of Italian design. However, in the last decades, only few researchers 
have gone deeper into this topic, trying to understand the motivations at the base, or enhancing this given Italian peculiarity (Bosoni, Ferrara, 2014). Relevant historical issues provide a documentary evidence of the particular attention of Italian Design to materials, technologies and productive processes (Bosoni, Ferrara, 2014). During the 40's and the 50 's, for instance, Italian design was still emerging, but thanks to the synergy between designers and the raising industries, especially those in the field of new plastic materials, it was possible to launch new products that also determined remarkable aesthetic innovations, opening up new markets. This is, for instance, the case of those companies founded with the specific intent of focusing on a new material challenge, such as Pirelli (Ferrara, 2014), Arflex, Kartell, B\&B (Ferrara, 2012), Gufram, Abet laminate (Lecce, 2014), and many others. They were capable to turn into practice a true rising of the material, such as rubber, polypropylene, foaming polyurethane, and plastic laminates that became the core of their whole production in terms both of products as well as added value. Several design practices of these previously unknown materials, lacking of a proper heritage. Using material in a new direction and addressing new problem, insteed of only substitute the old materials, designers have allowed them to acquire a true identity to be renewed at every new application to functional objects.

\section{A truly Italian Material Design Story: the case of G.B Pirelli \& C and the intersections between technical and humanities competences}

A notable case of radical innovation is indeed that of the rubber industry and company G.B. Pirelli $\& C$. founded in Milan in 1872, with the intent of taking advantage of a new challenging material, like rubber, launching a production on the Italian market. Compared to other Italian companies, instead of going through a transition from an artisanal to an industrial identity, since the very beginning, Pirelli started to be driven by a fully industrialfocused policy with rubber. During Post world war II period, though the company was already provided with an internal design office, dealing with new products implementation, relevant collaborations with external local designers started to be encouraged, besides the constitution of a Communication office, giving equal relevance to technical as well as communicational and marketing issues, with a significant impact on company policy and identity. Pirelli successfully applied a redesign of a growing differentiated production, conquering new market segments, implementing technology as well as the functionalaesthetic issues related on how making new products look more and more appealing, taking into account several aspects of products differentiation and consequently the company catalogue, such as shape, color, texture, smell and elements of affordance. In this way, Pirelli overtook the old and tough question concerning the separation between science/technology and humanities (one of the core questions of the time at Politecnico di Milano), encouraging and fostering a constructive and highly productive dialogue. On such a fertile ground, design started to play a main role, mediating between technology and communication, providing solutions and enhancing perception-focused issues for unusual user experiences while company identity got stronger and effective thanks to the launch, in 1948, of the Pirelli magazine. It was called Pirelli. Rivista di informazione tecnica 
and it soon became a tool of propaganda, a true House Organ created on purpose to let the company name gaining in consistency and effectiveness, also by grouping among the contributing editors some of the most reputed intellectuals of the time, who applied a sort of "inter semiotic translation" (Jakobsón, 1987) from technology to cultural values. The Pirelli's magazine and other visual communication artifacts (posters, brochure, etc.) had then a central role in generating a new consciousness of objects that started to be defined as design products, being at the core of the aesthetization of the new rising society as, while seizing the technological meaning of new products, they captured, at the same time, their very essence in terms of deep sense and interpretation (Ferrara, 2014). Profitable exchanges between intellectuals, engineers and designers turned out to characterize the production of Italian company Pirelli, that launched several products highly defined by a strong narrative value and enriched with metonymical and metaphorical meanings ${ }^{1}$ (Ferrara, 2014) (Fig.1).
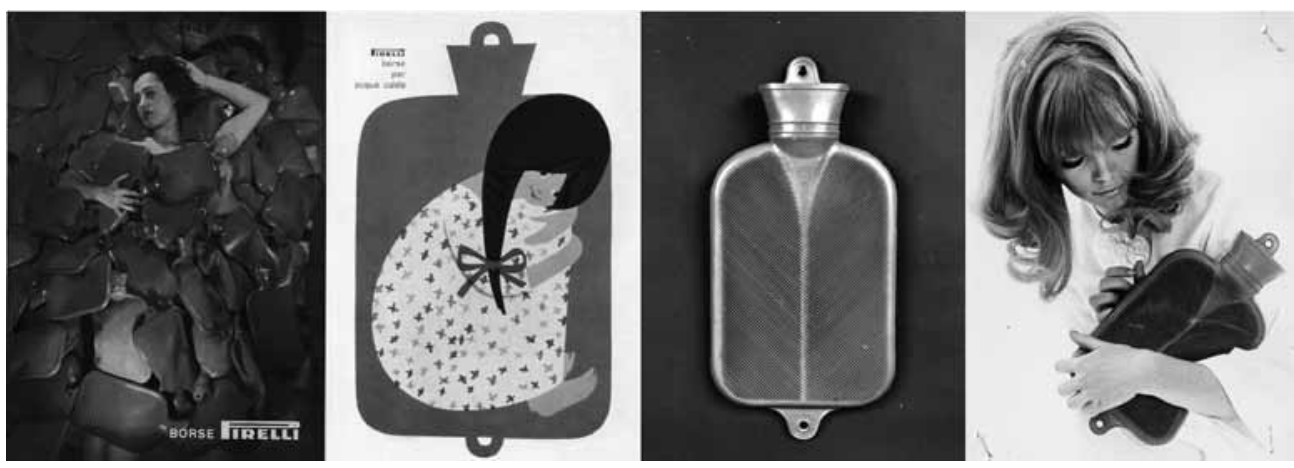

Figure 1. Pirelli rubber water bottles, visual communication and variants in texture of product. Courtesy Archivio Pirelli.

This practically announced what Umberto Eco theorized in his work Experiences in Translation (Eco, 2003), according to the process of translating from one system of signs to another, generating symbols and new values scale. In addition, the role of the industrial designer started to become central and freelancers, between tangibility and intangibility, started to be more and more involved in the company. Already in the 50's, as well as later on in the 60 's, designers, thanks to their intuition, indeed detected and opened new market opportunities to implement plastic materials and their use in relation to design, generating new aesthetics experiences. By designing amazingly shaped products, designers translated into 3D objects all the desires of the new born Italian society, slightly opening up to new life styles, increasing the demand for industrially produced furniture and houseware appliances. So that, the true scenario taking shape between the 50's and the 60's can be described as the very beginning of "l'Age Transesthétique" (Lipovetsky-Serroy, 2013), literally the Trans Aesthetic Age, basically a new era, the era in which we are still living, 
where design objects melt with the "star system", generating a sort of Communicational Hyper Culture (Lipovetsky, Serroy, 2013). Indeed, Umberto Eco in his essay Function and Sign: the Semiotics of Architecture had already introduced the idea of architectural objects, that is to say design objects, which are not designed to communicate, but rather to function, though they end up to work in everyday life as true communicational tools (Eco, 1997), and Vilém Flusser had gone even further, saying that design should be considered and approached as all the other media (Flusser, 1989).

\section{Humanities and Material Design: a consistent and open dialogue}

In order to investigate where such a deep osmotic exchange between technology and humanities applied by Pirelli originated from, it is necessary to look back in history and in the cultural background of the booming economy. If an open dialogue between industrial design and humanities had already started with the Avant-garde Movements of XX century, the new wave that hit the 50's and the 60's was essentially linked to the cultural landscape of the time. In 1957 Roland Barthes wrote Mythologies, stressing on the importance of looking at the semiotic process of myth creation trough the objects produced by modern capitalist society; in 1963 French Art Critic Pierre Restany started his long lasting collaboration with Italian magazine Domus and in 1968 Jean Baudrillard published the first edition of his essay The system of objects, showing how

Only a semiological model can decipher the meaning structure of the modern commodities. (...) in commodity the relation of word, image or meaning is broken and restructured so that its force is directed, not to the referent of use value or utility, but to desire (Poster, 2002).

Baudrillard's attention focused also on materials that, according to his analysis, can impact on different environments determining values, symbols, status, meanings. As for materials as for colours, once they reverse the traditional perception based on associations like "warm colours" or "cold colours", they penetrate different layers of society even in terms of symbols, morale, and habits. Once accepted by large groups of people, they automatically turn into cultural signs. Basically, the provocative sense produced in the early ' 60 's by the replacement of "matière naturelle" by plastic objects, previously realized in metal or wood, naturalizes its effects only once plastic became one of the consolidated aspects of everyday life and part of people's routine. Inspired by the atmosphere of those years, designers -also working for companies like Gufram or Kartell- used plastic materials to make items and furnishing objects that drastically shook up everyday imagery, in term of both form and materials. This generated not only a new way of looking at design objects as communicational tools, in a kind of "rising matter" process (Ferrara, 2014), as previously mentioned, but also generated a sort of sensory displacement. However, the Italian material approach to design generated, during the sixties and early seventies, a remarkable selection of products, while creating a specific identity that looked new, colorful, lively, easy, light and democratic, in the sense of broadly affordable by people. This identity was 
the new Italian landscape that was subsequently part of an exhibition at MoMa $N Y$ in 1972.

\section{Design Primario paradigms and around}

The Seventies represented another crucial timing for Italian Material Design Culture and its upgrade of knowledges, thanks to Design Primario, literally "basic material design". This approach was first started within the Montefibre Design Centre (Montedison Group) between 1974 and 1977 by Andrea Branzi, Trino Clini Castelli and Massimo Morozzi, with the Montefibre Fibermatching 25 Project, a method for the partitive colours definition, applied to polypropylene fibers and generating a perceptive colors definition, without any physical mixture of pigments through polypropylene filaments. Montefibre Design Centre obtained notable success at the point that design primario became the central theme of sophisticated industrial strategies of products differentiation in a saturated market, like in the case of the automotive sector. Design primario shifted the focus from products structural aspects to finishing and soft qualities (including color, texture, transparency, smell, sound, all the surface elements and their response to light variations), that is to say the expressive identity of materials, not considered as essential by Modern Movement. The sensorial, communicative and emotional quality of materials, compared to the seductive aspects of shapes became design's references, clearly destabilizing the functionalist approach (from Sullivan to Loos), according to which, the material is chosen only subsequently to design definition. This definitely inverted the paradigm, letting inspiration deriving straight from materials themselves. In other terms, the relation among form, function and materials still keeps the same value throughout the design process, though not necessarily in the traditional sequence. Here the roots of CMF (Colors, Materials and Finishing) Design, that starting from the 90's turned out to be a new professional profile specialized in the qualitative dimensions of products, and one of the most reputed specialist was Italian designer Clino Trini Castelli, who spread out a new consciousness for a systemic vision of design process, also deriving from Pirelli experience (Ferrara, 2014). CMF has been applied to products emotional definition, especially in the automotive sector for the paint and coating realization, according to a method first implemented in Italy and then exported in US and Japan. The innovations enhanced by Design Primario found a fertile ground also within the Italian company Abet Laminati, already established in 1946, but significantly blooming only in the seventies, thanks to the design collective grouped around Ettore Sottsass, through which it was possible to realize one of the most interesting cases of material design in collaboration with designers (Lecce, 2014). Among the newly created materials we can recall Lumiphos, a luminescent laminate by Clino Trini Castelli, still part of the Abet Print Catalogue though after 40 years. No more just products then, but situations, emotional and sensorial empathy between people, surfaces and surrounding space, as in the reactive surfaces, based on no-form products, no longer based on a formal value (Fig. 2). 

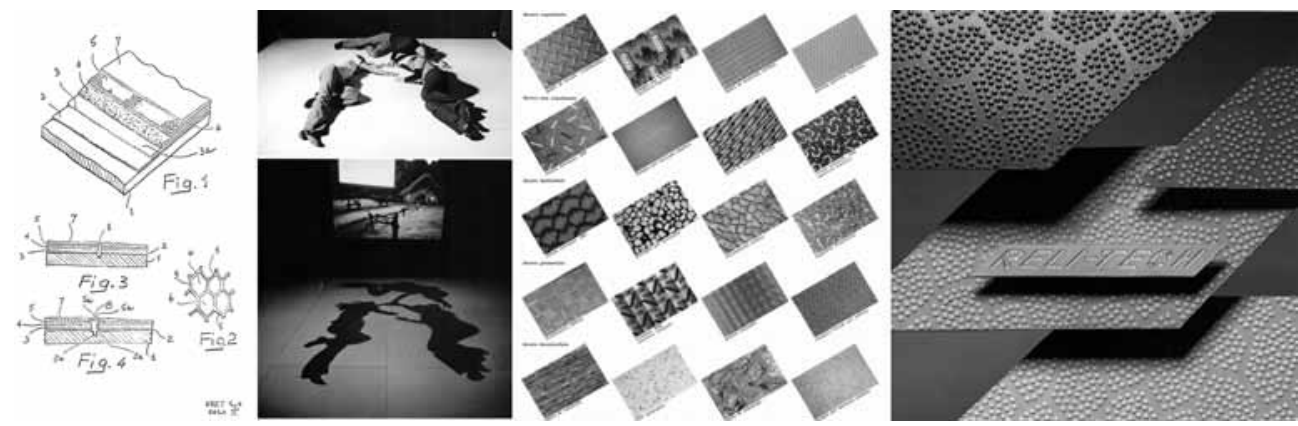

Figure 2. Abet Laminati different texture and grapfics, from Lumiphos (by C.Trini Castelli) to Relitech (by A.Branzi). Courtesy Archivio Castelli.

In the late 80 s the silent revolution of compounds led design towards a new previously unthinkable challenge of technology. Designers transferred technology from production sectors supported by big investments in research (like automotive sector) to others with small investments (like furniture sector). They worked exploring the combination of several materials and consequent innovative materials' new performances and went beyond technological boundaries that materials were pushed to their technical and expressive limits, giving unprecedented and surprising visions of their nature, creating an "increased sensory displacement" effect captured by MoMa exhibition Mutant Materials in Contemporary Design in 1995 at New York's MoMA, curated by Paola Antonelli, as well as appearing from 2003 in the iMade exhibition, curated by Frida Doveil. Those exhibitions were centered on new products performances and they were focused on how materials could adopt unexpected characteristics thanks to researches lead by designer with composite materials. That marked a time of "breaking up with a consolidate knowledge, introducing elements of discontinuity in relation to common thought" that would announce the changes and the essence of late society, as described in "Liquid Modernity" (Z. Bauman, 2000).

\section{Fostering Next Italian Material Design approach}

Starting from the late Eighties, researches from different branches, form chemistry to physics to engineer got more and more involved in developing new advanced and smart materials. In the design sector Ezio Manzini was the first scholar who started to get involved since 1986 in exploring the new perspective of designing with advanced materials. He zoomed on the fact that design process was undeniably getting more complex and that it was necessary to keep control of technical complexity, no more manageable only by designers. This led to a sort of new chapter in the history of design, envisioning a new framework and even a method, involving also other actors in order to reach a concrete innovation and outlining a new interactive nature of objects (Ferrara, 2015). These premises strongly 
impacted outside Italy, especially in The Netherlands, where the successful combination of technologies and humanities, typical of Italian design, was highly appreciated. Dutch design collectives like Droog Design, developed their first projects already in the late nineties in collaboration with some departments of Delft University of Technology, in order to stick to a sort of dry (droog in Dutch) tech design, where materials and new emerging tech could be the core of the project itself, or design schools like the Eindhoven College of Design turned them into challenging philosophies of approaching contemporary design. Droog Design approach, for instance, remained faithful to their first steps, leading to accomplishments like those showed at the Material Matters Exhibition during DDW Dutch Design Week in 2010 and in 2012, enhancing research and design focus on traditional models of recycling/upcycling, to new and speculative ways.

Today it is possible to state that the "creative approach to technology", this Italian way, spread out all over the world, and especially throughout Europe, where it drove researchers', designers' and other professionals' attention towards materials transformation in order to tell stories. Several European cases, all belonging to the same sector, and all pooled by the same current environmental awareness, pushing to conduct researches in order to turn wastes into raw materials for new productions, were collected in the book "Material Revolution 2: New Sustainable and Multi-Purpose Materials for design and architecture". Below we give some examples that can be included as significant in the material design research that has been developed since the 90's (Fig. 3-5).

Designers' skills in creating new material visions, which turn into high added value products, got recognized even on a political side. Indeed, EU Institutions started promoting the diffusion of the creativity-driven material innovation within small and big sized companies. As in the case of the integration of D-DMI methodology (Ferrara, Lecce 2015 and 2016), developed within MADEC Research Center at Politecnico di Milano and then spread around the 28 EU countries' small and middle sized companies, starting from 2015, thanks to "Design for Enterprises" Program, aiming to enhance companies' innovation skills through a design-driven innovation approach.

What's the next step? The current frontier in product innovation is based on nanotechnologies and applications for material inventions. These are often far from obvious in the context of microscopes and lab benches and, at the same time, are quite distant from every freelance designer resources, usually working on a DIY basis and with a traditional, instead of a strong technical, background. For this reasons, one of the biggest challenges about innovation for the future times of European industry is that of filling the gap between fundamental material science and its applications, anticipating design contribution in the material innovation process, while gearing towards developing product ideas based on scientific work with materials. These setting process will be based on strong interaction and hybridization between science (rational-deductive-analytical) and design (empirical-inductive-synthetic) methods, in order to generate disruptive innovation, based on materials both in terms of performances, aesthetics and meaning. Following up to the "transition from the atom to the bit" the development of nanotechnologies, smart materials and biomimetic, what turned to be the core of material design research is the concept of "interactive material system", or "computational composites" which implies material components, considering the application of compound 


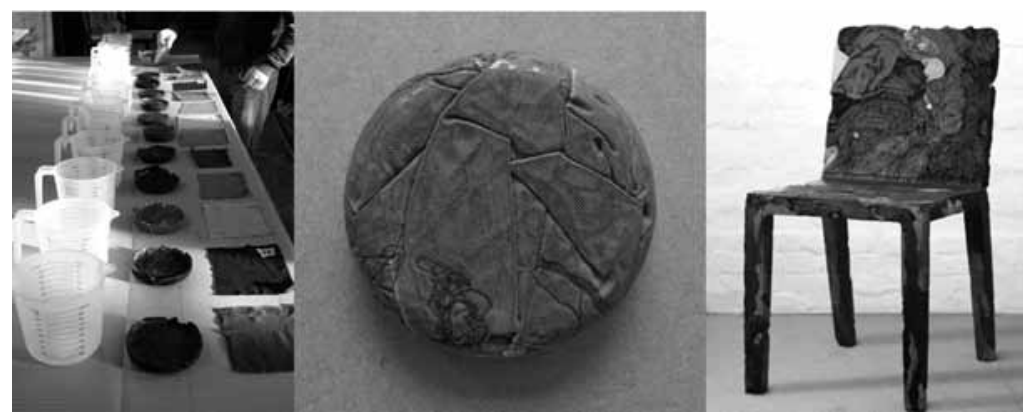

Figure 3.
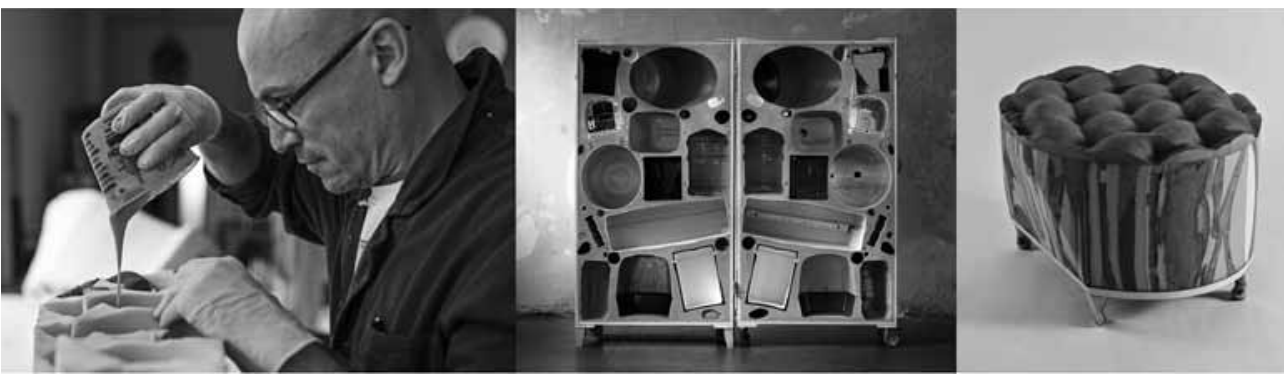

Figure 4.
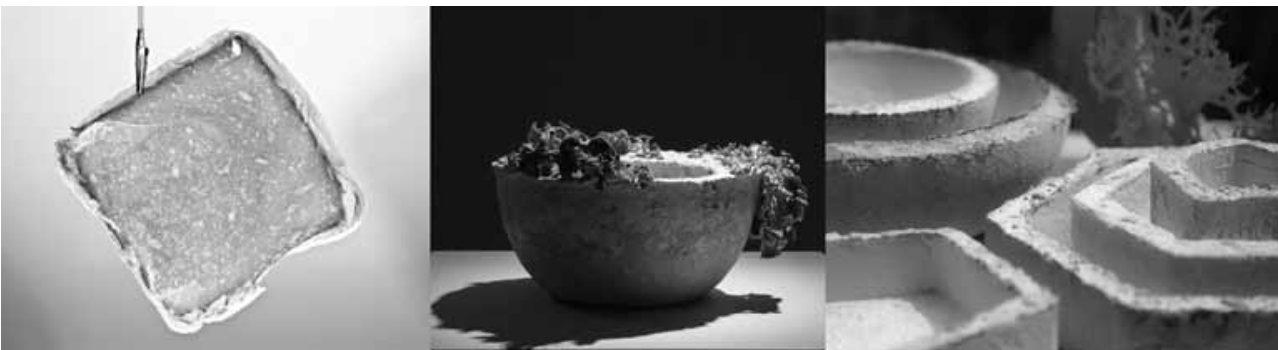

Figure 5

Figure 3. RememberMe, furniture collection realized with compressed old clothes saturated with a mix of resins. Designed by Tobias Juretzek for Casamania. Figure 4. Example of plastic experiment for furniture collection realized by upcycling plastic scraps: from plastic bottles to toys, pc and TV shells, all inserted in a framework and imbedded in a casting of polyurethane foam. Different assemblages and cuts zooms on sections and shapes variously texturized.

Design and self- production by Massimiliano Adami. Figure 5. Compostable Mycelium biomaterial by Maurizio Montalti, aiming to turn scraps, wrapped by layers of agricultural wastes, into new composites. According to the type of wastes and the consequent parameters of Mycelium growth, it is possible to create different materials with specific characteristics. (resistant, elastic, waterproof, homogenous). The research focus on how turning polluting plastic wastes into new compostable biomaterial. 
material systems, as well as behaviour and the theoretical function of the system. That is to say that the project defines the complex reciprocity between materiality (form and structure of the material-product and the related processes of assembly/production) and the various performative effects. It is required a deep understanding of the material shape and structure, as well as of the environment in which the material itself is put, not just as an external component, but as an interrelated aspect, following to all the action-reaction complex relations, that activate changes within the system itself.

Does the concept of interactive material system or "smart interface materials" imply a new approach to design? Certainly, new interdisciplinary approaches are needed to manage design technical side ${ }^{2}$, as well as aesthetic one. According to Bill Verplank's definition of an interaction design process, we deal with three fundamental questions, dealing with design cross-fertilization with other disciplines:

1. "how do we do?" It is related to how we "touch", how we "poke" the world around us. This question is related to the integration of design with engineer world

2. "how do we feel?" It is related on how people/users perceive the world, how the world responds to people action. This question is related to the art realm and to the design on how to build the understanding of perception of the world by the user.

3. "how do we know?" It is related to how user understand the interaction and how they build a mental model in order to use the product proposed. This question is related to the integration of design with social science disciplines.

Bringing up to the already mentioned Italian design approach and to the metaphorical meaning, we agree with Ross \& Wensveen (2010) that claim that if the use of metaphors ${ }^{3}$ and their representation is fundamental when dealing with static objects, it becomes even more important when dealing with smart interactive system and objects. Many authors (Schon, 1993; Lakoff and Johnson) have been examining the use of metaphors as tools of design process that support innovative products while generating new solutions. Some authors consider this an analytical tool in design, others more a communication tool to describe the characteristics of a new product and make it more approachable and usable, i.e. a tool for introducing new concepts to users. All this meanings and tasks of metaphor depend on the ability to picture the immaterial attributes of a material or product and its interaction and to create conceptual synaesthesia. This is a perceptual experience in which a stimulus in one modality gives rise to an experience in different sensory modality. In other terms, by giving a description of the metaphor through text or images we are able to evoke the feeling of a sound or a movement which otherwise are difficult to describe therefore to talk about (Cytowic 2002; Cytowic 2003).

If we want to deal with the complexity related to the material behaviour and product design in the "interaction paradigm", taking into account principles of aesthetics experience and not only efficiency, and if we want to design the behaviour in a consistent way, we cannot avoid the use of metaphors. The metaphor turns into a key concept in the communicational process with the user. Within the design process, metaphors are used in order to design the behaviour of a material/product according to a consistent inner logic, and in order to nurture the communication of different actors/competences within 
interdisciplinary meta design teams and co-design framework. The need for appropriate innovation at all levels, includes the metaphorical language that serves to sustain a given paradigm, adding considerable complexity to the task of managing actions and outcomes. To do a set of verbally metaphors and other represented through mood-board, mind maps or other visual representation tools, are usually used by designers, we not only describe the thing, but we conceptualize it and we are able to associate to it a structure and a functioning. These metaphors accomplish the task of summing up and defining the borders for further development of the project, but at the same time represents a powerful tool to inspire different possible design solution in the successive steps of the thing we want to design. According to neuroscience, in the communicational process metaphors transfer the material/product meaning to the potential users. The use of metaphors get insight about how to communicate the designer intentions better with users and create more innovative design solutions. Designers can use metaphors to create pleasurable and meaningful products likely to build brand identities that convey company values and make consumers identify themselves with. Therefore, products can definitely tell stories while generating full-experiences, as in the best of the Italian tradition.

\section{Conclusion}

The osmotic process between technology and humanities is the core of the Italian Material Design approach. Focusing on relevant studies, the authors pointed out how communicating products' value turned into a central issue to create a link between enterprises and consumers, and how this led to the implementation of close collaborations between designers and intellectuals in postwar times. Those challenging exchanges spawned a production pay off and became an input for designers' creativity, opening a new communication channel with the users by metaphorical associations, likely to generate meanings and increase products' value. Leveraging this approach, Italian designers and the creative industries of post-war decades were capable to break up with a consolidate knowledge, introducing elements of discontinuity in relation to common thought. By using materials in a new direction and addressing new problems, instead of just substituting the old resources, they anticipated social aspirations and supported the growth of new life styles, inspired by a flourishing cultural background. The "Italian way" of doing innovation trough materials interpretation has been constantly revived, acquiring a mighty role, especially during some specific times.

The Seventies represented also another crucial timing for Italian Material Design Culture and its knowledge upgrade, thanks to Design Primario. The communicative, i.e. sensorial and emotional quality of materials, compared to the seductive aspects of shapes, became design's references, clearly destabilizing the functionalist approach. This Design Primario and no-form approach started the roots of the CMF (Colors, Materials and Finishing) Design, that from the 90's turned out to be a new professional profile of designer specialized in the qualitative dimensions to products emotional definition. A new consciousness of the systemic vision of the Italian design process was spread worldwide, 
enriching the design processes pursued also in other countries with the consistency of values and meaning, deriving from humanities.

Nowadays the smartness of materials and the interaction paradigm add interest in the field of Material Design getting more and more aware of such a porosity and richness of a multidisciplinary approach, while also enhancing new concepts with a strong environmental and sustainable conscience.

\section{Notes}

1. A literature review (Antoniades, A. (1992) Poetics of Architecture: Theory of Design. Chapter 2, Metaphor. John Wiley \& Sons: United Kingdom) indicates the use of metaphor in architecture begining in the Renaissance. Leon-Battista Alberti in his discussion of the origin of building proposed a house is city metaphor. More than two millennia ago, Aristotle (Aristotle (1952) Poetics: The works of Aristotle, Vol. 11, W. D. Ross Ed. Clarendon Press: Oxford) had remarked, "midway between the unintelligible and the commonplace, it is metaphor which most produces knowledge".

2. Multidisciplinary research is getting to the highest level of excellence at the Harvard's Material Processes and Systems (MaPS) Group, which looks at materiality as a starting point for design research, with a special interest in robotic and computer-numerically controlled (CNC) fabrication processes as well as small scale work on Nano-materials. Another stronghold of contemporary research is the morphogenetic approach of Integrative Design Computation and Materialization, developed within Stuttgart University for ICD design research, according to which the design of the material system has to deploy the morphological complexity and the performative skill of material compound system, with no distinction between design and materialization processes. This allows a direct link between the ontogenesis and the chronology of structural modifications of a material - product and its interaction with external energetic strengths and last but not least its sustainable behavior.

3. As from this part on, we will refer to the concept of "metaphor", according to the sense expressed in neuroscience. We reserve to analyse and question more in details the relation exhisting between rethotic figures, as in Linguistics and Communication, and Design, in further studies.

\section{References}

Bauman, Z. (2000). Liquid Modernity. Cambridge: Polity Press.

Bosoni G. \& Ferrara, M. (eds) (2014). Editorial, Italian Material Design. Learning from the History. AIS/Design. Storia e Ricerche 4.

Cytowic, R. E. (2002). Synesthesia: A union of the senses. Boston: The MIT Press.

Cytowic, R. E. (2003). The Man Who Tasted Shapes. Boston: The MIT Press.

Eco, U. (1997). Function and Sign: The Semiotics of Architecture, in Leach, N. Rethinking Architecture. London: Routledge Editions. 
Eco, U. (2003). Experiences in Translation. Journal of Literary Semantics 32: 2.

Ferrara, M. (2012). Materiali e processi produttivi tra anonimato e protagonismi del design. DIID 55, 62-66.

Ferrara, M. \& Lucibello, S. (2012). Teaching Material Design. Research on teaching methodology about materials in industrial design. Strategic Design Research Journal $5: 2,75-83$.

Ferrara, M. (2014). "Lievitare" la materia. Pirelli, la gomma, il design e la dimensione politecnica. AIS/Design Storia e Ricerche 4, 0401.

Ferrara, M. \& Lecce, C. (2015). MADEC. Material Design Culture. In E. Duarte, C. Duarte, F. Carvalho Rodrigues (Eds.), Senses \& Sensibility '15: Design as a Trade, proceedings of the UNIDCOM/IADE 8th International Conference, pp. 490-497. Lisbon: IADECreative University.

Ferrara, M. \& Lecce C. (2016). The Design-driven Material Innovation Methodology. In IFDP`16 - Systems \& Design Beyond Processes and Thinking, pp. 431-448. València: Universitat Politècnica.

Flusser, V. (1989). La force du quotidien. Paris: Mame.

Goodman, N. (1978). Ways of Worldmaking. Cambridge MA: Hackett Publishing.

Jakobsón, R. (1987). On Linguistic Aspects of Translation. In Pomorska K.; Rudy, S. (ed). Language in Literature, pp 428-435. Cambridge: Harvard University Press.

Lakoff, G. \& Johnson, M. (1980). Metaphors we live by. Chicago: The University of Chicago Press.

Lecce C. (2014). Abet Laminati: il design delle superfici. AIS/Design Storia e Ricerche 4 - 0407.

Lipovetsky, G. \& Serroy, J. (2013). L'esthétisation du monde. Vivre à l'age du capitalisme artiste. Paris: Gallimard.

Margolin, V. \& Buchanan, R. (1995). The Idea of Design. Cambridge MA: The MIT Press.

Poster, M. (2002). Jean Baudrillard: Selected Writings. Palo Alto: Stanford University Press, p 1.

Peters, S. (2011). Material Revolution 2: New Sustainable and Multi-Purpose Materials for Design and Architecture. Basel: Birkhäuser.

Ross, P. R. \& Wensveen, S.A. G. (2010). Designing Behavior in Interaction: Using Aesthetic Experience as a Mechanism for Design. IJDesign 4:2

Schön, A. (1993). Metaphor and Thought. Generative metaphor: A perspective on problemsetting in social policy, p. 137-161. Cambridge University Press: New York.

Valéry, P. (1977). Introduction to the method of Leonardo da Vinci. In Valéry, P. An Anthology. Princeton: Princeton University Press, p. 71-72.

Verplank, B. (2009). Interaction design sketchbook, [online] available at: http://www. designinteractions.com

Abstract: This article deals with the Italian Design approach to Materials based on a long tradition of challenging exchanges between intellectual practices. Focusing on design and enterprises history, the authors, on the basis of their previous studies, explain the approach and the reasons of the osmotic process between technology and humanities in Italy, and how those challenging exchanges impacted on production as well as on further 
developments. An overview of European cultural landscape of the times helps to focus on the leading theories that still represent a stronghold of Design Humanities. Exploring the semiotic meaning of materials enhance the investigations on their applications as well as new, ongoing researches in the field of Material Design, also in terms of sustainability and interaction.

Key words: Italian Design Approach - Material Design - Design History - Creative Use of Technology - Design Metaphorical Analysis - Design Humanities.

Resumo: Este artigo discute a abordagem do design italiano de materiais, com base em uma longa tradição de desafios de intercâmbio entre práticas intelectuais. Com base em seus estudos anteriores, os autores se concentram no design e na história das companhias, explicando a perspectiva e as razões para o processo osmótico entre tecnologia e humanidades na Itália e como esses intercâmbios desafiantes afetam tanto a produção como os desenvolvimentos futuros. Uma visão geral do cenário europeu de todos os tempos ajuda a se concentrar sobre as principais teorias que ainda representam um bastião de humanidade do design. Explorar o significado semiótico dos materiais melhora as investigações sobre suas aplicações, bem como as pesquisas novas e em curso no campo de Design de Materiais, também em termos de sustentabilidade e interação.

Palavras chave: Italian Design - Materiais de design - história do design - criativo uso da tecnologia - análise de projeto metafórico - humanidade do design. 
Fecha de recepción: octubre 2017 Fecha de aceptación: mayo 2018 Versión final: diciembre 2018

\section{Designing for a start; irreversible dynamic textile patterns}

Linda Worbin *

Resumen: Los textiles son tradicionalmente diseñados para mantener una expresión dada. Un patrón floral se supone que debe permanecer floral. Sin embargo, la tecnología contemporánea y el desarrollo de materiales están cambiando tanto la producción como la expresión, y requiere un replanteamiento de la producción y la práctica del diseño para satisfacer el futuro de los textiles.

A través de la experimentación, investigación de diseño basada en la práctica, este proyecto se centra en la noción de cambio como una variable central de diseño. Los colores textiles que se elaboraban a partir de tintas vegetales, han evolucionado con el tiempo.

El objetivo de este proyecto es mostrar una dimensión alternativa hacia la sostenibilidad a través del cambio incorporado en una expresión. En lugar de reemplazar un objeto cuando necesitamos/deseamos otro color, función o apariencia, la expresión cambiante podría integrarse en la materialidad y en el diseño mismo; creando un diseño que aparece y se desarrolla con el tiempo, con un punto de partida, pero sin fin.

Palabras clave: diseño textil - patrones textiles dinámicos - temporalidad como material de diseño.

[Resúmenes en inglés y portugués en las páginas 87-88]

(*) PhD. Professor in textile design at the Swedish School of Textiles at the University of Boras, Smart Textile Design Lab. Her career includes four years at the Interactive Institute in Sweden collaborating with PLAY studio in the research project called IT+Textile. The overall theme for her research in the last years was the exploration of the potential of dynamic textile expression both from an artistic experimental and industrial perspective.

A tradition in (textile) design in general, is to design expressions with a given, static expression meant to stay more or less the same during a planned lifespan. Of course, there arises friction and imprint of what it will be exposed to, such as wear, stains, rips or sun-bleached parts, etc. There are traditionally few examples in textile design where change is actively taken into account, and when reading descriptions on color achieved from plant based dye stuff, a color is rarely mentioned or described as a color if it got a bad color fastness (Von Linné, 2010 Sandberg \& Sisefsky, 1978 Cardon, 2007). Still colors are described from its light fastness to specific fibers, on a scale from poor to more sustaining 
colors. Still, the stability of colored textiles implies a definition of color expressions in relation to light fastness. Of course the difference in color/light fastness is brought up and exemplified as something that can be re-dyed etc. but still color/light fastness is seen and presented as something admirably. During the last decades, due to development in material science, information technology etc. we see material qualities that turn around traditional and fundamental design variables and techniques. For example by smart textiles (Tao, 2001) that sense and react to environmental stimuli, like thermo chromatic and photo chromatic materials that adapt to different light and temperature conditions with different expressions. This is something that influences central design variables like color and form on a foundational level, and ask for new printing and weaving techniques as well as a new understanding for dynamic expressions. Those materials that perform beyond a "static" pre expected expression as seen in textile works by (Berzina, 2004; Worbin, 2010; Jansen, 2013; Kooroshnia, 2015) can be described as a kind of reversible textile design. Showing an expression with the intention to be changing over time, in a series of expressions, from $\mathrm{A}$ to $\mathrm{B}$ to $\mathrm{C}$ etc. and back to $\mathrm{A}$. We can also see dynamic textile expressions being irreversible, not returning to any fixed "first" expression (Dumitrescu, 2013; Persson, 2013; Worbin, 2010; Talman, 2015). Through practiced based design research they experimented with how to handle a shift from static towards dynamic, from reversible towards irreversible. By their design projects, they involve "change" as a concept in textile and product design by introducing series of new design variables. This have familiarities with different kind of patina, and aging in design, like in the philosophy of Japanese design, sabi is used to describe something that is influenced from age. A designed and crafted object is not seen as a static object, rather as an object gain value by aging over time (De Mente, 2006). So, how to raise awareness about what an even more planned and conscious aging would mean in the design practice?

Design variables creates a foundation for design, grasping everything that a design practitioner need to take decisions on when designing a textile/object/product. To start with the practitioner need to know what the main purpose with the design is, will it for example be a textile for a car interior, home furnishing, fashion etc. is it made as a textile product or a raw material, so to say a carpet or meters of silk fabric? Further on, is it a textile/object/product that is chosen from a selection or designed for a specific purpose (Nilsson, 2016). From a textile designers perspective design variables covers every decision that needs to be taken during the preparations for the actual making of textile/object/ product, covering choice of quality and structure of the fibre, the density in the yarn, through color and form spectrum to later be transformed into a physical textile/ object/ product in a specific technique and manufacturing process. The list of design variables can be long, but it is seldom that a designer take active decision about all possible design variables in their daily practice, still the result of all different variables is seen in the final textile/object/ product. From an academic perspective design variables creates a kind of design foundation for identifying choices that have been made or are to be made to create a specific textile/object/ product. By identifying every possible choice in a design process as a isolated design variable, one is narrowing down what a specific design actually is about on a very concrete and systematic manner. It will both give depth to details and give a more holistic understanding of the complexity of a design. When being able to reflect 
and identify some central design variables in separate, this may lead the design researcher from traditional assumptions towards a new understanding for the present materials. Foundational investigations, reflections etc. strive to find work methods that can ensure "correct" design with respect to given specifications, etc. This perhaps corresponds to well-defined and meaningful programs - both in the sense of general design programs and in the sense of a particular design brief... design practice, due to its complex nature, always will be open for this type of questions, there seem to be basic inherent conceptual circles that as a matter of principle will guarantee that we always will walk on "shaky foundations". (Cf. Hallnäs, Redström, 2006. p. 34)

Temporality is becoming a central design variable along with new material qualities with changeability in color, structure, density etc. This shows a lot of contradiction in expressiveness, design methods and understanding compared to traditional textiles/ objects/products, and creates these shaky grounds that tell us that we need to prepare for something new to come. Of course, all different materials will need to be designed differently, but a common design variable due to changeable materiality, like smart textiles etc. is that it is closely related to time. The common aspect is the ability to build in the changing expressions (and/or functions) from the start, literally in the design process as well as for the physical textile/object/product. From a design practitioner perspective, it means for example to design for a series of expressions to happen from a starting point.

\section{Design examples of irreversible dynamic textile patterns}

Irreversible dynamic textile patterns can be seen as an design program focusing on temporality as a central design variable in and for textile design. Textile colors are crafted to evolve over time, so in contradiction to the conventional idea about static color, an irreversible expression is enhanced. Textiles are plant dyed without any added mordant, meaning no added chemical or salts that will influence on the color nor the color fastness. The idea is to investigate and use the time span that color "naturally" will change within when designing textile expressions. This is done through a series of three design projects.

1. Color scales. A series of plant-dyed textiles (dyed with no added mordant) creates a first basic foundation of a color map of irreversible dynamic textile colors and are to be evaluated in two steps. The samples are documented and presented as visual scanned textile color samples presented with foundational information such as; material, plant, dyeing method, etc. Evaluation of first phase in the project covering what visual color you get from different combinations of textile materials/fibre and plants (Worbin, L., 2013), further on, the same samples to be juxtaposed and presented a second time, after being exposed to $\mathrm{x}$ time sequences (work in progress). The samples should not be seen as static descriptions, rather as an attempt to grasp and visualize the dynamic behavior of color. The color scales are in temporal progress. (Figure 1)

2. Evolving textile patterns. A series of single colored plant dyed textiles have been folded and exposed to natural light (kept outdoor for two weeks day and night, during spring 
time in Sweden), when unfolded it shows a pattern achieved from a kind of light reserving technique. (Figure 2)

3. Irreversible color on garments. To learn more about expectations and enlarge the understanding of irreversible temporal textile expressions, a collection of clothing was made using plant-dyed textiles and yarns. In the knitted sweater some parts of the pattern are more color dominant than others and by being so it bring back or forth the initial expression, the start. The garment is designed to change the pattern relation, by the color change forms will be brought back or forward in the expression. (Figure 3 )

From a design perspective, designing with irreversible colors means that we have a changing expression built into the design itself, with a starting point, but without a given end. The difference in a textile expression that has been aging, for example as a pair of jeans, compared to textiles that have been designed with an intention to change (and not towards threadbare) then lies in the designer's understanding of how a material may perform over time, along with how he or she emphasizes different design methods, variables, techniques and material choices.

By looking at the color phenomena as something dynamic, this could of course be achieved from either plant dye, synthetic dye stuff, or from other technically advanced material (like involving light, shrinkage etc. etc).

The three presented design projects show a specific color appearance in certain time spans and suggest how one could think differently upon temporality as a central design variable when creating evolving textile patterns from irreversible colors.

Color scales are to be seen as a foundation for learning about the speed of change, and what color you achieve from a specific plant when dying without influencing on the color stability with chemicals. The speed of change is important, because we need to see and learn about the complexity between traditional design variables and change that will happen in minutes, hours, days, weeks, months or years.

Evolving textile pattern shows one way of experimenting with the design method due to temporality by taking advantage of the different steps in the pattern making as a start of a series of textiles expression, before unfolding or after unfolding etc. In this case the textile will continue to change after the unfolding, it is so to say the unfolding that is the start.

In the project Irreversible color on garments the knitted sweater is crafted from yarn that is colored to change over time. The starting point, the ready knitted sweater show a certain expression that looks like a traditional knitted sweater, also after several years the sweater will look like a traditional knitted sweater even if it got a slightly new expression in the rhythm and balance of the pattern. The change is not something that will be possible to notice when seeing the pattern/ garment for the first time. Rather it highlights the viability and awareness in different types of change - should it be visible to grasp from time to time, or when experiencing the textile only once?

The temporal perspective within irreversible dynamic textile pattern challenge our mindset from thinking that a color in textile design should be treated as a static phenomena towards a dynamic nature, it also implies new expectations and understandings of color in general. From an academic viewpoint design variables are crucial as a method for being 


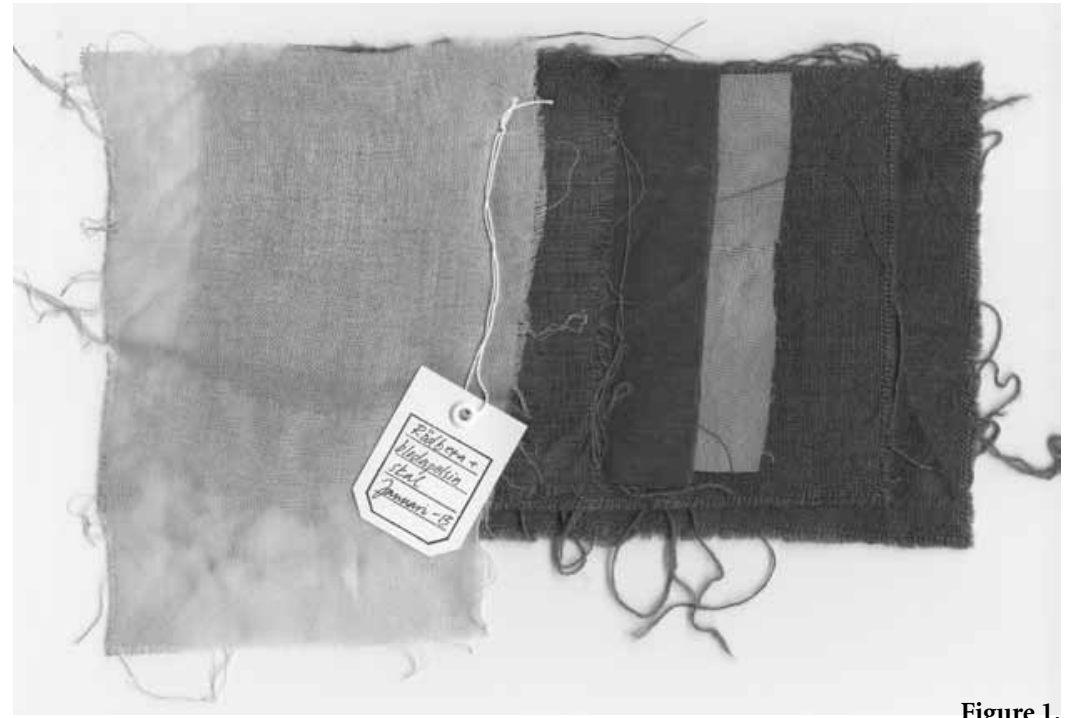

Figure 1.
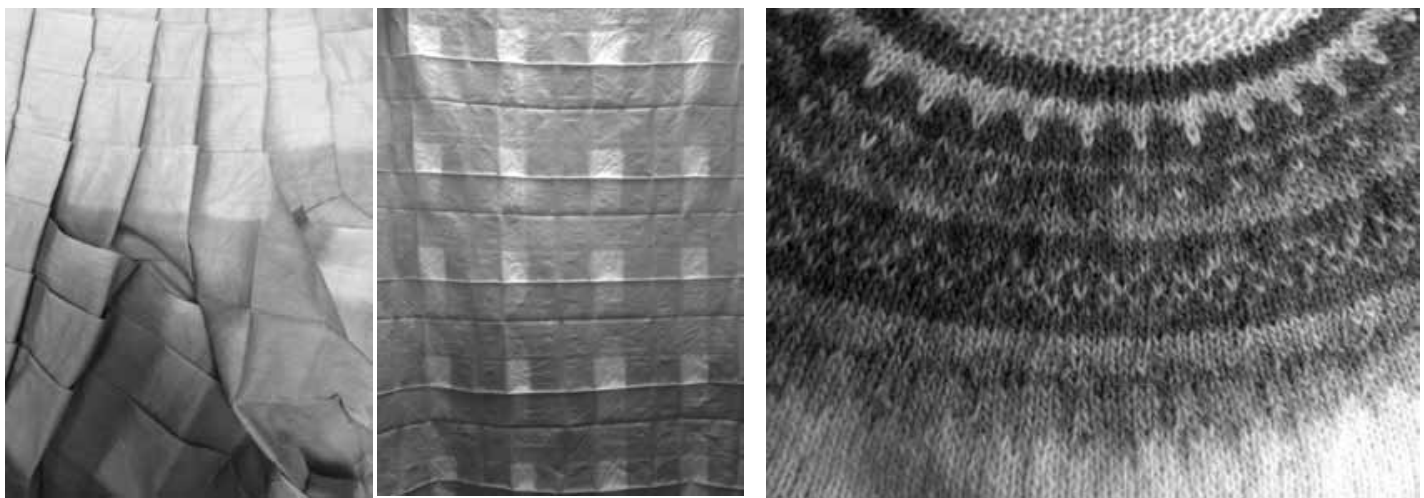

Figure 2.

Figure 3.

Figure 1. The color samples is dyed from different ready made non colored wool, silk and cotton fabrics. All the samples are dyed in one and the same dye bath from beetroot and blood orange peel. Figure 2. The textile is dyed from a dye bath made out of beetroots and peel from blood orange in tap water and show when it is about to be unfolded and when out folded. Figure 3. The knitted sweater; hand knitted from wool yarn that is dyed in five separate dye baths; liliac in tap water, lady's bedstraw in tap water, rhubarb in tap water, buckthorn in tap water and buckthorn in sea water. 
able to draw new perspectives and from that learn more about possible expressions and functions. So, going from designing variants of known textiles/objects/products (like designing a new color on a known textile/object/product) towards designing for a starting point, we need to treat new materials for their specific new/unknown qualities, so to say gain a new take on materiality by careful identifying and examine materiality in relation to new and old design variables.

A start can be described as a beginning of a series of subsequences to appear gradually over time. From a practitioners perspective it means to advantage dynamic qualities both in new, and more traditional materials and by doing so being able to move from static towards dynamic expressions in design. Simply and traditionally described a designers task is in a way to foresee a textile/object/product by making a sketch and a series of instructions that is to be followed and later on resulting in a physical textile/object/product. When temporality are added as a central design variable and the designer is designing for change it is no longer a design of something that should be experienced as a ready or finished textile/object/product. It is not one given static expression, it is a series of more or less given expression, so to say a design for a start containing several expressions appearing over time. How irreversible color expressions will influence our relationship with textiles and garments is, of course, impossible to say, but from an ethics/sustainability perspective this provides a new take. When looking at a color with the nature of change we could see a future of irreversible color expressions that implies a movement from designing/ consuming several different textiles/garments/objects towards the actual wearing/ usage as a part of the revealing of the next design/expression itself. So instead of replacing one garment with another (to show a new expression), one may just use it, wear it, wash it to make it change expression. This also gives a new dimension upon ethic and sustainability - instead of changing a textile/object because we want another color/expression we could have the changing expression built into the design itself, with a starting point but without an end.

The objective in this project was not to come up with concepts of right or wrong, rather to give an alternative to existing "static" color expressions and to shed light on a new design philosophy towards a changing, dynamic color nature. This is of course not only a challenge for the designer, and the production industry, it is just as much a new take for the audience of the textile/object/ product. Traditionally we would ask for and expect either pink or umber color on a textile/garment, tomorrow we may ask for a color going from pink towards umber in 5-10 -years, weeks or days.

\section{References}

Berzina, Z. (2004). Skin Stories, Charting and Mapping the Skin: research using analogies of human skin tissue in relation to my textile practice. The London college of fashion, University of the Arts London.

Cardon, D. (2007). Natural dyes, sources, tradition, technology and science. (Original title: Le monde des teintures naturelles). Translated into English by Caroline Higgitt. Italy by Printer Trento srl: Archetype Publications Ltd. 
De Mente, B. (2006). Elements of Japanese design. Tuttle Publishing.

Dumitrescu, D. (2013). Relational textiles: Surface expressions in space design. University of Borås studies in artistic research, no. 7.

Hallnäs, L.; Redström, J. (2006). INTERACTION DESIGN foundations, experiments. The Interactive Institute, The Swedish School of Textiles, University of Borås.

Jansen, B. (2013). Composing over time, temporal patterns: in textile design. University of Borås studies in artistic research, no.12.

Kooroshnia, M. (2015). Creating diverse color-changing effects on textiles. University of Borås studies in artistic research, no.11.

Nilsson, L. (2015). Textile Influence: exploring the relationship between textiles and products in the design process. University of Borås studies in artistic research, no. 15.

Persson, A. (2013). Exploring textiles as materials for interaction design. University of Borås studies in artistic research, no. 4.

Sandberg, G.; Sisefsky, J. (1978). Växtfärgning. 4th ed. Stockholm: Norstedts Tryckeri.

Talman, R. (2015). Exploring the relationship between material and textile structure in creating changing textile expressions. Proceedings of Eksig-conference, Kolding, Denmark.

Tao, X. (ed.) (2001). Smart Fibres, fabrics and clothing: fundamentals and applications. Cambridge, Woodhead.

Von Linné, C. (2010). Färgväxter. (Original title: Plantæ Tinctoriæ) Translated from Latin into Swedish by Johnny Strand. Akademisk avhandling under Linnés presidium: Uppsala 1759.

Worbin, L. (2010). Designing Dynamic Textile Patterns. University of Borås studies in artistic research, no. 1 .

Worbin, L. (2013). Irreversible Color Expressions Åland 2013 _ report no. 1. Research Outlet, accessible from the digital archive DIVA: http://urn.kb.se/resolve?urn=urn:nb n:se:hb:diva-9985

\begin{abstract}
Textiles are traditionally designed to keep a given expression; a floral pattern is supposed to stay floral. However, contemporary technology and material development is changing both production and expression and requires rethinking in production and the design practice to meet the future of textiles.

Through experimental, practiced based design research this project focus on the notion of change as a central design variable. The textile colours are crafted from plant dye to evolve over time.

The objective of this project is to show an alternative dimension towards sustainability through changeability built into an expression. Instead of replacing an object when we need/want another color, function or expression, the changing expression could be integrated in the materiality and design itself. Creating a design that appears and develops over time, with a starting point, but without an end.
\end{abstract}

Key words: textile design - dynamic textile patterns - temporality as a design material. 
Resumo: Os têxteis são tradicionalmente concebidos para manter uma determinada expressão. Um padrão floral deve permanecer floral. No entanto, a tecnologia contemporânea e desenvolvimento de materiais estão mudando tanto a produção e expressão, e exige um repensar da produção e design prático para atender o futuro dos têxteis.

Através da experimentação, pesquisa em design baseada na prática, este projeto centra-se na noção de mudança como uma variável de projeto central. As cores têxteis que foram produzidas a partir de tintas vegetais evoluíram ao longo do tempo.

O objetivo do presente projeto é mostrar uma dimensão alternativa para a sustentabilidade através da mudança incorporada numa expressão. Em vez de substituir um objeto quando precisamos / quer outra cor, função ou aparência, a expressão dinâmica poderia ser integrada no material e no design mesmo; a criação de um projeto que surge e se desenvolve ao longo do tempo, com um ponto de partida, mas não tem fim.

Palavras chave: design têxtil - padrões têxteis dinâmicos - temporalidade como material de concepção. 
Educating smart materials

Zurich Manuel Kretzer*

Resumen: Nuestro entorno diario está claramente ocupado por las tecnologías digitales, que influyen en la forma en que nos comportamos, nos movemos o interactuamos unos con otros. Para que los arquitectos puedan mantenerse al día con el progreso tecnológico continuo y estar preparados para los próximos desafíos e incertidumbres, necesitan ser capacitados en el uso de nuevas tecnologías y poseer habilidades en el intercambio interdisciplinario. Especialmente con respecto a la aplicación de nuevos materiales, que a menudo provienen de áreas como ciencia de los materiales, la biología o la química, los arquitectos no sólo necesitan una comprensión de las distinciones específicas de la disciplina, sino especialmente estar familiarizados con una forma de expresión compartida.

El siguiente artículo presenta un modelo didáctico para la educación integradora y exploratoria de materiales inteligentes como un medio para enriquecer los marcos educativos existentes. Sin embargo, en vez de prescribir un método particular o una solución predefinida, el enfoque pretende proporcionar un acceso abierto a la información y sugerir una amplia gama de posibilidades relevantes. Por lo tanto, a los estudiantes no se les enseña "qué hacer" sino que se les anima a aprender "cómo hacer" ofreciendo un marco estable y rico para el autodesarrollo independiente.

Palabras clave: Educación - Alfabetización - Materiales inteligentes - Arquitectura adaptable - Fabricación, Bricolaje - Open Source.

[Resúmenes en inglés y portugués en la página 96]

${ }^{*}$ Dr. Sc. ETH. Architect, researcher and educator. He is currently visiting professor at the Braunschweig University of Art, leading and teaching the subject 'Digital Crafting'. Manuel is the founder of the 'materiability research network', an educational platform that provides open access to cutting edge new material developments and technologies.

\section{Introduction}

Science and technology multiply around us. To an increasing extent they dictate the languages in which we speak and think. Either we use those languages, or we remain mute.

J. G. Ballard, Crash, 1974 
Digital technologies nowadays infiltrate, and to some extent even dominate, almost every aspect of human life. Just as such progress constantly influences our environment, behavior, and culture it does have an undeniable impact on architecture and the way space is used and perceived. In order to keep up with continuous technological advancement and be skillful in its spatial integration, the role and proficiency of the architect has to steadily evolve. This means especially for architectural education to efficiently prepare students for upcoming challenges and uncertainties. While this involves the theoretical and philosophical discussion of current tendencies, beliefs, and developments it also demands the training of practical skills and powers, such as the use of new tools, technologies, and materials but especially capabilities in interdisciplinary communication and exchange. Cliff Moser, author of Architecture 3.0 - The Disruptive Design Practice Handbook, argues that architectural education today is too much concentrated on growing experts in 'design for building, which leads to isolated and overspecialized individuals. Instead architecture schools should show students how to think broadly and develop design "solutions leveraged with collaboration and networking". (Moser, 2014)

Similarly Nic Clear, head of architecture and landscape at the University of Greenwich, believes that multi- and interdisciplinary ways of working are essential to acquire an open understanding of collective power to overcome the old-fashioned idea of the architect representing the one and only lead expert. At the core of interdisciplinary progress is however not only a non-hierarchic structure and a common curiosity in approaching a shared goal but especially the ability of all involved parties to successfully communicate and converse. This becomes even more evident when areas like materials science, biology, or chemistry, the birthplaces of many newly emerging materials, are involved in the discussion. These areas are not only accustomed to very particular means of representation and the use of specialist language but for example also have a fundamentally different idea of scale and efficiency. Thus for architects to successfully collaborate with such areas for the development of new, technology-enhanced spatial experiences they not only need an understanding of discipline-specific distinctions but especially be literate in a shared way of expression.

\section{The inherent dynamics of smart materials}

As Jeffrey Karl Ochsner notes, all materials are inherently dynamic, continuously shrinking, expanding, moving and changing, yet largely in a non-directly perceivable way (Ochsner, 2012). Smart or adaptive materials however, materials which can adjust their properties in response to external influences, are fundamentally distinct from traditional materials and therefore need to be approached in a very different way. Such materials can change their color in response to changes in temperature or UV radiation, they can adjust their transparency, light up or move through electricity, they can store heat and energy, they can convert sunlight, heat or mechanical distortion into electrical power or even have the ability to self-heal and repair. For the development of dynamic architectural solutions such materials have great potential and many advantages over existing, mechanically complex systems not only due to their dynamic properties but especially because of 
their inherently holistic setup. Yet in order to apply them progressively it is necessary to understand their behavior over time and evaluate the range within which they perform. This requires knowledge in their transformative capabilities as well as a general idea of their internal processes and composition. One option to gain such understanding is to break the materials down into their normative ingredients, explore the properties of these ingredients, and then put them back together. Through this one comprehends how changes in assembly relate to particular material properties or behaviors, which then can be tuned to special demands or requirements that vary from commercially available products. At the core of this idea is not the development of a specific expertise or the improvement of existing systems but rather the mediation of a basic notion of certain principles necessary to communicate and exchange with specialists from the various disciplines. Such exchange might then stimulate the discovery of formerly unknown applications or even incept the development of new materials.

A possible way to approach this is by starting with a brief (online) search into new material discoveries or developments. This search can relate to certain material phenomena such as color-change, movement, light-emittance, energy conversion etc. or focus on novelty and recent discoveries. Once a particular material has been found it needs to be understood in more detail by studying scientific papers, technical articles, or other related information. When a basic theoretical knowledge of the material's working principle, composition, and fabrication has been acquired, experts can be approached to receive more specific details. This can involve gaining first-hand insights in (industrial) production procedures, solving or improving certain assembly issues, understanding trends in commercial application, or even collaborating throughout the course of a project and especially during an introductory expert workshop. The next step involves acquiring the necessary ingredients and tools to build the material. Once again expert support can help in finding the right sources. A particularly difficult part is to estimate the required quantities since usually the ingredients are quite expensive and therefore purchasing too much will result in high costs, but having too little might unnecessarily delay the progress of the work. Generally ten to twenty percent above the calculated estimate provide for good contingency. In some cases it might also make sense to look for ready-made kits, which allow for the manufacture of a certain set of prototypes and which usually also come with wellexplained instructions. As soon as all the necessary tools and substrates are at hand one can begin building the first samples. What should always be remembered is that failure and breakage are essential elements of the process. Once one feels confident enough in making a working material, this knowledge can either be used to continue experimenting more focused, aiming for example at emphasizing a certain effect, or become the basis to start teaching others. In the case of a course or workshop for students of architecture the participants should be divided into small teams of three to four people. While physically experiencing the functionality of the materials, comprehending their working principles, and the relationship between fabrication procedures and material behavior they can in parallel be asked to speculate about architectural situations in relation to a specific theme. In the beginning the correlation between the material and hypothetical usage can be very loose but should be intensified towards the end of the course. Lectures on related topics, selected literature, as well as a collection of case studies support the students to get started 
within a commonly unknown field. Throughout this part they should be encouraged to relate to spaces in terms of dynamic territories, considering architecture not as being static and immobile but as an assembly of places that constantly evolve and change in relation to time and occupancy. Finally the two approaches, the material exploration and the architectural scenario, can be brought together through a spatial installation or prototype. The relation to reality and presence is depending on the theme of the course, however leaving it to the students can lead to unexpected and surprisingly entertaining results. (Figure 1)

While this approach definitely makes for a lot of fun among workshop participants and will provide them with useful skills in respect to a particular material it is impossible to go through such an intense process for every smart material available. Therefore a more general strategy is required.

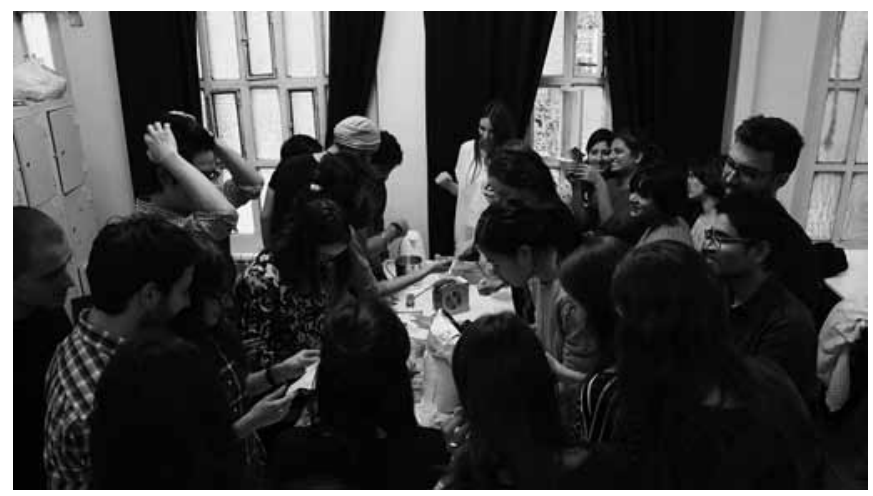

Figure 1. Students exploring new materials during a workshop at the Institute for Advanced Architecture of Catalonia (IAAC) in 2015.

\section{The materiability research network: access to smart materials}

Common ways for the conveyance of material knowledge include libraries, catalogs, and databases, both physical, in print, and virtual. Within these, materials are generally sorted and categorized in relation to certain similarities. In print this is often based on either their dominant material class or other defining properties. Physical libraries employ similar means of categorization but also place a specific focus on size, appearance, and possibly usage of the samples on display. Online databases offer more flexibility since their contents can be sorted dynamically according to relevant taxonomies but sometimes seem less detailed and more superficial. In respect to traditional materials such types of categorization in combination with a two-dimensional representation through photographs and technical drawings work quite well. Especially when having a technical 
background one can anticipate how a material feels or behaves simply by looking at it or reading about its properties. Regarding smart materials however, which are much less known and available, it is far more difficult to forecast their usage.

An attempt to make these materials more commonly available is the materiability research network (www.materiablity.com), a community platform, an educational network, and an open materials database that provides in-depth access to emerging material developments. The aim of the network, which was instigated in 2012, is to demystify smart materials and reveal their complexity while fostering inter-disciplinary exchange and cooperation. The website forms a constantly growing database on a broad range of materials, provides do-it-yourself instructions to self-make them, and promotes their usage in speculative spatial explorations. This trinity, inspiration, information, and instructions is ought to help advance a common language to communicate across disciplines and bridge the gap between research, education, and practice.

Registration to the network is free of charge and allows members to unlimitedly access all provided information, converse with fellow members, engage in forum discussions, and submit their own projects or experiments. The content is split into three areas: 'projects,' 'materials,' and 'tutorials.' 'Projects' are openly accessible and focus on innovative and inspirational usage of smart materials in an architecture or design context. They can be sorted according to rating, views, and age, as well as several tags, such as material class, creative discipline, scale, phenomenological behavior, or physical and optical properties. 'Materials' and 'Tutorials' are only visible to active members of the network, who are registered and logged-in. The information on materials is intended to present a scientifically funded context, providing in-depth but easily understandable details on particular smart materials. The graphically illustrated posts are usually split into a short introduction, an excerpt on the material's historical development and usage, an explanation of its structure and operation principle, a brief description of its fabrication, and an overview of existing and potential (architectural) applications. In addition to this theoretical material information, tutorials are offered, which are often developed in junction or with the help of specialists from the respective fields. Each tutorial follows a similar structure and provides both photographic and text-based step-by-step instructions to self-make the material in an informal environment.

To further promote exchange and collaboration among the steadily growing community, the network provides an internal messaging service, allowing members to directly contact each other. Persons who have connected in this way will appear on each other's profile page as 'friends.' The profile page, which is only visible to logged-in members, also displays a user's personal information and latest network activity, like posts, comments, and forum topics and replies. The materiability research network thus not only represents a website that delivers information on smart materials, but also encourages its users to get actively involved in its future development. Becoming a member of the network means to identify oneself with the content and become part of the community. By publishing information on the platform users have to take responsibility for their work and review and expose it within the larger context. This means that they have to be aware of the information they consume but also the content they produce and its further impact. The aim of the network is to provide a community-driven, growing overview of smart materials in an architecture 
and design context, while encouraging its members to exchange and critically reflect upon their potential usage. (Figure 2)

\section{Towards a smart material literacy}

The hope is that through these two approaches, the physical experience of smart materials during associated workshops and the potentially unlimited access to similarly comprehensive information on the website, it will eventually become possible to anticipate the functionality, behavior, and usage of any type of smart material without necessarily requiring a working prototype, just as one, with a little experience in craftsmanship, doesn't require to touch a piece of wood in order to know how it feels, looks, or what it can be used for.

This will eventually free smart materials from persistent associations to mechanically infused paradigms, which to date still mark the main form of describing dynamics, movement, and behavior. The herein presented approach as a didactic model has been tested and verified throughout numerous workshops and student courses. Despite its brevity of a little more than five years it can so far be considered a largely successful method to engage students in exploring new territories and encourage them to think in terms of processes rather than fixed states, yet it obviously always needs to be adapted to the respective context and situation. Especially the display of dynamic behaviors still requires further investigation and will need the development and acceptance of good alternatives to established means of architectural representation such as plans and models. One possibility would be to shift the focus towards working demonstrators and physical prototypes instead of their graphical display. Another option is to draw inspiration from the Internet and online visualizations, which allow the seamless combination of video, audio, image, and text based content.

As mentioned earlier the impact of these materials on architecture could be massive not only leading to dynamic and adaptive spaces but also more efficient and much lighter, less material intense structures. Yet in order to arrive there a number of elementary challenges need to be overcome. Firstly a serious awareness among material-related fields in regards to architectural possibilities has to be created and then multi-disciplinary collectives should be formed to progress the development of materials tailored for architectural usage. It is important to immerse oneself into such collaboration unbiased, driven by curiosity and not oppressed by thinking in terms of limitations, be it scale, durability, affordance or even resources. Instead constant technological progress should be seen as an opportunity, which allows daring and experimenting and which eventually will make any kind of development increasingly cheaper and available. But even more importantly the focus should move beyond concentrating purely on the functionality and efficiency of smart materials and the advantages they have over existing systems but equally consider their emotive aspects and the more sublime impact they have on human senses. Engaging in possibilities and implications rather than the actual effects will hence become crucial to develop truly revolutionary products, spaces, or experiences. (Figure 3 ) 


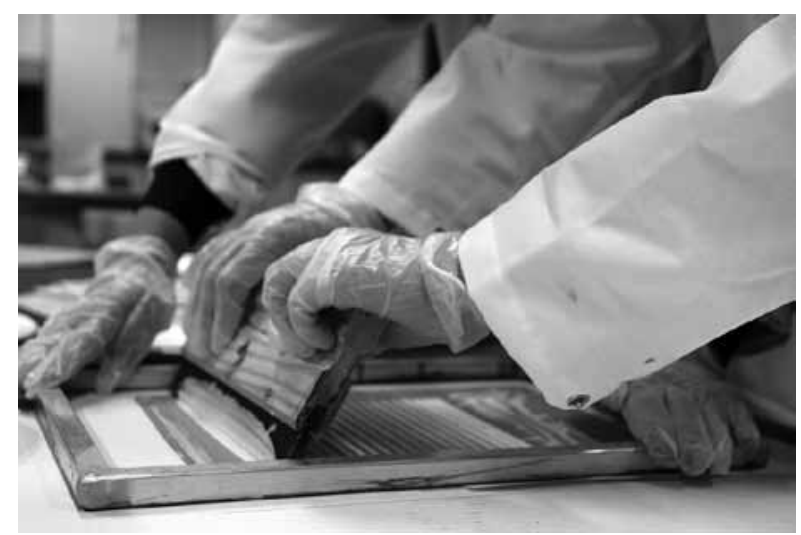

Figure 2.

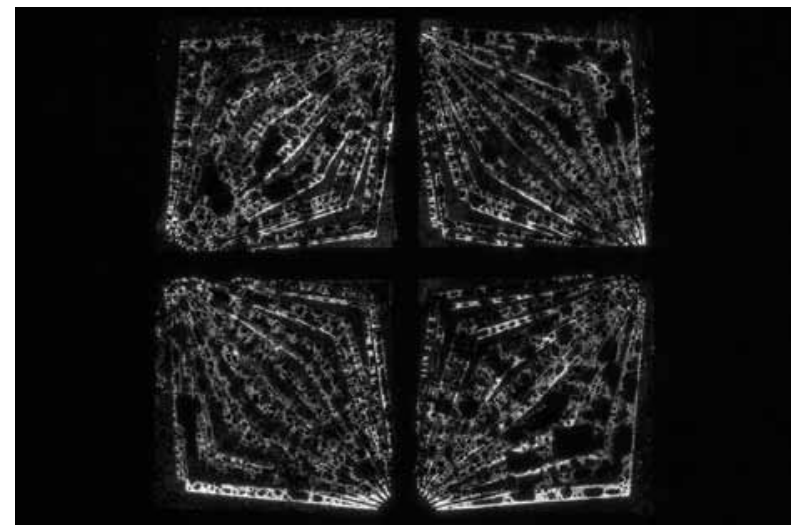

Figure 3.

Figure 2. Screen-printing electroluminescent foils during a workshop at the Swedish School of Textiles, Boras in late 2015. Instructions can be found at www.materiability.com. Figure 3. A self-made electroluminescent display showing different colors and textures. More information and images on this project can be found here: http://materiability.com/luminous-textiles.

\section{References}

Ballard, J. G. (1995). Crash. London: Vintage, 7.

Moser, C. (2014). Architecture 3.0: The Disruptive Design Practice Handbook. New York: Routledge, 15-17.

Ochsner, J. K. (2012). Furniture Studio: Materials, Craft, and Architecture. Seattle: University of Washington Press, 6. 


\begin{abstract}
Our daily environment is clearly occupied by digital technologies, which influence the way we behave, move, or interact with one another. In order for architects to keep up with continuous technological advancement and be prepared for upcoming challenges and uncertainties they need to be educated in the use of new technologies and possess skills in interdisciplinary exchange. Especially in respect to the application of new materials, which often stem from areas like materials science, biology, or chemistry, architects not only need an understanding of discipline-specific distinctions but especially be literate in a shared way of expression. The following article presents a didactic model for integrative and explorative smart material education as a means to enrich existing educational frameworks. Yet rather than prescribing a particular method or predefined solution the focus of this idea is on providing open access to information and suggest a broad range of relevant possibilities. The students are thus not taught "what-to-do" but instead encouraged to learn "how-to-do" by offering a stable and rich framework for independent self-development.
\end{abstract}

Key words: Education - Literacy - Smart Materials - Adaptive Architecture - Fabrication - DIY - Open Source.

Resumo: O nosso ambiente diário é claramente ocupado pelas tecnologias digitais que influenciam a forma como nos comportamos, nos movemos e interagimos uns com os outros. Para que os arquitetos possam acompanhar o progresso tecnológico contínuo e estar preparados para os próximos desafios e incertezas, precisam ser treinados no uso de novas tecnologias e possuem habilidades interdisciplinares. Especialmente no que diz respeito à aplicação de novos materiais, que muitas vezes vêm de áreas como a ciência dos materiais, biologia ou química, os arquitetos devem ter não só uma compreensão das diferenças específicas de a disciplina, mas principalmente estar familiarizados com uma forma de expressão compartilhada.

$\mathrm{O}$ artigo apresenta um modelo didático para a educação integradora e exploratória dos materiais inteligentes como um meio para enriquecer estruturas educacionais existentes. No entanto, em vez de prescrever um determinado método ou uma solução pré-definida, a abordagem pretende proporcionar acesso aberto à informação e sugerir uma ampla gama de possibilidades relevantes. Portanto, os alunos não são ensinados a "o que fazer", mas são incentivados a aprender "como fazer", proporcionando um quadro estável e rico para o autodesenvolvimento.

Palavras chave: educação - alfabetização - materiais inteligentes - arquitetura adaptativa - fabricação - Home Improvement - Open Source. 


\section{Biomimetic materials and design}

Murat Bengisu *

Resumen: El campo interdisciplinario de la biomimética ha sido objeto de creciente atención en los últimos años. La comunidad científica e industrial entiende que el daño que hemos estado haciendo a la naturaleza puede ser resuelto por la naturaleza misma. El diseño biomimético también ha ido ganando impulso gracias a las nuevas investigaciones y tecnologías. La biomimética no se limita a la forma y la estética solamente, sino que también hace uso de una comprensión más profunda de los aspectos funcionales, procesos y sistemas encontrados en la naturaleza. Este artículo desarrolla cinco enfoques biomiméticos: imitación, inspiración, funcionalidad, basado en procesos y basado en ecosistemas. Los estudios de casos cortos explican cómo la investigación biomimética puede ayudar a resolver diferentes problemas en el diseño.

Palabras claves: Biomimética - materiales - bioinspiración - biofílica.

[Resúmenes en inglés y portugués en la página 103]

${ }^{(*)}$ M.S. and Ph.D. degrees in the field of Materials Science, New Mexico Tech, USA, is full professor at the Industrial Design Department at Izmir University of Economics (IUE). He teaches undergraduate courses about materials for design, manufacturing processes, ergonomics, design engineering, design studio, and graduate courses he developed for the Design Studies Master's and PhD Programs.

\section{Introduction}

Scientists and engineers have been working on biomimetic innovations since the 1970s. D’Arcy W. Thompson studied biological systems as engineering structures as early as 1917 (Torgal et al. 2015). The number of publications in the field of biomimetics has grown tremendously since the mid-1990s, reaching currently to about 3000 per year (Lepora et al. 2013). The interdisciplinary field of biomimetics aims to study biological materials, structures, and processes to develop similar materials, structures, or systems for human benefit. Various terms exist that have a similar meaning to biomimetics, including biomimesis, bio-inspired design, biomimicry, bionics, biophilic design, and biognosis (Vincent et al. 2006). One of the leading advocates of bioinspired problem solving is Janine Benyus. She has been promoting the idea of biomimicry since the 90 s through 
public talks, publications (Benyus, 1997; Benyus, 2008), and the Biomimicry Institute that she had founded in 2006. Biomimicry has been applied to many fields including energy generation, production, agriculture, engineering, information storage, and even business.

\section{Approaches for biomimetic design}

Before looking into some case studies, it would be useful to briefly analyze some of the approaches used in biomimetic design. Although the words biomimicry and biomimetic imply imitation of nature, they are normally not used in that sense. For example, Janine Benyus recommends a focus on function rather than form in biomimetic practice. Current engineering research also focuses mostly on function, as would be expected from its orientation towards end results, applications, new technologies, and new products. However, there is more than only form and function in biomimetics. The main approaches of biomimetic design could be listed as follows: imitation, inspiration, functional, processbased, and ecosystem-based.

The imitative approach tries to meticulously copy nature or real objects derived therefrom. A good example would be artificial flowers. Today, the level of sophistication in these products is so high that it is almost impossible to tell top quality artificial flowers apart from real ones, just by looking at them. However touching them spoils the magic because they are made of plastic or textile (although this may change in the near future as well). Sampuru (Japanese food models) are another interesting utilization of representation by faithfully copying the original item. These food models have been used in Japan since the 1920s in order to represent food items sold in cafeterias and restaurants, without the risk of spoiling the sample and having to throw it away each day (Lombardi \& Hashi, 2014). Earlier sampuru were made of wax but today they are made from durable polymers and they are crafted in such realistic detail that they look quite appetizing.

A second biomimetic approach is bioinspiration. Nature has always been an inspiration for artists and designers. Proof of this pattern can be found as early as the paleolithic era, depicted in cave paintings of animals such as cattle, horses, birds, and feline. One of the peak periods of inspiration for artists, architects, and designers was the Art Nouveau (Jugendstil) movement (1890-1910). This style emphasized organic forms and natural elements (Sağocak, 2003). The artistic illustrations of plants, animals, and marine creatures by German biologist Ernst Haeckel in his book Kunstformen der Natur (Art Forms of Nature, 1899-1904), posters, drawings, and oil paintings of the Czech artist Mucha, the famous organic-shaped buildings and furniture of Spanish architect Gaudi, and glass items designed by Émile Gallé in Nancy and Louis Comfort Tiffany in New York are just some examples from this brilliant period.

The main focus of biomimetic design research today is towards a functional one. This approach emphasizes functional problem solving based on benchmarks in nature. It involves careful analysis of the organism's innovative solutions to problems or environmental conditions, followed by skillfully adapting them using the designer's perspective. Some examples to this approach will be discussed under case studies (see Bloom, Fastskin, and water collection in arid regions inspired by the Stenocara beetle). 
The process-based approach focuses on certain processes that occur through the participation of an organism or the ones that occur within the organism. For example, bone formation or osteogenesis occurs in all vertebrate including humans. A dynamic software program was developed based on stress optimization processes in trees and mass optimization processes in bones (Mattheck \& Tesari, 2002). Using this software, engineers of Daimler-Chrysler reduced the weight of a new car that they designed, resulting in a mere $3,4 \mathrm{lt} / 100 \mathrm{~km}$ fuel consumption. This concept car was inspired by the shape of boxfish which inhabits coral-reefs. Designer Joris Laarman and his colleagues used a similar software developed at Opel to design chairs that optimize their strength to mass ratio replicating processes of bone growth. Repeated software simulations add material where more strength is required and remove material where it is not critical (Benyus, 2008). The aim of the process-based approach may be to realize a certain function or property as explained in this example (a lightweight but strong product) or to develop a new process as well (for example, a water purification process based on examples from nature).

Probably the most complex approach to apply in design is the ecosystem-based approach. This approach considers not only the designed product, building, landscape, or city, but it also takes into account how it is integrated with natural ecosystems and how it contributes to their regeneration (Pedersen Zari \& Storey, 2007). A recent pilot project presented at the Venice Architecture biennale in 2016 by Danish studio EFFEKT uses the ecosystembased approach at the scale of a village. The first ReGen village will be built in Almore, just outside Amsterdam. The aim of this project is to build a self-sustaining farm village. The village will apply sustainable organic farming in greenhouses, grow about half of the food the inhabitants need, and use high technology to generate green energy (Frearson, 2016). While the project has high hopes with regard to sustainability, time will show whether it will function as planned.

The approach-based categories are not absolute, but rather, they are intended to demonstrate that there are a multitude of options when learning from nature.

\section{Case studies}

Several projects have been accomplished by designers using biomimetic approaches and making use of biomimetic materials. It should be noted that the success of biological models and biomimetic counterparts discussed here are not only dependent on materials but also their micro- and nanoscale texture, morphology, arrangement, and functional strategy.

Architects and designers started to emphasize bioinspired approaches recently. For example, Sung (2016) used manganese-nickel bimetals as smart materials that respond to environmental temperature changes. Bloom is a pavilion designed by Sung and realized by combining approximately 14000 laser-cut bimetals (Figure 1). These bimetals respond to temperatures above $22^{\circ} \mathrm{C}$ by curling up and letting air to flow in and out of the façade. This installation demonstrates the feasibility of the concept which aims to balance internal heat accumulation in buildings with a biomimetic approach. Sung is an architect with a biology background. She was inspired by human skin that naturally regulates the temperature of the body (Sung, 2012). 
Designer and chemist Lauren Bowker successfully commercialized several bioinspired fashion accessories including bags, wallets, and wrist straps. A team of anatomists, engineers, chemists, and designers designed and developed a collection of products under the title Unseen. The collection is composed of items that incorporate natural materials such as feathers, quills, and leather. These items change color depending on the environment. For instance, a leather bag changes color with a slight pressure, a scarf displays different patterns with changes in temperature, or a calligraphy quill flourishes a peacock color palette upon contact with air (TheUnseen, 2015).

Badarnah and Kadri (2014) developed a methodology for the generation of biomimetic design concepts they called BioGen. Their methodology involves various steps including the definition of a design challenge, exploration and biophysical investigation, pinnacle analysis (analysis of organisms and natural systems that accomplish the desired function), abstraction via pinnacle analysis and design path matrices, generation of a design concept, and estimation of performance. Applying this process to the design challenge of collecting water in arid regions, storing it, and optionally humidifying and cooling an interior space, they adapted the morphological features of the elytra (fused overwings) of the Namib Desert beetle. The Stenocara beetle's elytra contain randomly distributed hydrophilic (water-loving) nonwaxy bumps surrounded by hydrophobic (water-repelling) wax coated grooves (Figure 2). When the beetle tilts its back wings into the fog, microcondensation causes water droplets to collect on the bumps and the hydrophobic grooves channel the water droplets into the beetle's mouth (Garrod et al. 2007). The diffusion of collected water from the skin to the interior space in the design concept involves a fibrous material that attracts water via capillary action. This was inspired by the Thorny devil's semi tubular capillary system that allows transport of water to the mouth (Badarnah and Kadri, 2014). Designers at Philips developed Bio-light in collaboration with Dr. Maarten Merkx from the Eindhoven University of Technology. Bio-light is an experimental lighting system that makes use of bioluminescent bacteria found in organisms such as fireflies, glow-worms, and certain marine creatures. The system is composed of glass compartments containing a fluid that houses bacteria, a bio-digester unit that generates methane from composted bathroom solids and kitchen vegetable waste, and silicone tubes that carry methane from the bio-digester to the glass compartments in order to feed the bacteria. Although the green luminescence is not bright enough to replace artificial lighting yet, some applications such as warning strips on curbs, exit signs for dark public spaces, and nighttime edge indicators for roads are envisioned. The system does not require any electricity, it is a sustainable solution since it converts household waste into domestic lighting, and has the potential of functioning for a very long time, as long as methane is fed to the bacteria (Jonsson, 2011). Microscopic tooth-like scales of shark skin have ribs with longitudinal grooves (Figure 3) that result in a reduction of water drag by 5-10\%. In 2006 Speedo introduced the Fastskin swimsuit inspired by the texture and low drag coefficient of shark skin. The swimsuit used polyurethane woven fabric that incorporated built- in ridges to reduce drag and water turbulence around the body. A large number of world records broken by swimmers wearing this swimsuit suggest that the biomimetic design has been quite successful (Bhushan, 2009). 


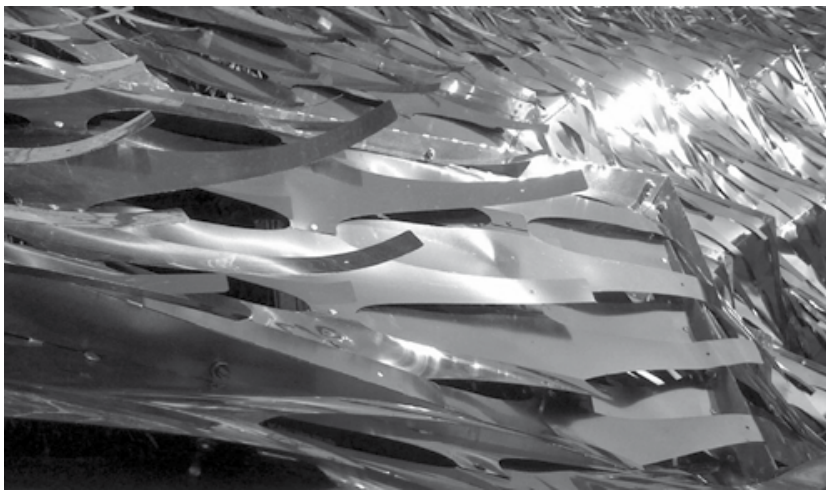

Figure 1.
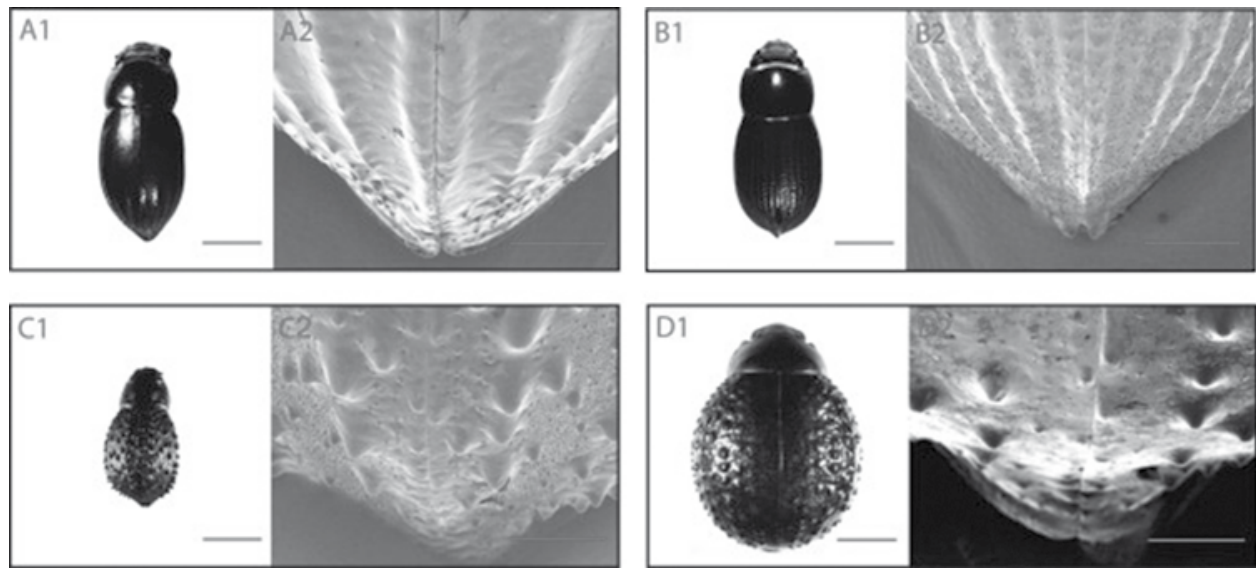

Figure 2.

Figure 1. Bloom skin detail, an architectural research installation displayed at the Materials and Application Gallery in Los Angeles, 2011. Courtesy Doris Kim Sung. Figure 2. Scanning electron micrographs of elytra structures of Namib Desert Darkling beetles A) Onymacris unguicularis, B) Onymacris laeviceps, C) Stenocara gracilipes, and D) Physasterna cribripes (Norgaard and Dacke 2010). Figure 3. Scanning electron micrograph of a lemon shark's dermal scales (Pascal Deynat/Odontobase, Wikimedia).

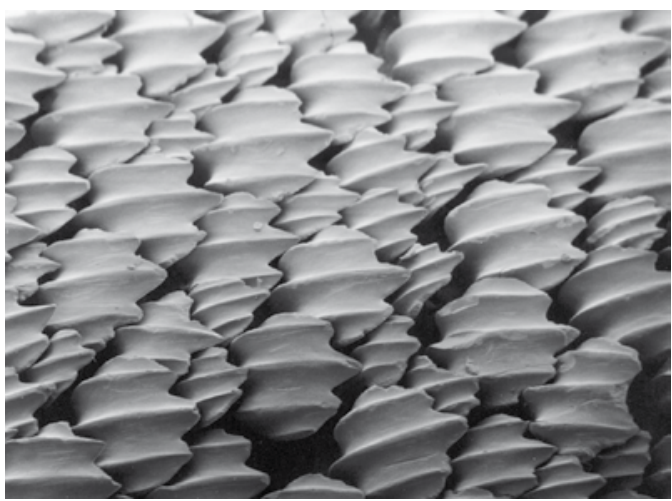

Figure 3 . 


\section{Outlook}

Commonly most biomimetic materials research is intended for engineering applications but designers may also benefit from their unusual structure and properties. Based on this limited review, it can be said that biomimetic materials need to prove themselves or become commercialized before they are used by designers even in the conceptual stage. There are very few examples where designers or design teams are directly inspired from natural materials and apply them in a new design. This is probably what one should expect since designers are typically not well-equipped with materials science knowledge. To bypass commercialization of biomimetic materials and go directly from nature to biomimetic design using biomimetic materials, one approach could be to facilitate collaboration of designers with materials engineers.

As discussed above, various biomimetic projects have already been realized but there is still a vast ocean of possibilities to explore for designers. Particularly, there are many design opportunities with regard to processes such as self-assembly, mass-shape-strength optimization, and fractal growth. Materials with biomimetic capabilities of self-healing, responding to changes in environmental conditions, transport of light and matter, transformation, motion, and growth are worth exploring and developing for innovative design solutions. These biomimetic materials, processes, and designs will no doubt contribute to the solution of many environmental and social problems faced in our world today.

\section{References}

Badarnah, L. \& Kadri, U. (2014). A methodology for the generation of biomimetic design concepts. Architectural Science Review, 58(2), 120-133.

Benyus, J. M. (1997). Biomimicry. New York: William Morrow.

Benyus, J. (2008). A good place to settle: Biomimicry, biophila, and the return to nature's inspiration to architecture. Biophilic design: The theory, science, and practice of bringing buildings to life. Hoboken, NJ: Wiley.

Bhushan, B. (2009). Biomimetics: lessons from nature-an overview. Philosophical Transactions of the Royal Society of London A: Mathematical, Physical and Engineering Sciences, 367(1893), 1445-1486.

Frearson, A. (2016). EFFEKT designs villages that produce all food and energy. http://www. dezeen.com/2016/05/20/effekt-designs-regen-villages-produce-own-food-energydanish-pavilion-venice-architecture-biennale-2016/ accessed 30.05.2016

Garrod, R. P.; Harris, L. G.; Schofield, W. C. E.; McGettrick, J.; Ward, L. J.; Teare, D. O. H. \& Badyal, J. P. S. (2007). Mimicking a stenocara beetle's back for microcondensation using plasmachemical patterned superhydrophobic-superhydrophilic surfaces. Langmuir, 23(2), 689-693.

Jonsson, R. (2011). Philips Bio-light concept lights the home using bacteria. http://www. gizmag.com/philips-bio-light-concept-taps-bioluminescence-for-home-use/20632/ accessed 25.07.2016

Lepora, N. F; Verschure, P. \& Prescott, T. J. (2013). The state of the art in biomimetics. Bioinspir. Biomim. 8 (2013) 1-11. 
Lombardi, L. \& Hashi (2014). Sampuru: Japanese food models. https://www.tofugu.com/ japan/sampuru/ accessed 28.05.2016

Mattheck, C. \& Tesari, I. (2002). Integrating biological optimisation methods into engineering design process. Design and Nature, 27-36.

Nørgaard, T. \& Dacke, M. (2010). Fog-basking behaviour and water collection efficiency in Namib Desert Darkling beetles. Frontiers in zoology, 7(1), 18.

Pedersen Zari, M. \& Storey, J. B. (2007). An ecosystem based biomimetic theory for a regenerative built environment. In Sustainable Building Conference 07, Lisbon, Portugal.

Sağocak, M. (2003). Tasarım tarihi (design history). Bursa, Turkey: Vipaş.

Sung, D. (2016). Smart geometries for smart materials: taming thermobimetals to behave. Journal of Architectural Education, 70(1), 96-106.

Sung, K. D. (2012). Metal that breathes, TEDxUSC http://www.ted.com/talks/doris_kim_ sung_metal_that_breathes, accessed 18.05.2016

TheUnseen (2015). TheUnseen Emporium. http://theunseenemporium.co.uk/ accessed 22 July 2016.

Torgal, J.A. F.P. et al. (2015). Biotechnologies and biomimetics for civil engineering. Heidelberg: Springer.

Vincent, J. F.; Bogatyreva, O. A.; Bogatyrev, N. R.; Bowyer, A. \& Pahl, A. K. (2006). Biomimetics: its practice and theory. Journal of the Royal Society Interface. 3(9), 471-482.

\begin{abstract}
The interdisciplinary field of biomimetics has been enjoying increasing attention in recent years. The scientific and industrial community understands that the harm we have been doing to nature can actually be solved by nature herself. Biomimetic design has also been gaining impetus thanks to new research and technologies. Biomimetics is not limited to form and aesthetics only but also makes use of a deeper understanding of functional aspects, processes and systems found in nature. This paper elaborates on five biomimetic approaches: imitation, inspiration, functional, process-based, and ecosystem-based. Short case studies explain how biomimetic research can help solve different problems in design.
\end{abstract}

Key words: Biomimetic - biomimicry - materials - bioinspiration - biophilic.

Resumo: O campo interdisciplinar de biomimética tem recebido atenção crescente nos últimos anos. A comunidade científica e industrial entende que os danos que temos feito à natureza podem ser resolvidos pela própria natureza. O design biomimético também vem ganhando força graças a novas pesquisas e tecnologias. Biomimética não está limitado a apenas a forma e estética, mas também faz uso de uma compreensão mais profunda dos aspectos funcionais, processos e sistemas encontrados na natureza. Este artigo tem cinco abordagens biomiméticos: imitação, inspiração, funcionalidade, com base em processos e com base nos ecossistemas. Os estudos de caso explicam como a pesquisa biomimética pode ajudar a resolver problemas diferentes em design.

Palavras chave: biomimética - materiais - Bioinspiration - biophilic. 



\section{Material activism. New hybrid scenarios between design and technology}

Valentina Rognoli * and Camilo Ayala Garcia **

Resumen: La década pasada es, según algunos académicos, caracterizada por una onda hacia una nueva revolución industrial [1]. Principalmente gracias al hecho que la tecnología ha salido del dominio de la industria para quedar en las manos de la gente común. Los materiales están poco a poco comenzando a presentar el mismo tipo de comportamiento, dado que hoy en día mas y mas personas están experimentando con la creación de materiales de manera disruptiva. Este artículo presenta el concepto de Activismo Material como mecanismo para entender el fenómeno en crecimiento que esta permitiendo a los materiales democratizarse a través de una aproximación de base.

Palabras clave: democratización - conocimiento compartido - tecnologías poco sofisticadas - hacking - auto producción y hazlo tu mismo.

[Resúmenes en inglés y portugués en las páginas 114-115]

${ }^{(*)}$ Designer, $\mathrm{PhD}$ in Industrial Design and assistant professor at the Design Department of the Politecnico di Milano. She has been working in the field of materials for design for almost twenty years gaining expertise on this topic both in research and education. She has always been interested on the expressive-sensorial dimension of materials and their emotional aspects.

${ }^{(*)}$ Ph.D. Candidate - Politecnico di Milano, Italy. Assistant Professor - Design Department Universidad de los Andes Bogotá, Colombia.

\section{Introduction}

Our material experience (Giaccardi \& Karana, 2015) is, thanks to the materials, artifacts and objects that surround us, a conditioned experience. It is ruled by the fact that everything we enter in contact with, come from an industrial mass production. That is to say that our material experience is based mainly from industrial materials that have been developed to be coherent with shapes efficient in a mass productive system. This is the result of decades and decades of development of the industry and will not change in the immediate future (Rognoli et al., 2015) although other remarkable phenomena are emerging. 
We have witnessed in the past 15 years an exciting change of scope when it comes to the understanding of the relationship between design and technology in a contemporary world. Materials influence tremendously that relationship back and forth as they are embodied in everyday artefacts through mass production. We are surrounded by industrial materials industrially processed. There are two main established forces that drive materials development:

On one side we have the search for solutions to the technical/technological problems in strategic sectors like medicine or military, and on the other side the research of more affordable materials solutions that can be scaled up easily to fulfill industrial demands (Lindstrom, Razavi \& Nobell, 2014). This established forces of materials development are starting to see a third one coming that is going to establish as well; the one that deals with bio-based materials development to fulfill environmental affairs.

Another important issue that drives material development throughout industry, is around the concept of Material Surrogate (Rognoli \& Levi, 2015). This concept states that through history all materials in different scales have been replaced by other materials, that in the beginning of their development and application were considered surrogate: precious stones were replaced by glass, Majolica clay or porcelain were take over by terracotta, Ivory and turtle shell by Plastics. The value attributed to a surrogate material is not only economical, but also expressive, which refers to quality, aesthetics and the imaginary of the matter itself. Surrogate materials can be understood also as materials that imitate other materials, therefore they lack on language innovation. This panorama is very common in the industrial materials world. Important to underline though, is the fact that the new materials that substitute others should be compatible with the technologies and processes available in order to improve possible applications and enter in the more efficient way, the industrial system. This approach becomes very unstimulating to designers as the expressive sensorial qualities of materials (Rognoli, 2004) become alike among them and no room for innovation can sparkle.

An additional relevant consideration is that during the process of materials development, the designers seldom enter into the development team, in the main composed by Engineers and Scientists. In this exclusive rigid industrial system with a large amount of entrance barriers, designers have been used to employ materials and processes already available in the market as they rarely contribute in the development of any particular material. In other words, designers have become experts in material selection or select materials thanks to instruments available, as no other source appears at hand.

One of the instruments available for designers regarding selection are the materials libraries. In the past twenty years we have witnessed a growing interest among designers to become closer to the materials domain that was took apart from our discipline founded with deep roots in crafts and physical experimentation with materials. Thanks to the scientific materials development that closed materiality in laboratories and in Industry $\mathrm{R} \& \mathrm{D}$ sections for almost half of a century, few or no room remained for several generations of designers to interact with materials aside from the selection perspective. To this point material libraries become a display of materials that come from an industrial mass production systems and therefore our expressive sensorial possibilities (Rognoli, 2004) of application are limited with what the industry can provide. 
The opening of material libraries has been a key point in the design field as they have triggered once again a closeness relationship between materials and designers, considering that they were already excluded form the closed engineering and scientist materials development circle. Those libraries opened a chance for designers to get in contact with hundreds of materials samples in the same place allowing themselves to contribute to the project by understanding the properties of a material available on the market. Mainly the contribution appears as the designer is capable of extract the expressive-sensorial qualities of a material sample and therefore perform the right selection for a particular application or take them as a source of inspiration to develop a new project. Many industries recognize this ability as part of the CMF (Color, Materials and Finishes) domain where designers are capable to deal with the sensorial attributes of materials and finishes to support both functional and emotional attributes of products. Liliana Becerra (2016) states that "the work of the CMF designer combines aesthetics and practical knowledge of materials and technologies with intangible human perceptions of value". Although this domain is growing and catching interest among designers, we believe it cannot be the only place where designers can get in contact with the materials development system.

\section{Material activism}

We introduce the concept of activism as a provocative exhortation to the designers in order to start a vigorous protest against this closed system of materials development, that exclude designers on the basis of lack of knowledge on one side and a dependence on the system to select the materials for a project on the other side. The term materials activism was firstly coined by Miriam Ribul (2014) as an expression to identify a lowtech approach that will democratize the production and development of materials. In her open source publication, the author invite through a collection of recipes for in-house material experimentation, to understand how its possible to develop alternative models to replace traditional industrial ones, creating also new aesthetics and innovating through new materials languages.

What comes into evidence and will later become our target on the discussion in this paper, is that the approach and all the examples that will be presented here shows the emergence of another way to see materials and processes. An alternative and parallel view that carries within a new dimension of the relationship between designers, technology processes and materials.

The key words that emerge from this alternative material approach such as democratization, sharing, low-technologies, hacking, self production and Do-It-Yourself, very contemporary terms of the second decade of the XXI century, interconnect to configure a very precise context and a particular approach to the project that consider above all the hands on technique and a new way of tinkering with materials (Jacobsson, 2013; Karana et al., 2015). The interrelation of those factors have given the possibility to this new or emerging materials experiences (Karana et. al, 2014) to emerge.

The new appreciation of being an artisan, the acceptance of Do-It-Yourself practices as a possible practice within the society, supported thanks to the internet and the open- 
source philosophy (Anderson, 2012, p. 58) became the fertile ground that gave the proper goldilocks conditions for materials activism to appear. The democratization of the means of production, combined with the people`s wish for personalization (Anderson, 2012, p. 102) have opened an alternative to the closed system of industrial materials development. A designer can feel right now the will to go home, enter into the kitchen and start any materials experimentation experience that may find interesting in any website. After some iterations with the material it may also will go and buy any open-sourced instrument that can help improve what have created. Suddenly this designer will be part of this emerging group of activists that create a project starting with the material development.

That possible scenario was not so long ago impossible to imagine as materials and processes were developed and improved inside a closed system inside labs and Industry's R\&D sections and not in a home or workshop. (Figure 1)

We have always argued in the field that designers are multi-disciplinary entities as we share some capabilities with other fields in Social Sciences, Arts or Engineering. But based on our premises of this introduction, we can state also that today the designer can be seen better a trans-disciplinary entity. That means that the designer can work transversally with other disciplines collaborating in their will to understand the complexity of a problem to tackle. Designers are now open to biology, chemistry, medicine, math's. Not as a person to confront Humanities and Science but a bridge to connect them, specially when it comes to materials world.

\section{The material activists}

By stating that designers in the role of activism when it comes to materials development, are triggering new scenarios, it is wise to say that part of that role in a trans-disciplinary way, is to become some times artisan, sometimes chef, sometimes an alchemist.

The word alchemist is what is going to introduce this part of the study where several types of materials activists are shaping the phenomena around the globe. We are presenting here briefly three activists we consider started to make visible in an structured way the phenomena we have been discussing in this manuscript.

\section{Material alchemy}

The first one, and the one who published a book with this name Material Alchemy, Jenny Lee (2015) states in her book how from a trans-disciplinary point of view materials for design are growing worldwide. As a declaration in the book, "is how to redefine the materiality of the XXI century". Which means, what is the concept of materiality that emerge from the materials that can be developed today. Interesting from this activist approach is to understand how these materials can be developed from an alchemist manner.

We believe it is a clever asset to bring Alchemy concept into this phenomena, based on the fact that Alchemy as a form of Chemistry and speculative Philosophy practiced in the Middle Ages and the Renaissance was engaged principally with the discovery of different 


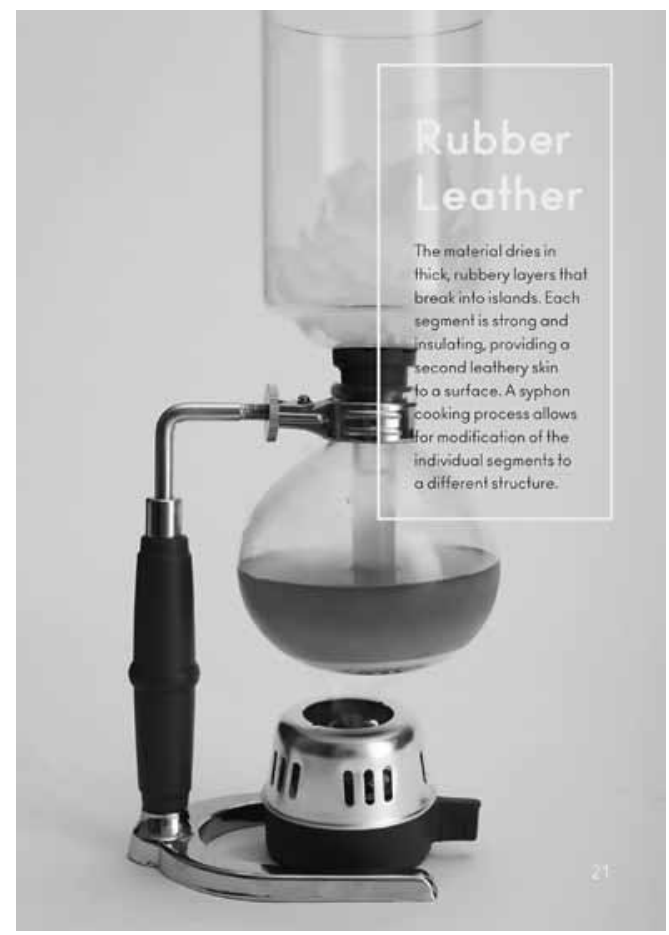

Figure 1. Material Activism e-book. Courtesy of Miriam Ribul.

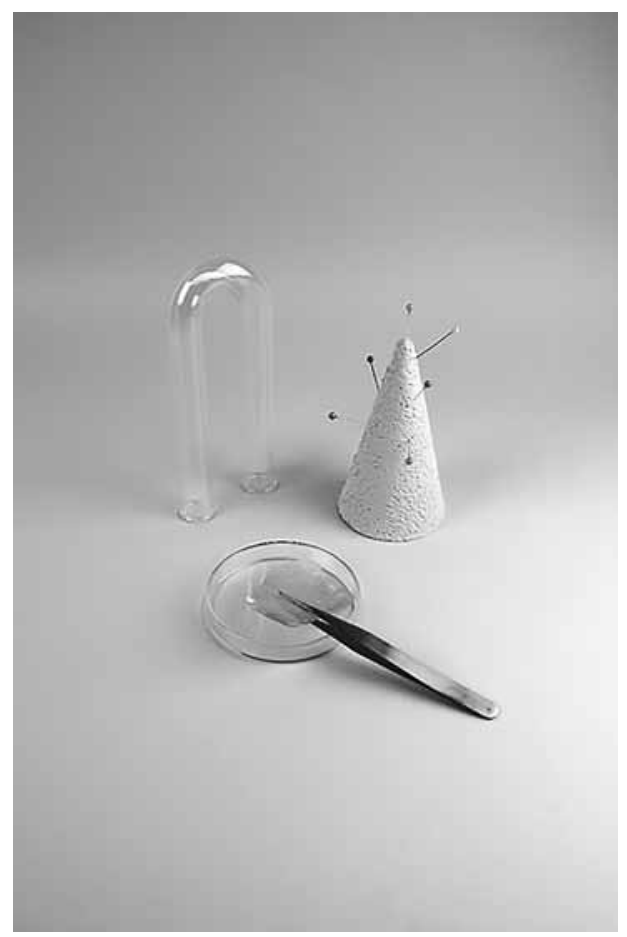

Figure 2. Material Alchemy Book. Courtesy of Studio Akieu.

methods to transform matter. One of the aims was to transform Lead, which at that time and even today is a material associated with bad and negative outcomes into Gold which on the contrary is perceived as the perfect material and the representation of a greater good. To change from evil to holy, from what is bad into something superb. In this contemporary activist approach, it is interesting to see how this alchemist intent remains as one of the key drivers for designers that enroll in materials development where one of the main aims is to change industrial waste into a valuable material once again. (Figure 2) Another valuable issue that can be pulled out of the Alchemist metaphor through the idea of transforming what is bad into something better, is the possibility to gain independence. We believe that designers who experiment with materials through this activist approach, are gaining several material knowledge that provide a certain amount of independence from the closed system of traditional material development. 
The complete collection of cases presented in the book Material Alchemy can be seen with this perspective as well. All the material samples provided by a collective of designers have in common in one way or another, the willing for a change. The change that independence from traditional materials developing systems can provide. The more independent designers are to develop a project by starting with the materials source, the further can go with the goal achievement. This goal of a designer, different form any other discipline, is that can be systemic, which means it can tackle different sides of the project at the same time. When a material alchemist starts the project by transforming matter into a purposed goal, not only creates an artifact; it studies the relationship between the artifact and the user, the environment, the life cycle and the afterlife of it. That perspective is what enlighten our research on material development within the design field.

Of course designers cannot do it alone. It will be simply not possible to achieve such goals without the support and collaboration of other areas of knowledge. That's why the transdisciplinary approach illustrated in this publication shows examples from biology to new technologies where designers and scientist get involved together as collaborative partners redefining the materiality of the $21^{\text {st }}$ century.

\section{Cooking materials}

Another recent example of material activism is found in the work of the Belgian Laurence Humier (2012) who for some years started a research called cooking materials, in which the hybridation between design, material physics and molecular gastronomy (a discipline that studies the transformation suffered by aliments during the preparation stages, aiming to transform cooking empirical knowledge into a true and proper science). In the words of one of the founders of this area of gastronomy Hervé This (2006, p. 2) "Molecular gastronomy deals with culinary transformations and the sensory phenomena associated with eating". When looking the definition of molecular gastronomy, one can immediately connect the kitchen domain with the design domain. Both create, transform matter to create sensorial experiences through products. In fact, there is a strong connection between the manufacturing processes of the industry and the ones of the professional kitchens. Some of them can be used to teach designers how to produce things by understanding the principles of the cooking crafts (Ayala, 2015). With industrial waste as ingredients, blenders and ovens as instruments, Humier presents a collection of recipes in which the material world is explored with this novel approach. In other words, composing from the molecular basis the matter of these ingredients to develop new materials. (Figure 3)

\section{Open materials}

The last example of materials activists in which a novel approach can be perceived is called Open Materials from the social scientist Catarina Mota (2009). Here is visible through the relationship between design and technology, through the so called smart materials, how it is possible to develop trough an open source platform, a research around materials and 
applications with the aid of Do-it-Yourself techniques. The research team leaded by Mota, present in a virtual platform all different experimentations guided by the open-sourced approach to materials development. Many of the developments presented come from what is known the makers Movement. The maker's movement began when the Do-it-yourself culture, who was a result of the cottage industry of the British XIX century met the web culture of the end of the XX century (Anderson, 2012, p. 72). That is what is known these days as the new industrial revolution, where thousands of makers working together in an open source model create a new kind of manufacturing economy (Anderson, 2012, p. 67). Catarina Mota states that "if we are to live in a world made of smart materials, we should know and understand them" (Mota, 2013). This statement invites, as part of the maker's movement philosophy, to hack knowledge of science and put it into the hands of "non experts". Designers are adapting this methodologies of hacking as a way to understand how the world is made so maybe it will be possible to make it better. Jonathan Lukens states that the DiY subculture is able to do things that work better than the classical infrastructure of the society (Lukens, 2013), therefore, everybody who gets involved in the movement like Catarina Mota, regardless of the background as social scientist instead of being trained as designer, is invited to re-think the infrastructure of the society and propose new ways of improving our world. (Figure 4)

\section{Discussion}

The previous examples of materials activists presented above, have served to introduce the phenomenon in which contemporary designers are demonstrating the will of compose, develop, transform, modify and self produce their own materials. This emerging phenomena can be better defined under the category recently known as Do-it-Yourself Materials (Rognoli et al., 2015). The DiY Materials are defined as materials developed through techniques of self production (individual or collective) with low technologies, easy accessible material sources and with an aesthetical language that evokes the craftsmanship and imperfect of its conception. Can be a new materials development or a modification of an existing material source. The development of DiY Materials is characterized by the integration of the development and production phases, combined with the autonomy that the designer can acquire in production by accessing the three examples of material activism described above.

Although Do-it-Yourself Materials are realized by informal and non-industrial producers outside the traditional companies and laboratories (can be called no-corporate materials as well), they might inspire scientists and engineers inside a company to go further in the development and scaling of the proposed material.

The panorama of industrial materials development is nowadays quite uninspiring and unexciting from the design perspective since the lack of stimuli for designers appears due to certain absence of scientific knowledge. We have argued that designers do not enter or rarely intervene into these logics of scientific materials development, therefore, this approach of self production of materials is favoring designers as empower them to become the promoters of a new material development. This activist materials approach 


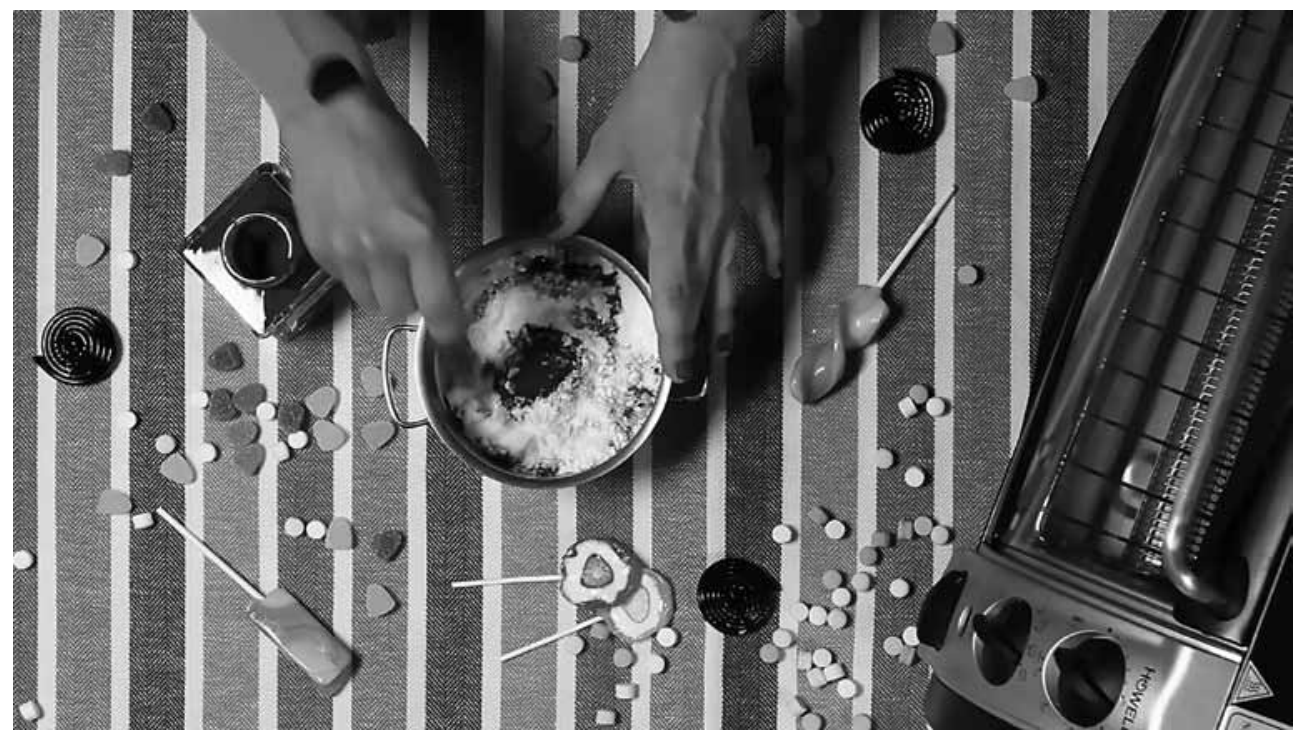

Figure 3. Cooking Materials Book. Courtesy of Laurence Humier.

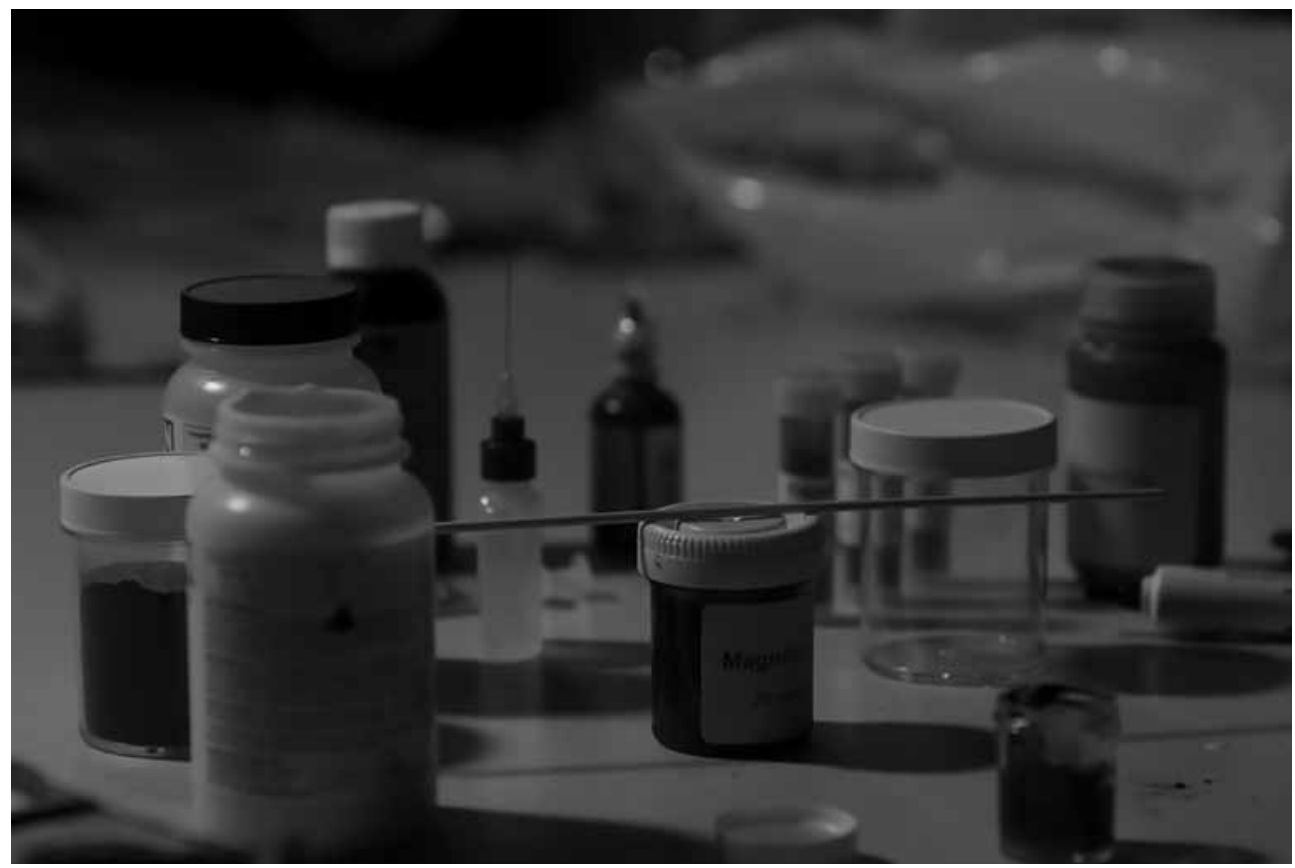

Figure 4. Open Materials. Courtesy of Catarina Mota. 
of self production is allowing designers not only to "rebel" to the actual industrial system. It allows them to create and project from the beginning, the material experience that they desire. The material experience then will be born with the material contrary to what has happened form several years where designers at the last link in the chain were called to project the expressive-sensorial dimension of an industrial material already developed by someone else.

This is an enormous change of perspective for the design field when it comes to materials knowledge. Think globally, fabricate locally (Gershenfeld, 2012) becomes now more than ever of superb importance in terms of materials activism as invites to create the materials with what is known as Kilometer Zero impact, a term coined by the food industry (Cavanaugh, 2016). By sharing the knowledge, no matter when the idea comes, the material can be locally developed.

\section{Conclusion}

This paper has introduced and defined the new concept of Material Activism as an extension of what has been previously defined as Do-It-Yourself Materials (Rognoli et al., 2015).

Through the analysis of three main actors around this phenomenon, we aimed to illustrate the relevance and the opportunities that these movement is representing for the design field. We have argued and discussed the key elements that are driving designers to take part in this new industrial revolution wave. Although Material Activism is a very novel concept it is important to study it properly as it will represent a balance in the future of materials development in the upcoming years. We believe that the research of materials development from the design perspective will allow designers to achieve a broader, richer future in complete equilibrium with the planet when creating artifacts and their emerging material experiences. Everything that will be created by following this phenomenon we described, will me full of meaning and value. Therefore, we believe people will be more attached to what will be produced redefining the goals and scopes of mass production and product life cycles in the future.

\section{References}

Anderson, C. (2012). Makers-The New Industrial Revolution. Random House Business Books. Ayala, C. (2015). The Basis of Processes - Experimenting with Food to Re-Shape the Industry Language. In: Proceedings of Cumulus Conference, The Virtuous Circle: Design Culture and Experimentation. Milan: McGraw-Hill Education.

Becerra, L. (2016). CMF Design - The Fundamental Principles of Colour, Material and Finish Design. Frame Publishers.

Cavanaugh, J. (2016). Talk as work: Economic sociability in Northern Italian heritage food production. Journal of Language and Communication 48,41-52. 
Gershenfeld, N. (2012). How to Make Almost Anything. The Digital fabrication revolution. In Foreign affairs November/December 2012

Giaccardi, E. and Karana, E. (2015). Foundations of Materials Experience: An Approach for HCI, CHI'15 Proceedings of the 33rd Annual ACM Conference on Human Factors in Computing Systems, pg. 2447-2456.

Humier, L. (2012). Cooking Material. Could Molecular Gastronomy Help Discover New Matter? E-Book of Exhibition on Triennale Design Museum, Milano.

Jacobbson, M. (2013). Thinkering with Interactive Materials: Studies, concepts and prototypes. Royal Institute of Technology.

Karana, E.; Barati, B.; Rognoli, V. \& Zeeuw van der Laan, A. (2015). Material driven design (MDD): A method to design for material experiences. International Journal of Design, 9(2), 35-54.

Karana, E.; Pedgley, O.; Rognoli, V. (2014). Materials Experience: Fundamentals of Materials and Design. Elsevier.

Lindstrom, M.; Razavi, F.; Nobell, N. (2014). The superhero and the DJ: Science meets design. Journal of Professional Communication 3(2), pp. 125-136.

Lukens, J. (2013). DIY Infrastructure. Georgia Institute of Technology.

Mota, C. (2012). "Open Materials homepage. Open source materials collection". Retrieved from http://openmaterials.org.

Mota, C. (2013). Open Sourcing Materials. In The Open Book. Eds. Kaitlyn Braybrooke and Jussi Nissila. The Finnish Institute in London.

Pedgley, O.; Rognoli, V. \& Karana, E. (2015). Materials Experience as a Foundation for Materials and Design Education. International Journal of Technology and Design Education, vol. 25; DOI 10.1007/s10798-015-9327-y

Rognoli, V. (2004). I materiali per il design: un atlante espressivo-sensoriale. Politecnico di Milano.

Rognoli, V.; Bianchini, M.; Maffei, S.; Karana, E. (2015). DIY Materials. Materials and Design, 86(2015), 692-702.

Rognoli, V.; Levi, M. (2005). Materiali per il design. Espressività e sensorialità. Milano: Polipress.

Ribul, M. (2013). Receipts for materials activism. Retrieved from: https://issuu.com/ miriamribul/docs/miriam_ribul_recipes_for_material_activism/chlj

This, H. (2005). Molecular Gastronomy: Exploring the Science of Flavor. Columbia University Press.

Abstract: The past decade it is considered by many scholars as the new industrial revolution wave [1], mainly by the fact that technology has jumped out of the industry into the hands of the people. Materials are also starting to perform the same behavior as more and more people are starting to deal with the creation of materials in a disruptive way. In this paper we present the concept of Material Activism as a way to understand the growing phenomena that is allowing materials to democratize through a bottom up approach. 
Key words: democratization - sharing - low-technologies - hacking - self production and Do-It-Yourself.

Resumo: A década passada é, segundo alguns acadêmicos, caraterizada por uma onda até uma nova revolução industrial, devido ao fato que a tecnologia saiu do domínio da indústria para ficar nas mãos das pessoas comuns. Os materiais estão pouco a pouco começando a apresentar o mesmo tipo de comportamento, já que hoje mais e mais pessoas estão experimentando com a criação de materiais de modo disruptivo. Este artigo apresenta o conceito de Ativismo Material como mecanismo para entender o fenômeno em crescimento que está permitindo aos materiais democratizar-se através de uma aproximação de base.

Palavras chave: democratização - conhecimento compartilhado - tecnologias pouco sofisticadas - hacking - auto-produção - faça-você-mesmo. 



\section{Diffuse materiality in public spaces between expressiveness \\ and performance \\ Giulia Gerosa * and Laura Daglio **}

Resumen: Hoy en día, el design de los espacios públicos es frecuentemente aproximado como los interiores de design urbano, con tal que la instalación y l'ajustamento de los espacios abiertos con el método y concepto parecido a los de interiores. En el papel se analiza el uso innovador de los materiales tradicionales o el uso de nuevo materiales en espacios públicos, destacando dos tendencias posibles en busca de mejorar la calidad de los espacios urbanos: expresividad y funcionamiento. Estudios de casos seleccionados son revelados de presentar como las nuevas formas, una tensión en los valores de percepción y el impacto medioambiental y comodidad tanta como durabilidad son los principales objetivos de innovación de materiales en este campo.

Palabras clave: Expresividad - rendimiento - materiales - diseño de interiores - espacio público - identidad - bienestar.

[Resúmenes en inglés y portugués en las páginas 123-124]

${ }^{(*)}$ Architect and $\mathrm{PhD}$ in Industrial Design and Multimedia Communication is an assistant professor in Interior design at the Politecnico di Milano where she works on research issues concerning the communicative component of the architectural project and the brand identity in retail spaces. She is involved in research programmes funded by Public Bodies at different levels and in international projects. She is the author of books, essays, articles in reviews and of academic papers presented at international Seminars.

${ }^{(* *)} \mathrm{PhD}$ is a registered architect and an associate professor of Architectural Technology at the Politecnico di Milano where she works on research issues concerning environmental design and sustainability in architecture, at different scales, related to new construction as well as renovation. She is involved in research programmes funded by Public Bodies at different levels and in international projects. She is the author of books, essays, articles in reviews and of academic papers presented at international Seminars

Point of contact with the user who is immersed within it, interior space assumes the right value when architecture is conceived as the space where life is carried out, a concept extensively developed by Carlo de Carli in his theory of the "primary space", the relation space where actions are accomplished making sense of the space itself. Bruno 
Zevi declared first that architecture exists when there is interior space, whether it is in a building or in a city and that it acquires a value only when used by people. Starting with the assumption that interior architecture occurs when there is a space which can be entered, the scope of the discipline broadens to include all the environments where users take action, encompassing private and public spaces, residential and working spaces, health, retail, transport and accommodation facilities.

Moreover, functional instability and a growing trend from monofunctional towards multifunctional space are characteristics of contemporary architecture leading to the need of a reconsideration of the role of interiors. As highlighted by Andrea Branzi:

... there is in fact no function, program or urban zoning which hasn't been denied in the last ten years; the decommissioning of industrial facilities is the first and more obvious phenomenon of a process involving the other urban functions, from retail to housing from offices to services. People work at home, live in offices, do business in their houses, study in factories and gasometers are converted in museums... (Branzi, 2004)

Temporary settlements within specific spaces can be observed, as well as the specific design of spaces based on a predetermined lifecycle typical of industrial design, applied to containers of functions where more and more frequently also the dismantling and the total or partial recycle of the structure are programmed in advance. The time variable is declined according to different meanings leading to examples of temporary, transformable or transportable spaces up to temporary or ephemeral installations related to the phenomenon of the city of events where great flows of transient visitors experience a changing and poriferous city which quickly responds to momentary needs. The resulting projects are thus more aimed at reinventing rather than interpreting places through the fitting of new functions and new forms with the infinite freedom of a set up design approach.

Public spaces are rendered as urban interiors where to create new artifices, installations and the setting up of a renovated urban symbolism interpreting the issues of contemporary society which means temporariness and flexibility, but they are also simultaneously civic spaces as well as related to a heideggerian concept of living, and therefore should respond to the need of building a collective identity and of developing a sense of belonging in relationship to the sense of place. "Living is being at home everywhere" (La Pietra, 1977-79). The complexity and the contradictions of this double approach, combining the temporariness of installations with the durability entailed by the shared values of citizenship and urbanity, is also recognizable in the choice and use of materials and technologies ${ }^{1}$. A considerable role in the design of public spaces is in fact played by the application of new materials and the new application of traditional materials as well as by technologies for environmental comfort and by services to enrich the use and fruition of space leading to the enhancement of both the physical and the sensorial ergonomics of space, related to its evocative and communication aspects.

Two are the possible trends which an analysis and evaluation of recent projects of public spaces may offer: solutions with a high added value show typical and substantial qualities that affect expressiveness and performance. 


\section{Expressiveness}

Regarding the urban design approach, Kevin Lynch (1960) wrote about the necessity of providing a new meaning to the cities where the user isn't able anymore to recognise himself in the historic monuments, but needs instead new signs to be oriented in the urban texture; Lynch thus underlines the concept of readability of a place, in other words the ability of the community to adapt, orientate and understand a specific urban space. The goal of providing a strong sense of identity to the places with or without a relationship to the existing context is also achieved through the use of iconic forms or sometimes interactive devices creating a dialogue between user and space and frequently through amazing and astonishing solutions.

Historically used, light as construction material can still transform and make sense of the urban space, allowing for the "rebirth" of abandoned buildings. It's the case of the Overhead Crane in Sesto San Giovanni (2006), an extremely important part of the manufacturing history characterising Italian industrial landscape, which becomes a monumental element in the ex-Breda Industrial Archaeology Park. Today it's a symbol of the transformations which the town has experienced: a reminder of the great factories but, at the same time, also a challenge set by the new schemes for interpreting the urban spaces freed of the sheds and the impenetrable walls which enclosed those factories and hid them from view, a concept stressed by the evocative red LED lighting at night.

A similar approach can be recognised in Valle Sophie's project for the conversion of 1980s petrol station canopies into new landmarks highlighting the entrance to the new Noorderpark in Amsterdam. False ceilings of light were installed to replicate artificial skies where 20 different light animations shelter different kinds of open-air cultural activities. Daan Roosegaarde proposes instead with the Dune project (2012), in Rotterdam, a different use of light more in relationship with the natural landscape: a public interactive landscape along the river that interacts with human behaviour. This hybrid of nature and technology is composed of large amounts of fibres that brighten only according to the sounds and motions of the passing visitors.

In addition, colour is often used as a tool for modifying perceptively the space, whether in a punctual way, as in the "Magic Blocks" (Institutul Cultural Roman - Programul Cantemir, ERSTE Stiftung, Bucharest 2010) or in a diffused way, as in the Superkilen project (Topotek, Copenhagen, 2012). In the first case, a limited, symbolic response to a problem that is both huge and serious, the bright optimistic orange unifying the interventions, not only points out but also presents the problematic areas as spaces of opportunity. In the second case the space is conceived as a giant exhibition of urban best practice, a sort of collection of globally found objects coming from the 60 different nationalities of the immigrants inhabiting the area, celebrating diversity and creating a new identity of the public space underlined by the red colour.

A shifting perception of space can often be found in projects using mirroring surfaces, changing the environment according to the density of the people present throughout the day, also disclosing an atmospheric scan of the space. In the new Els Encants market in Barcelona (2014) b720 Fermin Vazquez Arquitectos design a giant canopy clad with triangular facets of polished, gilded stainless steel to reflect the activities below like a 
broken mirror, a kaleidoscopic ceiling. The ephemeral structure of the Serpentine Gallery Pavilion (SANAA, 2009) adopts reflective materials to create a seamless natural landscape mirroring both the park and the sky around it.

Finally, public spaces are designed with a holistic approach involving the perception of different senses, adopting design attitudes typical of the interiors, as in the Beatbox Olympic Pavilion in London (Asif Kahn and Pernilla Ohrstedt, 2012), an experimental fusion of architecture and technology that creates a multi-sensory experience combining technology, sound, and light. The circular walls were covered in ETFE (Ethylene tetrafluoroethylene) plastic pillows that are sensitive to both movement and touch and the 230 red and white cushions that incorporate audio and interaction technology, enabling visitors to create a musical collage of sounds. The Horticultural Spa \& Apothecary Experience (2015), developed by the London firm Loop.pH, is an inflatable plastic dome pumped full of scented vapour to create a gathering space intended to replicate the atmosphere of a traditional bathhouse. In this case also the music was designed in order to create a global experience: in fact the soundtrack will be provided by a sonic artist who generates music from the electro-magnetic emissions of plants.

A second path towards the development of amazing spaces with a strong identity is pushing form and expressiveness of language to the extreme through the reinterpretation of existing traditional materials or new materials.

Computer numerical control machines and digital design allows in fact to obtain tailormade materials as the Ombrae panels that reproduce digital images by using threedimensional pixels or the traditional wire fence which becomes decorative as it can reproduce any kind of pattern typical of lace as in the Bicycle Apple in Alphen aan den Rijn (Kuiper Compagnons, 2011).

Poor materials can be used to fit up spaces that can become manifest to communicate a lifestyle mindful of civic values with regard to the urban space, as in the "Place au Changement" (Change Square) project in Saint-Étienne (2011), in which residents were asked to take part in a project of constructing a new space using durable materials and simple techniques that anyone could manage.

This is evidence of the prolonged debate taking into account the interests lurking behind urban transformations, their economic, political and social effects and the ways in which people can get prepared to influence the destiny of their cities.

\section{Performance}

As the quality of public space in our towns and cities has a positive impact on the wellbeing of residents and visitors, the quest for the performance enhancement in public spaces design embraces all the different aspects of quality and is thoroughly influenced by the principles of sustainability as an essential character of contemporary culture. The control and improvement of environmental comfort of open public spaces is thus achieved also through the rediscovery of natural materials such as water and vegetation, though revisited through new technologies and integrated solutions. The steel structures of the Eco Boulevard in Vallecas (Ecosistema Urbano, 2007) support climbing plants and 
water vaporizers to cool through evapotranspiration processes the harsh summer climate of continental Spain. In Tooley Street, London, a temporary, mobile miniature modular park (WMB Studio, 2015) offers plant-covered seating for passersby providing a shelter against the polluting and noisy traffic and also monitors air quality sending data back to an app and website. Vegetation and water are used not only within environmental comfort strategies but become construction and design materials such as in the MFO-Park in Zurich (Burckhardt+Partner, 2002) creating a new living multi-storey interior, or in Patrick Blanc installations or in the jardín vertical y plaza pública delicias in Zaragoza, (Sicilia y Asociados Arquitectura, 2008): a metal structure containing an accessible hanging garden which hides two flank walls that were an eyesore in the urban landscape. In Herbert Dreiseitl urban parks water and green are not just design features but fundamental instruments to control the hydrology of the place and to create climate adaptive and resilient cities; moreover the irrigation system at the Thermal Orchards in Caldes de Montbui waterways recovery is not just the main focus of the intervention but it also reactivates agricultural activity with both social and environmental sustainability goals.

The research for materials with a high durability has always been a special target of open spaces design, less engaged in program, structure and client as in architectural design but certainly focusing on the effects of weathering and ageing due to climate and intensive use. Technological innovation is oriented mainly towards the augmentation of natural materials to become artificial or the creation of new polymeric compounds assessing once more the preponderance of chemical industry in the construction sector. Wood for example is specially thermo treated to reach the same properties of the tropical species for long lasting street furniture or is modified (e.g. acetylated wood) to optimize its dimensional stability, durability and paint retention to be used in extreme conditions such as in the underwater structure of the Moses Bridge in Halsteren (RO\&AD Architecten, 2011). A new ultra high performance concrete (UHPC) is now commonly used for products, proprietary components or customized projects as it is 6 to 8 times stronger than conventional concrete, ductile, containing metal fibres, and resistant to external aggressions such as abrasion, pollution, weathering and scratching; its special properties are highlighted for instance in the h2o bench, a modular furniture system designed for the main square of Valenciennes in northern France by h2o Architectes in 2008. Also biodynamic and photocatalytic concrete used for paving blocks allow the transformation of harmful organic and inorganic matters into harmless compounds in order to diminish air pollutants.

Self-cleaning coatings can preserve aesthetical quality over time and new varnishes and lacquers have been developed in order to cope with the second type of threats towards the permanence of finishes and installations due to man's action: graffiti and vandalism. High performance transparent panels can replace glass thanks to the durability and the versatility of the applications as seen for example in the polycarbonate San Francisco Transit bus shelters (Lundberg Design, 2009-13), which also embeds a photovoltaic film and provides free public Wi-Fi. The multi-functionality of these canopies also introduces two other important fields of performance enhancement: fruition and energy production. The urban interiors are in fact more and more fitted with cutting edge digital technologies for Wi-Fi connection as well as augmented reality, almost erasing the differences with our 
homes equipment and also improving accessibility for the disabled as in the Responsive Street Furniture project by designers Ross Atkin and Jonathan Scott presented at Designs of the Year exhibition at London's Design Museum in 2015.

Energy production together with resources and materials conservation are clear manifestos of sustainability issues. Though integrated photovoltaic cells are the main feature of covers and canopies in significant urban design projects (e.g. Martínez Lapeña Torres Arquitectos, Photovoltaic power plant, Barcelona, 2004 or the Photovoltaic canopy in Figueres by Rafael de Cáceres \& Xavier de Cáceres, 2011), the industrial design research of PV integrated components (especially street lights) can be considerably enlarged and improved.

If reducing the consumption of material is one of the advantages of special construction technologies such as inflatable structures (e.g. BIG's Bubble cloud inflatable pavilion in Roskilde for the 2016 Music-Festival in Denmark) the environmental impact control through recycle, upcycle and reuse of materials makes the sustainability concept more straightforward. Though some new materials for urban design produced through recycle technologies are yet to be improved from the aesthetical point of view (especially from plastics and tires) reuse and upcycle practices can be witnessed especially in participated public spaces redevelopment initiatives involving citizens through self-build or selfmanagement activities. Old furniture and recycled construction materials were used in the workshop of the Cantiere Barca Project in Turin (raumlabor Berlin, 2013) and also in the Campo de Cebada in Madrid (El Campo De Cebada, 2010).

In the design of temporary pavilions and installations the short life of the construction inspires the use of recyclable or low impact materials such as in the I love Green installation $(2 \mathrm{~A}+\mathrm{P}, \mathrm{Rome}, 2007)$, involving the use of vegetation and rough wood planks. In the MoMA PS1 gallery pavilion (The Living, New York 2014) this concept is brought to the extreme consequences: the structure is built entirely from biodegradable materials; each of the bricks used to construct it were grown rather than manufactured, using a combination of agricultural by products and mushroom mycelium, allowing for its natural degradation and melting within a few weeks.

As the civic character of public space summons the representation of community and citizenship, the use of materials can acquire an instrumental role in terms of communication and promotion for sharing social and environmental values. It's the case of the Stylized Trash outdoor furniture by Designo Patagonia, in Argentina, displaying perfectly clean recyclable paper, tin, glass, pet, nylon, expanded polystyrene, aluminium and tetra-brick, with the aim of helping people understand that rubbish can be a precious raw material.

The prevalence of the ethical message triggers a possible question whether the materials used in the design of these spaces should be simultaneously beautiful (expressive), right (environmentally sustainable) and good (high performance). A further consideration addressing the sense of belonging to be encouraged by urban public spaces, focuses on the material identity of the place. The quest for innovation towards performance enhancement or, conversely, cost control restraints, favouring cheaper foreign stones imports from other continents, also poses consistent questions whether genius loci also involving the use and interpretation of local traditional materials cannot still be considered as a design 
inspiration to convey sense of place and identity. But how can we redefine the idea of identity in an era of globalization?

\section{Notas}

1. "Some are spaces for the public and others are urban public spaces. Public space combines "urban things", physical materials that are able to make perceptible an idea of the city. Hegel said that beauty is the perceptible expression of an idea. And this is the grandeur and difficulty of public spaces. Ground and mud, cobblestones and slabs, asphalt and concrete, wood and leaves on the trees shift here from being generic to components for making urban quality a material thing. Walls, land, lamp posts, doorways, ramps, vehicles, corners and crannies establish the sensations of the mind that bring people into relation". (Solà Morales, 2010)

2. The first contemporary solutions and experimentations date back to Expo '92 in Seville.

\section{References}

Branzi, A. (april 2004). L'autonomia del Design degli interni, AL mensile di informazione degli architetti lombardi, n.4, Milano.

De Giorgi, G. (2005). Nuovi interni metropolitani Interni Urbani, ArchitetturaCittà - rivista di architettura e cultura urbana, Torino, Agorà edizioni.

de Solà-Morales, M. (2010). The impossible project of public space, 2010, (available at: http:// www.publicspace.org/en/text-library/eng/c006-l-impossible-projecte-de-l-espai-public, accessed July 13th 2016)

La Pietra, U. (2013). Interno / Esterno. Per arredare e abitare la città, La Pietra U., Attrezzature urbane per la collettività, Mantova, Corraini.

Lynch, K. (1960). The Image of the City. Cambridge MA, MIT Press.

Docci, M. (2005). Interni urbani, Interni Urbani, ArchitetturaCittà - rivista di architettura e cultura urbana, Torino, Agorà edizioni.

Giuffrè, R. (2005). Fra antinomia e tecnologia. Un problema di spazialità diffusa, Interni Urbani, ArchitetturaCittà - rivista di architettura e cultura urbana, Torino, Agorà edizioni.

Lamunière, J. M. (2005). Interni urbani. Miti generativi, Interni Urbani, ArchitetturaCittà - rivista di architettura e cultura urbana, Torino, Agorà edizioni.

Abstract: Public spaces design is today frequently approached as urban interiors design where to create new artifices and the setting up of a renovated urban symbolism providing the installation and the fitting up of open spaces with methods and concepts akin to those of Interiors. The paper discusses the innovative use of traditional materials or the use of new materials in public spaces design, highlighting two possible trends in the search for the quality enhancement of urban places: expressiveness and performance. Selected 
case studies are disclosed to present how new forms, a stress on perceptual values and the environmental impact and comfort as well as durability are the main goals of material innovation in this field.

Key words: Expressiveness - performance - materials - interior design - public space identity - wellbeing.

Resumo: O Design de espaços públicos é hoje muitas vezes tratado como design interior urbano, onde os novos recursos são criados e um simbolismo renovado é estabelecido proporcionando espaços abertos com métodos semelhantes aos conceitos de interiores. Este artigo discute o uso inovador de materiais tradicionais e o uso de novos materiais na concepção de espaços públicos, incluindo duas possíveis tendências na busca da melhoria da qualidade dos espaços urbanos: a expressividade e o desempenho. São apresentados estudos de casos para mostrar como as novas formas, a ênfase nos valores perceptuais, impacto ambiental, o conforto, e a durabilidade são os principais objetivos da inovação de materiais neste campo.

Palavras chave: expressividade - desempenho - materiais - design de interiores - espaço público - identidade - bem-estar. 
Resumen: En el contexto globalizado actual en el que la fertilización cruzada entre disciplinas y diferentes campos de proyecto se mezcla generando formas, sistemas y procesos, el diseño de Tejidos de Punto puede marcar la diferencia en la producción y en el consumo de los productos.

En realidad, son ideas reales sobre los diversos temas que caracterizan esta área. Actualmente el diseño en áreas muy específicas como diseño de tejido de punto italiano, realizado por artistas, diseñadores, hilanderos, empresas, continuamente entre la tradición y el producto manual industrial, hace de la investigación un desafío realmente complicado. En los escenarios contemporáneos el diseño de tejido de punto es un proceso complejo, que combina antiguas técnicas tradicionales de conocimiento con la experimentación y la innovación tecnológica. Es un desafío que alimenta la curiosidad y el deseo de buscar más.

Palabras clave: Tejido de punto - fertilización cruzada - Innovación - pensamiento de diseño - hilos - materiales.

[Resúmenes en inglés y portugués en la página 134]

${ }^{(*)} \mathrm{PhD}$ in Design, assistant professor at the Design Department, School of Design at the Politecnico di Milano. He is currently the Coordinator of Knitwear design Lab - Knitlab of the Fashion Design Degree at the Politecnico di Milano. His fields of interest are focused on contemporary design with a specialization on Knitwear and Fashion Design.

The essence and beauty of knit lies in the fact that the designer invents everything from scratch; he creates the stitch, the handle, the weight and chooses the colour, deciding on texture and shape at the same time, mastering his own finishings and detailing.

(Edelkoort L., in Sissons J., 2010, Basics Fashion Design: knitwear, Ava Publishing, Lausanne)

A loose thread in a knit is not a defect but a hint of the story behind its presence (Conti G. $\mathrm{M}, 2014$, p. 84). Yarn is not just a collection of fibres - it may be the element that underpins a work of art, a three-dimensional object, a product to wear. It is an element imbued with symbolic values and it is one of the first images introduced even in childhood, with the Brothers Grimm fairy tale Sleeping Beauty, in which the princess pricks her finger with 
a spindle, with yarn thus evoking the world of weaving, knitting, of the handmade, of tradition. Knitwear uses different types of yarn, like wool, cotton and flax, but also synthetic yarns, blends from plant or animal sources. It is perhaps one of the most ancient manual skills in the world. All women, young or old, rich or poor, single or married, have knitted something at some point, from items for a bottom drawer to small pieces for their families.

Knitting requires yarn to be twisted in a special way, tightened at a specific point and then serial repetition of the gesture, only to stop the series with a variation, then return to the multiple reproduction of identical actions. The knitter must be able to follow a pattern. (Silvana Annicchiarico, Tramate tramate, le streghe son tornate, in Dritto Rovescio, Electa Mondadori, Milan 2009, p. 10)

Specifying that there is a difference between knitting by hand with needles, and mass production using linear artisanal or industrial machines, i.e. on a trade scale, we can say that the design challenge posed by knitting lies in understanding how a single yarn can make a desirable, comfortable and wearable garment.

The design has historically been characterized by the habit to think at the project as an inventive act that builds something additional to the existing reality. An idea incompatible with the idea of Central European project as an act intended to change the reality, directing it towards a horizon of order and logic. The attitude of Italian design is to develop an original model of operation based on the interaction with the small and medium industries, with their extraordinary ability to experiment, transforming the "absence" of a unified methodology in a large internal diversification of languages and trends. It's in this way that today Italian design develops new paths and pushes its boundaries beyond the traditional ones. Knitwear is one of these new paths: the knitting project involves many aspects and it allows a high degree of intervention and testing at all levels of the production chain.

In the contemporary design scenarios knitting is a really fertile project area. Even if most of the people think about it as an old-fashioned hobby, reserved to old grannies making ugly jumpers, it's clear that today knitting is a very interesting challenge from a designer point of view.

\section{Dress design in the contemporary scenario ${ }^{1}$}

Too often the study of dress and fashion has been undertaken with a simple iconic approach, limited to a purely aesthetic discourse between the creator and the user. In this way the analysis and consequent reading result in fashion appearing decontextualized from the mechanisms that induce its ideation, production, and consumption. The common concept of "fashion" is still centred on unrestrained consumption, beauty, luxury, elegance, and distinction: a sort of "magic world", considered by many to be ephemeral, in which "image" is the only fundamental element. 
Fashion details today represent speech, a sort of continual "narration" between product and consumer. If it is true that from the 1960s onwards we no longer speak of Fashion in the singular but of Fashions in the plural and since the 80s we no longer speak of style but of styles, always in the plural, then today we can talk about the "style details" that each brand has gradually built up. Fashion products, at least designer products, are today characterized by the ability to express content of a "cultural" kind: this has gradually become the constant characterizing element. Objects become icons that testify each culture's origin; design becomes a necessary interface between tradition and modernity. The role of design to become an engine for innovation through the reinterpretation of the local's cultures and crafts productions. In the contemporary design scenarios knitting is a really fertile project area. Even if most of the people think about it as an old-fashioned hobby, reserved to old grannies making ugly jumpers, it's clear that today knitting is a very interesting challenge from a designer point of view.

Knit design involves many aspects and allows intervention and experimentation in every part of the production chain. It's a complex project that matches an ancient know-how with design experimentation and technological innovation. Objects become icons that testify each culture's origin.

Their power is conveyed through memory. Indeed, its narrative can combine archetypical images and future suggestions within a fascinating present. This new paradigm provokes new experiences and interdisciplinary encounters, like between architecture and medicine, or between fashion and crafts.

\section{The research, the design, the knitwear}

The design of knitwear is a rather new field within the broader view of fashion design education.

Unlike the latter, it has almost never been treated as a sector that can conduct design research although in Italy, as we have seen, it represents one of the oldest manufacturing industries. Industrial research in this area is developed mainly in the spinning mills, one of the areas of the Italian manufacturing sector that still counts with different excellences in Italy; the type of search is often of industrial one, mainly applied to fibers and yarns and to their consequent performances in relation to the final product that they will become. Today, it's possible to intervene on the yarn quality, its composition, its weight to modify the hand, wearability, the comfort directly on the skin. The research may be historicalartistic, in other words it's possible to analyze a range of experiences of the past that tell certain experiments, which then became textile innovations. It is also technologic linked to the evolution of industrial machines that are used in this sector. In fact the production of knitwear, unlike clothing fabric, appears directly connected and conditioned in its marketing characteristics of style, by the requirements of the available machinery and looms; therefore, Italy has been one of the leading countries in this field starting with a production made in the most part with flat knitting machines operated by hand, in 1950, passing to the great boom of the construction of electronic machines and the introduction of the circular ones, and today where electronics, combined with advanced technology, 
allow machines to simulate the hand processes directly on the drapes that are made mechanically.

\section{Some interesting stories}

To speak of a textile product, then, we cannot disregard its soul, as represented by thread and the different qualities of yarn that exist; it is a product that lives in the contemporary world and, since technology has permeated this particular field as well, undergoes various treatments to increase its performance characteristics. The finishing treatments can be divided into two main groups: there are those designed to improve technical qualities such as antistatic, crease-resistant, non-shrink, anti-infiltrating, impermeability, waterproofing, fireproofing and mothproofing treatments. Or else there are those treatments that affect the appearance of the fabrics and sometimes even disguise the original material such as ironing, dyeing, scouring, felting, flocking, coating, embroidery, countergluing and lacing. Especially in the period of Italian autarchy, the development of new fibres and yarns will ensure that thoughts will turn to dressing in a different way; it will no longer be necessary, because of their total or partial absence, to wear garments made with the better-known yarns like cotton, wool or silk, but gradually innovative fabrics will be placed in the market, including those stemming from previously unknown production processes. The invention, for example, of the spinning centrifuge in 1900 provided a major contribution to the development of the processing of viscose, destined to become the world's most popular man-made fibre.

SNIA is founded in 1919 as the Società di Navigazione, Industria e Commercio, and in those years acquires control of the artificial fibres industries Anonima Viscosa Pavia, the Unione Italiana Fabbriche Viscosa in Venaria Reale and the Società Italiana Seta Artificiale, until it divested its maritime activities completely in 1929 to become one of the largest groups controlling the production of artificial fibres in the world.

SNIA Viscosa will be the producer of the first Italian casein fibre, which was even celebrated by Filippo Tommaso Marinetti in The poem of the milk outfit, 1937 will see the introduction of Cisalfa, "the new fibre for woollens which presents a number of economic solutions for the department stores that would allow a still agricultural Italy to dress to impress" 2 . From the point of view of "fashion", knitwear will become an area of research for Luisa Spagnoli, one of the first women to play a very important role in this area: in the suburb of Santa Lucia in Perugia she will open her home-workshop in which she will create a fibre known as Spagnoli Angora, a successful experiment in the autarchic period in which the fulcrum lies in the "production process": the angora rabbits are not killed or even shorn, but lovingly combed to derive the Angora wool which will then be spun to become the high-quality material for beautiful shawls, boleros and sweaters.

With nylon and polyester we witness another major innovation in the way of dressing and producing clothing: with nylon, introduced in Italy in the late forties by Rhodiatoce, a subsidiary of the Montecatini Group, the use and relationship with the body of women's stockings changed. The invention of the polyester in the fifties radically changed the textile industry by introducing fabrics that were easy to maintain and possess a "memory", that 
is, that are able to quickly resume their original shape. As underlined by Garofoli (1991, p. 44 ), polyester, whether pure or in a blend with cotton, and wool and in silk uses, gave rise to the first "wash and wear" clothes because they needed almost no ironing.

\section{Re-Active H2Dry and K-Wool H2Dry}

Nature has given us the best wool. Human ingenuity has transformed it into something unique, able to push the performance boundaries of a pure wool yarn. Re-Active H2Dry and K-Wool H2Dry are an ideal synthesis between artisan craftsmanship and technological research, two yarns of superior technical properties, with an excellent aesthetic quality ${ }^{3}$.

Technological research passes through here too, from the desire to turn a thread into something unique and special; Re-Active is a yarn in pure superfine wool (17.5 micron), and $\mathrm{K}$-Wool is a yarn in extra-fine pure wool (19.5 micron) both born from the continuous research developed by Zegna Barney Lane Borgosesia in its laboratories. H2Dry is a special treatment that allows the skin to breathe, whisking moisture away from the body. The two yarns together with this particular treatment permit knitted fabrics to be worn more comfortably directly against the skin, whether a polo shirt or a dress shirt, because the surface of the body stays perfectly dry, giving the garment a surprising drying speed.

Knitwear is certainly one sector that understands the need to understand the 'spirit of the times' and thus it is the thread, the soul of any knit, not to mention any fabric that we wear, which is the very subject of research for Zegna Baruffa Lane Borsosesia: "The tests performed in the laboratory at the Turin Polytechnic, according to the international Moisture Management Test AATCC 195-2009, demonstrated the exceptional ability of Re-Active and K-Wool to pull moisture from the body to the exterior of the garment". If the wool itself already has the right features, Re-Active H2Dry and K-Wool H2Dry enhance it by creating wrinkle-free garments. For example, a knit packed in a suitcase for a long trip stays intact and remains fresh, with no traces of wrinkles or creases. The innate elasticity of the fibers, enhanced by H2Dry finishing, make the two yarns even more flexible and lighter both in classic and more elaborate workings, rendering the fabric more comfortable and wearable; a practical and concrete advantage for every day clothing: every garment is always ready to be worn.

Just like how in the early'70s, technological research allowed for the creation of Cashwool ${ }^{\circledR}$ (extra-fine Merino wool) currently stocked in 300 colors, today H2Dry represents the future of the knits, expressing contemporary style and addressing unspoken needs and desires of a customer that is constantly evolving. 


\section{Reflective and phosphorescent yarns}

The companies Ledal S.p.A. and Sinterama S.p.A., active with technological research on fibres, produced reflective and phosphorescent yarns. The first developed Lamè Litelife, a security yarn that ensures visibility in the dark and is ideal for casual wear.

It's made with films containing glass pearls that act as spherical lenses bouncing incoming light to the original light source: a yarn to keep in mind while designing outerwear, suits, sportswear in general.

The second has obtained a phosphorescent yarn, the Ghost, that is charged in a wide spectrum of visible light and even more through ultraviolet light and is discharged in the dark by emitting a visible light. The intrinsic phosphorescence of Ghost, thanks to a new generation additive, is ten times more brilliant and durable than normal phosphorescent pigments to zinc sulphate. It has several uses in clothing and decor.

These yarns are used in the development of a Bachelor's degree Thesis at Politecnico di Milano, within the Knit Design Lab. (Figures 1, 2, 3)

\section{Dryarn}

Dryarn is a special polypropylene microfiber produced exclusively by Aquafil, an Italian company specialized in research, development and production of synthetic fibres since 1970. Thanks to its unique structure, Dryarn is a light yarn $(10 \mathrm{~km}$ of yarn weigh only 1 gram), it floats on water, is $100 \%$ recyclable, waterproof and temperature controller, which makes it particularly suitable for athletes, especially in intensive activities and muscle strain.

Dryarn ensures a high level of hygiene: it cannot be attacked by moths, insects or other microorganisms, secondly, thanks to the high surface tension of microfiber, the yarn is able to trap mold or bacteria. That's why, in addition to being adopted as yarn for Italian national ski team athletes' uniforms, it has been used for creating gowns and other work wear for the medical field.

\section{Solvron}

Solvron is a synthetic yarn belonging to the family of polyvinyl alcohol (PVA) yarns exclusively produced by Nativy Co., Ltd. of Tokyo which dissolves when immersed in hot or boiling water without the aid of chemical agents.

This feature makes Solvron an ideal yarn to intervene in the critical phases of the process of garment construction, and to solve some of the problems that occur during processing. It can be used as support when blended with low resistance yarns, which tend to break if machined by themselves. Once all the fabrics are done without breaking, Solvron dissolves and remains the original yarn. It may be useful for speeding up operations that usually require manual intervention, such as the assembly of various pieces of a sock through the elimination of the separation, necessary for the achievement at the machine: if Solvron is 
used for separation it won't be needed to remove it by hand but just dip your socks in hot water.

Immerging Solvron in cold water, and gradually raising the temperature, will make it shrink without breaking or flaking. Only when the water reaches the required temperature Solvron will melt.

\section{Conclusion}

"Excellence is achieved when good taste, technique and experience are able to express with balance and stability the qualities of a selected raw material".

Alberto Barberis-Canonico

Knitwear Design is a quite new area of Fashion Design. Unlike the latter it has never been treated as a research field even if, in Italy, it represents one of the most ancient industrial sectors: the collections of Italian brands like Missone, Malo, Falconeri are 100\% made by knitwear and in the latest years knitwear has a rate of approximately $35-40 \%$ in the collections of several Italian and international brands.

The research in this area comes mainly from spinning industries: this manufacturing sector has yet different realities of excellence in Italy, especially in geographic areas around Biella, in Piemonte, Carpi, in Emilia Romagna, Valdagno, in Veneto.

It could be an industrial kind of research, which aims to intervene on the quality of yarns, on its meshes, its touch, its fit and comfort when put directly on the skin.

Who is then responsible for projecting (from the Latin "pro-jacere", "throw over") from the present known, with knitwear design has one more tool: innovation is sometimes told as something different from everything there was before. Think instead that, in this sector, the innovation can also be given by changing the point of view; if Proust said that "the real voyage of discovery consists not in seeking new landscapes, but in having new eyes" then paraphrasing him we could say that in the fashion industry the real discovery is not to present a collection of clothes different from season to season but is to understand how to move from tradition, in this case the Italian one, through the tools and design methodologies to innovate "from inside" a complex and multifaceted sector. Innovation is not a revolution, it's a way to deal with all sorts of problems day after day. The goal is to make it even more efficient than it already is, providing cutting-edge standards of excellence.

Innovation so as knowledge to reinterpret the past by reading the zeitgeist; innovation as the ability to act on materials, starting from their characteristics, and then upset them and create something unexpected. Finally, innovation through research in the project Culture without constraints or prejudices. 


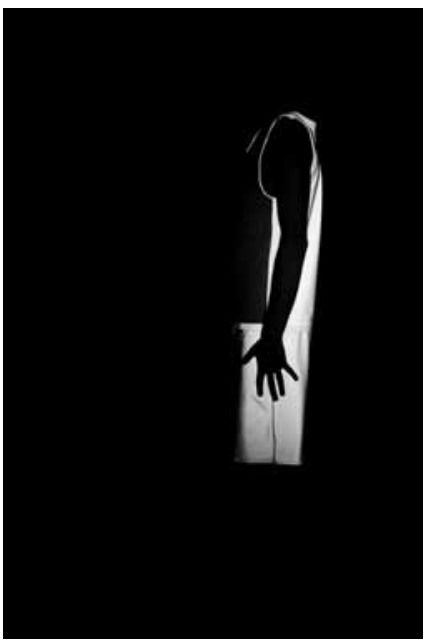

Figure 1.

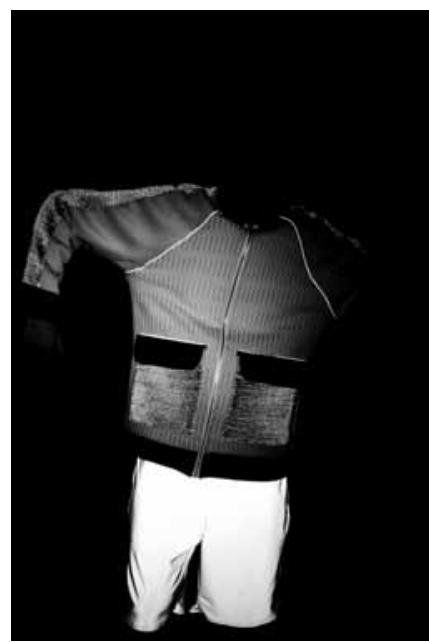

Figure 2.

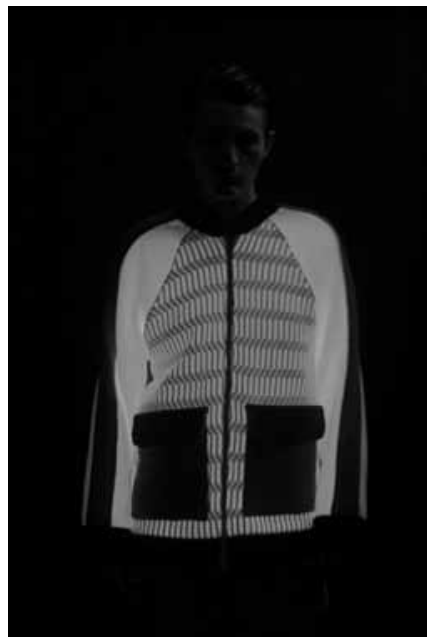

Figure 3.
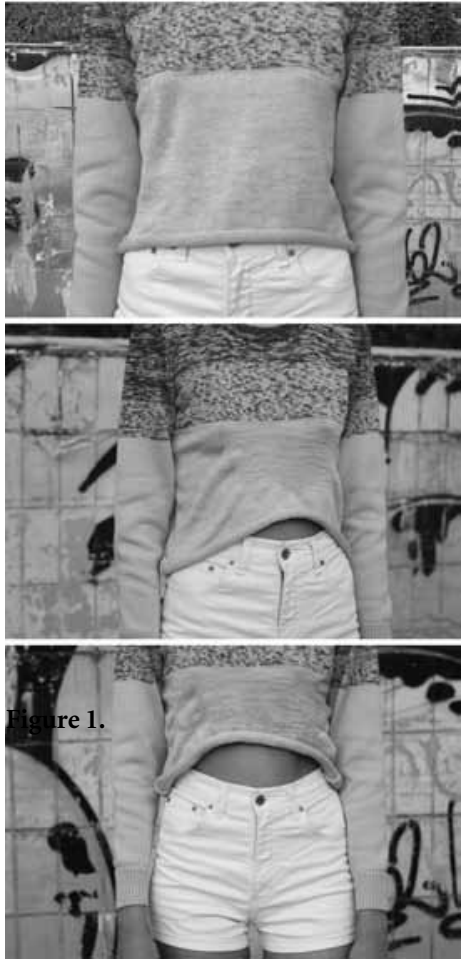

Figure 4.
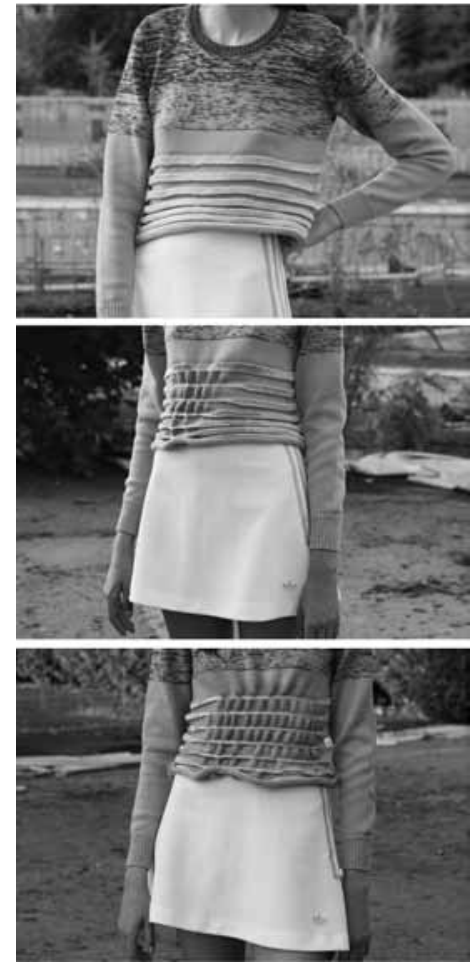

Figures 1, 2, 3: "Urban Glare", Bachelor's degree Thesis in Knitwear Design by Anna Paola Braga, Politecnico di Milano, July 2015.

Figure 4: The pictures refers to the experiments carried out in the Knitwear Design Lab at Politecnico di Milano during the development of a Master's degree Thesis in Design for the Fashion System, by Alessandra Cavagnoli, July 2015. 


\section{Notes}

1. Many of the parts of this paper come from different theoretical reflections published by the author in: Sul filo dell' innovazione. Progetti e visioni tra moda, tessuti, filati, in (catalogo della mostra) AA. VV. Textile Vivant. Percorsi, esperienze e ricerche del textile design, Editoriale Silvana Spa, 2014.

With Martina Motta, Teaching Knitwear Design: Design Practice for Traditional Manual Knowledge Innovation, 10th International Conference on Design Principles and Practices and the Design Principles and Practices knowledge community, PUC Rio de Janeiro, 2016. With Silvia Amorosino, Narrative design objects. Towards a multidimensional society valorizing the "heritage". "Sealing on a DressBone" project,1st International Conference on Environmental Design 06th/07th of March 2015, Agrigento.

With Martina Motta, Knit Design. Ovvero progettare con un filo, Ottagono, № 268, Marzo 2014, Milano.

With Federico Poletti, Costanza Rinaldi, Maglieria Made in Italy Knitwear. Stories and Talks, Silvana Editoriale, Milano, 2016,

2. B. Giordani Aragno, "Storie sul filo di lana", in V.A., Maglifico! 50 anni di straordinaria maglieria Made in Italy, Skira, Milan 2012, p. 18.

3. In "The H2dry By Zegna Barney Lane Borgosesia", Conti G.M., Technological Research as Applied to Yarns, in Conti G.M., Poletti F., Rinaldi C., (2016), Maglieria Made in Italy Knitwear. Stories and Talks, Silvana Editoriale, Milano, p. 189

\section{References}

Aa.Vv., Maglifico! (2012). 50 anni di straordinaria maglieria Made in Italy. Milano: Skira. Annichiarico, S. (2009). Tremate tremate, le streghe son tornate, in Aa.Vv. Milano: Dritto Rovescio, Electa Mondadori.

Caoci, A.; Lai, F. (2007). Gli oggetti culturali. L'artigianato tra estetica, antropologia e sviluppo locale. Milano: Franco Angeli.

Conti, G.; Motta, M. (2014). Knit Design. Ovvero progettare con un filo, Ottagono, $\mathrm{N}^{\circ} 268$, Marzo.

Conti, G. M.; Colonetti, A. (2014). Design \& Moda. Firenze - Milano: Giunti Editore S.p.a.

Conti, G. M., Vacca F. (2008). Traditional Textile on Fashion Design. New path for experience. Paper for "Changing the Change. Design, Visions Proposals and Tools: Torino 2008", Proceedings "Changing the Change. Design, Visions Proposals and Tools", Umberto Allemandi \& C.

Conti, G. M.; Zanolla Mancini, A. S. (2014). Strategic Analysis on the Multan Handicrafts. Springer, Springer international Publishing Switzerland.

Davis, F. (1993). Moda: cultura, identità, linguaggio. Bologna: Baskerville.

Dorfles, G. (2008). La (nuova) moda della Moda. Milano: Costa\&Nolan.

Durante, V. (2004). Sportsystem, the fashion performance. Caerano San Marco (TV); Danilo Zanetti Editore.

Fiorani, E. (2005). I panorami del contemporaneo. Milano: Lupetti. 
Fiorani, E. (2000). Il mondo degli oggetti. Milano: Lupetti.

Frassine, R.; Rubertelli, M.; Soldati, M. G. (2008). Textile design. Materiali e tecnologie. Milano: Franco Angeli.

Kennedy, S. (2010). Vintage Swimwear, a History of Twentieth-Century Fashions. Londra: Carlton Books Ltd.

Micelli, S. (2011). Futuro artigiano. Venezia: Marsilio.

San Martin, M. (2010). Materiali innovativi per la moda. Modena: Logos.

McGregor, S. Traditional Scandinavian Knitting. Lusekofte: Dover Publications Inc.

Paris, I. (2006). Oggetti cuciti. L'abbigliamento pronto in Italia dal primo dopoguerra agli anni settanta. Milano: Franco Angeli.

Poiret, D. E. (2003). Tennis Fashion. NY, USA: Assouline Publishing; s.n.

Udale, J. (2014). Fashion Knitwear. Laurence King Publishing.

\begin{abstract}
In the actual globalized context in which the cross-fertilization among disciplines and different fields of project mixes together forms, systems and processes, Knitwear Design can make the difference in the production and in the consumption of the products.

Actually they are real insights on the various issues that characterize this area; today designing in very specific areas such as Italian knitwear, made of artists, designers, spinners, companies, perpetually poised between tradition and manual industrial product, makes research a really complicated challenge.

In contemporary scenarios knitwear design is a complex process, combining ancient techniques of traditional knowledge with experimentation and technological innovation. It's a challenge that feeds the curiosity and the desire to seek more.
\end{abstract}

Key words: Knitwear Design - Cross Fertilization - Innovation - Design Thinking - Yarns - Materials.

Resumo: No contexto globalizado de hoje, em que a fertilização cruzada entre diferentes disciplinas e áreas de projeto é misturada gerando formas, sistemas e processos, Design de tecidos pode fazer a diferença na produção e consumo de produtos.

Na realidade, são ideias reais sobre várias questões que caracterizam esta área. Atualmente o projeto em áreas muito específicas, como ponto de design de tecido italiano por artistas, designers, spinners, empresas continuamente entre tradição e manual do produto industrial, torna a pesquisa um desafio realmente difícil.

Em cenários de design contemporâneo, tricô é um processo complexo que combina técnicas tradicionais antigos de conhecimento através da experimentação e inovação tecnológica. É um desafio que alimenta a curiosidade e o desejo de procurar ainda mais.

Palavras chave: confecção de malhas - a fertilização cruzada - inovação - design thinking - fios - materiais. 


\section{Slow + Design as sustainable sensoriality: an innovative approch aimed to explore the new relationships among design, innovation and sustainability}

Giulio Ceppi ${ }^{\star}$

\begin{abstract}
Resumen: A partir de la experiencia de Slow Food y su éxito internacional, el autor, junto con Giacomo Mojoli (ex vicepresidente de Slow Food) comienza a cuestionar el transferimento del enfoque slow en la práctica del diseño.

Esto significa discutir si puede y cómo puede el diseño contribuir al campo de los sistemas y dirigir las transformaciones en curso hacia formas sostenibles de vivir y producir. La expresión Sensorialidad Sostenible quiere combinar ambos mundos de sensorialidad y sostenibilidad, dimensiones conceptuales y operacionales del diseño, pero profundamente practicadas en las actividades de los autores como arquitecto y diseñador, y explicitada en muchas prácticas de enseñanza y en muchos casos de estudio de diseño.
\end{abstract}

Palabras clave: Sostenibilidad - Sensorialidad - Enfoque slow - Innovación - Diseño de sistemas - Cambios en la práctica.

[Resúmenes en inglés y portugués en la página 146]

${ }^{(*)}$ Architect designer, $\mathrm{PhD}$, researcher and assistant professor at the Design School of Politecnico di Milano, and member of MADEC at Design Department. His activities are focused on sensorial design, development of new materials and technologies, and on design strategy. He was the coordinator of the Domus Academy Research Center in Milan and senior design consultant at Philips Design. In 1999 he founded Total Tool Milano, a design network with offices in Milan, Buenos Aires and Tokyo, consulting and designing new business ideas for international group.

\title{
1. Reason Why
}

\subsection{Taking the slow culture in account}

Our departure point was the Slow Food experience. Slow Food has met with great and growing international success which, contrary to dominant trends, has demonstrated the real possibility of linking food quality research to the safeguarding of typical local products and to the sustainable valorisation of the skills, expertise and organisational 
models from which such products originate. In so doing it has played an important role on two complementary fronts:

1. firstly, in regenerating such a precious collective good as the biological and cultural diversity of local food production

2. secondly, in proposing and initially setting up new food networks.

However, though the specific scope of Slow Food lies in these new food networks, its experienceis of more general value and is significant for those working in other fields and addressing other problems. Its experience is encapsulated in the new meanings that, thanks to its activities, have been attributed to the adjective "slow" and that we can refer to as the "slow approach".

Above all, the slow approach means the simple, but in current times revolutionary, affirmation that it is not possible to produce and appreciate quality if we do not allow ourselves the time to do so, in other words, if we do not activate some kind of slowdown. However, slow does not only mean this. It also means a concrete way of actually putting this idea into practice. It means cultivating quality: linking products and their producers to their places of production and to their end-users who, by taking part in the production chain in different ways, become themselves coproducers.

So, the slow approach outlines a new production and consumption model that is at the same time both subversive and feasible. While clashing head on with the ideas and practices of today's prevailing globalisation, it can be enacted locally both immediately and, as Slow Food has proved, successfully.

In our opinion, the great potential of the Slow Food experience needed to be better understood, both in terms of its nature as a strategic project for the development of new food networks and, as is of greater interest to us here, in its more general potential as a contribution to the definition of new ideas on quality, well-being and development models.

\subsection{Design as a continuous change}

Design is changing. The issues it addresses are changing. Its tools are changing. Whether aware of it or not, the people who design are changing. There is nothing strange or new in this: in a society in transformation, design, by its very nature, cannot but change.

At the same time, the way this change in design is taking place is contradictory: on one hand it is becoming more and more spectacular in its actions and in the media role of its actors, with design becoming an integral part of the communication system and (some) designers taking part in the star system. We are by now familiar with this spectacular evolution in design, but as we said,something else is also happening, something that is very interesting. Briefly, we can observe that a "new design" is emerging: a design that adopts a systemic view, that looks at the complexities of social networks, develops a capacity for listening and interrelates with the creativity and diffuse entrepreneurship that characterise contemporary society. In so doing it becomes an active part of the 
transformation processes underway and in those that must take place, confronted as we are with the enormous issues at stake.

This second line of evolution is, in our opinion, what lends design a potentially strategic role in the definition of new ideas of well-being and of ways to achieve it. At the same time, it proposes a new idea of a design potential that is as yet scarcely understood. This is not only because it materialises in complex activities that are not exactly easy to photograph, but also because it breaks so deeply with tradition that many of those who successfully "design" in this emerging mode are neither designers nor see themselves as such. Vice versa, many who are indeed designers, do not recognise these activities as being a true design mode.

Consequently, we need to facilitate a debate that makes the nature and potentiality of this "new design" clearer. This means discussing whether and how design can contribute in the field of systems and steer the transformations underway towards sustainable ways of living and producing.

\subsection{Why Slow+Design}

For numerous reasons we thought, since the end of the 90's, that it was opportune to bring these two themes of slow approach and new design together for the mutual support they can offer each other: the slow approach can open up new opportunities for design while this new design can bring useful conceptual and operational tools to the slow approach. Before expanding on this statement some preliminary remarks are due. The encounter between design and Slow Food has already taken place. In particular, thanks also to Slow Food, the design community has long recognised the cultural value of food and has become particularly dynamic in this direction and towards associated places, services and products. However, in our opinion, there are worrying aspects in the way the phenomenon has been presented so far.

The risk we see is that design interest in food field may be limited to its spectacularisation, i.e. to the superficial designing of food experiences as an end in themselves, and to the spectacular consumption of what remains of a precious historical heritage of skills and expertise, flavours, places and social customs. In other words, the risk is that the meeting of design with food may develop in the opposite direction to what the Slow Food experience, if correctly interpreted, is proposing. In so doing we also risk losing the possibility of using the fundamental lessons that Slow food has taught us in other fields of instruction i.e. what we have called the slow approach.

So, the convergence of slow approach and design merits further study. This means that Slow Food must be seen as an extraordinary example of "de facto design" from which the designer (i.e. the "explicit design") community has much to learn and vice versa, that new design must propose and bring to light skills and abilities able to foster the consolidation and extension of the slow approach. 


\section{Project experiences}

\subsection{The match between Primary Design and Ecodesign}

The Sustainable Sensoriality expression wants to combine both worlds of sensoriality and sustainability, conceptual and operational dimensions of design, perhaps too long disjointed and not communicating, but that I have had the occasion to deeply practice into the casualty of my career as an architect and designer. I will not make it here, however, the subject of a theoretical or conceptual discourse, but I want to give a simple tale of what happened through experiences.

On one hand my experiences in the world of sensory quality and the design of the subjective variables, started with the students of Clino Trini Castelli and Antonio Petrillo, at Domus Academy Master programme in the mid-80s in the Primary Design classrom. In the coordination of the Domus Academy Research Centre, I was able to experience the design and enhancement of sensory qualities to new materials (Abet Laminati and Lorica projects), the definition of quality perception of artificial environments like auto (Bertrand Faure Automobile project) rather than control rooms in power plants (Mitsubishi Heavy Industries). In addition, through pilot projects, such NEOLITE for Assoplast about the identity and performance of recycled plastics from collection of municipal solid waste, they were anticipated and insights in a nutshell some of the arguments on traceability that we will better undestood later on.

On the other hand there are my experiences between principles and pragmatic formulations on EcoDesign and Design for Sustainability, through many authors, texts and testimonies that helped us to understand the complex, cyclical and systemic value of our environment. In 1994, the environmental issue exploded in Italy, and I was appointed to set the Design section of the first exhibition on aspects of environmental sustainability at the Mole Antonelliana in Turin.

Consequently I participated to many initiatives, from 18th Milan Triennale (il giardino delle cose) as well thanks to the NationaI Institute of Bio-architecture: I have often been involved in research projects and exploration around the concept of sustainability, as it happened for example also in Solid Side project with the idea of minimum goods. However these worlds and research proceeded in a parallel way: the first dimension is exploring the sensory qualities and criteria of phenomenological enjoyment of our artificial landscape, while in the second were defined criteria and attention to ensure ethically and pragmatically, a better world, able to withstand the increasing complexity of production logic and consumption.

At the center of the process it was always placed the individual and the quality of its artificial environment, but in the first case the focus was on experiential and individual processes, while in the second those productive and social.

I should thank my next experience from 1997 to 2000 within Philips Design and mainly the attitude of Stefano Marzano's visioning project team, if I began to glimpse the close connection between the two faces of the same coin, to combine aspects of perception and cultural links with the technical dimension and management, sensory and politics, phenomenology and business. 


\subsection{Exploration of the SLOW model extensions at the Design Faculty of Milan Politecnico}

Returning now to the empirical definition of the concept of Sustainable Sensoriality, it is certainly not by the sum of two terms, rather by the theoretical merge of two disciplinary worlds, or just listing the heterogeneity of my professional experiences, that we create a new design dimension.

So the story starts to produce a summary, after my meeting with Giacomo Mojoli, when he was vice president of Slow Food.

In 2001, following the provocative reflections useful for the japanese exhibition Design as Lifestyle in Kobe and Yokohama, where I invited Slow Food to represent the category of Leisure time into the exhibition (direction by Andra Branzi, setting design by Toyo Ito), we decided to explore some more about of the issues raised together, in a new and unprecedented joint educational activities: we orchestrated a project laboratory at the Faculty of Design of Politecnico di Milano (Academic year 2001/2002 ) called SlowLife, together with Aristide Barone, designer manager of Mares.

We identified as design theme the "slow qualities": the sensory and cognitive understanding of the processes experienced by the consumer, in tourism and into the virtual world that anticipates the experience, defining a format of travel agencies intended as "portals of slowness". I still remember this workshop as one of the happiest and more surprising among those I carried in more than 20 years of teaching experience at the Politecnico di Milano: several of my following design partners, such as Stefano Mandato, emerged from this unique opportunity, between refined tastings of Barolo Chinato and chocolate, charismatic lessons from the free diving world champio.

Later on, in 2003/2004, with Giacomo we repeated the experience during the Bormio 2005 Ski World Cup and Torino 2006 Olympics, working with students on how a global formats, such as World Cup or the Olympics precisely, could in fact serve to discover, evaluate and communicate local dimensions of product and specific sensory experiences. Also on this occasion, besides the tasting of the Valtellina Sfurzat or understanding of tactile quality in a Zegna cashmere, it has revealed how much local identity, submerged and not valued, it can explode and become tangible if you manage to make it traceable, traslating processes into forms not necessarily complex and airtight.

\subsection{Extending the Slow approach from Politecnico to other institutions and partners}

As a corollary on our educational experiments, with Giacomo Mojoli we published some articles that appeared in Lineagrafica magazine: Slow Communication and Slow cities. The aim was to identify and describe, with cases and concrete examples, the obvious transmigration of typical values from the Slow Food philosophy into other sectors.

I remember that the same issue about the valorization of local identities, it was part of a series of interesting projects along with Ampelio Bucci brought forward in the second mid-90s in the Master in Design Direction of Domus Academy, making students work, after a year of full internationalization in the Milano design world, on their own places of 
origin and on their cultural roots, inviting them to find a business idea that exploit local resources: landscape, crafts, gourmet products, materials, plant or animal species...wete intended as design objects.

This issue was also addressed in a seminar (organized by myself and Giacomo Mojoli) at Domus Academy in 2004 into the first Master in Business Design, with the participation of companies such as Zegna, Mares, Barilla, and then further developed into an interesting thesis presented at the Politecnico di Milano, entitled Slow Design - from the preservation of material culture to design paradigm, conducted by Guido Parlato, who was a student in our first workshop. It looked like we were to closing a loop.

So the final consequence of all these action its was the international seminar we organized putting together the main design schools in Milan (Politecnico di Milano, Domus Academy, Istituto Europeo di Design) in 2006: we wanted to help to clarify both the nature of the slow approach and the potential of the new design mode, putting them to the test by confronting problematical issues and real, significant cases.

The seminar was organised in sections where the general theme was introduced and developed along 3 lines of reflection, with the presentation of typical concrete cases:

- The valorisation of local resources and the distributed economy, relevant to local development and its new economy facilitators;

- Transparency in production systems and de-intermediation, relevant to the extended development of new producer and co-producer networks

- Product experience and sustainable sensoriality, relevant to quality and its social and environmental sustainability.

Among the subscriber of the SLOW + DESIGN manifesto, A slow approach to distributed economy and sustainable sensoriality, we do include: Alberto Capatti, Giulio Ceppi, Aldo Colonetti, Ezio Manzini, Anna Meroni and Giacomo Mojoli.

Sustainable sensoriality has reachen its thoeretical peak.

\section{Case histories}

Designing new relationship to envision innovation through sustainable sensoriality.

Sustainable sensoriality means today to develop and built new scenarios and to generate new behavioural attitudes, as this is not trustable or builtable just pushing technologies or generating new business strategies.

The sociocultural issue is the real and unique link to innovation and the acceptance and deep understanding of overall processes are the only tools and leverages that could guarantee satisfaction and feasibility.

According to this vision, where social actors and stakeholders are the key to success, design is a fundamental ingredient to the innovation process itself, it is the fuel for the eco-business where people have to trust and share, to modify their habits and produce a new attitude and culture. 
Envisioning new services, new behaviours through communication and new spaces and architectures, finding the right aesthetics and interface to talk to people: this is what ecodesign is today, not the application of technical and engineeristical rules form some green manual or eco-dictionary.

Here you have some case histories and concrete practice, starting from the 90's (let's say in parallel with Slow Food, without consciuosness maybe...)

\subsection{Silea power plant in Lecco (1995)}

To build an office addiction to an incinerator plant, effected by the so called NIMBY sindrome (Not In My BackYard), as in the SILEA case, does not mean to built just a Zeroimpact architecture (one of the first realized in Italy), but to generate a relational platform, to convey and produce people energies into new channels, to relate the external world with the inner problems of the company.

The eco-park, generated using hot water coming from the chimney, means a place of educational value and a relational platform open to the local citizens, an accessible and free place to interact with the local community as well as with specific actors (biologists, gardeners...) to transform energy into life, and viceversa.

\subsection{Arinaga wind park in Canary islands, 1999 (E)}

To understand the visual impact of something thought as absolutely clean and sustainable, as it happens for an eolic park, it means for UNELCO (the local energy provider) in Canary Islands to give a different potential to their business. Analysing the different strategies and opportunities in term of color matching and balance of the visual pollution of these big environmental structures, we did create a new path to make the local communities feel as they were the real owners of the technology, not viceversa, as it happens too often.

After 2001, together with Giacomo Mojoli we developed several projects in a 4 hands modality, always based on sustainable sensoriality approach, such as:

\subsection{Womb glass for Averna (2006)}

The design of an amaro liquoer tasting glass was coincived on an experience based research aimed at enhancing amaro liquoeur Mediterranean qualities and let the customer get closer to the product by mean of a multi-sensorial ritual.

Presentation and communication event at Milano Triennale used a strong iconographic apparatus, including rosemary -scented cards sas memorabilia for guided tasting. When Campari company bought the sicilian brand from Averna family in 2015, a strong advertising campaign featuring the american actor Andy Garcia and based on Womb ritual has been activated and promoted on different media, from television to Facebook. (Figure 1) 


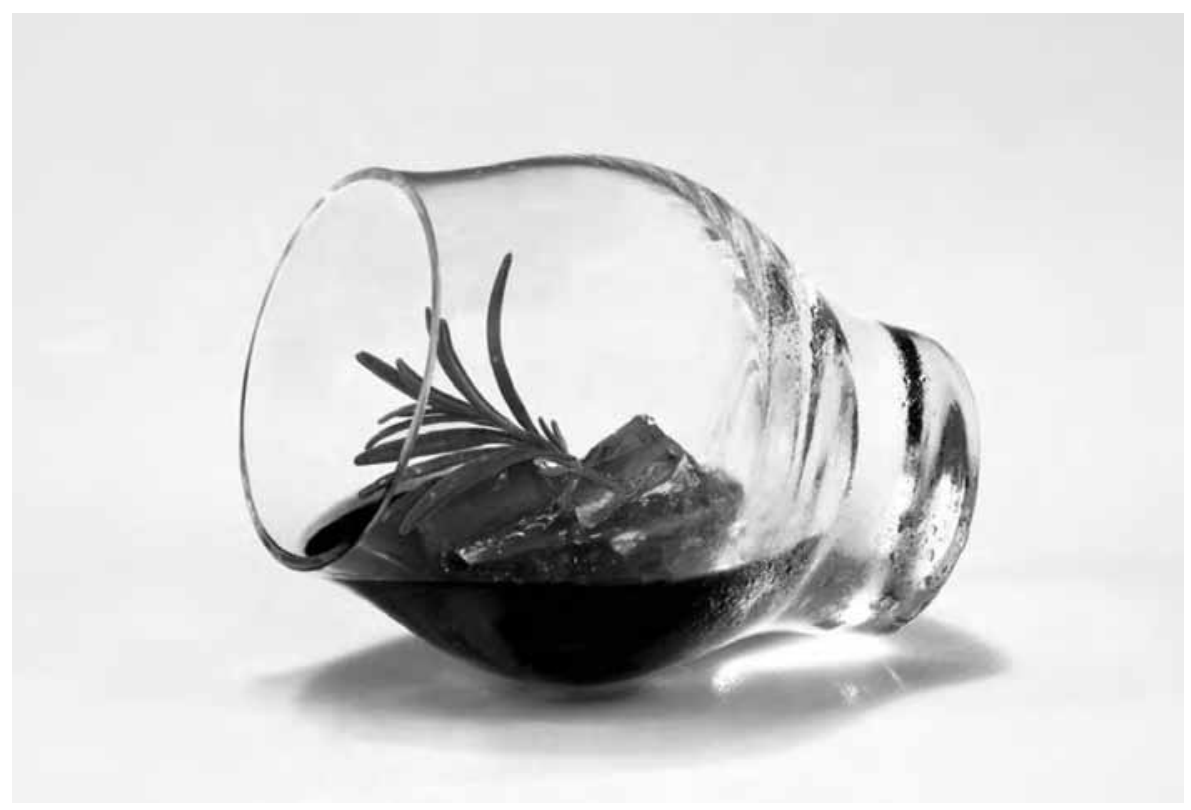

Figure 1. Womb glass for Averna.

\subsection{Ottagono dei valori identitari del nuovo artigianato for Confartigianato (2008)}

The project developed with Confartigianato is aimed at interpretating the new role of craftmanship according to the global market and the new developing scenario between craft production and industrial competition.

Eight polarities have been outlined: each one is based on a couple of values helping craftsmen to find their emerging role, understanding their specific skills and communication qualities.

Workshops and fairs (Milan and Rome) have been the places selected to present and test the strategic tool: a special session has been organized with Fondazione Giannino Bassetti in 2013 in San Francisco, facing the american makers culture.

\subsection{Cuvee design kit for Contadi Castaldi (2009)}

Cuveè design kit is linked to the process of making a special Contadi Castaldi cuveè and to the all variables in it, such as know how, identitary values and sustainable sensoriality criteria.

The kit is meant for a use during wine tasting (instead of the former Gioco delle cuvèè, too expensive indeed), not only as a tool for a deeper acknowledgement, studied for 
connoisseurs as well as amateurs, explains the overall process and at the same time communicates the product in its unique complexity.

The kit as been presented at PAC-Padiglione di arte contemporanea in Milan and then tested in many occasions:

In 2010 a Roseè garden has been design in the vegetable garden of the Villa Reale di Monza, translating the kit into a multisensorial natural setting, expliciting smells, colours, textures...normally embedded into a cuveè.

\subsection{Autogrill Villoresi est, Lainate (2013)}

In terms of the effect of this energy, Villoresi East was conceived as a living organism sensitive to natural cycles and fed through the innovative combination of solar and geothermal energy,combining the energy of the earth and the sun. A sustainability project to 360 degrees has developed following the principles of the LEED Protocol (Leadership in Energy and Environmental Design) with design choices and plant aimed at reducing the energy and environmental impacts and to ensure integration with the territory and the surrounding landscape.

Technological and environmental impact:

- Geothermal plant to "thermal stack" with 420 probes lowered into the ground covering $85 \%$ of the needs during summer time.

- Captating roof with a surface of 350 square meters that capture, seasonally, hot or cold;

- Free cooling system that takes full advantage of natural ventilation for cooling;

- LED lighting for both the exterior and the interior area;

- System of rainwater and ground water collection for air conditioning, irrigation, toilet and fire reserve;

- $19.000 \mathrm{mq}$ green area (about $30 \%$ of the total area), with the planting of one tree per six parking spaces, in continuity with the landscape vegetation.

The building is spread over an area of about 2,500 square meters with a skeleton made entirely of laminated wood PEFC certified from forests managed in a sustainable manner. Is also characterized by the use of environmentally friendly construction materials and $100 \%$ recyclable.

Overall accessibility of services is one of the most significant features of Villoresi, where the design of the layout, furnishings and equipment, is based on the principles of Design for all and DASA Certification Register with the aim of obtaining the homonyms quality marks for accessibility.

In terms of interior design Villoresi East is a pioneering experience of architectural barriers and restrictions to the free movement of customers, which elevates the service area to best practices for accessibility for all. The interior design has been elaborated from the multiplicity of needs of people traveling (businessmen, families, women truckers, children, elderly, disabled, blind, etc.... ). (Figure 2) 


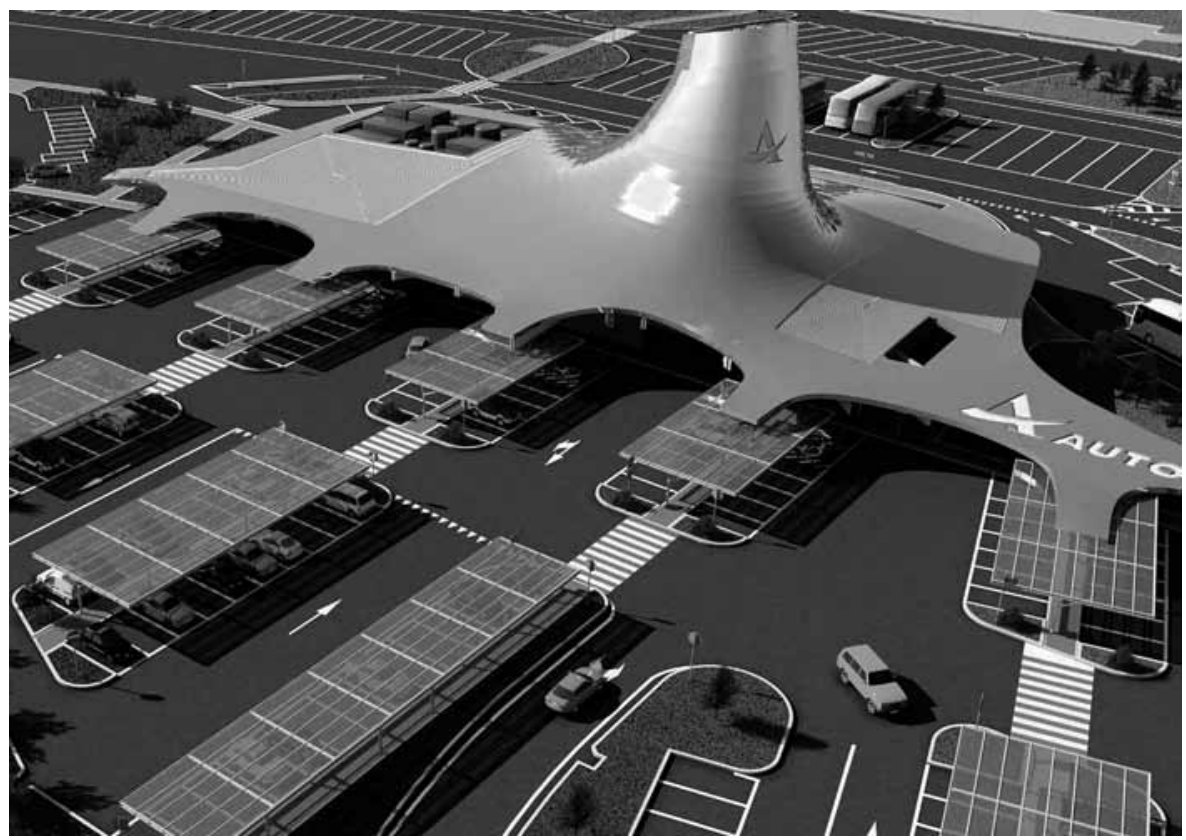

Figure 2. Autogrill Villoresi est, Lainate.

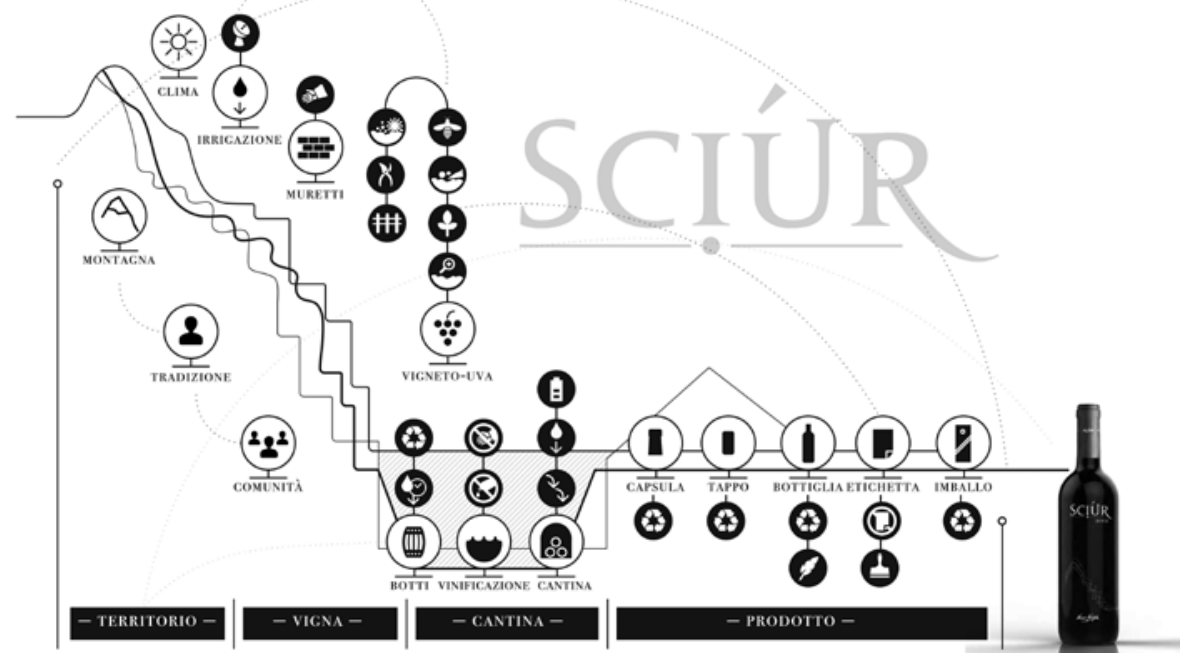

Figure 3. Sciur wine for Nino Negri, Valtellina. 


\subsection{Sciur wine for Nino Negri, Valtellina, 2014}

The original and bold choice to set up the project of a fully sustainable wine required interaction and verification with young people of different countries and cultures from a path of studies based on a systemic approach, similar to that of the Master in Strategic Design form Politecnico di Milano.

This is because Sciur, nevertheless of its 15.000 bottles a year, is not a mere product. It is not just the end result of a varied production line but it involves a set of planning sequences and activities intended to be a potentially repeatable virtuous example.

We hope that this wine can be considered an operational tool, a dynamic means of transformation, and that it may become a pragmatic example of how in the "world of wine" (and not only) the rules of the game are changing in terms of demand and supply, and how only discussion, meetings, trips, experimentation and respect for tradition may provide valid feedback for the future.

The word "Sciur" cannot be found in an Italian dictionary but only in a dictionary of the Lombardy dialect. In Valtellina, as a sign of respect, it was the name given to Carlo Negri, who founded the winery of the same name in 1897. Apart from this interesting fact, any reference to dialect is incidental, since Sciur is used as an acronym for serendipity thanks to research by the students of the Polytechnic University of Milan who found 5 key words that characterise the project and the wine to be produced.

They are explicit thanks to their meaning, and attractive and virtuous due to their practical and cultural implications: Sustainable, Concrete/practical, Innovative, Unique, Responsible.

The project includes Internship projects for young builders in collaboration with the Polo di Formazione Professionale Valtellina for learning the techniques of maintenance and construction of dry stone walls and 1 euro for each bottle of Sciur sold it is donated to projects concerning the protection and preservation of dry stone walls, a very important heritage for Valtellina. (Figure 3)

I hope that all these examples are clear and succesfull enough to show you as we do not get anything sustainable (and profitable) if not because through design we try to show people a different world where new qualities are clearly emerging and where realtionships among different actors are more fluid, transparent and friendly.

This is the meaning for design, today and hopefully, tomorrow.

\section{Bibliography}

Agamben, G. (2004). Genius. Nottetempo.

Ceppi, G. (2011). Design storytelling. Milano: Fausto Lupetti editore.

Ceppi, G. \& Zini, M. (1996). Bambini, spazi, relazioni. Edizioni Reggio Children.

Leroi-Gourhan, A. (1965). Le geste et la parole. Editions Albin Michel.

Manzini, E. (1990). Artefatti. Milano: Edizioni Domus Academy. 
Moles, A. \& Rohmer, E. (1982). Labyrinthes du vecù. L'espace: matiere d'actions. Paris: Librairie de Meridiens.

Petrini, C. (2005). Buono, Giusto, Pulito. Milano: Il saggiatore.

Pine, J. \& Gilmore, J. (1999). The experience economy. Boston: Harvard Business School press. Trini Castelli, C. \& Petrillo, A. (1986). Il lingotto primario. Milano: Arcadia edizioni.

\begin{abstract}
Starting from the Slow Food experience and its international success, the author, together with Giacomo Mojoli (former vicepresident of Slow Food) starts to question about the trasfer of the slow approach into design practice.

This means discussing whether and how design can contribute in the field of systems and steer the transformations underway towards sustainable ways of living and producing. The Sustainable Sensoriality expression wants to combine both worlds of sensoriality and sustainability, conceptual and operational dimensions of design, but deeply practiced into the authors's activities as architect and designer and explicited in many teaching practices and design case histories.
\end{abstract}

Key words: Sustainability - Sensoriality - Slow approach - Innovation - System design Changment by doing.

Resumo: A partir da experiência do Slow Food e seu sucesso internacional, o autor, juntamente com Giacomo Mojoli (ex-vice-presidente do Slow Food) começa a questionar a abordagem slow na prática do design. Isto significa que discutir se o design pode e como pode contribuir para a área de sistemas e direcionar as transformações em curso produzindo modos de vida sustentáveis. O termo Sensorialidade Sustentável quer combinar os mundos da sensualidade e da sustentabilidade, dimensões conceptuais e operacionais do design, mas profundamente praticada nas atividades dos autores como arquiteto e designer, e explicitada em muitas práticas de ensino e em muitos casos estúdio de design.

Palavras chave: Sustentabilidade - sensorialidade - abordagem slow - inovação - sistemas de design - mudanças na prática. 


\section{Publicaciones del Centro de Estudios en Diseño y Comunicación}

El Centro de Estudios en Diseño y Comunicación de la Facultad de Diseño y Comunicación de la Universidad de Palermo desarrolla una amplia política editorial que incluye las siguientes publicaciones académicas de carácter periódico:

\section{- Cuadernos del Centro de Estudios en Diseño y Comunicación [Ensayos]}

Es una publicación periódica que reúne papers, ensayos y estudios sobre tendencias, problemáticas profesionales, tecnologías y enfoques epistemológicos en los campos del Diseño y la Comunicación.

Se publican de dos a cuatro números anuales con una tirada de 500 ejemplares que se distribuyen en forma gratuita.

Esta línea se edita desde el año 2000 en forma ininterrumpida, recibiendo colaboraciones remuneradas, dentro de las distintas temáticas.

La publicación tiene el número ISSN 1668.0227 de inscripción en el CAICYT-CONICET y tiene un Comité de Arbitraje.

- Creación y Producción en Diseño y Comunicación [Trabajos de estudiantes y egresados] Es una línea de publicación periódica del Centro de Producción de la Facultad. Su objetivo es reunir los trabajos significativos de estudiantes y egresados de las diferentes carreras. Las producciones (teórico, visual, proyectual, experimental y otros) se originan partiendo de recopilaciones bibliográficas, catálogos, guías, entre otros soportes.

La política editorial refleja los estándares de calidad del desarrollo de la currícula, evidenciando la diversidad de abordajes temáticos y metodológicos realizados por estudiantes y egresados, con la dirección y supervisión de los docentes de la Facultad.

Los trabajos son seleccionados por el claustro académico y evaluados para su publicación por el Comité de Arbitraje de la Serie.

Esta línea se edita desde el año 2004 en forma ininterrumpida, recibiendo colaboraciones para su publicación. El número de inscripción en el CAICYT-CONICET es el ISSN 16685229 y tiene Comité de Arbitraje.

\section{- Escritos en la Facultad}

Es una publicación periódica que reúne documentación institucional (guías, reglamentos, propuestas), producciones significativas de estudiantes (trabajos prácticos, resúmenes de trabajos finales de grado, concursos) y producciones pedagógicas de profesores (guías de trabajo, recopilaciones, propuestas académicas).

Se publican de cuatro a ocho números anuales con una tirada variable de 100 a 500 ejemplares de acuerdo a su utilización. 
Esta serie se edita desde el año 2005 en forma ininterrumpida, su distribución es gratuita y recibe colaboraciones para su publicación. La misma tiene el número ISSN 1669-2306 de inscripción en el CAICYT-CONICET.

\section{- Reflexión Académica en Diseño y Comunicación}

Las Jornadas de Reflexión Académica son organizadas por la Facultad de Diseño y Comunicación desde el año 1993 y configuran el plan académico de la Facultad colaborando con su proyecto educativo a futuro. Estos encuentros se destinan al análisis, intercambio de experiencias y actualización de propuestas académicas y pedagógicas en torno a las disciplinas del diseño y la comunicación. Todos los docentes de la Facultad participan a través de sus ponencias, las cuales son editadas en el libro Reflexión Académica en Diseño y Comunicación, una publicación académica centrada en cuestiones de enseñanza-aprendizaje en los campos del diseño y las comunicaciones. La publicación (ISSN 1668-1673) se edita anualmente desde el 2000 con una tirada de 1000 ejemplares que se distribuyen en forma gratuita.

\section{- Actas de Diseño}

Actas de Diseño es una publicación semestral de la Facultad de Diseño y Comunicación, que reúne ponencias realizadas por académicos y profesionales nacionales y extranjeros. La publicación se organiza cada año en torno a la temática convocante del Encuentro Latinoamericano de Diseño, cuya primera edición fue en Agosto 2006. Cabe destacar que la Facultad ha sido la coordinadora del Foro de Escuelas de Diseño Latinoamericano y la sede inaugural ha sido Buenos Aires en el año 2006.

La publicación tiene el Número ISSN 1850-2032 de inscripción y tiene comité de arbitraje.

A continuación se detallan las ediciones históricas de la serie Cuadernos del Centro de Estudios en Diseño y Comunicación:

Cuadernos del Centro de Estudios de Diseño y Comunicación [ ISSN 1668-0227 ]

$>$ Cuadernos del Centro de Estudios en Diseño y Comunicación. [Ensayos]:Presente y futuro del diseño latino. María Verónica Barzola: Prólogo de la Universidad de Palermo | Rita Ribeiro: Prólogo da Universidade do Estado de Minas Gerais. FILOSOFÍA DEL DISEÑO Y CONTEXTO SOCIAL: Jorge Gaitto | María Verónica Barzola | Celso Carnos Scaletsky, Chiara Del Gaudio, Filipe Campelo Xavier da Costa, Gerry Derksen, Guilherme Corrêa Meyer, Juan de la Rosa, Piotr Michura y Stan Ruecker $\mid$ Anderson Antonio Horta. EL DISEÑO COMO AGENTE DE TRANSFORMACIÓN SOCIAL: María Ledesma | Silvia Sasaoka, Giselle Marques Leite, Mônica Cristina de Moura y Luís Carlos Paschoarelli | Caroline Salvan Pagnan y Artur Caron Mottin | Simone Abreu | Zulma Buendía De Viana | Elisangela Batista. EL DISEÑO COMO FACTOR DE DESARROLLO ECONÓMICO: María del Rosario Bernatene y Guillermo Juan Canale | Liliana Durán Bobadilla y Luis Daniel Mancipe Lopez | Ana Urroz-Osés | Camilo de Lelis Belchior. FORMACIÓN PARA EL DISEÑO SOCIAL: Rita Aparecida da Conceição Ribeiro | Cristian Antoine, Santiago 
Aránguiz y Carolina Montt | Polyana Ferreira Lira da Cruz y Wellington Gomes de Medeiro | Carlos Henrique Xerfan do Amaral, André Ribeiro de Oliveira y Sandra Maria Nunes Vivone | Ana Beatriz Pereira de Andrade y Henrique Perazzi de Aquino. (2018). Buenos Aires: Universidad de Palermo, Facultad de Diseño y Comunicación, Centro de Estudios en Diseño y Comunicación. Vol. 69, septiembre. Con Arbitraje.

$>$ Cuadernos del Centro de Estudios en Diseño y Comunicación. [Ensayos]: Cine e Historia. Pluralidad de voces y miradas sobre el autoritarismo y el totalitarismo. Zulema Marzorati y Mercedes Pombo: Prólogo | Rodolfo Battagliese: Poder estatal y dominación de género: sus representaciones en La linterna roja (China, 1991) de Zhang Yimou | Lizel Tornay: Representaciones de mujeres en el cine de realizadoras feministas durante los períodos posdictatoriales. España y Argentina | Zulema Marzorati y Mercedes Pombo: El fascismo en la pantalla: Vincere (Italia, Bellochio, 2009) | Victoria Alvarez: Cine, represión y género en la transición democrática. Un análisis de La noche de los lápices $\mid$ Tzvi Tal: La estética del trauma y el discurso de la memoria: personajes infantiles ante el terror estatal en Infancia clandestina (Ávila, Argentina, 2011) | Moira Cristiá: Frente el autoritarismo,la creación. La experiencia de AIDA y su relectura en el film El Exilio de Gardel (Fernando Solanas, Francia / Argentina, 1985) | Sonia Sasiain: El lugar del Estado en la representación de la vivienda popular: desde la construcción de la opinión pública hacia la censura | Mónica Gruber: Medios y poder: 1984. (2018). Buenos Aires: Universidad de Palermo, Facultad de Diseño y Comunicación, Centro de Estudios en Diseño y Comunicación. Vol. 68, julio. Con Arbitraje.

$>$ Cuadernos del Centro de Estudios en Diseño y Comunicación. [Ensayos]: La dimensión ideológica de la enseñanza del diseño. Cecilia Mazzeo: Prólogo. La dimensión ideológica de la enseñanza del diseño | Constanza Necuzzi: Educación, enseñanza y didáctica en la contemporaneidad | Inés Olmedo: La Dirección de Arte en el cine, desafíos disciplinares y pedagógicos | Beatriz Galán: Reconstruyendo el entramado de una sociedad creativa. Estrategias para la formación de diseñadores en contextos de complejidad | Clara Ben Altabef: Intenciones para una didáctica proyectual. Caso: asignatura Proyecto y Forma en la FAU-UNT | Diego Giovanni Bermúdez Aguirre: El estado de posibilidad de la Historia del Diseño | María Ledesma: Luces y sombras en la enseñanza del Diseño. Una reflexión sobre su transformación en saber universitario | Ana Cravino: Enseñar Diseño: La emergencia de la teoría | Mabel Amanda López: Modos de decir y modos de ser: palabra e ideología en el taller de diseño | Ana María Romano: La construcción de la cosmovisión durante la enseñanza. (2018). Buenos Aires: Universidad de Palermo, Facultad de Diseño y Comunicación, Centro de Estudios en Diseño y Comunicación. Vol. 67, mayo. Con Arbitraje.

$>$ Cuadernos del Centro de Estudios en Diseño y Comunicación. [Ensayos]: Componentes del diseño audiovisual experimental. Gonzalo Aranda Toro y Alejandra Niedermaier: Prólogo | Alejandra Niedermaier: Introducción | María José Alcalde: Reflexión acerca del ejercicio audiovisual como medio de expresión del diseño gráfico experimental | Eugenia Álvarez Saavedra: El diseño en las representaciones audiovisuales de la etnia Mapuche | Laura Bertolotto Navarrete y Katherine Hetz Rodríguez: Reflexión respecto de la conexión entre la disciplina del diseño y la audiovisual, como factor estratégico de 
desarrollo | José Luis Cancio: Cerebus, un modelo de edición independiente | Rosa Chalkho: La música cinematográfica y la construcción del sentido en el film | Antonieta Clunes: Experimentación con medios análogos y su aplicación como recurso audiovisual, reflejo de un contexto latinoamericano | Daniela V. Di Bella: Ex Obra, la rematerialización de la imagen en movimiento | Pamela Petruska Gatica Ramírez: Ver y sentir (pantallas). Diseño, dispositivos y emoción | Ricardo Pérez Rivera: Acerca del método de la observación y algunos alcances al estudio experimental para la construcción de imágenes | Juan Manuel Pérez: Sobre subjetividades en la educación visual contemporánea: algunos componentes | Eduardo A. Russo: Aspectos intermediales de la enseñanza audiovisual. Un abordaje transversal, entre el cine y los nuevos medios | Gisela Massara, Camila Sabeckis y Eleonora Vallazza: Tendencias en el Cine Expandido Contemporáneo. (2018). Buenos Aires: Universidad de Palermo, Facultad de Diseño y Comunicación, Centro de Estudios en Diseño y Comunicación. Vol. 66, marzo. Con Arbitraje.

$>$ Cuadernos del Centro de Estudios en Diseño y Comunicación. [Ensayos]: Maestría en Diseño de la Universidad de Palermo [Catálogo de Tesis. 5a Edición. Ciclo 2014-2015]. (2017). Buenos Aires: Universidad de Palermo, Facultad de Diseño y Comunicación, Centro de Estudios en Diseño y Comunicación. Vol. 65, diciembre. Con Arbitraje.

$>$ Cuadernos del Centro de Estudios en Diseño y Comunicación. [Ensayos]: Los procesos emergentes en la enseñanza y la práctica del diseño. M. Veneziani: Prólogo | M. Veneziani: Moda y comida: Una alianza que predice hechos económicos | M. Buey Fernández: Involúcrame y entenderé | F. Bertuzzi y D. Escobar: El espíritu emprendedor. Un acercamiento al diseño independiente de moda y las oportunidades de crecimiento comercial en el contexto actual argentino | X. González Eliçabe: Arte popular y diseño: los atributos de un nuevo lujo | C. Eiriz: Creación y operaciones de transformación. Aportes para una retórica del diseño| P.M. Doria: Desafío creativo cooperativo | V. Fiorini: Nuevos escenarios de las prácticas del diseño de indumentaria en Latinoamérica. Conceptos, metodologías e innovación productiva en el marco de la contemporaneidad | R. Aras: Los nuevos aprendizajes del sujeto digital | L. Mastantuono: Tendencias hacia un cine medioambiental. Concientización de una producción y diseño sustentable | D. Di Bella: El cuerpo como territorio | V. Stefanini: La mirada propia. El autorretrato en la fotografía contemporánea | S. Faerm: Introducción | A. Fry, R. Alexander, and S. Ladhib: Los emprendimientos en Diseño en la economía post-recesión: Parson`s E Lab, la Incubadora de Negocios de Diseño | S. Faerm: Desarrollando un nuevo valor en diseño; del "qué" al "cómo" | A. Kurennaya: Moda como práctica, Moda como proceso: los principios del lenguaje como marco para entender el proceso de diseño | L. Beltran-Rubio: Colombia for Export: Johanna Ortiz, Pepa Pombo y la recreación de la identidad cultural para el mercado global de la moda | A. Fry, G. Goretti, S. Ladhib, E. Cianfanelli, and C. Overby: "Artesanías de avanzada" integradas con el saber hacer; el papel del valor intangible y el rol central del artesano en el artesanato de alta gama del siglo 21 | T. Werner and S. Faerm: El uso de medios comerciales para involucrar e impactar de manera positiva en las comunidades. (2017). Buenos Aires: Universidad de Palermo, Facultad de Diseño y Comunicación, Centro de Estudios en Diseño y Comunicación. Vol. 64, septiembre. Con Arbitraje. 
$>$ Cuadernos del Centro de Estudios en Diseño y Comunicación. [Ensayos]: Programa de Investigación de la Facultad de Diseño y Comunicación [Catálogo de Investigaciones. $1^{\text {a }}$ Edición. Ciclo 2007-2015). Investigaciones (abstracts) organizadas por campos temáticos: a. Empresas y marcas | b. Medios y estrategias de comunicación |c. Nuevas tecnologías |d. Nuevos profesionales | e. Diseño y producción de objetos, espacios e imágenes | f. Pedagogía del diseño y las comunicaciones $\mid$ g. Historia y tendencia. Selección de Investigaciones (completas): Patricia Dosio: Detección y abordaje de problemas o tendencias actuales en el arte y el diseño | Débora Belmes: Nuevas herramientas de la comunicación. Un estudio acerca del amor, la amistad, la educación y el trabajo en jóvenes universitarios | Eleonora Vallaza: El Found Footage como práctica del video-arte argentino de la última década | Andrés Olaizola: Alfabetización académica en entornos digitales | Marina Mendoza: Hacia la construcción de una ciudadanía mediática. Reflexiones sobre la influencia de las políticas neoliberales en la configuración de la comunicación pública argentina | Valeria Stefanini: Los modos de representación del cuerpo en la fotografía de moda. Producciones fotográficas de la Revista Catalogue. (2017). Buenos Aires: Universidad de Palermo, Facultad de Diseño y Comunicación, Centro de Estudios en Diseño y Comunicación. Vol. 63, julio. Con Arbitraje.

$>$ Cuadernos del Centro de Estudios en Diseño y Comunicación. [Ensayos]: Cine documental. Fernando Mazás: Prólogo | Igor Dimitri Gonçalves: Werner Herzog, documentales de viaje: Fata Morgana, La Soufrière, A la espera de una catástrofe inevitable, Wodaabe, Pastores del sol, Jag Mandir | Nerea González: La doble lectura de Canciones para después de una guerra explicada desde el marco teórico de las problemáticas del documental | Lucía Levis Bilsky: De artistas, consumidores y críticos: dinámicas del cambio, el gusto y la distinción en el campo artístico actual. Jean-Luc Godard y su Adiós al Lenguaje | Claudia Martins: Péter Forgács: imágenes de familia y la memoria del Holocausto | Fernando Mazás: Edificio Master: la tecnología audiovisual como escritura étnica | Carlos Gustavo Motta: La antropología visual | Gonzalo Murúa Losada: Por un cuarto cine, el webdoc en la era de las narraciones digitales | Antonio Romero Zurita: El cine intelectual de Fernando Birri. Antecedentes a la conformación del Documental Militante en Argentina | Maria A. Sifontes: El acto performático como expresión del pensamiento en obras realizadas por artistas venezolanos. (2017). Buenos Aires: Universidad de Palermo, Facultad de Diseño y Comunicación, Centro de Estudios en Diseño y Comunicación. Vol. 62, mayo. Con Arbitraje.

> Cuadernos del Centro de Estudios en Diseño y Comunicación. [Ensayos]: Imágenes/ escrituras: trazos reversibles. Laura Ruiz y Marcos Zangrandi: Presentación. El lazo imagen/escritura en los nexos de la cultura contemporánea. 1. Blogs/escrituras. Diego Vigna: Lo narrado en imágenes (o las imágenes narradas). Ficciones, pruebas, trazos y fotografías en las publicaciones de los escritores en blogs | Mariana Catalin: Daniel Link y la televisión: ensayos entre la clase y la cualificación. 2. Cine/escrituras. Vanina Escales: El ensayo a la búsqueda de la imagen | Diego A. Moreiras: Dimensiones de una masacre en la escuela: traducción intersemiótica en We need to talk about Kevin | Nicolás Suárez: Pueblo, comunidad y mito en Juan Moreira de Leonardo Favio y en Facundo. La sombra del Tigre de Nicolás Sarquís | Marcos Zangrandi: Antín / Cortázar: cruces y destiempos entre la escritura y el cine. 3. Imágenes/escrituras. Álvaro Fernández Bravo: Imágenes, trauma, 
memoria: miradas del pasado reciente en obras de Patricio Guzmán, Adriana Lestido y Gustavo Germano | Laura Ruiz: Bronce y sueños, los gitanos. Nomadismo, identidades por exclusión y otredad negativa en Jorge Nedich y Josef Koudelka | Santiago Ruiz y Ximena Triquell: Imágenes y palabras en la lucha por imposición de sentidos: la imagen como generadora de relatos. (2017). Buenos Aires: Universidad de Palermo, Facultad de Diseño y Comunicación, Centro de Estudios en Diseño y Comunicación. Vol. 61, marzo. Con Arbitraje.

$>$ Cuadernos del Centro de Estudios en Diseño y Comunicación. [Ensayos]: Lecturas y poéticas del arte latinoamericano: apropiaciones, rupturas y continuidades. María Gabriela Figueroa: Prólogo | Cecilia Iida: El arte local en el contexto global | Silvia Dolinko: Lecturas sobre el grabado en la Argentina a mediados del siglo XX | Ana Hib: Repertorio de artistas mujeres en la historiografía canónica del arte argentino: un panorama de encuentros y desencuentros | Cecilia Marina Slaby: Mito y banalización: el arte precolombino en el arte actual. La obra de Rimer Cardillo y su apropiación de la iconografía prehispánica | Lucía Acosta: Jorge Prelorán: las voces que aún podemos escuchar | Luz Horne: Un paisaje nuevo de lo posible. Hacia una conceptualización de la "ficción documental" a partir de Fotografías, de Andrés Di Tella | María Cristina Rossi: Redes latinoamericanas de arte constructivo | Florencia Garramuño: Todos somos antropófagos. Sobrevivencias de una vocación internacionalista en la cultura brasileña | Jazmín Adler: Artes electrónicas en Argentina. En busca del eslabón perdido. (2016). Buenos Aires: Universidad de Palermo, Facultad de Diseño y Comunicación, Centro de Estudios en Diseño y Comunicación. Vol. 60, diciembre. Con Arbitraje.

$>$ Cuadernos del Centro de Estudios en Diseño y Comunicación. [Ensayos]: La experiencia fotográfica en diálogo con las experiencias del mundo. Alejandra Niedermaier: Prólogo | François Soulages: Geoestética de idas-vueltas (a modo de introducción) | Eric Bonnet: Partir y volver. Cuba, tierra natal de Wifredo Lam y Ana Mendieta | María Aurelia Di Berardino: Lo que oculta una frontera: el para qué escindir la ciencia del arte | Alejandro Erbetta: La experiencia migratoria como posibilidad de creación | Raquel Fonseca: En la frontera de las imágenes de una inmigración en doble sentido; ida y vuelta | Denise Labraga: Fronteras blandas. Posibilidades de representación del horror | Alejandra Niedermaier: La imagen síntoma: construcciones estéticas del yo | Pedro San Ginés Aguilar: Hijo de la migración | Silvia Solas: Fronteras artísticas: sentidos y sinsentidos de lo visual | François Soulages: Las fronteras \& el ida-vuelta | Joaquim Viana: Las transformaciones diagramáticas: imágenes y fronteras efímeras. (2016). Buenos Aires: Universidad de Palermo, Facultad de Diseño y Comunicación, Centro de Estudios en Diseño y Comunicación. Vol. 59, septiembre. Con Arbitraje.

$>$ Cuadernos del Centro de Estudios en Diseño y Comunicación. [Ensayos]: Cine y Moda. P. Doria: Prólogo Universidad de Palermo | M. Carlos: Moda en cine: signos y simbolismos | D. Ceccato: Cortos de moda, un género en auge | P. Doria: Brillos y utopías |V. Fiorini: Moda, cuerpo y cine | C. Garizoain: De la pasarela al cine, del cine a la pasarela. El vestuario y la moda en el cine argentino hoy | M. Orta: Moda fantástica | S. Roffe: Vestuario de cine: El relator silencioso | M. Veneziani: Moda y cine: entre el relato y el ropaje | L. Acar: La seducción del cuerpo vestido en La fuente de las mujeres | F. di 
Cola: Moda y autenticidad histórica en el cine: nuevos ecos de la escuela viscontina $\mid \mathrm{E}$. Monteiro: El amor, los cuerpos y las ropas en Michael Haneke | D. Trindade: Vestes del tiempo: telas, movimientos e intervalos en la película Lavoura Arcaica | N. Villaça: Almodóvar: Cineasta y diseñador | F. Mazás: El cine come metalenguaje. Haciendo visible el código de la moda | Cuerpo, Arte y Diseño. P. Doria: Prólogo Universidad de Palermo | S. Cornejo y P. Estebecorena: Cuerpo, imagen e identidad. Relación (im)perfecta | D. Ceccato: Cuerpos encriptadas: Entre el ser real e irreal | L. Garabieta: Cuerpo y tiempo | G. Gómez del Río: Nuevos soportes, nuevos cuerpos | M. Matarrese: Cestería pilagá: una aproximación desde la estética al cuerpo |C. Puppo: El arte de diseñar nuestro cuerpo | S. Roffe: Ingeniería y arquitectura de la Moda: El cuerpo rediseñado | L. Ruiz: Imágenes de la otredad. Arte, política y cuerpos residuales en Daniel Santoro | V. Suárez: Cuerpos: utopías de lo real | S. Avelar: El futuro de la moda: una discusión posible | S. M. Costa, Esteban F. Tuesta \& S. A. Costa: Residuos agro-industriales utilizados como materiasprimas en estudios de desarrollo de fibras textiles | F. Dantas Mendes: El Diseño como estrategia de Postponement en la MVM Manufactura del Vestuario de la Moda | B. Ferreira Pires: Cuerpo trazado. Contexturas orgánicas e inorgánicas | C. R. Garcia Vicentini: El lugar de la creatividad en el desarrollo de productos de moda contemporáneos. (2016). Buenos Aires: Universidad de Palermo, Facultad de Diseño y Comunicación, Centro de Estudios en Diseño y Comunicación. Vol. 58, julio. Con Arbitraje.

$>$ Cuadernos del Centro de Estudios en Diseño y Comunicación. [Ensayos]: Moda en el siglo XX: una mirada desde las artes, los medios y la tecnología. Matilde Carlos: Prólogo Melisa Perez y Perez: Las asociaciones entre el arte y la moda en el siglo XX | Mónica Silvia Incorvaia: La fotografía en la moda. Entre la seducción y el encanto | Gladys Mercado: Vestuario: entre el cine y la moda | Gabriela Gómez del Río: Fotolectos: cuando la imagen se vuelve espacio. Estudio de caso Para Ti Colecciones | Valeria Tuozzo: La moda en las sociedades modernas | Esteban Maioli: Moda, cuerpo e industria. Una revisión sobre la industria de la moda, el uso generalizado de TICs y la Tercera Revolución Industrial Informacional | Las Pymes y el mundo de la comunicación y los negocios. Patricia Iurcovich: Prólogo | Liliana Devoto: La sustentabilidad en las pymes, ¿es posible? | Sonia Grotz: Cómo transformar un sueño en un proyecto | María A. Rosa Dominici: La importancia del coaching en las PYMES como factor estratégico de cambio | Victoria Mejuto: La creación de diseño y marca en las Pymes | Diana Silveira: Las pymes argentinas: realidades y perspectivas | Christian Javier Klyver: Las Redes Sociales y las PyMES. Una relación productiva | Silvia Martinica: El maltrato psicológico en la empresa | Debora Shapira: La sucesión en las PYMES, el factor gerenciamiento. (2016). Buenos Aires: Universidad de Palermo, Facultad de Diseño y Comunicación, Centro de Estudios en Diseño y Comunicación. Vol. 57, marzo. Con Arbitraje.

$>$ Cuadernos del Centro de Estudios en Diseño y Comunicación. [Ensayos]: Pedagogías y poéticas de la imagen. Julio César Goyes Narváez y Alejandra Niedermaier: Prólogo | Vanessa Brasil Campos Rodríguez: Una mirada al borde del precipicio. La fascinación por lo siniestro en el espectáculo de lo real (reality show) | Mônica Ferreira Mayrink: La escuela en escena: las películas como signos mediadores de la formación crítico-reflexiva 
de profesores | Jesús González Requena: De los textos yoicos a los textos simbólicos | Julio César Goyes Narváez: Audiovisualidad y subjetividad. Del icono a la imagen fílmica Alejandro Jaramillo Hoyos: Poética de la imagen - imagen poética | Leopoldo Lituma Agüero: Imagen, memoria y Nación. La historia del Perú en sus imágenes primigenias | Luis Martín Arias: ¿Qué queremos decir cuando decimos “imagen"? Una aproximación desde la teoría de las funciones del lenguaje | Luis Eduardo Motta R.: La imagen y su función didáctica en la educación artística $\mid$ Alejandra Niedermaier: Cuando me asalta el miedo, creo una imagen | Eduardo A. Russo: Dinámicas de pantalla, prácticas postespectatoriales y pedagogías de lo audiovisual | Viviana Suarez: Interferencias. Notas sobre el taller como territorio, la regla como posibilidad, la obra como médium | Lorenzo Javier Torres Hortelano: Aproximación a un modelo de representación virtual lúdico (MRVL). Virtual Self, narcisismo y ausencia de sentido. (2016). Buenos Aires: Universidad de Palermo, Facultad de Diseño y Comunicación, Centro de Estudios en Diseño y Comunicación. Vol. 56, marzo. Con Arbitraje.

$>$ Cuadernos del Centro de Estudios en Diseño y Comunicación. [Ensayos]: Maestría en Diseño de la Universidad de Palermo [Catálogo de Tesis. 4 ${ }^{a}$ Edición. Ciclo 2012-2013]. Tesis recomendada para su publicación: Mariluz Sarmiento: La relación entre la biónica y el diseño para los criterios de forma y función. (2015). Buenos Aires: Universidad de Palermo, Facultad de Diseño y Comunicación, Centro de Estudios en Diseño y Comunicación. Vol. 55, septiembre. Con Arbitraje.

$>$ Cuadernos del Centro de Estudios en Diseño y Comunicación. [Ensayos]: Reflexiones sobre la imagen: un grito interminable e infinito. Jorge Couto: Prólogo | Joaquín Linne y Diego Basile: Adolescentes y redes sociales online. El photo sharing como motor de la sociabilidad | María José Bórquez: El Photoshop en guerra: algo más que un retoque cosmético | Virginia E. Zuleta: Una apertura de Pina. Algunas reflexiones en torno al documental de Wim Wenders | Lorena Steinberg: El funcionamiento indicial de la imagen en el nuevo cine documental latinoamericano | Fernando Mazás: Apuntes sobre el rol del audiovisual en una genealogía materialista de la representación | Florencia Larralde Armas: Las fotos sacadas de la ESMA por Victor Basterra en el Museo de Arte y Memoria de La Plata: el lugar de la imagen en los trabajos de la memoria de la última dictadura militar argentina | Tomás Frère Affanni: La imagen y la música. Apuntes a partir de El artista | Mariana Bavoleo: El Fileteado Porteño: motivos decorativos en el margen de la comunicación publicitaria | Mariela Acevedo: Una reflexión sobre los aportes de la Epistemología Feminista al campo de los estudios comunicacionales | Daniela Ceccato: Los blogs de moda como creadores de modelos estéticos | Natalia Garrido: Imagen digital y sitios de redes sociales en internet: ¿más allá de espectacularización de la vida cotidiana? | Eugenia Verónica Negreira: El color en la imagen: una relación del pasado - presente y futuro | Ayelén Zaretti: Cuerpos publicitarios: cuerpos de diseño. Las imágenes del cuerpo en el discurso publicitario de la televisión. Un análisis discursivo | Jorge Couto: La "belleza" im-posible visual/digital de las tapas de las revistas. Aportes de la biopolítica para entender su u-topia. (2015). Buenos Aires: Universidad de Palermo, Facultad de Diseño y Comunicación, Centro de Estudios en Diseño y Comunicación. Vol. 54, septiembre. Con Arbitraje. 
$>$ Cuadernos del Centro de Estudios en Diseño y Comunicación. [Ensayos]: Interpretando el pensamiento de diseño del siglo XXI. Marisa Cuervo: Prólogo | Marcia Veneziani: Introducción Universidad de Palermo. Tendencias opuestas | Leandro Allochis: La mirada lúcida. Desafíos en la producción y recepción de imágenes en la comunicación contemporánea | Teresita Bonafina: Lo austero. ¿Un estilo de vida o una tendencia en la moda? | Florencia Bustingorry: Moda y distinción social. Reflexiones en torno a los sentidos atribuidos a la moda | Carlos Caram: Pedagogía del diseño: el proyecto del proyecto | Patricia M. Doria: Poética, e inspiración en Diseño de Indumentaria | Verónica Fiorini: Tendencias de consumo, innovación e identidad en la moda: Transformaciones en la enseñanza del diseño latinoamericano | Paola Gallarato: Buscando el vacío. Reflexiones entre líneas sobre la forma del espacio | Andrea Pol: Brand 2020. El futuro de las marcas | José E. Putruele y Marcia C. Veneziani: Sustentabilidad, diseño y reciclaje | Valeria Stefanini: La puesta en escena. Arte y representación | Steven Faerm: Introducción Parsons The New School for Design. Nuevos mundos extremos | David Caroll: El innovador transgresor: ser un explorador de Google Glass | Aaron Fry y Steven Faerm: Consumismo en los Estados Unidos de la post-recesión: la influencia de lo "Barato y Chic" en la percepción sobre la desigualdad de ingresos | Steven Faerm: Construyendo las mejores prácticas en la enseñanza del diseño de moda: sentido, preparación e impacto | Robert Kirkbride: Aguas arriba/Aguas Abajo | Jeffrey Lieber: Aprender haciendo | Karinna Nobbs y Gretchen Harnick: Un estudio exploratorio sobre el servicio al cliente en la moda. (2015). Buenos Aires: Universidad de Palermo, Facultad de Diseño y Comunicación, Centro de Estudios en Diseño y Comunicación. Vol. 53, julio. Con Arbitraje.

$>$ Cuadernos del Centro de Estudios en Diseño y Comunicación. [Ensayos]: Cincuenta años de soledad. Aspectos y reflexiones sobre el universo del video arte. E. Vallazza: Prólogo | S. Torrente Prieto: La sutura de lo ausente. El espec-tador como actor en el videoarte | G. Galuppo: Frente al vacío cuerpos, espacios y gestos en el videoarte | C. Sabeckis: El videoarte y su relación con las vanguardias históricas y cinematográficas | J. P. Lattanzi: La crisis de las grandes narrativas del arte en el audiovisual latinoamericano: apuntes sobre el cine experimental latinoamericano en las décadas de 1960 y 1970 | N. Sorrivas: El videoarte como herramienta pedagógica | M. Cantú: Archivos y video: no lo hemos comprendido todo | E. Vallazza: El video arte y la ausencia de un campo cultural específico como respuesta a su hibridación artística $\mid$ D. Foresta: Los comienzos del videoarte (entrevista) | G. Ignoto: Borrado | J-P Fargier: Grand Canal \& Mon Gil! | R. Skryzak: Las ensoñaciones de un videasta solitario | G. Kortsarz: El sol en mi cabeza | La identidad nacional. Representaciones culturales en Argentina y Serbia. $Z$. Marzorati y B. Pantović: Prólogo | A. Mardikian: Múltiples identidades narrativas en el espacio teatral | D. Radojičić: Identidad cultural. La película etnográfica en Serbia | M. Pombo: La fotografía argentina contemporánea. Una mirada hacia las comunidades indígenas | T. Tal: El Kruce de los Andes: memoria de San Martín y discurso político en Revolución (Ipiña, 2010) | B. Pantović: Serbia en imágenes: mensajes visuales de un país | V. Trifunović y J. Diković: La transformación post-socialista y la cultura popular: reflejo de la transición en series televisivas de Serbia | S. Sasiain: Espacios que educan: tres momentos en la historia de la educación en Argentina $\mid$ M. E. Stella: A un cuarto de 
siglo, reflexiones sobre el Juicio a las Juntas Militares en Argentina | A. Stagnaro: Representaciones culturales e identitarias en cambio: habitus científico y políticas públicas en ciencia y tecnología en la Argentina | A. Pavićević: El Ángel Blanco. Desde Heraldo de la Resurrección hasta Portador de Fortuna. Comercialización del Arte Religioso en la Serbia post-comunista $\mid$ M. Stefanović Banović: Ejemplos del uso de los símbolos cristianos en la vida cotidiana en Serbia (2015). Buenos Aires: Universidad de Palermo, Facultad de Diseño y Comunicación, Centro de Estudios en Diseño y Comunicación. Vol. 52, mayo. Con Arbitraje.

$>$ Cuadernos del Centro de Estudios en Diseño y Comunicación. [Ensayos]: Diseño de arte Tecnológico. Alejandra Niedermaier: Prólogo. Apartado: Acerca de FASE: Marcela Andino: Diseño de políticas culturales | Pelusa Borthwick: Nuestra inserción en la cadena de producción nacional | Patricia Moreira: FASE La necesidad del encuentro | Graciela Taquini: Textos curatoriales de los últimos cinco años de FASE. Apartado: Acerca de la esencia y el diseño del arte tecnológico. Rodrigo Alonso: Introducción a las instalaciones interactivas | Emiliano Causa: Cuerpo, Movimiento y Algoritmo | Rosa Chalhko: Entre al álbum y el MP3: variaciones en las tecnologías y las escuchas sociales | Alejandra Marinaro y Romina Flores: Objetos de frontera y arte tecnológico | Enrique Rivera Gallardo: El Virus de la Destrucción, o la defensa de lo inútil | Mariela Yeregui: Encrucijadas de las artes electrónicas en la aporía arte/investigación | Jorge Zuzulich: ¿Qué nos dice una obra de arte electrónico? Este cuaderno acompaña a FASE 6.0/2014. Tesis recomendada para su publicación. Valeria de Montserrat Gil Cruz: Gráficos animados en diarios digitales de México. Cápsulas informativas, participativas y de carácter lúdico. (2015). Buenos Aires: Universidad de Palermo, Facultad de Diseño y Comunicación, Centro de Estudios en Diseño y Comunicación. Vol. 51, marzo. Con Arbitraje.

$>$ Cuadernos del Centro de Estudios en Diseño y Comunicación. [Ensayos]: Diseños escénicos innovadores en puestas contemporáneas. Catalina Julia Artesi: Prólogo | Andrea Pontoriero: Vida líquida, teatro y narración en las propuestas escénicas de Mariano Pensotti | Estela Castronuovo: Lote 77 de Marcelo Mininno: el trabajoso oficio de narrar una identidad | Catalina Julia Artesi: Representaciones expandidas en puestas actuales | Ezequiel Lozano: La intermedialidad en el centro de las propuestas escénicas de Diego Casado Rubio | Marcelo Velázquez: Mediatización y diferencia. La búsqueda de la forma para una puesta en escena de Acreedores de Strindberg | Distribución cultural. Yanina Leandra: Prólogo | Andrea Hanna: El rol del productor en el teatro independiente. La producción es ejecutiva y algo más... | Roberto Perinelli: Teatro: de Independiente a Alternativo. Una síntesis del camino del Teatro Independiente argentino hacia la condición de alternativo y otras cuestiones inevitables | Leila Barenboim: Gestión Cultural 3.0 | Rosalía Celentano: Ámbito público, ámbito privado, ámbito independiente, fronteras desplazadas en el teatro de la Ciudad de Buenos Aires | Yoska Lazaro: La resignificación del término "producto" en el ámbito cultural | Tesis recomendada para su publicación: Rosa Judith Chalkho. Diseño sonoro y producción de sentido: la significación de los sonidos en los lenguajes audiovisuales (2014). Buenos Aires: Universidad de Palermo, Facultad de Diseño y Comunicación, Centro de Estudios en Diseño y Comunicación. Vol. 50, diciembre. Con Arbitraje. 
$>$ Cuadernos del Centro de Estudios en Diseño y Comunicación. [Ensayos]: El Diseño en foco: modelos y reflexiones sobre el campo disciplinar y la enseñanza del diseño en América Latina. María Elena Onofre: Prólogo | Sandra Navarrete: Abstracción y expresión. Una reflexión de base filosófica sobre los procesos de diseño | Octavio Mercado G: Notas para un diseño negativo. Arte y política en el proceso de conformación del campo del Diseño Gráfico | Denise Dantas: Diseño centrado en el sujeto: una visión holística del diseño rumbo a la responsabilidad social | Sandra Navarrete: Diseño paramétrico. El gran desafío del siglo XXI | Deyanira Bedolla Pereda y Aarón José Caballero Quiroz: La imagen emotiva como lenguaje de la creatividad e innovación | María González de Cossío y Nora A. Morales Zaragoza: El pensamiento proyectual sistémico y su integración en el aula | Luis Rodríguez Morales: Hacia un diseño integral | Gloria Angélica Martínez de la Peña: La investigación y el diagnóstico de proyectos de diseño | María Isabel Martínez Galindo y Nora A. Morales Zaragoza: Imaginando otras formas de leer. La era de la sociedad imaginante | Paula Visoná y Giulio Palmitessa: Metodologías del diseño en la promoción de aprendizaje organizacional. El proyecto Melissa Academy | Leandro Brizuela: El diseño de packaging y su contribución al desarrollo de pequeños y medianos emprendimientos | Dolores Delucchi: El Diseño y su incidencia en la industria del juguete argentino | Pablo Capurro: Sin nadie en el medio. El papel de internet como intermediario en las industrias culturales y en la educación | Fabio Parode e Ione Bentz: El desarrollo sustentable en Brasil: cultura, medio ambiente y diseño. (2014). Buenos Aires: Universidad de Palermo, Facultad de Diseño y Comunicación, Centro de Estudios en Diseño y Comunicación. Vol. 49, septiembre. Con Arbitraje.

$>$ Cuadernos del Centro de Estudios en Diseño y Comunicación. [Ensayos]: Los enfoques multidisciplinarios del sistema de la moda. Marisa Cuervo: Prólogo | Marcia Veneziani: Introducción Universidad de Palermo. El enfoque multidisciplinario: un desafío pedagógico en la enseñanza de la moda y el diseño | Leandro Allochis: De New York a Buenos Aires y del Hip Hop a la Cumbia Villera. El protagonismo de la imagen en los procesos de transculturación | Patricia Doria: Sobre la Enseñanza del Diseño de Indumentaria. El desafío creativo (enseñanza del método) | Ximena González Eliçabe: Arte sartorial. De lo ritual a lo cotidiano | Sofía Marré: El asociativismo en las empresas de diseño de indumentaria de autor en Argentina | Laureano Mon: Los caminos de la innovación en la Argentina | Marcia Veneziani: Costumbres, dinero y códigos culturales: conceptos inseparables para la enseñanza del sistema de la moda | Maximiliano Zito: La ética del diseño sustentable. Steven Faerm: Introducción Parsons The New School for Design. Industria y Academia | Lauren Downing Peters: ¿Moda o vestido? Aspectos Pedagógicos en la teoría de la moda | Steven Faerm: Del aula al salón de diseño: La experiencia transicional del graduado en diseño de indumentaria | Aaron Fry, Steven Faerm y Reina Arakji: Realizando el sueño del nuevo graduado: construyendo el éxito sostenible de negocios en pequeña escala | Robert Kirkbride: Velos y veladuras | Melinda Wax: Meditaciones sobre una simple puntada. (2014). Buenos Aires: Universidad de Palermo, Facultad de Diseño y Comunicación, Centro de Estudios en Diseño y Comunicación. Vol. 48, junio. Con Arbitraje. 
$>$ Cuadernos del Centro de Estudios en Diseño y Comunicación. [Ensayos]: Tejiendo identidades latinoamericanas. Marcia Veneziani: Prólogo | Manuel Carballo: Identidades: construcción y cambio | Roberto Aras: "Ortega, profeta del destino latinoamericano: la identidad como 'autenticidad' " | Marisa García: Latinoamérica según Latinoamérica | Leandro Allochis: La fotografía invisible. Identidad y tapas de revistas femeninas en la Argentina | Valeria Stefanini Zavallo: Pararse derechita. El cuerpo y la pose en la fotografía de moda. Un análisis de producciones fotográficas de la revista Catalogue | Marcia Veneziani: Diseñar a partir de la identidad. Entre el molde y el espejo | Paola de la Sotta Lazzerini - Osvaldo Muñoz Peralta: La intención de diseño. El caso del Artilugio Chilote | Ximena González Eliçabe: Arte textil y tradición en la Provincia de Catamarca, noroeste argentino | Lida Eugenia Lora Gómez - Diana Carolina Aconcha Díaz: FIBRARTE | Marina Porrúa: Claves de identidad del programa Identidades Productivas | Marina Porrúa: Diseño con identidad local. Territorio y cultura, como eje para el desarrollo y la sustentabilidad | Georgina Colzani: Entramado: moda y diseño en Latinoamérica | Andrea Melenje Argote: Itinerario: Diseño Gráfico, Cultura Visual e identidades locales | Nicolás García Recoaro: Las cholas y su mundo de polleras. (2014). Buenos Aires: Universidad de Palermo, Facultad de Diseño y Comunicación, Centro de Estudios en Diseño y Comunicación. Vol. 47, marzo. Con Arbitraje.

$>$ Cuadernos del Centro de Estudios en Diseño y Comunicación. [Ensayos]: Maestría en Diseño de la Universidad de Palermo [Catálogo de Tesis. 3a Edición. Ciclo 2010-2011]. Tesis recomendada para su publicación: Yina Lissete Santisteban Balaguera: La influencia de los materiales en el significado de la joya. (2013). Buenos Aires: Universidad de Palermo, Facultad de Diseño y Comunicación, Centro de Estudios en Diseño y Comunicación. Vol. 46, diciembre. Con Arbitraje.

$>$ Cuadernos del Centro de Estudios en Diseño y Comunicación. [Ensayos]: Transformaciones en la comunicación, el arte y la cultura a partir del desarrollo y consolidación de nuevas tecnologías. T. Domenech: Prólogo | J. P. Lattanzi: ¿El poder de las nuevas tecnologías o las nuevas tecnologías y el poder? | G. Massara: Arte y nuevas tecnologías, lo experimental en el bioarte | E. Vallazza: Nuevas tecnologías, arte y activismo político | C. Sabeckis: El séptimo arte en la era de la revolución tecnológica | V. Levato: Redes sociales, lenguaje y tecnología Facebook. The 4th Estate Media? | M. Damoni: Democracia y mass media... ¿ ¿mayor calidad de la información? | N. Rivero: La literatura en su época de reproductibilidad digital $\mid \mathrm{M}$. de la P. Garberoglio: Literatura y nuevas tecnologías. Cambios en las nociones de lectura y escritura a partir de los weblogs $\mid \mathrm{T}$. Domenech: Políticas culturales y nuevas tecnologías - Aportes interdisciplinares en Diseño y Comunicación desde el marketing, los negocios y la administración. S. G. González: Prólogo | A. Bur: Marketing sustentable. Utilización del marketing sustentable en la industria textil y de la indumentaria $\mid$ A. Bur: Moda, estilo y ciclo de vida de los productos de la industria textil | S. Cabrera: La fidelización del cliente en negocios de restauración | S. Cabrera: Marketing gastronómico. La experiencia de convertir el momento del consumo en un recuerdo memorable $\mid$ C. R. Cerezo: De la Auditoría Contable a la Auditoría de las Comunicaciones | D. Elstein: La importancia de la motivación económica | S. G. Gonzá- 
lez: La reputación como ventaja competitiva sostenible | E. Lissi: Primero la estrategia, luego el marketing. ¿Cómo conseguir recursos en las ONGs? | E. Llamas: La naturaleza estratégica del proceso de branding $\mid \mathrm{D}$. A. Ontiveros: Retail marketing: el punto de venta, un medio poderoso | A. Prats: La importancia de la comunicación en el marketing interno. (2013). Buenos Aires: Universidad de Palermo, Facultad de Diseño y Comunicación, Centro de Estudios en Diseño y Comunicación. Vol. 45, septiembre. Con Arbitraje.

$>$ Cuadernos del Centro de Estudios en Diseño y Comunicación. [Ensayos]: Moda y Arte. Marcia Veneziani: Prólogo Universidad de Palermo | Felisa Pinto: Fusión Arte y Moda | Diana Avellaneda: De perfumes que brillan y joyas que huelen. Objetos de la moda y talismanes de la fe | Diego Guerra y Marcelo Marino: Historias de familia. Retrato, indumentaria y moda en la construcción de la identidad a través de la colección Carlos Fernández y Fernández del Museo Fernández Blanco, 1870-1915 | Roberto E. Aras: Arte y moda: ¿fusión o encuentro? Reflexiones filosóficas | Marcia Veneziani: Moda y Arte en el diseño de autor argentino | Laureano Mon: Diseño en Argentina. "Hacia la construcción de nuevos paradigmas” | Victoria Lescano: Baño, De Loof y Romero, tres revolucionarios de la moda y el arte en Buenos Aires | Valeria Stefanini Zavallo: Para hablar de mí. La apropiación que el arte hace de la moda para abordar el problema de la identidad de género | María Valeria Tuozzo y Paula López: Moda y Arte. Campos en intersección | Maria Giuseppina Muzzarelli: Prólogo Università di Bologna | Maria Giuseppina Muzzarelli: El binomio arte y moda: etapas de un proceso histórico | Simona Segre Reinach: Renacimiento y naturalización del gusto. Una paradoja de la moda italiana | Federica Muzzarelli: La aventura de la fotografía como arte de la moda | Elisa Tosi Brandi: El arte en el proceso creativo de la moda: algunas consideraciones a partir de un caso de estudio | Nicoletta Giusti: Art works: organizar el trabajo creativo en la moda y en el arte | Antonella Mascio: La moda como forma de valorización de las series de televisión. (2013). Buenos Aires: Universidad de Palermo, Facultad de Diseño y Comunicación, Centro de Estudios en Diseño y Comunicación. Vol. 44, junio. Con Arbitraje.

$>$ Cuadernos del Centro de Estudios en Diseño y Comunicación. [Ensayos]: Acerca de la subjetividad contemporánea: evidencias y reflexiones. Alejandra Niedermaier - Viviana Polo Flórez: Prólogo | Raúl Horacio Lamas: La Phantasía estructurante del pensamiento y de la subjetividad | Alejandra Niedermaier: La distribución de lo inteligible y lo sensible hoy | Susana Pérez Tort: Poéticas visuales mediadas por la tecnología. La necesaria opacidad | Alberto Carlos Romero Moscoso: Subjetividades inestables | Norberto Salerno: ¿Qué tienen de nuevo las nuevas subjetividades? | Magalí Turkenich - Patricia Flores: Principales aportes de la perspectiva de género para el estudio social y reflexivo de la ciencia, la tecnología y la innovación | Gustavo Adolfo Aragón Holguín: Consideración de la escritura narrativa como indagación de sí mismo | Cayetano José Cruz García: Idear la forma. Capacitación creativa | Daniela V. Di Bella: Aspectos inquietantes de la era de la subjetividad: lo deseable y lo posible | Paola Galvis Pedroza: Del universo simbólico al arte como terapia. Un camino de descubrimientos | Julio César Goyes Narváez: El sujeto en la experiencia de lo real | Sylvia Valdés: Subjetividad, creatividad y acción colectiva | Elizabeth Vejarano Soto: La poética de la forma. Fronteras desdibujadas entre 
el cuerpo, la palabra y la cosa | Eduardo Vigovsky: Los aportes de la creatividad ante la dificultad reflexiva del estudiante universitario | Julián Humberto Arias: Desarrollo humano: un lugar epistémico | Lucía Basterrechea: Subjetividad en la didáctica de las carreras proyectuales. Grupos de aprendizaje; evaluación | Tatiana Cuéllar Torres: Cartografía del papel de los artefactos en la subjetividad infantil. Un caso sobre la implementación de artefactos en educación de la primera infancia | Rosmery Dussán Aguirre: El Diseño de experiencias significativas en entornos de aprendizaje | Orfa Garzón Rayo: Apuntes iniciales para pensar-se la subjetividad que se expresa en los procesos de docencia en la educación superior | Alfredo Gutiérrez Borrero: Rapsodia para los sujetos por sí-mismos. Hacia una sociedad de localización participante | Viviana Polo Florez: Habitancia y comunidades de sentido. Complejidad humana y educación. Consideraciones acerca del acto educativo en Diseño. (2013). Buenos Aires: Universidad de Palermo, Facultad de Diseño y Comunicación, Centro de Estudios en Diseño y Comunicación. Vol. 43, marzo. Con Arbitraje.

$>$ Cuadernos del Centro de Estudios en Diseño y Comunicación. [Ensayos]: Perspectivas sobre moda, tendencias, comunicación, consumo, diseño, arte, ciencia y tecnología. Marcia Veneziani: Prólogo | Laureano Mon: Industrias Creativas de Diseño de Indumentaria de Autor. Diagnóstico y desafíos a 10 años del surgimiento del fenómeno en Argentina | Marina Pérez Zelaschi: Observatorio de tendencias | Sofía Marré: La propiedad intelectual y el diseño de indumentaria de autor | Diana Avellaneda: Telas con efectos mágicos: iconografía en las distintas culturas. Entre el arte, la moda y la comunicación | Silvina Rival: Tiempos modernos. Entre lo moderno y lo arcaico: el cine de Jia Zhang-ke y Hong Sang-soo | Cristina Amalia López: Moda, Diseño, Técnica y Arte reunidos en el concepto del buen vestir. La esencia del oficio y el lenguaje de las formas estéticas del arte sartorial y su aporte a la cultura y el consumo del diseño | Patricia Doria: Consideraciones sobre moda, estilo y tendencias | Gustavo A. Valdés de León: Filosofía desde el placard. Modernidad, moda e ideología | Mario Quintili: Nanociencia y Nanotecnología... un mundo pequeño | Diana Pagano: Las tecnologías de la felicidad privada. Una problemática tan vieja como la modernidad | Elena Onofre: Al compás de la revolución Interactiva. Un mundo de conexiones | Roberto Aras: Principios para una ética de la ficción televisiva | Valeria Stefanini Zavallo: El uso del cuerpo en las revistas de moda | Andrea Pol: La marca: un signo de identificación visual y auditivo sinérgico. (2012). Buenos Aires: Universidad de Palermo, Facultad de Diseño y Comunicación, Centro de Estudios en Diseño y Comunicación. Vol. 42, septiembre. Con Arbitraje.

$>$ Cuadernos del Centro de Estudios en Diseño y Comunicación. [Ensayos]: Arte, Diseño y medias tecnológicas. Rosa Chalkho: Hacia una proyectualidad crítica. [Prólogo] | Florencia Battiti: El arte ante las paradojas de la representación | Mariano Dagatti: El voyeurismo virtual. Aportes a un estudio de la intimidad | Claudio Eiriz: El oído tiene razones que la física no conoce. (De la falla técnica a la ruptura ontológica) | María Cecilia Guerra Lage: Redes imaginarias y ciudades globales. El caso del stencil en Buenos Aires (2000-2007) | Mónica Jacobo: Videojuegos y arte. Primeras manifestaciones de Game Art en Argentina | Jorge Kleiman: Automatismo \& Imago. Aportes a la Investigación de 
la Imagen Inconsciente en las Artes Plásticas | Gustavo Kortsarz: La duchampizzación del arte | María Ledesma: Enunciación de la letra. Un ejercicio entre Occidente y Oriente | José Llano: La notación del intérprete. La construcción de un paisaje cultural a modo de huella material sobre Valparaíso | Carmelo Saitta: La banda sonora, su unidad de sentido | Sylvia Valdés: Poéticas de la imagen digital. (2012) Buenos Aires: Universidad de Palermo, Facultad de Diseño y Comunicación, Centro de Estudios en Diseño y Comunicación. Vol. 41, junio. Con Arbitraje.

$>$ Cuadernos del Centro de Estudios en Diseño y Comunicación. [Ensayos]: Relaciones Públicas al sur de Latinoamerica II. Una mirada regional de los nuevos escenarios y desafíos de la comunicación. Marisa Cuervo: Prólogo | Claudia Gil Cubillos: Presentación | Fernando Caniza: Lo público y lo privado en las Relaciones Públicas. Cómo pensar la identidad y pertenencia del alumno en estos ámbitos para comprender mejor su desempeño académico y su inserción profesional | Gustavo Cóppola: Gestión del Riesgo Comunicacional. Puesta en práctica | Maria Aparecida Ferrari: Comunicación y Cultura: análisis de la realidad de las Relaciones Públicas en organizaciones chilenas y brasileñas | Constanza Hormazábal: Reputación y manejo de Crisis: Caso empresas de telefonía móvil, luego del 27F en Chile | Patricia Iurcovich: La Pequeña y Mediana empresa y la función de la comunicación | Carina Mazzola: Repensar la comunicación en las organizaciones. Del pensamiento en línea hacia una mirada sobre la complejidad de las prácticas comunicacionales | André Menanteau: Transparencia y comunicación financiera | Edison Otero: Tecnología y organizaciones: de la comprensión a la intervención | Gabriela Pagani: ¿¿Se puede ser una empresa socialmente responsable sin comunicar? | Julio Reyes: Las Cuatro Dimensiones de la Comunicación Interna. (2012) Buenos Aires: Universidad de Palermo, Facultad de Diseño y Comunicación, Centro de Estudios en Diseño y Comunicación. Vol. 40, abril. Con Arbitraje.

$>$ Cuadernos del Centro de Estudios en Diseño y Comunicación. [Ensayos]: Alquimia de lenguajes: alfabetización, enunciación y comunicación. Alejandra Niedermaier: Prólogo | Eje: La alfabetización de las distintas disciplinas. Beatriz Robles. Bernardo Suárez. Claudio Eiriz. Gustavo A. Valdés de León. Mara Steiner. Hugo Salas. Fernando Luis Rolando Badell. María Torre. Daniel Tubío | Eje: Vasos comunicantes. Norberto Salerno. Viviana Suárez. Laura Gutman. Graciela Taquini. Alejandra Niedermaier | Eje: Nuevos modos de circulación, nuevos modos de comunicación. Débora Belmes. Verónica Devalle. Mercedes Pombo. Eduardo Russo. Verónica Joly. (2012) Buenos Aires: Universidad de Palermo, Facultad de Diseño y Comunicación, Centro de Estudios en Diseño y Comunicación. Vol. 39, marzo. Con Arbitraje.

> Cuadernos del Centro de Estudios en Diseño y Comunicación. [Ensayos]: Maestría en Diseño de la Universidad de Palermo [Catálogo de Tesis. 2a Edición. Ciclo 2008-2009]. Tesis recomendada para su publicación: Paola Andrea Castillo Beltrán: Criterios transdiciplinares para el diseño de objetos lúdico-didácticos. (2011) Buenos Aires: Universidad de Palermo, Facultad de Diseño y Comunicación, Centro de Estudios en Diseño y Comunicación. Vol. 38, diciembre. Con Arbitraje. 
$>$ Cuadernos del Centro de Estudios en Diseño y Comunicación. [Ensayos]: El Diseño de Interiores en la Historia. Roberto Céspedes: El Diseño de Interiores en la Historia. Andrea Peresan Martínez: Antigüedad. Alberto Martín Isidoro: Bizancio. Alejandra Palermo: Alta Edad Media: Románico. Alicia Dios: Baja Edad Media: Gótico. Ana Cravino: Renacimiento, Manierismo, Barroco. Clelia Mirna Domoñi: Iberoamericano Colonial. Gabriela Garófalo: Siglo XIX. Mercedes Pombo: Siglo XX. Maestría en Diseño de la Universidad de Palermo. Tesis recomendada para su publicación. Mauricio León Rincón: El relato de ciencia ficción como herramienta para el diseño industrial. (2011) Buenos Aires: Universidad de Palermo, Facultad de Diseño y Comunicación, Centro de Estudios en Diseño y Comunicación. Vol. 37, septiembre. Con Arbitraje.

$>$ Cuadernos del Centro de Estudios en Diseño y Comunicación. [Ensayos]: Picas (2011) Buenos Aires: Universidad de Palermo, Facultad de Diseño y Comunicación, Centro de Estudios en Diseño y Comunicación. Vol. 36, junio. Con Arbitraje.

$>$ Cuadernos del Centro de Estudios en Diseño y Comunicación. [Ensayos]: Relaciones Públicas, nuevos paradigmas ¿más dudas que certezas? Paola Lattuada: Relaciones Públicas, nuevos paradigmas ¿más dudas que certezas? Fernando Arango: Comunicaciones corporativas. Damián Martínez Lahitou: Brand PR: comunicaciones de marca. Manuel Montaner Rodríguez: La gestión de las PR a través de Twitter. Orlando Daniel Di Pino: Avanza la tecnología, que se salve el contenido! Lucas Lanza y Natalia Fidel: Política 2.0 y la comunicación en tiempos modernos. Daniel Néstor Yasky: Los públicos de las comunicaciones financieras. Investor relations \& financial communications. Andrea Paula Lojo: Los públicos internos en la construcción de la imagen corporativa. Gustavo Adrián Pedace: Las Relaciones Públicas y la mentira: ¿inseparables? Gabriel Pablo Stortini: La ética en las Relaciones Públicas. Gerardo Sanguine: Las prácticas profesionales en la carrera de Relaciones Públicas. Paola Lattuada: Comunicación Sustentable: la posibilidad de construir sentido con otros. Adriana Lauro: RSE - Comunicación para el Desarrollo Sostenible en una empresa de servicio básico y social: Caso Aysa. (2011) Buenos Aires: Universidad de Palermo, Facultad de Diseño y Comunicación, Centro de Estudios en Diseño y Comunicación. Vol. 35, marzo. Con Arbitraje.

$>$ Cuadernos del Centro de Estudios en Diseño y Comunicación. [Ensayos]: La utilización de clásicos en la puesta en escena. Catalina Artesi: Tensión entre los ejes de lo clásico y lo contemporáneo en dos versiones escénicas de directores argentinos. Andrés Olaizola: La Celestina en la versión de Daniel Suárez Marzal: apuntes sobre su puesta en escena. María Laura Pereyra: Antígona, desde el teatro clásico al Derecho Puro - Perspectivas de la enseñanza a través del método del case study. María Laura Ríos: Manifiesto de Niños, o la escenificación de la violencia. Mariano Saba: Pelayo y el gran teatro del canon: los condicionamientos críticos de Unamuno dramaturgo según su recepción en América Latina. Propuestas de abordaje frente a las problemáticas de la diversidad. Nuevas estrategias en educación superior, desarrollo turístico y comunicación. Florencia Bustingorry: Sin barreras lingüísticas en el aula. La universidad argentina como escenario del multiculturalismo. Diego Navarro: Turismo: portal de la diversidad cultural. El turismo receptivo 
como espacio para el encuentro multicultural. Virginia Pineau: La Educación Superior como un espacio de construcción del Patrimonio Cultural. Una forma de entender la diversidad. Irene Scaletzky: La construcción del espacio académico: ciencia y diversidad. Maestría en Diseño de la Universidad de Palermo. Tesis recomendada para su publicación. Yaffa Nahir I. Gómez Barrera: La Cultura del Diseño, estrategia para la generación de valor e innovación en la PyMe del Área Metropolitana del Centro Occidente, Colombia. (2010) Buenos Aires: Universidad de Palermo, Facultad de Diseño y Comunicación, Centro de Estudios en Diseño y Comunicación. Vol. 34, diciembre. Con Arbitraje.

$>$ Cuadernos del Centro de Estudios en Diseño y Comunicación. [Ensayos]: Relaciones Públicas, al sur de Latinoamérica. Paola Lattuada: Relaciones Públicas, al sur de Latinoamérica. Daniel Scheinsohn: Comunicación Estratégica ${ }^{\circledR}$. María Isabel Muñoz Antonin: Reputación corporativa: Trustmark y activo de comportamientos adquisitivos futuros. Bernardo García: Tendencias y desafíos de las marcas globales. Nuevas expectativas sobre el rol del comunicador corporativo. Claudia Gil Cubillos: Comunicadores corporativos: desafíos de una formación profesional por competencias en la era global. Marcelino Garay Madariaga: Comunicación y liderazgo: sin comunicación no hay líder. Jairo Ortiz Gonzales: El rol del comunicador en la era digital. Alberto Arébalos: Las nuevas relaciones con los medios. En un mundo de comunicaciones directas, ¿es necesario hacer media relations? Enrique Correa Ríos: Comunicación y lobby. Guillermo Holzmann: Comunicación política y calidad democrática en Latinoamérica. Paola Lattuada: RSE y RRPP: ¿un mismo ADN? Equipo de Comunicaciones Corporativas de MasterCard para la región de Latinoamérica y el Caribe: RSE - Caso líder en consumo inteligente. (2010) Buenos Aires: Universidad de Palermo, Facultad de Diseño y Comunicación, Centro de Estudios en Diseño y Comunicación. Vol. 33, agosto. Con Arbitraje.

> Cuadernos del Centro de Estudios en Diseño y Comunicación. [Ensayos]: txts. (2010) Buenos Aires: Universidad de Palermo, Facultad de Diseño y Comunicación, Centro de Estudios en Diseño y Comunicación. Vol. 32, mayo. Con Arbitraje.

$>$ Cuadernos del Centro de Estudios en Diseño y Comunicación. [Ensayos]: Maestría en

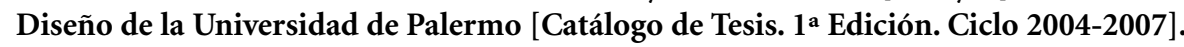
Tesis recomendada para su publicación: Nancy Viviana Reinhardt: Infografía Didáctica: producción interdisciplinaria de infografías didácticas para la diversidad cultural. (2010) Buenos Aires: Universidad de Palermo, Facultad de Diseño y Comunicación, Centro de Estudios en Diseño y Comunicación. Vol. 31, abril. Con Arbitraje.

$>$ Cuadernos del Centro de Estudios en Diseño y Comunicación. [Ensayos]: El paisaje como referente de diseño. Jimena Martignoni: El paisaje como referente de diseño. Carlos Coccia: Escenografía. Teatro. Paisaje. Cristina Felsenhardt: Arquitectura. Paisaje. Graciela Novoa: Historia. Marcas a través del tiempo. Paisaje. Andrea Saltzman: Cuerpo. Vestido. Paisaje. Sandra Siviero: Antropología. Pueblos. Paisaje. Felipe Uribe de Bedout: Mobiliario Urbano. Espacio Público. Ciudad - Paisaje. Paisaje Urbe. Patricia Noemí Casco y Edgardo M. Ruiz: Introducción Paisaje Urbe. Manifiesto: Red Argentina del Paisaje. 
Lorena C. Allemanni: Acciones sobre el principal recurso turístico de Villa Gesell "la playa". Gabriela Benito: Paisaje como recurso ambiental. Gabriel Burgueño: El paisaje natural en el diseño de espacios verdes. Patricia Noemí Casco: Paisaje compartido. Paisaje como recurso. Fabio Márquez: Diseño participativo de espacios verdes públicos. Sebastián Miguel: Proyecto social en áreas marginales de la ciudad. Eduardo Otaviani: El espacio público, sostén de las relaciones sociales. Blanca Rotundo y María Isabel Pérez Molina: El hombre como hacedor del paisaje. Edgardo M. Ruiz: Patrimonio, historia y diseño de los jardines del Palacio San José. Fabio A. Solari y Laura Cazorla: Valoración de la calidad y fragilidad visual del paisaje. (2009) Buenos Aires: Universidad de Palermo, Facultad de Diseño y Comunicación, Centro de Estudios en Diseño y Comunicación. Vol. 30, noviembre. Con Arbitraje.

> Cuadernos del Centro de Estudios en Diseño y Comunicación. [Ensayos]: Typo. (2009) Buenos Aires: Universidad de Palermo, Facultad de Diseño y Comunicación, Centro de Estudios en Diseño y Comunicación. Vol. 29, agosto. Con Arbitraje.

$>$ Cuadernos del Centro de Estudios en Diseño y Comunicación. [Ensayos]: Relaciones Públicas 2009. Radiografía: proyecciones y desafíos. Paola Lattuada: Introducción. Fernando Arango: La medición de la reputación corporativa. Alberto Arébalos: Yendo donde están las audiencias. Internet: el nuevo aliado de las relaciones públicas. Alessandro Barbosa Lima y Federico Rey Lennon: La Web 2.0: el nuevo espacio público. Lorenzo A. Blanco: entrevista. Lorenzo A. Blanco: ¿Nuevas empresas... nuevas tendencias... nuevas relaciones públicas...? Carlos Castro Zuñeda: La opinión pública como el gran grupo de interés de las relaciones públicas. Marisa Cuervo: El desafío de la comunicación interna en las organizaciones. Diego Dillenberger: Comunicación política. Graciela Fernández Ivern: Consejo Profesional de Relaciones Públicas de la República Argentina. Carta abierta en el $5^{\circ}$ aniversario. Juan Iramain: La sustentabilidad corporativa como objetivo estratégico de las relaciones públicas. Patricia Iurcovich: Las pymes y la función de la comunicación. Gabriela T. Kurincic: Convergencia de medios en Argentina. Paola Lattuada: RSE: Responsabilidad Social Empresaria. La tríada RSE. Aldo Leporatti: Issues Management. La comunicación de proyectos de inversión ambientalmente sensibles. Elisabeth Lewis Jones: El beneficio público de las relaciones públicas. Un escenario en el que todos ganan. Hernán Maurette: La comunicación con el gobierno. Allan McCrea Steele: Los nuevos caminos de la comunicación: las experiencias multisensoriales. Daniel Scheinsohn: Comunicación Estratégica ${ }^{\circledR}$. Roberto Starke: Lobby, lobistas y bicicletas. Hernán Stella: La comunicación de crisis. (2009) Buenos Aires: Universidad de Palermo, Facultad de Diseño y Comunicación, Centro de Estudios en Diseño y Comunicación. Vol. 28, abril. Con Arbitraje.

$>$ Cuadernos del Centro de Estudios en Diseño y Comunicación. [Ensayos]: Sandro Benedetto: Borges y la música. Alberto Farina: El cine en Borges. Alejandra Niedermaier: Algunas consideraciones sobre la fotografía a través de la cosmovisión de Jorge Luis Borges. Graciela Taquini: Transborges. Nora Tristezza: El arte de Borges. Florencia Bustingorry y Valeria Mugica: La fotografía como soporte de la memoria. Andrea Chame: 
Fotografía: los creadores de verdad o de ficción. Mónica Incorvaia: Fotografía y Realidad. Viviana Suárez: Imágenes opacas. La realidad a través de la máquina surrealista o el desplazamiento de la visión clara. Daniel Tubío: Innovación, imagen y realidad: ¿Sólo una cuestión de tecnologías? Augusto Zanela: La tecnología se sepulta a sí misma. (2008) Buenos Aires: Universidad de Palermo, Facultad de Diseño y Comunicación, Centro de Estudios en Diseño y Comunicación. Vol. 27, diciembre. Con Arbitraje.

$>$ Cuadernos del Centro de Estudios en Diseño y Comunicación. [Ensayos]: Catalina Julia Artesi: ¿Un Gardel venezolano? “El día que me quieras” de José Ignacio Cabrujas. Marcelo Bianchi Bustos: Latinoamérica: la tierra de Rulfo y de García Márquez. Reflexiones en torno a algunas cuestiones para pensar la identidad. Silvia Gago: Los límites del arte. María José Herrera: Arte Precolombino Andino. Alejandra Viviana Maddonni: Ricardo Carpani: arte, gráfica y militancia política. Alicia Poderti: La inserción de Latinoamérica en el mundo globalizado. Andrea Pontoriero: La identidad como proceso de construcción. Reapropiaciones de textualidades isabelinas a la luz de la farsa porteña. Gustavo Valdés de León: Latinoamérica en la trama del diseño. Entre la utopía y la realidad. (2008) Buenos Aires: Universidad de Palermo, Facultad de Diseño y Comunicación, Centro de Estudios en Diseño y Comunicación. Vol. 26, agosto. Con Arbitraje.

$>$ Cuadernos del Centro de Estudios en Diseño y Comunicación. [Ensayos]: Guillermo Desimone. Sobreviviendo a la interferencia. Daniela V. Di Bella. Arte Tecnomedial: Programa curricular. Leonardo Maldonado. La aparición de la estrella en el cine clásico norteamericano. Su incidencia formal en la instancia enunciativa del film hollywoodense. (2008) Buenos Aires: Universidad de Palermo, Facultad de Diseño y Comunicación, Centro de Estudios en Diseño y Comunicación. Vol. 25, abril. Con Arbitraje.

$>$ Cuadernos del Centro de Estudios en Diseño y Comunicación. [Ensayos]: Rosa Judith Chalkho: Introducción: artes, tecnologías y huellas históricas. Norberto Cambiasso: El oído inalámbrico. Diseño sonoro, auralidad y tecnología en el futurismo italiano. Máximo Eseverri: La batalla por la forma. Belén Gache: Literatura y máquinas. Iliana Hernández García: Arquitectura, Diseño y nuevos medios: una perspectiva crítica en la obra de Antoni Muntadas. Fernando Luis Rolando: Arte, Diseño y nuevos medios. La variación de la noción de inmaterialidad en los territorios virtuales. Eduardo A. Russo: La movilización del ojo electrónico. Fronteras y continuidades en El arca rusa de Alexander Sokurov, o del plano cinematográfico y sus fundamentos (por fin cuestionados). Graciela Taquini: Ver del video. Daniel Varela: Algunos problemas en torno al concepto de música interactiva. (2007) Buenos Aires: Universidad de Palermo, Facultad de Diseño y Comunicación, Centro de Estudios en Diseño y Comunicación. Vol. 24, agosto. Con Arbitraje.

> Cuadernos del Centro de Estudios en Diseño y Comunicación. [Ensayos]: Sebastián Gil Miranda. Entre la ética y la estética en la sociedad de consumo. La responsabilidad profesional en Diseño y Comunicación. Fabián Iriarte. Entre el déficit temático y el advenimiento del guionista compatible. Dante Palma. La inconmensurabilidad en la era de la comunicación. Reflexiones acerca del relativismo cultural y las comunidades cerradas. Viviana Suárez. El 
diseñador imaginario [La creatividad en las disciplinas de diseño]. Gustavo A. Valdés de León. Diseño experimental: una utopía posible. Marcos Zangrandi. Eslóganes televisivos: emergentes tautistas. (2007) Buenos Aires: Universidad de Palermo, Facultad de Diseño y Comunicación, Centro de Estudios en Diseño y Comunicación. Vol. 23, junio. Con Arbitraje.

$>$ Cuadernos del Centro de Estudios en Diseño y Comunicación. [Ensayos]: Sylvia Valdés. Diseño y Comunicación. Investigación de posgrado y hermenéutica. Daniela Chiappe. Medios de comunicación e-commerce. Análisis del contrato de lectura. Mariela D’Angelo. El signo icónico como elemento tipificador en la infografía. Noemí Galanternik. La intervención del Diseño en la representación de la información cultural: Análisis de la gráfica de los suplementos culturales de los diarios. María Eva Koziner. Diseño de Indumentaria argentino. Darnos a conocer al mundo. Julieta Sepich. La pasión mediática y mediatizada. Julieta Sepich. La producción televisiva. Retos del diseñador audiovisual. Marcelo Adrián Torres. Identidad y el patrimonio cultural. El caso de los sitios arqueológicos de la provincia de La Rioja. Marcela Verónica Zena. Representación de la cultura en el diario impreso: Análisis comunicacional. Facultad de Diseño y Comunicación. Universidad de Palermo. (2006) Buenos Aires: Universidad de Palermo, Facultad de Diseño y Comunicación, Centro de Estudios en Diseño y Comunicación. Vol. 22, noviembre. Con Arbitraje.

$>$ Cuadernos del Centro de Estudios en Diseño y Comunicación. [Ensayos]: Oscar Echevarría. Proyecto Maestría en Diseño. Facultad de Diseño y Comunicación. Universidad de Palermo. (2006) Buenos Aires: Universidad de Palermo, Facultad de Diseño y Comunicación, Centro de Estudios en Diseño y Comunicación. Vol. 21, julio. Con Arbitraje.

$>$ Cuadernos del Centro de Estudios en Diseño y Comunicación. [Ensayos]: Rosa Chalkho. Arte y tecnología. Francisco Ali-Brouchoud. Música: Arte. Rodrigo Alonso. Arte, ciencia y tecnología. Vínculos y desarrollo en Argentina. Daniela Di Bella. El tercer dominio. Jorge Haro. La escucha expandida [sonido, tecnología, arte y contexto] Jorge La Ferla. Las artes mediáticas interactivas corroen el alma. Juan Reyes. Perpendicularidad entre arte sonoro y música. Jorge Sad. Apuntes para una semiología del gesto y la interacción musical. (2006) Buenos Aires: Universidad de Palermo, Facultad de Diseño y Comunicación, Centro de Estudios en Diseño y Comunicación. Vol. 20, mayo. Con Arbitraje.

$>$ Cuadernos del Centro de Estudios en Diseño y Comunicación. [Ensayos]: Trabajos Finales de Grado. Proyectos de Graduación. Facultad de Diseño y Comunicación. Universidad de Palermo. Catálogo 1993-2004. (2005) Buenos Aires: Universidad de Palermo, Facultad de Diseño y Comunicación, Centro de Estudios en Diseño y Comunicación. Vol. 19, agosto. Con Arbitraje.

$>$ Cuadernos del Centro de Estudios en Diseño y Comunicación. [Ensayos]: Sylvia Valdés. Cine latinoamericano. Leandro Africano. Funcionalidad actual del séptimo arte. Julián Daniel Gutiérrez Albilla. Los olvidados de Luis Buñuel. Geoffrey Kantaris. Visiones de la violencia en el cine urbano latinoamericano. Joanna Page. Memoria y experimentación en el cine argentino contempoáneo. Erica Segre. Nacionalismo cultural y Buñuel en 
méxico. Marina Sheppard. Cine y resistencia. (2005) Buenos Aires: Universidad de Palermo, Facultad de Diseño y Comunicación, Centro de Estudios en Diseño y Comunicación. Vol. 18, mayo. Con Arbitraje.

$>$ Cuadernos del Centro de Estudios en Diseño y Comunicación. [Ensayos]: Guía de Artículos y Publicaciones de la Facultad de Diseño y Comunicación de la Universidad de Palermo. 1993-2004. (2004) Buenos Aires: Universidad de Palermo, Facultad de Diseño y Comunicación, Centro de Estudios en Diseño y Comunicación. Vol. 17, noviembre. Con Arbitraje.

$>$ Cuadernos del Centro de Estudios en Diseño y Comunicación. [Ensayos]: Alicia Banchero. Los lugares posibles de la creatividad. Débora Irina Belmes. El desafío de pensar. Creación - recreación. Rosa Judith Chalkho. Transdisciplina y percepción en las artes audiovisuales. Héctor Ferrari. Historietar. Fabián Iriarte. High concept en el escenario del Pitch: Herramientas de seducción en el mercado de proyectos fílmicos. Graciela Pacualetto. Creatividad en la educación universitaria. Hacia la concepción de nuevos posibles. Sylvia Valdés. Funciones formales y discurso creativo. (2004) Buenos Aires: Universidad de Palermo, Facultad de Diseño y Comunicación, Centro de Estudios en Diseño y Comunicación. Vol. 16, junio. Con Arbitraje.

$>$ Cuadernos del Centro de Estudios en Diseño y Comunicación. [Ensayos]: Adriana Amado Suárez. Internet, o la lógica de la seducción. María Elsa Bettendorff. El tercero del juego. La imaginación creadora como nexo entre el pensar y el hacer. Sergio Caletti. Imaginación, positivismo y actividad proyectual. Breve disgresión acerca de los problemas del método y la creación. Alicia Entel. De la totalidad a la complejidad. Sobre la dicotomía ver-saber a la luz del pensamiento de Edgar Morin. Susana Finquelievich. De la tarta de manzanas a la estética bussines-pop. Nuevos lenguajes para la sociedad de la información. Claudia López Neglia. De las incertezas al tiempo subjetivo. Eduardo A Russo. La máquina de pensar. Notas para una genealogía de la relación entre teoría y práctica en Sergei Eisenstein. Gustavo Valdés. Bauhaus: crítica al saber sacralizado. (2003) Buenos Aires: Universidad de Palermo, Facultad de Diseño y Comunicación, Centro de Estudios en Diseño y Comunicación. Vol. 15, noviembre. Con Arbitraje.

> Cuadernos del Centro de Estudios en Diseño y Comunicación. [Relevamientos Temáticos]: Noemí Galanternik. Tipografía on line. Relevamiento de sitios web sobre tipografía. Marcela Zena. Periódicos digitales en español. Publicaciones periódicas digitales de América Latina y España. (2003) Buenos Aires: Universidad de Palermo, Facultad de Diseño y Comunicación, Centro de Estudios en Diseño y Comunicación. Vol. 14, noviembre. Con Arbitraje.

> Cuaderno: Ensayos. José Guillermo Torres Arroyo. El paisaje, objeto de diseño. (2003) Buenos Aires: Universidad de Palermo, Facultad de Diseño y Comunicación, Centro de Estudios en Diseño y Comunicación. Vol. 13, junio.

> Cuaderno: Recopilación Documental. Centro de Recursos para el Aprendizaje. Relevamientos Temáticos. Series: Práctica profesional. Diseño urbano. Edificios. Estudios 
de mercado. Medios. Objetos. Profesionales del diseño y la comunicación. Publicidad. (2003) Buenos Aires: Universidad de Palermo, Facultad de Diseño y Comunicación, Centro de Estudios en Diseño y Comunicación. Vol. 12, abril.

$>$ Cuaderno: Proyectos en el Aula. Creación, Producción e Investigación. Proyectos 2003 en Diseño y Comunicación. (2002) Buenos Aires: Universidad de Palermo, Facultad de Diseño y Comunicación, Centro de Estudios en Diseño y Comunicación. Vol. 11, diciembre

$>$ Cuaderno: Proyectos en el Aula. Plan de Desarrollo Académico. Proyecto Anual. Proyectos de Exploración y Creación. Programa de Asistentes en Investigación. Líneas Temáticas. Centro de Recursos. Capacitación Docente. (2002) Buenos Aires: Universidad de Palermo, Facultad de Diseño y Comunicación, Centro de Estudios en Diseño y Comunicación. Vol. 10, septiembre.

> Cuaderno: Proyectos en el Aula: Espacios Académicos. Centro de Estudios en Diseño y Comunicación. Centro de Recursos para el aprendizaje. (2002) Buenos Aires: Universidad de Palermo, Facultad de Diseño y Comunicación, Centro de Estudios en Diseño y Comunicación. Vol. 9, agosto.

> Cuaderno: Proyectos en el Aula. Adriana Amado Suárez. Relevamiento terminológico en diseño y comunicación. A modo de encuadre teórico. Diana Berschadsky. Terminología en diseño de interiores. Área: materiales, revestimientos, acabados y terminaciones. Blanco, Lorenzo. Las Relaciones Públicas y su proyección institucional. Thais Calderón y María Alejandra Cristofani. Investigación documental de marcas nacionales. Jorge Falcone. De Altamira a Toy Story. Evolución de la animación cinematográfica. Claudia López Neglia. El trabajo de la creación. Graciela Pascualetto. Entre la información y el sabor del aprendizaje. Las producciones de los alumnos en el cruce de la cultura letrada, mediática y cibernética. (2002) Buenos Aires: Universidad de Palermo, Facultad de Diseño y Comunicación, Centro de Estudios en Diseño y Comunicación. Vol. 8, mayo.

> Cuaderno: Relevamiento Documental. María Laura Spina. Arte digital: Guía bibliográfica. (2001) Buenos Aires: Universidad de Palermo, Facultad de Diseño y Comunicación, Centro de Estudios en Diseño y Comunicación. Vol. 7, junio.

> Cuaderno: Proyectos en el Aula. Fernando Rolando. Arte Digital e interactividad. (2001) Buenos Aires: Universidad de Palermo, Facultad de Diseño y Comunicación, Centro de Estudios en Diseño y Comunicación. Vol. 6, mayo.

> Cuaderno: Proyectos en el Aula. Débora Irina Belmes. Del cuerpo máquina a las máquinas del cuerpo. Sergio Guidalevich. Televisión informativa y de ficción en la construcción del sentido común en la vida cotidiana. Osvaldo Nupieri. El grupo como recurso pedagógico. Gustavo Valdés de León. Miseria de la teoría. (2001) Buenos Aires: Universidad de Palermo, Facultad de Diseño y Comunicación, Centro de Estudios en Diseño y Comunicación. Vol. 5, mayo. 
$>$ Cuaderno: Proyectos en el Aula. Creación, Producción e Investigación. Proyectos 2002 en Diseño y Comunicación. (2002) Buenos Aires: Universidad de Palermo, Facultad de Diseño y Comunicación, Centro de Estudios en Diseño y Comunicación. Vol. 4, julio.

> Cuaderno: Papers de Maestría. Cira Szklowin. Comunicación en el Espacio Público. Sistema de Comunicación Publicitaria en la vía pública de la Ciudad de Buenos Aires. (2002) Buenos Aires: Universidad de Palermo, Facultad de Diseño y Comunicación, Centro de Estudios en Diseño y Comunicación. Vol. 3, julio.

> Cuaderno: Material para el aprendizaje. Orlando Aprile. El Trabajo Final de Grado. Un compendio en primera aproximación. (2002) Buenos Aires: Universidad de Palermo, Facultad de Diseño y Comunicación, Centro de Estudios en Diseño y Comunicación. Vol. 2, marzo.

> Cuaderno: Proyectos en el Aula. Lorenzo Blanco. Las medianas empresas como fuente de trabajo potencial para las Relaciones Públicas. Silvia Bordoy. Influencia de Internet en el ámbito de las Relaciones Públicas. (2000) Buenos Aires: Universidad de Palermo, Facultad de Diseño y Comunicación, Centro de Estudios en Diseño y Comunicación. Vol. 1 , septiembre. 


\section{Síntesis de las instrucciones para autores}

Cuadernos del Centro de Estudios en Diseño y Comunicación [Ensayos]

Facultad de Diseño y Comunicación. Universidad de Palermo. Buenos Aires, Argentina. www.palermo.edu/dyc

Los autores interesados deberán enviar un abstract de 200 palabras en español, inglés y portugués que incluirá 10 palabras clave. La extensión del ensayo no debe superar las 8000 palabras, deberá incluir títulos y subtítulos en negrita. Normas de citación APA. Bibliografía y notas en la sección final del ensayo.

Presentación en papel y soporte digital. La presentación deberá estar acompañada de una breve nota con el título del trabajo, aceptando la evaluación del mismo por el Comité de Arbitraje y un Curriculum Vitae.

\section{Artículos}

- Formato: textos en Word que no presenten ni sangrías ni efectos de texto o formato especiales.

. Autores: los artículos podrán tener uno o más autores.

. Extensión: entre 25.000 y 40.000 caracteres (sin espacio).

. Títulos y subtítulos: en negrita y en Mayúscula y minúscula.

. Fuente: Times New Roman. Estilo de la fuente: normal. Tamaño: 12 pt. Interlineado: sencillo.

. Tamaño de la página: A4.

. Normas: se debe tomar en cuenta las normas básicas de estilo de publicaciones de la American Psychological Association APA.

. Bibliografía y notas: en la sección final del artículo.

. Fotografías, cuadros o figuras: deben ser presentados en formato tif a 300 dpi en escala de grises. Importante: tener en cuenta que la imagen debe ir acompañando el texto a modo ilustrativo y dentro del artículo hacer referencia a la misma.

\section{Importante:}

La serie Cuadernos del Centro de Estudios en Diseño y Comunicación sostiene la exigencia de originalidad de los artículos de carácter científico que publica.

Es sistema de evaluación de los artículos se realiza en dos partes. En una primera instancia, el Comité Editorial evalúa la pertinencia de la temática del trabajo, para ser publicada en la revista. La segunda instancia corresponde a la evaluación del trabajo por especialistas. Se usa la modalidad de arbitraje doble ciego, permitiendo a la revista mantener la confidencialidad del proceso de evaluación.

Para la evaluación se solicita a los árbitros revisar los criterios de originalidad, pertinencia, actualidad, aportes, y rigurosidad científica. Será el Comité Editorial quien comunica a los autores los resultados de la misma.

\section{Consultas}

En caso de necesitar información adicional escribir a publicacionesdc@palermo.edu o ingresar a http://fido.palermo.edu/servicios_dyc/publicacionesdc/vista/instrucciones.php 



\section{Facultad de Diseño y Comunicación}

Mario Bravo 1050 . Ciudad Autónoma de Buenos Aires C1175 ABT . Argentina . www.palermo.edu/dyc 